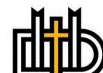

Integral Precast Girder-to-Cap Connections for Accelerated Bridge Construction in Seismic Regions

Justin Vander Werff

Dordt College, justin.vanderwerff@dordt.edu

Follow this and additional works at: https://digitalcollections.dordt.edu/faculty_work

Part of the Civil and Environmental Engineering Commons

\section{Recommended Citation}

Vander Werff, J. (2014). Integral Precast Girder-to-Cap Connections for Accelerated Bridge Construction in Seismic Regions. Retrieved from https://digitalcollections.dordt.edu/faculty_work/135

This Dissertation is brought to you for free and open access by Dordt Digital Collections. It has been accepted for inclusion in Faculty Work Comprehensive List by an authorized administrator of Dordt Digital Collections. For more information, please contact ingrid.mulder@dordt.edu. 


\title{
Integral Precast Girder-to-Cap Connections for Accelerated Bridge Construction in Seismic Regions
}

\begin{abstract}
Accelerated bridge construction $(A B C)$ is increasingly desired and needed, due to the aging transportation infrastructure across the United States and the always-growing demand placed on our nation's highway system. Precast concrete is a common way to incorporate ABC techniques. Advantages over typical castin-place concrete methods include speed of field construction, improved quality control, and decrease in detoured traffic during construction, among others. However, precast concrete structures have not been used to their full potential in high seismic regions, due to the deficiency of precast concrete connections in past earthquake events. The California Department of Transportation (Caltrans) is eager to incorporate $A B C$ methods if connections suitable for high seismic regions can be developed. Therefore, a study has been conducted to investigate the inverted-tee cap beam and Ishaped girder bridge system for its viability for implementation by Caltrans. A large-scale experimental investigation of the bridge system was conducted, verifying that the system has excellent potential for such use. The study identified an as-built connection detail that has been previously incorporated by Caltrans as being capable of providing an integral moment girder-to-cap connection. However, the study also introduced an improved connection detail utilizing grouted unstressed strands, similar to those used in post-tensioning applications, that has the promise of providing an even better connection alternative. A follow-up large-scale experimental study was conducted to provide a detailed investigation of the improved detail. In addition, the follow-up study was used to quantify the performance of another new girder-to-cap connection detail utilizing looped strands and dowel bars. Both connection details were verified to be very constructible and to provide excellent seismic performance, even when subjected to vertical acceleration demands significantly beyond typical design recommendations. Along with connection behavior, these experimental studies were used in conjunction with analytical approaches to investigate current approaches related to load distribution in integral bridges. This work showed that current recommendations are overly conservative in the amount of the column seismic moment that is required to be carried by adjacent girders in the superstructure. A better distribution model, based on the relative stiffness of the superstructure components, is proposed that matches well with the analytical and experimental results from this study and three other large-scale experimental seismic studies. Finally, analytical approaches for the incorporation of vertical acceleration effects were considered, and the results were used to verify the observed experimental performance of the proposed girder-to-cap connection details.
\end{abstract}

\section{Keywords}

accelerated bridge construction, bridges, seismic performance, precast concrete, l-shaped girders, inverted-tee cap beam, California Department of Transportation

\section{Disciplines}

Civil and Environmental Engineering | Engineering

\section{Comments}

- A dissertation submitted to the graduate faculty of lowa State University in partial fulfillment for the degree of DOCTOR OF PHILOSOPHY

- Dr. Sri Sritharan, Committee Chairperson

- (C) 2014 Justin R. Vander Werff 


\section{Creative Commons License}

\section{(c) $($ ) $\Theta(\theta$}

This work is licensed under a Creative Commons Attribution-NonCommercial-No Derivative Works 4.0 International License. 
Integral precast girder-to-cap connections for accelerated bridge construction in seismic regions

by

Justin R. Vander Werff

A dissertation submitted to the graduate faculty

in partial fulfillment of the requirements for the degree of

DOCTOR OF PHILOSOPHY

Major: Civil Engineering (Structural Engineering)

Program of Study Committee:

Sri Sritharan, Major Professor

Fouad Fanous

Jeramy Ashlock

Igor Beresnev

James Alleman

lowa State University

Ames, lowa 
TABLE OF CONTENTS

LIST OF TABLES vi

LIST OF FIGURES vii

ACKNOWLEDGEMENTS $x i$

ABSTRACT xiii

CHAPTER 1. INTRODUCTION 1

1.1. Historical Background 1

1.2. Design Approaches

1.3. Accelerated Bridge Construction 5

1.4. Connection systems: inverted-tee

1.5. Current Practice 10

1.5.1. Moment capacity of inverted-tee connection 12

1.5.2. Seismic lateral load distribution 12

1.5.3. Seismic vertical acceleration effects 14

1.6. Research Summary 16

1.7. Dissertation Organization 17

1.8. References 18 18

CHAPTER 2. LITERATURE REVIEW OF ABC IN SEISMIC REGIONS 22

2.1. Introduction 22

2.2. Accelerated Bridge Construction in Seismic Regions

2.2.1. Background 22

2.2.2. Use of $A B C$ in Seismic Regions 22

2.3. Connections for Segmental Construction in Seismic Regions __ 24

2.4. Girder Load Distribution in Integral Bridges ___ 25

2.4.1. Background 25

2.4.2. Current Design Practice ___ 26

2.5. Seismic Vertical Acceleration __ 28

2.5.1. Background__ 28

2.5.2. Models that approximate geological (seismologic) observations _ 28

2.6. References_ 34

CHAPTER 3. A COST-EFFECTIVE INTEGRAL BRIDGE SYSTEM WITH PRECAST I-GIRDERS FOR SEISMIC APPLICATION 41

3.1. Abstract

3.2. Introduction _ 41

3.3. Research Significance __ 43

3.4. A Precast Bridge System for Seismic Regions ___ 43

3.5. Prototype Bridge _ـ 46 
3.6. Experimental Investigation ___ 47

3.6.1. Test Unit Details __ 47

3.6.2. Test Unit Configuration _ 49

3.6.3. Construction _ 52

3.6.4. Staged Loading to Simulate Prototype Gravity Effects ___ 54

3.6.5. Seismic Load Protocol___ 56

3.7. Experimental Investigation: Phase I __ 56

3.7.1. General Summary of the Test Unit Performance ___ 57

3.7.2. Force-Displacement Response___ 58

3.7.3. Analytical Comparison _ 59

3.7.4. Connection Response __ 60

3.8. Experimental Investigation: Phase II__ 63

3.8.1. Load Protocol __ 64

3.8.2. General Observations___ 65

3.8.3. Force-Displacement Response___ 67

3.8.4. Behavior of Connection Details __ 68

3.9. Conclusions _ 71

3.10. References_ 72

CHAPTER 4. PRECAST CONNECTIONS DESIGNED FOR ABC IN SEISMIC REGIONS __ 75

4.1. Abstract 75

4.2. Introduction__ 76

4.3. Brief summary of the system test 79

4.4. Experimental configuration___ 81

4.4.1. General description __ 81

4.4.2. Cap beam and column design __ 82

4.4.3. Grouted Unstressed Strand Connection (GUSC) detail ___ 84

4.4.4. Looped Unstressed Strand Connection (LUSC) detail ___ 85

4.4.5. Girder, diaphragm, and deck design ___ 86

4.4.6. Load protocol __ 87

4.4.7. Construction 90

4.4.8. Instrumentation _ 93

4.5. Experimental results _ 93

4.5.1. Overall connection behavior

4.5.2. Failure mechanisms __ 95

4.5.3. Behavior of the connection interface___ 97

4.5.4. Performance of the GUSC detail __ 98

4.5.5. Performance of the LUSC detail___ 101

4.6. Preliminary design recommendations__ 103

4.6.1. GUSC Detail__ 103

4.6.2. LUSC Detail _ 104

4.7. Conclusions — 105

4.8. References 107

CHAPTER 5. GIRDER LOAD DISTRIBUTION FOR SEISMIC DESIGN OF INTEGRAL BRIDGES ___ 109

5.1. Abstract — 109 
5.2. Introduction 109

5.3. Current Design Practice__ 112

5.4. Analytical Approaches 114

5.4.1. SSM Background _ 114

5.4.2. SSM for Vertical Load __ 114

5.4.3. SSM for Lateral Load___ 118

5.4.4. Grillage and FEA Models__ 120

5.5. Summary of Large-Scale Tests __ 121

5.5.1. PBT Test Unit 122

5.5.2. SPC Test Units_ 123

5.5.3. ITB Test Unit 124

5.6. Comparison of Analytical and Experimental Load Distributions___ 125

5.6.1. Vertical Load___ 125

5.6.2. Horizontal Load __ 126

5.7. Lateral Load Distribution at Various Load Levels __ 129

5.8. Recommended Model for Lateral Load Distribution___ 132

5.9. Conclusions _ 133

5.10. Acknowledgements __ 134

5.11. References__ 135

CHAPTER 6. ANALYTICAL INVESTIGATION OF PRECAST GIRDER CONNECTIONS SUBJECTED TO SEISMIC MOTION INCLUDING VERTICAL ACCELERATION EFFECTS _ 137

6.1. Abstract 137

6.2. Introduction_ 138

6.3. Vertical Acceleration Analytical Approaches___ 139

6.3.1. Constant Vertical Acceleration___ 140

6.3.2. Vertical Acceleration as a Function of Horizontal Acceleration __ 140

6.3.3. Horizontal and Vertical Ground Motion___ 141

6.4. Connection Details and Experimental Validation __ 143

6.5. Development of the Analytical Model_____ 146

6.5.1. Column: Fiber-Based Beam-Column Elements Incorporating Strain Penetration Effects 147

6.5.2. Superstructure: Two-Dimensional Linear Elastic Elements __ 151

6.5.3. Staged Loading of the Superstructure

6.6. Analytical Verification of the Superstructure Performance ___ 158

6.6.1. Horizontal Loading for Verification of the Model _ـ 158

6.6.2. Analytical Results in the Girder-to-Cap Connection Region___ 160

6.6.3. Comparison of the Experimental and Analytical Results___ 165

6.7. Conclusions _ 168

6.8. References _ 170

CHAPTER 7. PRIMARY CONCLUSIONS__ 172

7.1. Inverted-tee bridge system ___ 172

7.2. Performance of GUSC and LUSC details _ 172

7.3. Integral bridge superstructure seismic load distribution ___ 173

7.4. Design recommendations for the GUSC and LUSC details _ 174

7.5. Two-dimensional model for overall system seismic response ___ 174 
7.6. Effect of vertical acceleration on integral bridge system performance 175

7.7. Analytical approaches for vertical acceleration simulation 


\section{LIST OF TABLES}

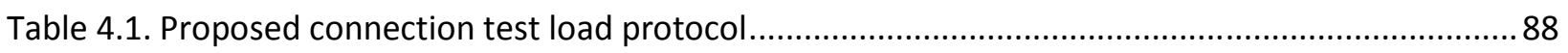

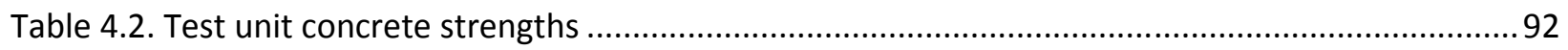

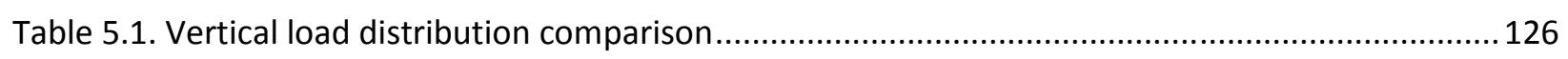

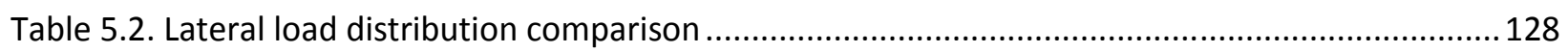

Table 6.1. Concrete material properties in OpenSees analysis.......................................................... 149

Table 6.2. Steel reinforcement material properties in OpenSees analysis ........................................... 149

Table 6.3. Steel reinforcement properties incorporating strain penetration effects............................. 150

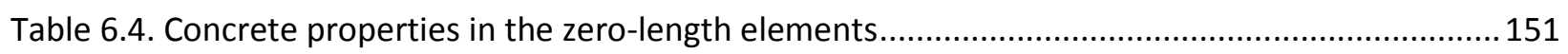

Table 6.5. Connection behavior under experimental loading ........................................................... 165

Table 6.6. Connection behavior from analytical models using El Centro ground motion........................167

Table 6.7. Connection behavior using recorded vertical ground motion ............................................... 168 


\section{LIST OF FIGURES}

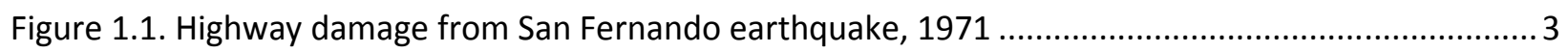

Figure 1.2. Seismic damage to Olive View Hospital, 1971 (USGS, 2005) ................................................. 4

Figure 1.3. Bay Bridge collapse, 1989 (Eskenazi, 2009) ...................................................................... 4

Figure 1.4. Cypress Street viaduct collapse, 1989 (USGS Online Publications Directory, 1999) ................. 5

Figure 1.5. Keg Creek Bridge constructed using ABC methods (AASHTO, 2011) ..................................... 7

Figure 1.6. Lambs Canyon Bridge constructed using ABC methods (FHWA, 2010) ................................. 9

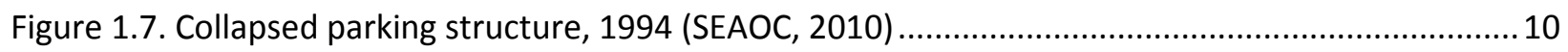

Figure 1.8. Inverted-tee and girder dapped end connection.............................................................. 11

Figure 1.9. Example of strut-and-tie analysis for a girder dapped end (Sanders, 2002) ......................... 12

Figure 1.10. AASHTO distribution of column overstrength moment to girders (elevation)......................14

Figure 1.11. Caltrans distribution of column overstrength moment to girders (plan) ............................. 15

Figure 1.12. Recorded peak ground accelerations during Christchurch earthquake February 22, 2011

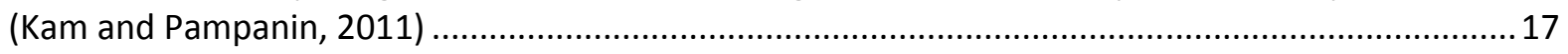

Figure 2.1. Segmental column test setup (Ou et at., 2010) ..................................................................2 24

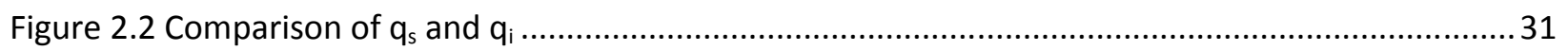

Figure 2.3. Horizontal and vertical component acceleration time histories on rock sites for the 1994 Northridge earthquake (top) and the 1989 Loma Prieta earthquake (bottom) ............................... 32

Figure 2.4. Horizontal and vertical component acceleration time histories recorded during the

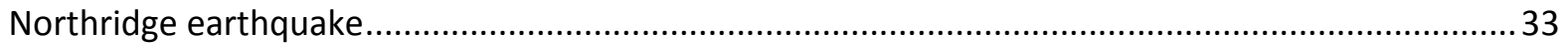

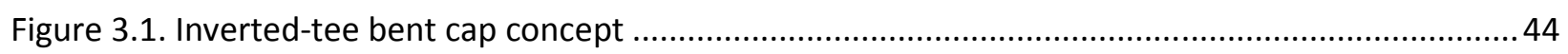

Figure 3.2. Influence of girder connection on column seismic moment demand ................................... 45

Figure 3.3. Prototype integral bridge structure ................................................................................ 46

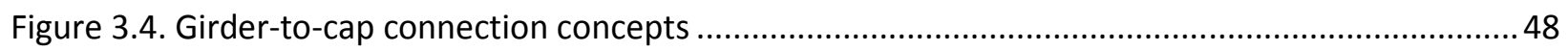

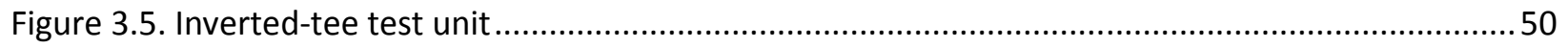

Figure 3.6. Test unit girder-to-cap connection detail ....................................................................... 51

Figure 3.7. Inverted-tee cap beam prior to girder placement ................................................................ 53

Figure 3.8. Photographs of construction ..................................................................................... 53 
Figure 3.9. Comparison of prototype and test unit moment profiles during stage loading (test unit scale).

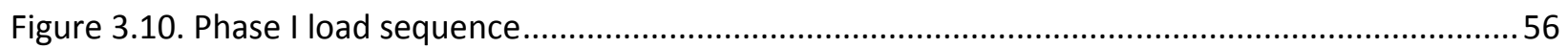

Figure 3.11. Test unit photographs during and after Phase I testing ....................................................58

Figure 3.12. Horizontal force-displacement response for system test unit .........................................59

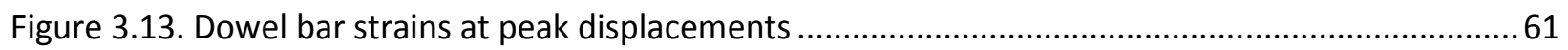

Figure 3.14. Unstressed strand strains in exterior and intermediate girders at peak displacements producing positive moment in the improved connection region ....................................................62

Figure 3.15. Gap opening at the bottom girder-to-diaphragm interface (Phase I) .................................63

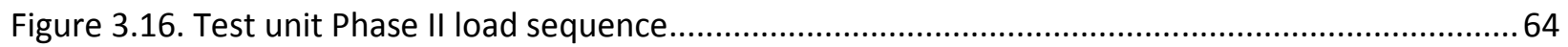

Figure 3.17. As-built connection region during the latter stages of Phase II testing.................................66

Figure 3.18. Comparison of as-built and improved connection moment behavior .................................68

Figure 3.19. Gap opening at the bottom girder-to-diaphragm interface (Phase II) ...............................69

Figure 3.20. Dowel bar strains in center girder mid-level bars at peak displacements............................69

Figure 3.21. Unstressed strand strains at interface of cap beam to intermediate and exterior girders

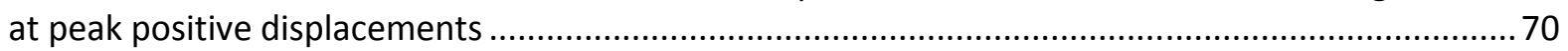

Figure 4.1. Prototype bridge utilizing the inverted tee system .......................................................... 77

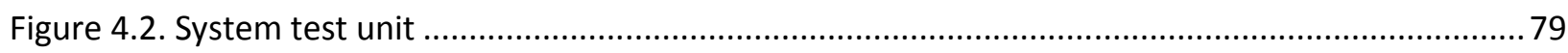

Figure 4.3. Horizontal force-displacement response envelope from system test Phase I ........................ 80

Figure 4.4. Moment-displacement behavior of system test unit due to peak vertical loads.................... 81

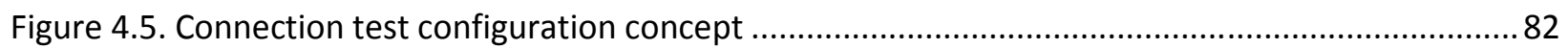

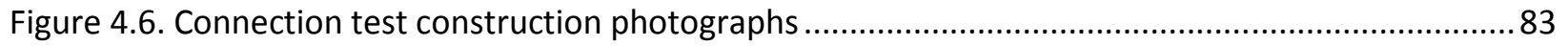

Figure 4.7. Reinforcement in grouted unstressed strand connection (GUSC) (test unit scale).................85

Figure 4.8. Looped unstressed strand connection (LUSC) (test unit scale) ............................................ 86

Figure 4.9. Test unit girder shear and moment diagrams at gravity simulation condition ....................... 89

Figure 4.10. Load protocol for connection test of GUSC detail ........................................................... 90

Figure 4.11. Construction and test configuration photographs ….................................................... 92

Figure 4.12. LED indicators to record position during experimental testing ........................................ 93

Figure 4.13. Recorded connection moment as a function of vertical displacement at the far actuator ...94 


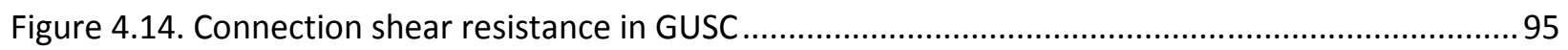

Figure 4.15. GUSC girder-cap interface during peak positive-moment displacement (looking up) ...........96

Figure 4.16. Condition of the diaphragm of LUSC detail at peak positive (upward) girder displacement

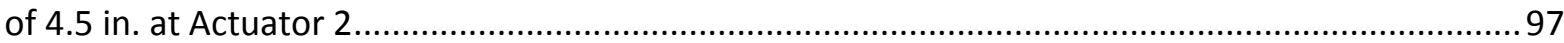

Figure 4.17. Relative displacement of lower interface between girder and diaphragm ........................98

Figure 4.18. Performance of unstressed strand and dowel bars in GUSC detail...................................99

Figure 4.19. Strand strain related to relative interface displacement.................................................. 100

Figure 4.20. LUSC dowel bar strain as a function of interface relative displacement ........................... 101

Figure 4.21. LUSC looped strand strain as a function of dowel bar strain........................................... 102

Figure 4.22. LUSC girder looped strain as a function of dowel bar strain ........................................... 103

Figure 5.1. Prototype structures used for the integral bridge investigations......................................... 111

Figure 5.2. Distribution of column overstrength moment to girders (plan) .........................................113

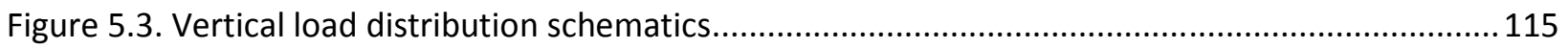

Figure 5.4. Lateral load distribution schematics ............................................................................... 119

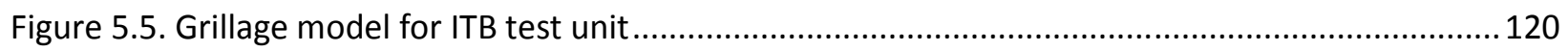

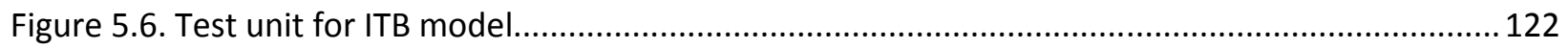

Figure 5.7. Horizontal load-displacement responses from experimental studies ................................. 123

Figure 5.8. Experimental load distribution for SPC2 ....................................................................... 130

Figure 5.9. Experimental load distribution for ITB test unit ............................................................. 131

Figure 5.10. Distribution comparison for interior girder lateral load ............................................... 133

Figure 6.1. Horizontal and vertical component acceleration time histories from the 1994 Northridge and 1989 Loma Prieta events (Silva, 1997) .................................................................................. 142

Figure 6.2. Connection concepts for inverted tee cap beam and dapped end girder........................... 144

Figure 6.3. Prototype bridge utilizing the inverted tee system ......................................................... 145

Figure 6.4. Experimental horizontal force-displacement response for the inverted-tee system ............145

Figure 6.5. Connection moment as a function of vertical girder end displacement .............................. 146

Figure 6.6. Fiber-based cross section for beam-column element used to model system test column in

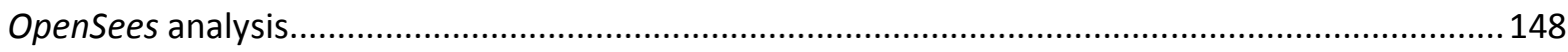

Figure 6.7. Analytical model of the system test unit, including column and superstructure...................152 
Figure 6.8. Connection behavior under cyclic horizontal ground motion analysis, comparing results with and without staged elements............................................................................................ 155

Figure 6.9. Superstructure behavior under horizontal static analysis .................................................157

Figure 6.10. Analytical horizontal force-displacement response for various excitation conditions ........ 159

Figure 6.11. Connection behavior with El Centro horizontal ground motion and constant vertical

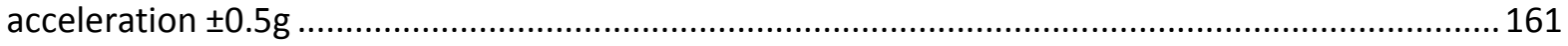

Figure 6.12. Connection behavior for El Centro horizontal ground motion and vertical ground motion

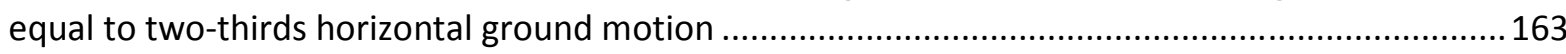

Figure 6.13. Connection behavior using recorded horizontal and vertical ground motion .....................163

Figure 6.14. Connection shear history for El Centro horizontal ground motion and constant vertical

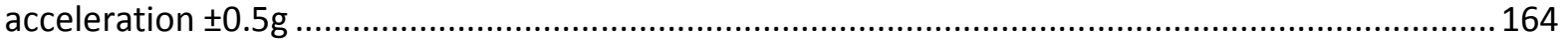




\section{ACKNOWLEDGEMENTS}

Community and relationships are a huge part of good education and research. The work contained in this dissertation certainly would not have materialized without the meaningful contribution of many others who came before or alongside me during this process. I gratefully acknowledge the following organizations and people who made this work possible:

- The California Department of Transportation (Caltrans), who funded most of the experimental and analytical work in this study.

- Sri Sritharan - for serving as my major professor, providing much direction and technical advice, and willingly working with my unconventional off-campus and on-campus schedule over the past several years as I balanced my lowa State work, Dordt work, and family life.

- Fouad Fanous, Jeramy Ashlock, Igor Beresnev, and James Alleman - for willingly and generously serving as members of my committee.

- Robert Peggar, Jay Holombo, Rick Snyder, Zach Theimann, Ryan Staudt, Robert Abendroth, and Lowell Greimann - for working over the years as professional engineers, graduate students, or faculty members on various portions of the work presented here.

- Owen Steffens and Douglas Wood - for managing, coordinating, and aiding with the construction and testing required for the extensive experimental efforts utilized in this study.

- Miranda - for generous and self-sacrificial love and encouragement, excellently and willingly bearing the burden of family responsibilities as together we traveled the journey of pursuing this graduate work along with full-time teaching demands, parenting responsibility, church service, and life in general.

- Mom, and Dad and Joy - for spiritual guidance, teaching me the value of hard work, and graciously encouraging me and my family throughout this journey.

- Lydia, Laiya Naomi, and Josiah - for teaching me the joy and responsibility of being a father, and graciously putting up with Daddy's unending lowa State and Dordt work throughout most of their entire young lives. 
- Our dear family and church friends - in Indiana, Illinois, central lowa, and northwest lowa, for care, companionship, concern, and spiritual mentorship to me and my family in various stages of this long journey.

- My Lord and Savior Jesus Christ - for giving me a reason to pursue this work, for providing us with this amazing world that reveals so much to us yet still holds so many amazing secrets waiting to be discovered, and for wonderfully revealing to me how my engineering work can bring glory to Him and show love to my neighbors next door and all over the world. 


\begin{abstract}
Accelerated bridge construction $(A B C)$ is increasingly desired and needed, due to the aging transportation infrastructure across the United States and the always-growing demand placed on our nation's highway system. Precast concrete is a common way to incorporate $A B C$ techniques. Advantages over typical cast-in-place concrete methods include speed of field construction, improved quality control, and decrease in detoured traffic during construction, among others. However, precast concrete structures have not been used to their full potential in high seismic regions, due to the deficiency of precast concrete connections in past earthquake events. The California Department of Transportation (Caltrans) is eager to incorporate $A B C$ methods if connections suitable for high seismic regions can be developed. Therefore, a study has been conducted to investigate the inverted-tee cap beam and Ishaped girder bridge system for its viability for implementation by Caltrans. A large-scale experimental investigation of the bridge system was conducted, verifying that the system has excellent potential for such use. The study identified an as-built connection detail that has been previously incorporated by Caltrans as being capable of providing an integral moment girder-to-cap connection. However, the study also introduced an improved connection detail utilizing grouted unstressed strands, similar to those used in post-tensioning applications, that has the promise of providing an even better connection alternative. A follow-up large-scale experimental study was conducted to provide a detailed investigation of the improved detail. In addition, the follow-up study was used to quantify the performance of another new girder-to-cap connection detail utilizing looped strands and dowel bars. Both connection details were verified to be very constructible and to provide excellent seismic performance, even when subjected to vertical acceleration demands significantly beyond typical design recommendations. Along with connection behavior, these experimental studies were used in conjunction with analytical approaches to investigate current approaches related to load distribution in integral bridges. This work showed that current recommendations are overly conservative in the amount of the column seismic moment that is required to be carried by adjacent girders in the superstructure. A better distribution model, based on the relative stiffness of the superstructure components, is proposed that matches well with the analytical and experimental results from this study and three other large-scale experimental seismic studies. Finally, analytical approaches for the incorporation of vertical acceleration effects were considered, and the results were used to verify the observed experimental performance of the proposed girder-to-cap connection details.
\end{abstract}




\section{CHAPTER 1. INTRODUCTION}

\subsection{Historical Background}

Structures are vital to our present-day way of life. However, structures can at times become our worst enemy during earthquake events, as deaths that occur due to earthquakes are usually related to structural failures and not pure natural phenomena. Bridges are one of the most common types of structures, vital to transportation infrastructure around the world. The prevalence of bridges in almost any part of the world means that there will be bridges that are affected by earthquakes, no matter where they strike. In the United States, the west coast region is well known for its vulnerability to earthquakes. As such, the states in this region have been active for decades in improving bridge systems to be better suited to withstand earthquake loads.

The state of California, as of 2010, had over 24,500 highway bridges (Shoup et al., 2011). California, like many other states, has been plagued by budget problems due to recent economic turmoil, so upkeep on the aging bridge infrastructure is a large concern. The average age of bridges in California is 44.4 years, with more than 8300 bridges over fifty years old (Shoup et al., 2011). Given that the current seismic design philosophy is primarily a product of the last 20-30 years, the seismic sufficiency of many of these bridges needed to be addressed, and the California Department of Transportation (Caltrans) has embarked on an ambitious and highly effective retrofit program. According to Caltrans' data, over $98 \%$ of the state-maintained bridges have undergone seismic safety retrofit work, as have about $45 \%$ of local agency bridges in the state (Caltrans, 2012). While some retrofit work remains, it is perhaps even more important to note that most bridges now in use have a rough life expectancy of about 50 years, and many bridges are nearing the end of this life span. Therefore, practical and easily-constructible methods for new construction of bridges that are seismic-sufficient must continue to be developed. Given California's propensity for earthquakes, Caltrans has been at the forefront of the development of seismic solutions for earthquake loading for decades, both for retrofits and new construction.

Historically, significant seismic events in California have produced awareness of seismic deficiencies in structural design and have led to improvements in design methods and construction. One of the first earthquakes that began to lead to developments in seismic design was the 1971 San Fernando earthquake. This magnitude 6.6 earthquake caused significant damage in the region about 15 miles 
northwest of downtown Los Angeles. According to the United States Geological Survey (USGS), "The most spectacular damage included the destruction of major structures at the Olive View and the Veterans Administration Hospitals and the collapse of freeway overpasses. "The newly built, earthquake-resistant buildings at the Olive View Hospital in Sylmar were destroyed" (Stover \& Coffman, 1993). Photographs of the highway damage are shown in Figure 1.1, along with a photograph of the damage to the Olive View structure is shown in Figure 1.2. A primary reason that structures that were thought to be "state-of-the-art" experienced significant damage is that seismic design at that time was primarily conducted using elastic design methods. Such elastic methods typically produced significant underestimation of seismic deflections, inadequately low and incorrect load patterns, and lack of consideration of inelastic structural actions (Priestley et al., 1996). The San Fernando earthquake exposed some of these deficiencies and brought about "a concerted effort to retrofit bridges, but the resolve eventually diminished" (Caltrans Seismic Advisory Board, 2003).

Interestingly, no earthquake events that were large enough to rekindle interest in improved seismic design occurred until the 1987 Whittier Narrows earthquake, which had a relatively modest magnitude of 6.0 and produced extensive damage to a major nine-span bridge that was a part of the interstate highway system in the Los Angeles area (Stover \& Coffman, 1993). Renewed vigor in the improvement of seismic sufficiency of bridges was finally realized after the 1989 Loma Prieta magnitude 6.9 earthquake that produced some spectacular bridge failures (Housner \& Thiel, 1990). A couple of failure examples from this event are shown in Figure 1.3 and Figure 1.4. Aggressive research following the Loma Prieta earthquake resulted in many developments in the years that followed, and the 1994 Northridge earthquake offered a bit of a test-run that proved that the newly developed design and retrofit details that were being implemented were working. 


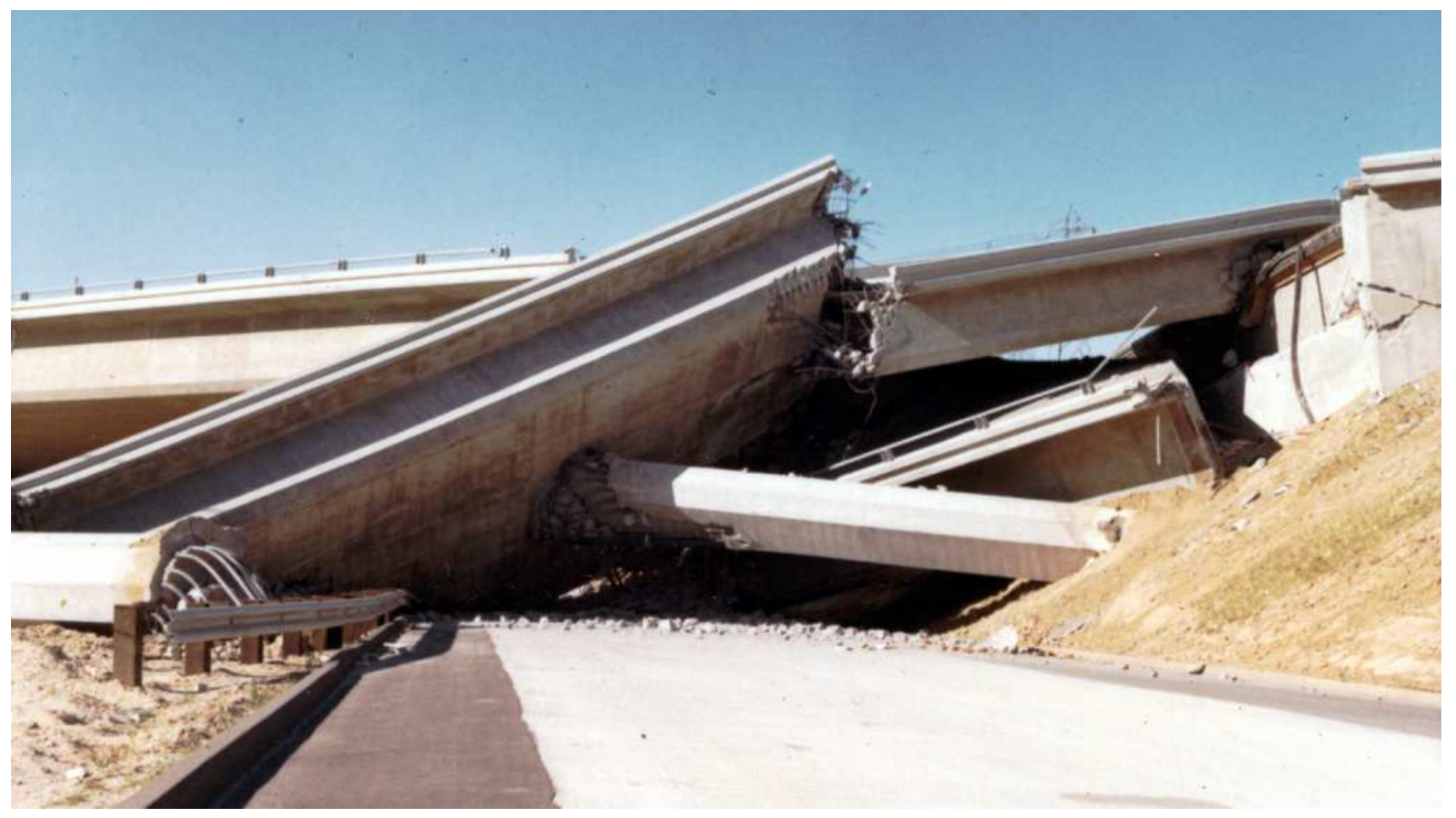

(a) Collapsed highway overpasses, Interstate 5 and Interstate 14 (USGS, 1971)

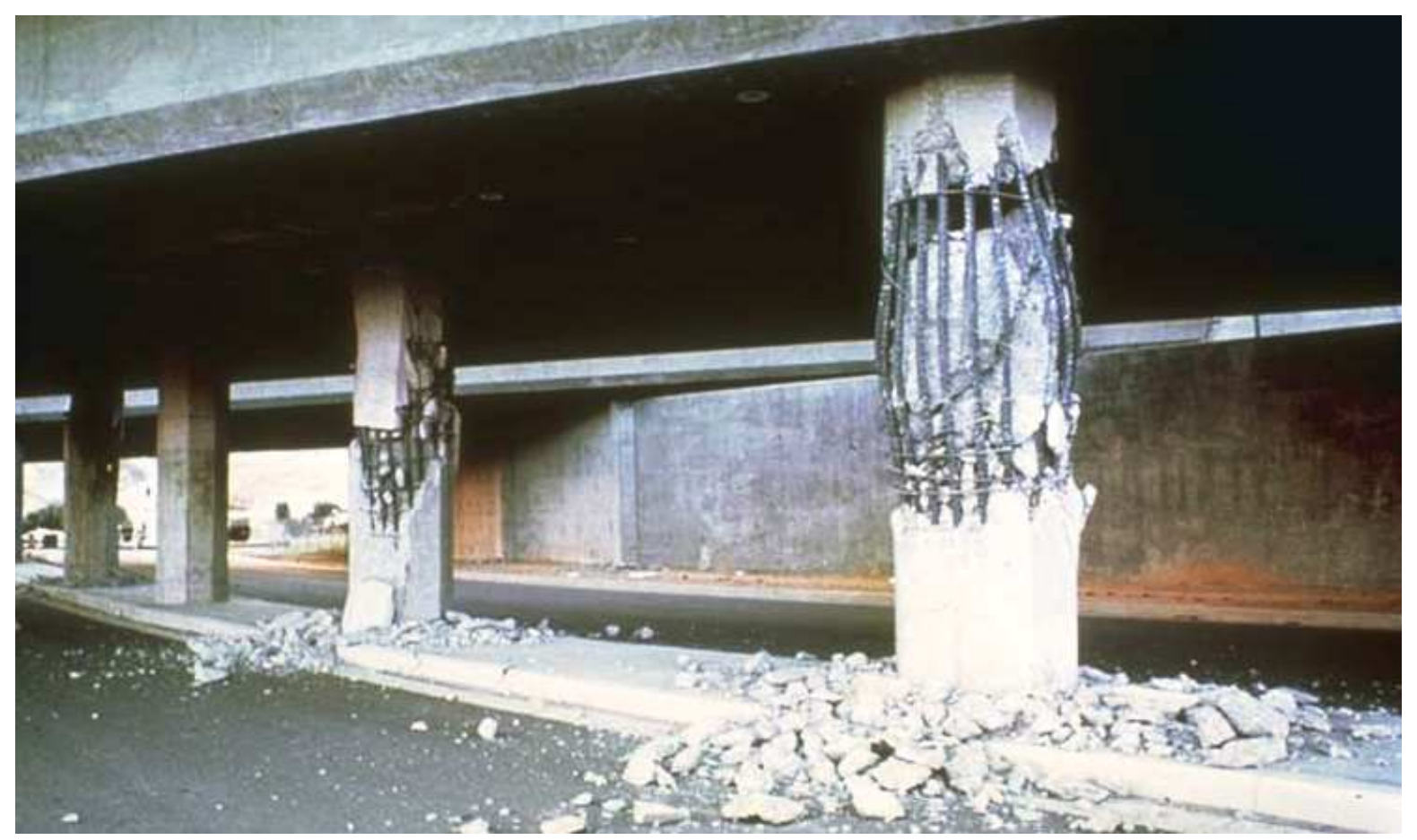

(b) Column damage, Foothills Freeway overpass (USGS, 1971)

Figure 1.1. Highway damage from San Fernando earthquake, 1971 


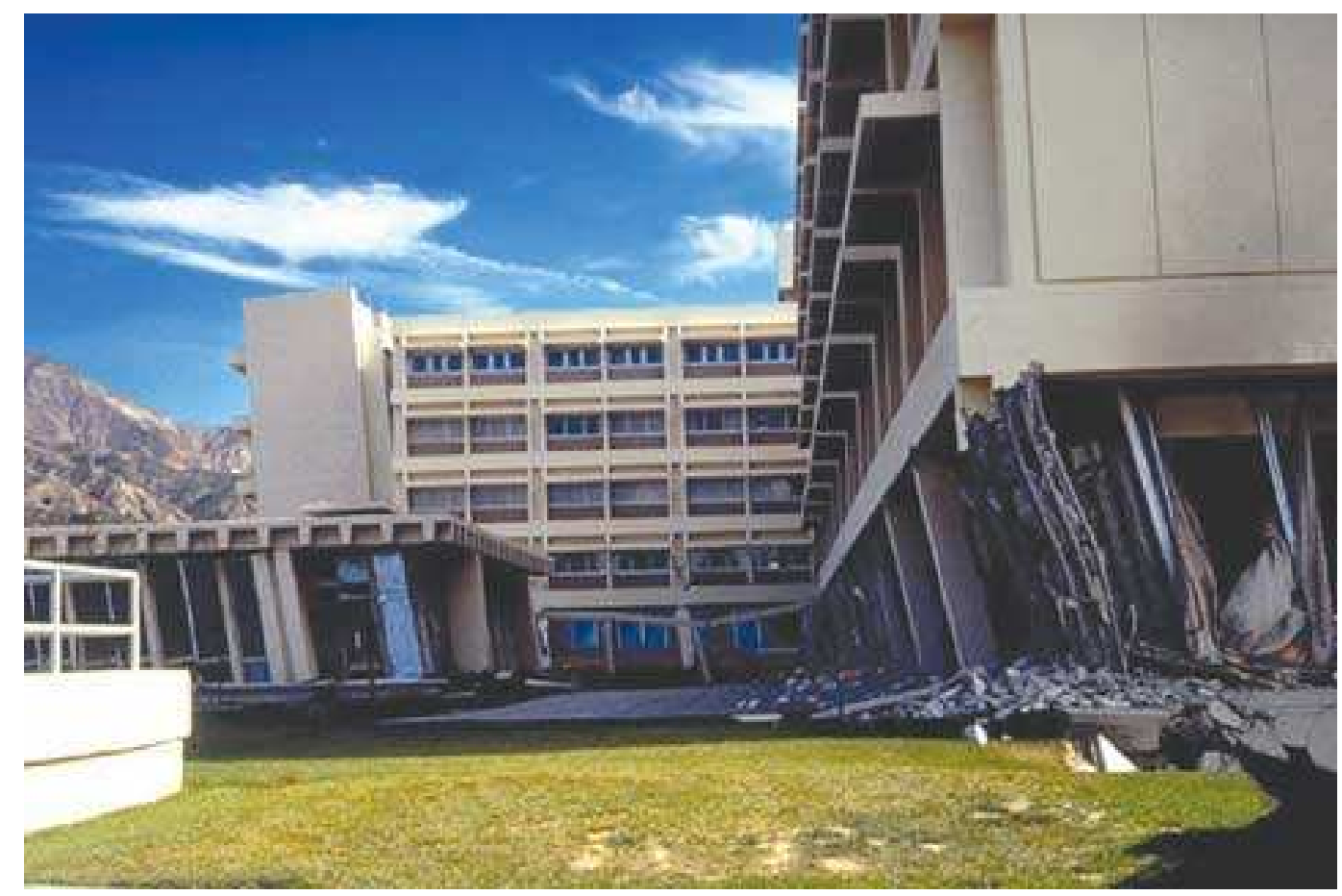

Figure 1.2. Seismic damage to Olive View Hospital, 1971 (USGS, 2005)

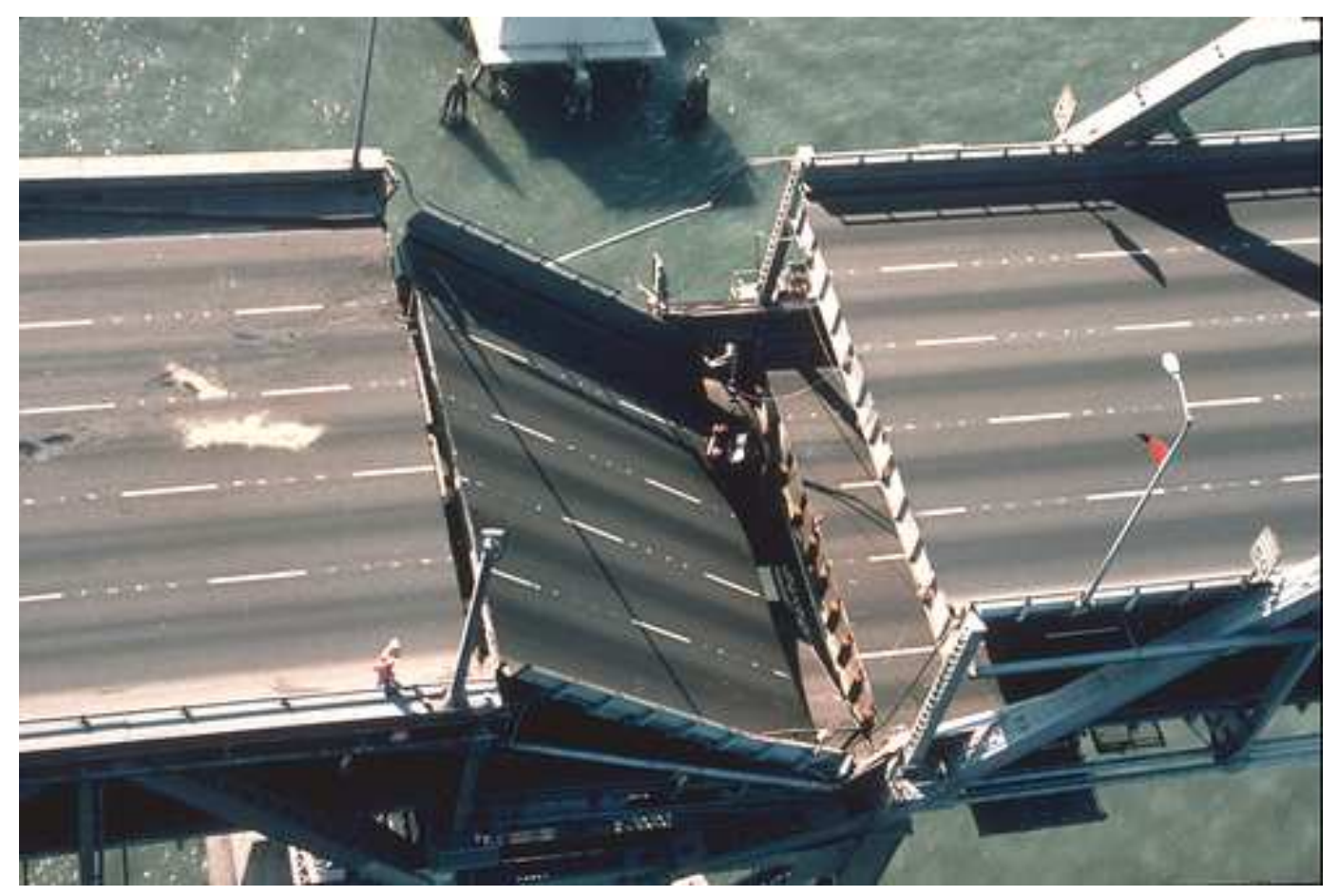

Figure 1.3. Bay Bridge collapse, 1989 (Eskenazi, 2009) 


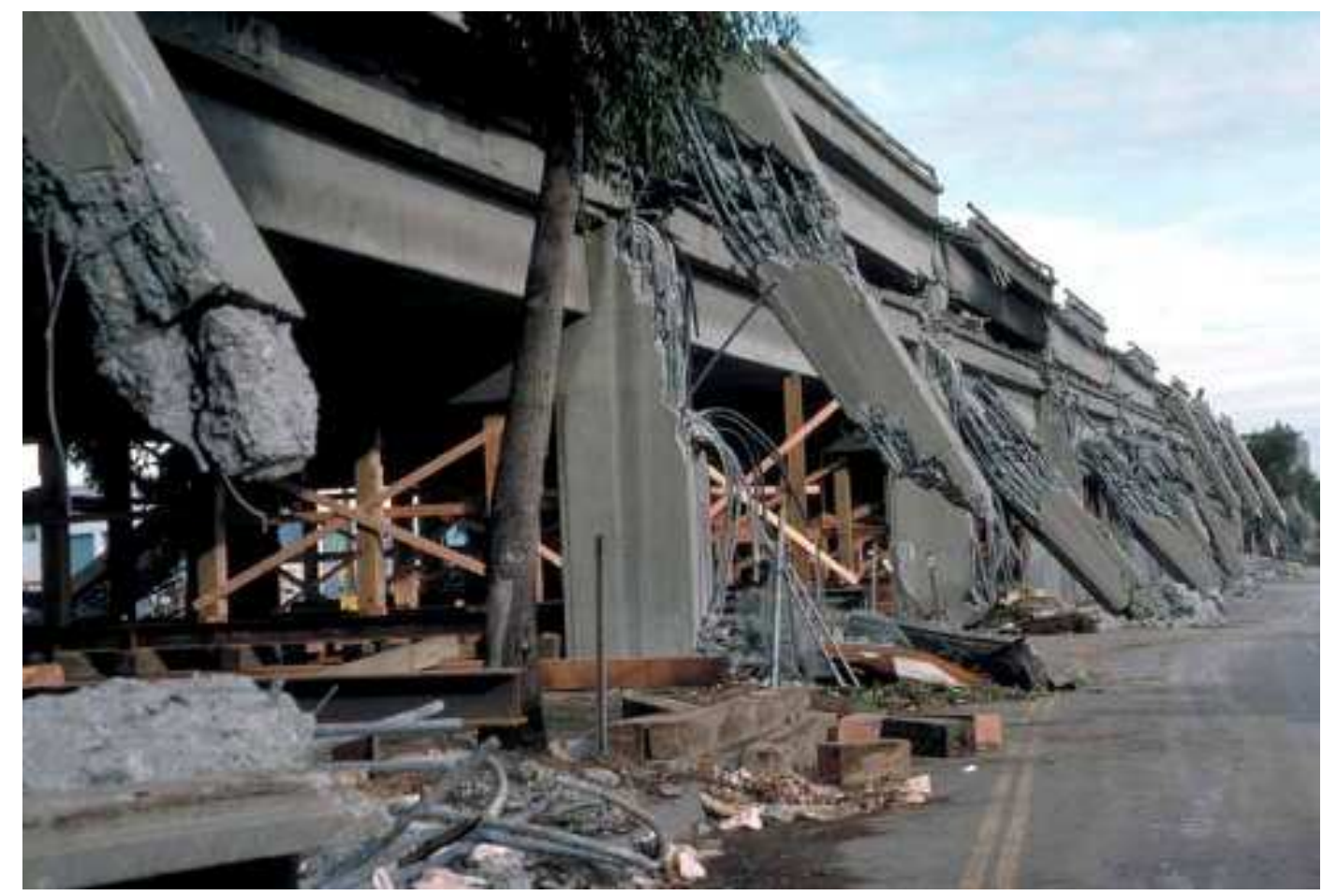

Figure 1.4. Cypress Street viaduct collapse, 1989 (USGS Online Publications Directory, 1999)

\subsection{Design Approaches}

The primary advancement in earthquake design in the years following the San Fernando earthquake and leading up to the Northridge earthquake was the transition from elastic design to ductile capacity design. With a more traditional elastic approach, the maximum expected earthquake loads are estimated and the structure is designed to remain elastic when exposed to the maximum loads. The capacity design philosophy implements a different approach. Rather than attempting to strong-arm the structure into remaining elastic under even the maximum earthquake loads, capacity design seeks to allow portions of the structure to behave inelastically under very large loads, recognizing that much more energy is dissipated in the structure if it is allowed to undergo inelastic deformation. The key to capacity design is that the inelastic behavior is restricted to carefully defined regions of the structure. These regions are typically referred to as plastic hinges, and they are intentionally detailed to maintain their strength even while undergoing plastic deformation. The plastic hinge formation allows the structure to undergo large deformations and dissipate large amounts of energy without producing inelastic behavior in the remainder of the structure. The result is that other regions of the structure remain elastic under large seismic loads, and the structure as a whole can experience large plastic 
deformations while retaining its strength and preventing collapse, with the inelastic damage restricted to the plastic hinge regions.

In bridges, designs typically seek to allow plastic hinge formation in the columns to prevent inelastic behavior in the superstructure. The columns become obviously crucial components to the seismic behavior of the bridge, needing to allow plastic hinge formation but maintain ability to support selfweight along with circumstantial live load at the time of an earthquake. The superstructure elements are also critical for proper capacity design behavior, because the superstructure needs to remain elastic in order to form the plastic hinge in the column. To accomplish such a design, the overstrength loads and moments are determined that will develop in the portions of the structure that are designed to experience inelastic behavior during large seismic events. These overstrength actions are then used as design forces for the remaining portions of the structure using a more typical elastic design approach.

\subsection{Accelerated Bridge Construction}

Accelerated Bridge Construction ( $A B C$ ) methods are increasingly desired to be implemented because of the many advantages such methods offer. $A B C$ methods allow the total field construction time to be significantly reduced when compared to traditional field construction techniques. The primary underlying technique to a variety of $A B C$ approaches is to use prefabricated components, thus diverting construction time from the field and into the controlled shop environment. Precast concrete members, in particular, are used heavily in $A B C$ projects. If precast concrete members are utilized, components can simply be pieced together in the field, rather than all of the formwork, concrete placement, and curing time that is required with traditional cast-in-place concrete techniques. One example of the time-savings that can occur with the implementation of $A B C$ methods is the U.S. 6 Keg Creek Bridge in lowa, as shown in a construction photograph in Figure 1.5. According to AASHTO, the construction time on this project was cut from approximately six months using normal field construction methods to a total time of only two weeks (AASHTO, 2011). 


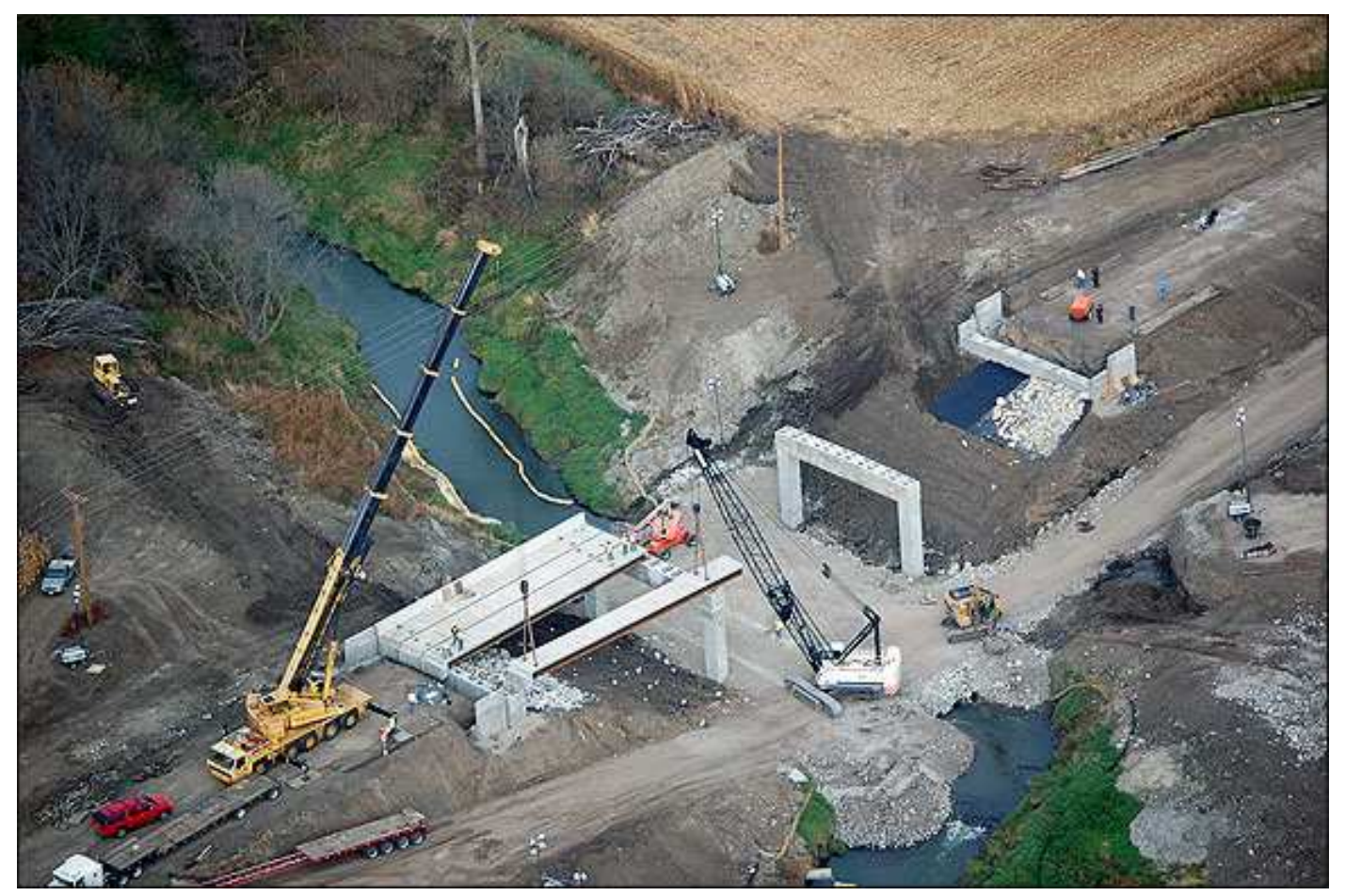

Figure 1.5. Keg Creek Bridge constructed using $A B C$ methods (AASHTO, 2011)

Such reduction in construction time brings many tangential benefits. First, traffic diversion during construction is significantly decreased, and consequently traffic and jobsite safety is increased (International Federation of Structural Concrete, 2007). Reduced time in the field also serves to minimize the environmental impact of such projects. In addition, because $A B C$ methods incorporate prefabricated components, further benefits are realized by moving much of the construction process into controlled shop environments. Some of the benefits of such prefabrication that have been observed and cited by the Federal Highway Administration (FHWA) over the years include improved constructability, increased quality, and lower life cycle costs (2006).

A topic that is still being explored is the cost of implementing $A B C$ methods versus conventional bridge construction. Since field labor tends to be more costly than shop work, the FHWA notes that $A B C$ methods can at times reduce overall cost by decreasing field time (2010). However, since the use of $A B C$ often implements new technology and introduces new challenges, the construction cost of $A B C$ projects can be higher than construction cost with conventional methods. For example, the construction cost of the lowa Department of Transportation's Keg Creek Bridge project, which was a demonstration ABC project, was about 30 percent higher than the expected cost of a similar bridge built using conventional 
construction techniques (lowa Department of Transportation, 2012). The FHWA has done some work in comparing costs of completed $A B C$ projects to costs of comparable conventional construction methods (FHWA, 2012). This investigation has shown that some completed ABC projects have cost more than would be expected using conventional methods, and some have cost less. However, the FHWA has concluded that the implementation of $A B C$ is very cost-competitive when considering total cost of projects, including lost income due to diversion of traffic and costs related to environmental impact during construction. In addition, as $A B C$ continues to be promoted and becomes more standard practice, the cost of $A B C$ will continue to be reduced because of multiple-use benefits and increasing familiarity with the technology.

As a result of the many benefits associated with $A B C$ techniques, states around the country are pursuing a variety of ways to incorporate such methods. While brief searches related to almost any one of the many state departments of transportation around the country will yield some mention of and interest in $A B C$ methods, states that the FHWA specifically cites as having undertaken significant $A B C$ work include Utah, Florida, New York, Virginia, lowa, Washington State, Louisiana, Texas, and South Carolina (FHWA, 2009 and 2010). Figure 1.6 shows a photograph of Utah's Lambs Canyon Bridge constructed using $A B C$ methods.

While it is clear, given its widespread cross-country implementation, that the $A B C$ era of bridge construction is being realized, bridge engineers in seismic regions have been hesitant to fully embrace $A B C$ methods given the difficulties with connection design between prefabricated components. Historically, precast concrete components have been not been the first choice for structures designed to withstand significant earthquake loads, because the connections between such components have not been observed to behave well under such conditions. The connection failures in such structures prevent plastic hinge formation and have been observed to produce significant failures and even structural collapse. Figure 1.7 shows an example of such a failure from the 1994 Northridge Earthquake, where the members themselves remain largely intact but the damage in the connection regions causes overall structural failure. This failure, along with other failures in similar structures, was due to poor connection details and the choice of an undesirable load path more suited to typical gravity load requirements but not carefully designed and detailed for lateral seismic effects. 


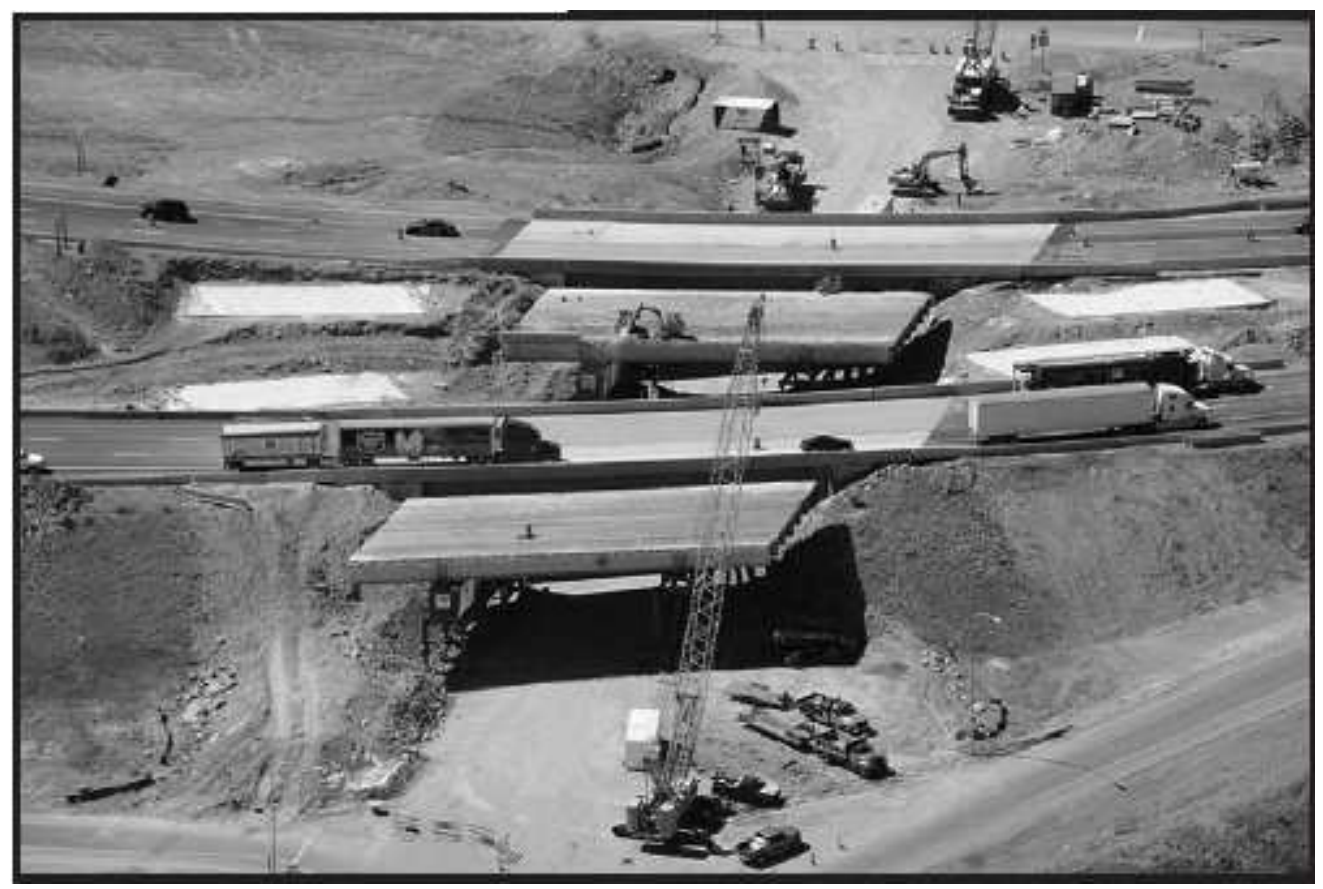

Figure 1.6. Lambs Canyon Bridge constructed using ABC methods (FHWA, 2010)

Despite the difficulties with connections related to high seismic loads, a recent NCHRP scan study shows the interest in developing seismic-sufficient connections suitable for $A B C$ techniques. The study, "Application of Accelerated Bridge Construction Connections in Moderate-to-High Seismic Regions," sought to identify connection details that are used in the United States and have performed well under extreme events (NCHRP, 2011). It included an extensive survey of nine states with one or more extreme events and a known history of interest in $A B C$ methods. 


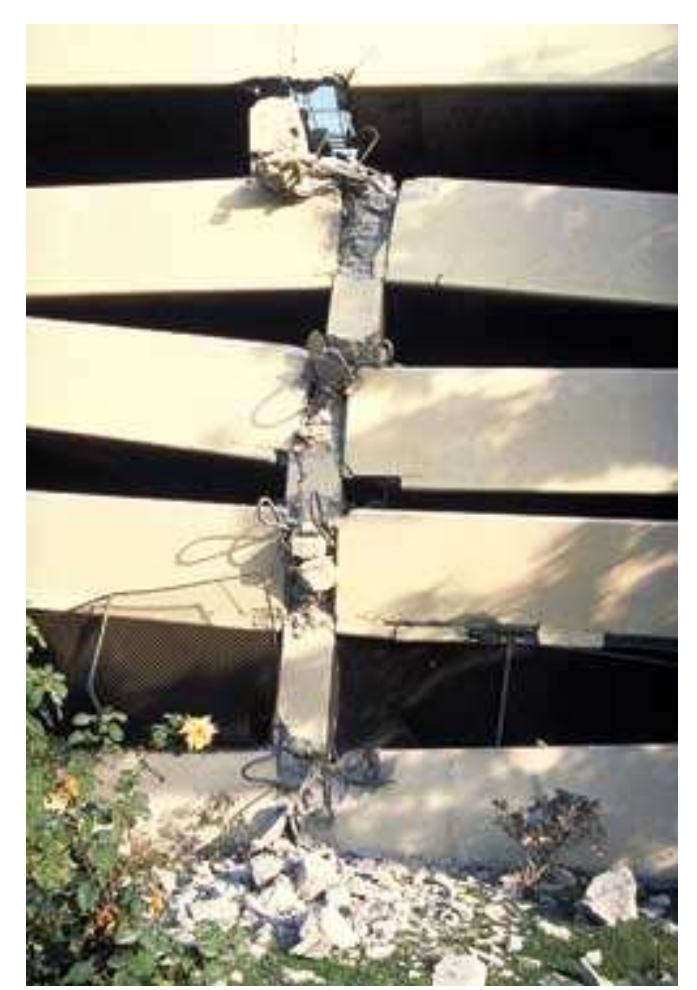

Figure 1.7. Collapsed parking structure, 1994 (SEAOC, 2010)

Caltrans in particular is eager to develop connection details that are suited to quick field installation of precast components, yet reliable and durable when subjected to seismic loading. The development of such details will allow and promote the use of precast concrete components designed according to capacity design principles that can also incorporate $A B C$ methods and all of the associated benefits. Increased experience with $A B C$ methods in seismic regions will also be beneficial in quickly and responsibly replacing damaged structures after future earthquakes.

\subsection{Connection systems: inverted-tee}

Current bridge data from Caltrans shows that cast-in-place concrete accounts for over $70 \%$ of the material in bridge projects, while precast concrete accounts for less than $25 \%$ of the material (Caltrans, 2010). A common design implemented by Caltrans is the use of cast-in-place box-girders integrally connected to a cast-in-place concrete cap beam (Caltrans, 2011). Cast-in-place designs are often still preferred because of the belief that such designs are more reliable in seismic events, tend to have lower construction costs, and can be better suited for longer spans. However, a different detail that utilizes an inverted-tee bent cap integrally connected to precast girders has been occasionally implemented for 
decades for bridges with shorter spans. This detail is increasingly desirable since its configuration tends to allow quick installation of girders and thus works well in projects where $A B C$ methods are needed or desired (Thiemann, 2009). It is typically implemented by using a cast-in-place column with an invertedtee cap beam that can be either cast-in-place or precast and set in place. Once the cap beam is positioned, the ledge, or corbel, on each side of the cap beam stem works well to support the dapped end of precast girders which can then be attached to the cap beam by the use of a cast-in-place diaphragm. The dapped-end-girder to inverted-tee concept is shown in Figure 1.8. Finally, the bridge deck can be cast-in-place over the completed superstructure. Such a configuration has recently been used in projects where existing structures are widened, to allow for relatively quick construction time and reduced field work.

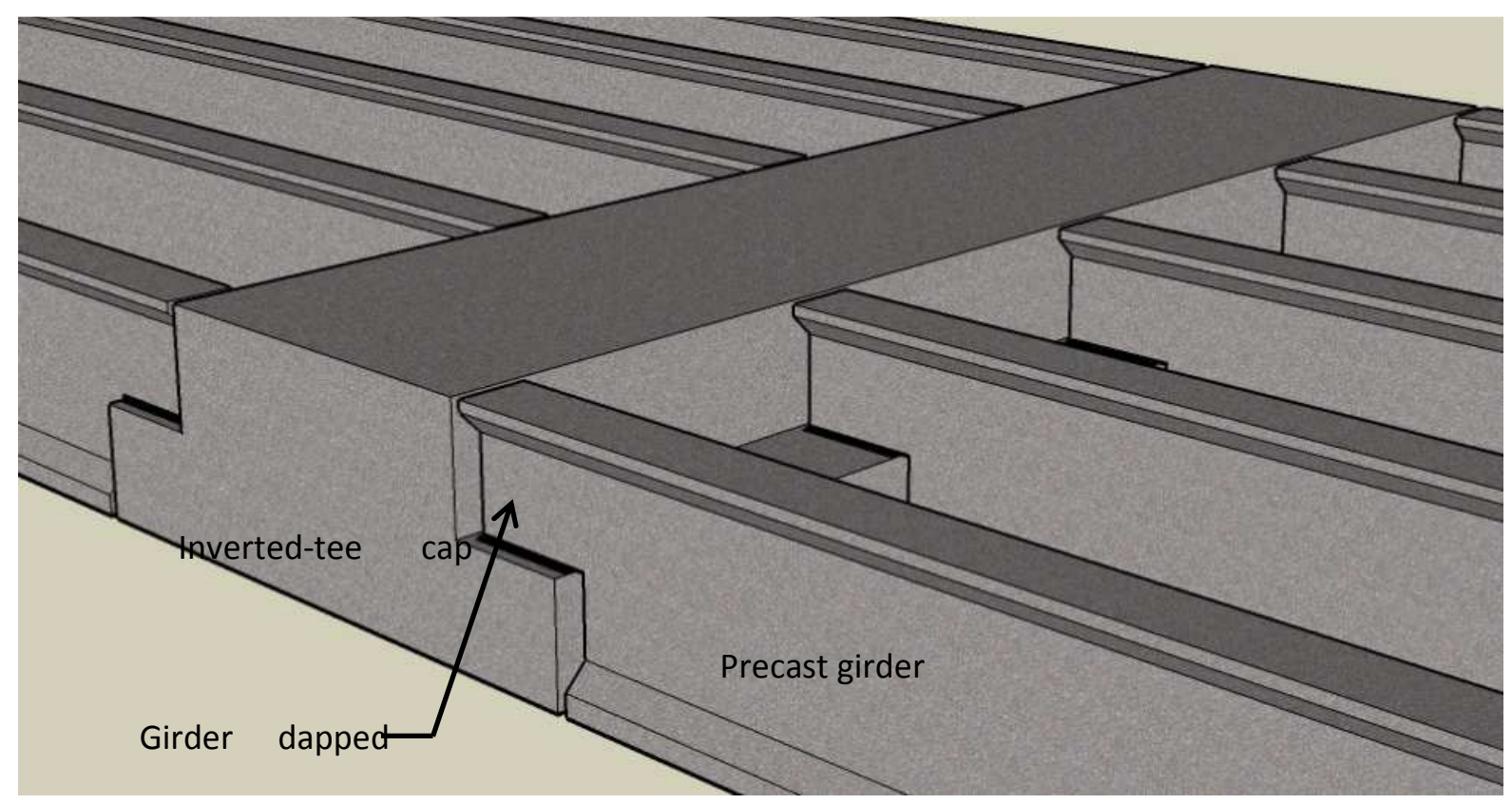

Figure 1.8. Inverted-tee and girder dapped end connection

The inverted-tee bent cap is well-suited to allow the use of precast concrete girders. Using precast components is advantageous in utilizing $A B C$ methods and the advantages discussed earlier. Also, the connection configuration of precast girders and inverted-tee cap beam allows increased clearance and thus reduced overall height from typical cap-girder configurations, since the girders can be located in line with the cap beam and do not need to be located on top of the cap beam. Such reduction in height 
will typically reduce material consumption and construction cost and will also normally be beneficial in improving seismic behavior (Snyder et al., 2011).

The approach that is typically implemented for the design of the dapped end is a strut-and-tie analysis, because this region is congested and experiences a complex load path that does not follow simple beam behavior. Using the strut-and-tie method, the forces in the connection region of the girder are approximated as compression struts and tension ties, so the end region of the girder is treated not so much as a solid, three-dimensional element but more like a combination of two-dimensional truss elements. An example a strut-and-tie model for a dapped end is shown in Figure 1.9, where the solid lines represent tension ties and the dashed lines represent compression struts. Design implementation of this analytical model is accomplished by ensuring that sufficient reinforcement is provided to carry the forces in the tension ties while sufficient confinement is provided to ensure that the concrete can successfully transfer the compression strut forces.

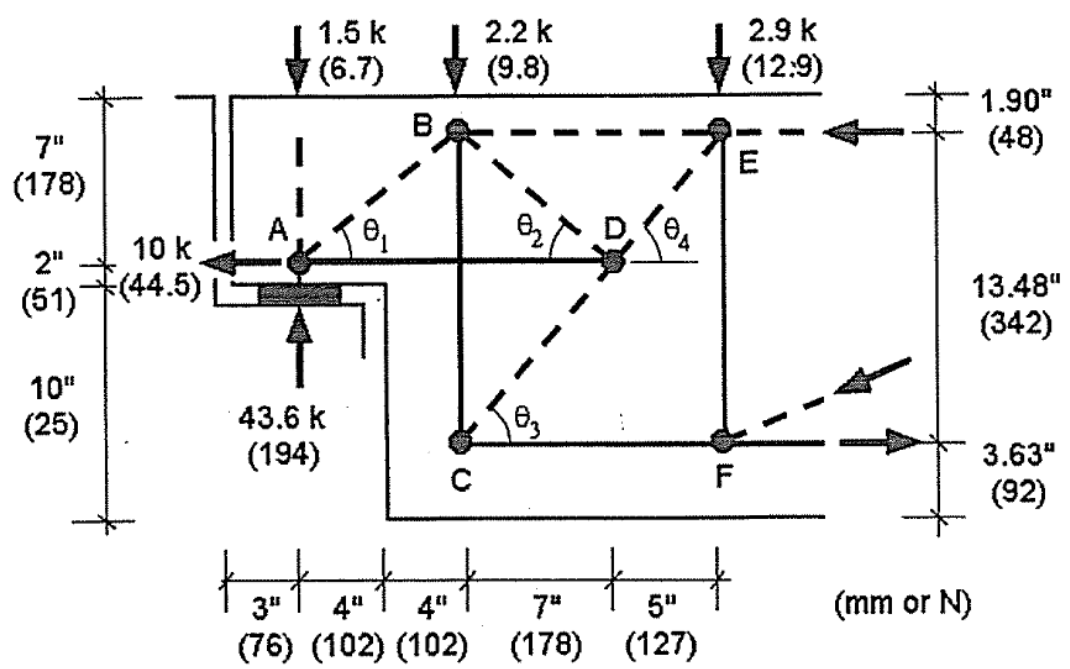

Figure 1.9. Example of strut-and-tie analysis for a girder dapped end (Sanders, 2002)

\subsection{Current Practice}

\subsubsection{Moment capacity of inverted-tee connection}

Current Caltrans design recommendations stipulate that the cap-to-girder connection in the standard inverted-tee detail be regarded as a connection with zero moment resistance under seismic loading. Development of a "pin" connection at the girder-to-cap connection disallows the opportunity of 
detailing the column top as a plastic hinge region, thus decreasing the effectiveness of the overall design for seismic regions. While Caltrans assumes the inverted-tee connection to behave as pinned under seismic loading, recent research (discussed more below) has shown that the connection in fact has significant moment capacity. This difference in assumed versus actual behavior leads to two items of interest. First, since the girder connection is assumed to be pinned under seismic loading, the top of the column may not be detailed appropriately for the moment that is actually developed in the cap-tocolumn connection, leading to possible loss of confinement and poor structural performance in the upper region of the column. Second, from a design standpoint, the base of the column is designed for a significantly larger-than-realistic moment. The design of the foundation, accordingly, will be significantly oversized and significantly more costly than necessary for the actual loads that will be experienced. Proper recognition of the moment capacity of the girder connection will allow the design concept for the structure to be adjusted, detailing both the top and bottom of the column as moment (and, subsequently, plastic hinge) regions, and designing the foundation more cost effectively because of the reduction in column base moment.

Significant analytical and experimental work examining the moment capacity of the inverted-tee connection detail has already been completed. This work included a large-scale experimental system test that was conducted jointly by lowa State University, the University of California-San Diego, and Caltrans in 2010 (Snyder et. al., 2011). The test consisted of a full bridge system test that utilized two phases of testing on a fifty-percent scale model test unit of the center portion of a prototype bridge consisting of an inverted-tee cap beam and five precast I-shaped girders. The test incorporated an asbuilt Caltrans connection for the five girders on one side of the cap beam while using an improved connection in the five girders on the opposite side of the cap beam. The system test revealed that although Caltrans currently treats the as-built connection as a pinned-connection, it actually has significant moment capacity and provided sufficient moment resistance to successfully form a plastic hinge at the top of the column. However, the system test also revealed that, while the as-built connection performed satisfactorily, the improved connection performed considerably better and exhibited higher moment strength than the as-built connection. In fact, deterioration of the as-built connection during the test prohibited full quantification of the improved connection, which remained essentially elastic for the entirety of the test. A detailed presentation of the experimental work in the system test, including further analysis of the results, are presented in Chapter 3 of this dissertation. 


\subsubsection{Seismic lateral load distribution}

Another limitation of current practice related to inverted-tee connections, and integral bridge connections in general, is that the load distribution of the column overstrength moment in a seismic event to the girders in the superstructure is generally approached very conservatively in an overly simplistic manner that does not recognize the true behavior of integral connections. Normal practice, including AASHTO's LRFD specifications (AASHTO, 2010) and AASHTO's seismic-specific recommendations (AASHTO, 2009) allow little or no distribution of the column moment due to lateral load beyond the girders that are immediately adjacent to the column, as shown in Figure 1.10. Caltrans' own design practice, as specified in their Seismic Design Criteria (Caltrans, 2010) and Bridge Design Aids (Caltrans, 1989), allows for the distribution of the lateral load in a fanning-out pattern as the distance from the connection region increases, as shown in Figure 1.11. However, this pattern does not allow for any more distribution of the load in the girder-to-cap connection region, which as has been mentioned previously is the critical portion of the superstructure when prefabricated components are utilized.

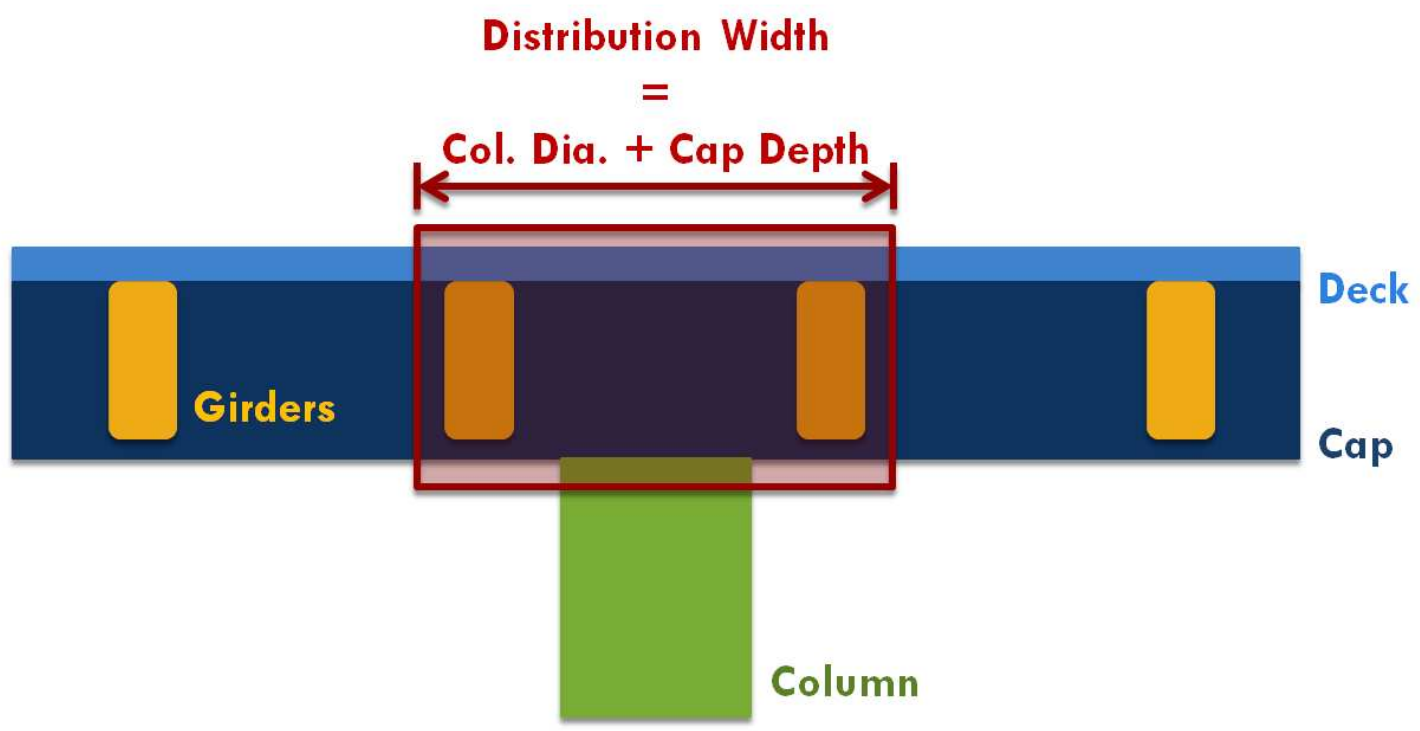

Figure 1.10. AASHTO distribution of column overstrength moment to girders (elevation) 


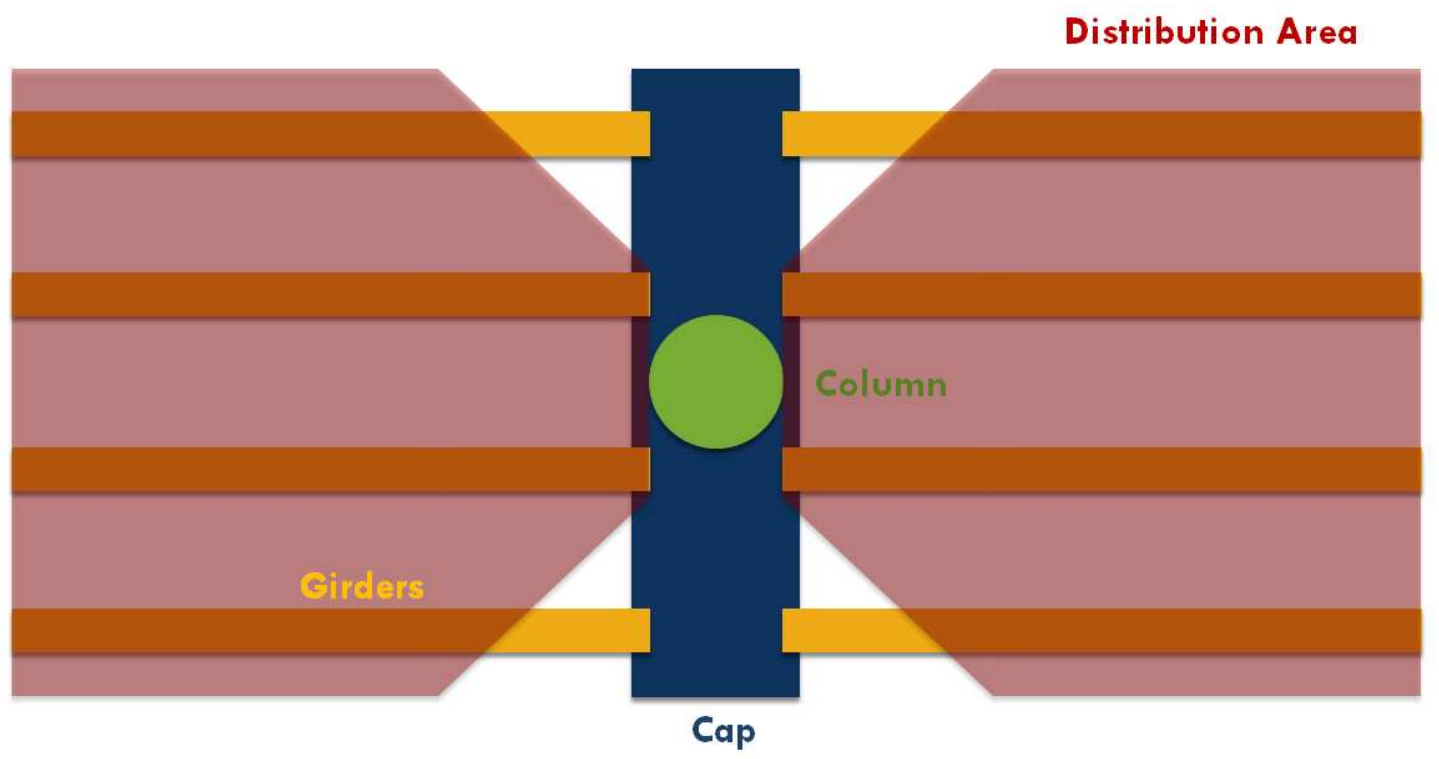

Figure 1.11. Caltrans distribution of column overstrength moment to girders (plan)

In contrast to the design recommendations, recent experimental work has shown significant distribution of the lateral load beyond the adjacent girders to intermediate and exterior girders in the superstructure. Strain-gage results from the Caltrans system test presented above have already been investigated to determine the amount of lateral load that was distributed from the center region near the column to the intermediate and exterior girders of the superstructure. This investigation has revealed that, as expected, significant levels of the lateral load were transferred to the intermediate and exterior girders, contrary to current design practice and recommendations. This distribution study has been extended to include experimental results from three other large scale tests that were conducted since the late 1990's on integral bridge structures, including a four-girder precast concrete structure tested at the University of California-San Diego (Holombo et al., 2000) and two four-girder steel structures tested at lowa State University in 2001 and 2002 (Sritharan et al., 2005). These structures have been found to have exhibited similar tendencies in providing significant load transfer of the lateral load to the exterior girders.

Progress related to this work was presented in 2012 (Vander Werff and Sritharan, 2012), and a detailed investigation of this issue is presented in Chapter 4 of this dissertation. Better recognition of the actual load distribution will simplify the design of the transitions between column, cap, and girders, 
since unrealistic amounts of load will no longer need to be designed for in the girder connections that are in immediate proximity to the column.

\subsubsection{Seismic vertical acceleration effects}

A facet of the seismic design of bridges that is under scrutiny is the ability of the structure to resist the effects of vertical acceleration during a seismic event. Historically, the focus of seismic load has been on lateral load due to horizontal ground motion. Primary focus on horizontal loading has merit, since horizontal seismic loads are typically significantly higher than the vertical seismic loads, maximum vertical seismic loads typically do not occur simultaneously with maximum horizontal seismic loads, and structures are typically better suited to handle vertical seismic loads since they are designed primarily to resist vertical dead and live loads.

However, recent seismic events have revealed that vertical acceleration might also play a role in increasing damage to structures. One example of such an event was the February 22, 2011, earthquake in Christchurch, New Zealand. Figure 1.12 shows horizontal and vertical accelerations recorded during the earthquake, with maximum vertical accelerations in the vicinity of $2 \mathrm{~g}$. Such large vertical accelerations greatly exceeded the expected 2500-year motion vertical spectra (Kam and Pampanin, 2011). The impact of large vertical accelerations on bridge structures has not been carefully considered in most seismic research. The contribution of vertical acceleration is of particular interest, since vertical acceleration will affect the vertical shear at the girder-to-cap connection, a region of the structure which is already subject to scrutiny for its seismic performance. The vertical acceleration effect in the connection region is of particular interest when considering the use of precast components versus castin-place techniques, since the connection region is so critical for good seismic performance, as discussed earlier. 


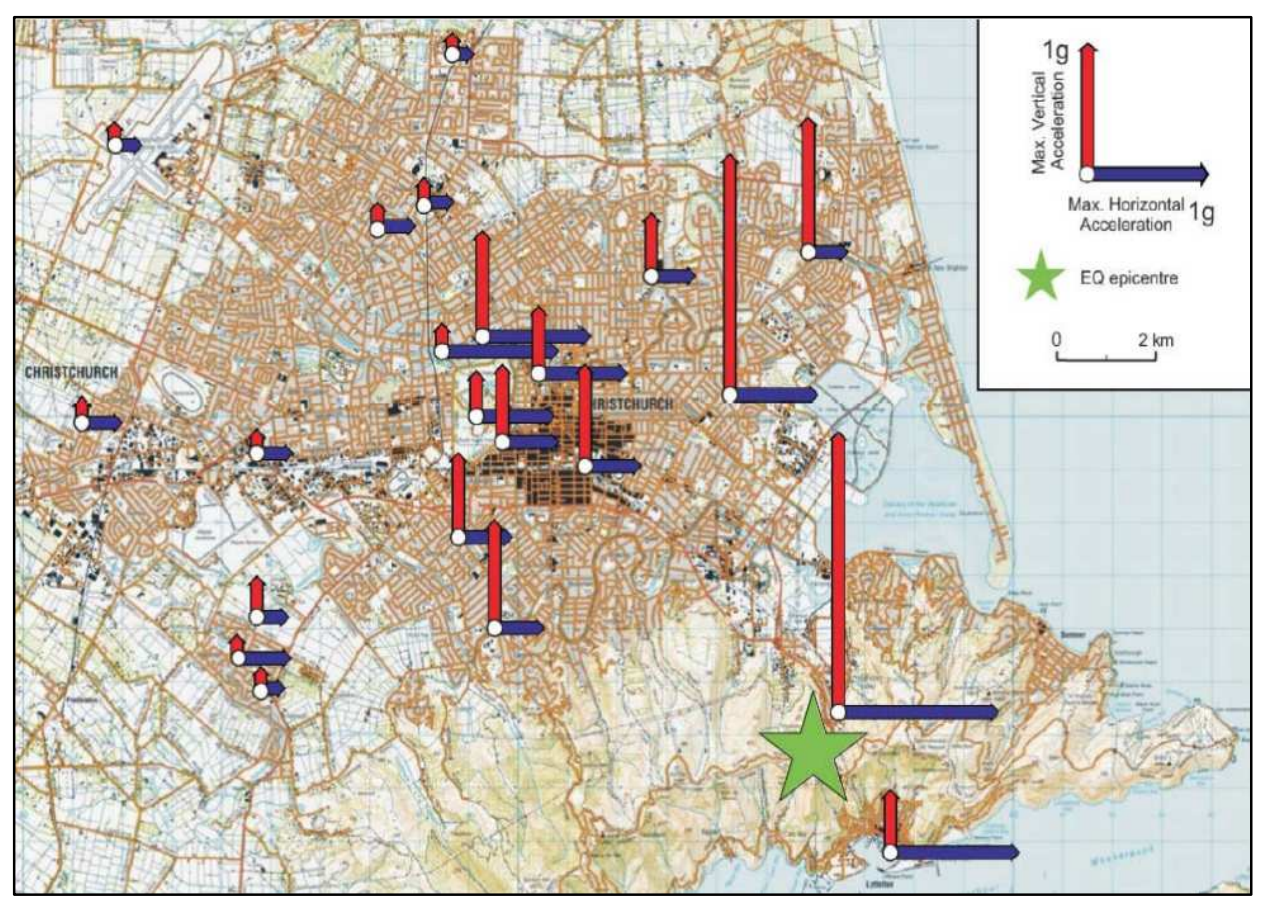

Figure 1.12. Recorded peak ground accelerations during Christchurch earthquake February 22, 2011 (Kam and Pampanin, 2011)

A detailed study of vertical acceleration effects on the inverted-tee bridge system has been conducted. Both the experimental results and different analytical approaches have been used to determine the sufficiency of integral bridge connections to withstand the influence of vertical ground motion. The results of this study are presented in Chapter 6 of this dissertation.

\subsection{Research Summary}

Challenges to the incorporation of precast concrete and $A B C$ techniques in seismic regions have briefly been presented in the preceding sections, including lack of confidence in the integral performance of precast connections, inaccurate methods of load distribution, and absence of research related to behavior related to seismic vertical acceleration. These issues have been addressed in the work presented in this dissertation by advancing the analytical and experimental investigation of the behavior of precast concrete girder-to-cap connections. Design recommendations related to girder load distribution and connection design have been developed, and the influence of vertical acceleration on the girder connections has been explored in depth. This work will continue to promote and advance the use precast concrete in the implementation of $A B C$ methods. 


\subsection{Dissertation Organization}

Following the introductory chapter, Chapter 2 presents a literature review of work related to seismic design for integral bridges and advancements in the area of accelerated bridge construction for such structures. Chapters 3, 4, 5, and 6 are written as journal articles. Chapter 3 presents the experimental investigation of the inverted-tee bridge system, examining the overall performance of the system and critiquing the sufficiency Caltrans' current girder-to-cap connection detail. Chapter 4 focuses on the experimental study of two specific girder-to-cap connection details, validating their sufficiency for high seismic regions. Chapter 5 examines the lateral load distribution through integral bridge superstructures and shows how non-adjacent girders carry significant amounts of lateral load, contrary to the current design recommendations. Chapter 6 focuses on the analytical investigation of the system and superstructure connections, with a specific focus on the behavior of integral bridge structures subjected to the vertical acceleration. Chapter 7 concludes the dissertation, providing a summary of the research presented in the preceding chapters and final recommendations.

\subsection{References}

AASHTO. (2011). "US 6 Keg Creek Bridge." America's Transportation Awards. Washington D.C: AASHTO. Online: http://www.americastransportationaward.org/Default.aspx?ContentID=250. Accessed October 2012.

AASHTO. (2010). LRFD Bridge Design Specifications, $5^{\text {th }}$ Edition. Washington, D.C.: AASHTO.

AASHTO. (2009). Guide Specifications for LRFD Seismic Bridge Design. Washington, D.C.: AASHTO.

Caltrans. (2012). Seismic Retrofit Program. Sacramento, California: Caltrans. Online: http://www.dot.ca.gov/hq/paffairs/about/retrofit.htm. Accessed October 2012.

Caltrans. (2011). Bridge Design Practice Manual. Sacramento, California: Caltrans. Online: http://www.dot.ca.gov/hq/esc/techpubs/manual/bridgemanuals/bridge-design-practice/bdp.html. Accessed August 2012.

Caltrans. (2010). "Caltrans Precast Concrete Committee Update." Presented at the 2010 Caltrans/PCMAC/Consultants Bridge Workshop, Nov. $3^{\text {rd }}$, 2010. Online: http://www.precastconcrete.org/seminars/2010/2010-09.pdf. Accessed December 2012.

Caltrans. (2010). Seismic Design Criteria, Version 1.6. Sacramento, California: Caltrans. Online: http://www.dot.ca.gov/hq/esc/earthquake_engineering/SDC_site/2010-11-

17_SDC_1.6_Full_Version_OEE_Release.pdf. Accessed August 2012. 
Caltrans. (1989). Bridge Design Aids. Sacramento, California: California Department of Transportation (Caltrans). Online: http://www.dot.ca.gov/hq/esc/techpubs/manual/bridgemanuals/bridge-designaids/bda.html. Accessed August 2012.

Caltrans Seismic Advisory Board, J. Penzien, Chairman. (2003). The Race to Seismic Safety, Protecting California's Transportation System. Submitted to the Director, California Department of Transportation.

Eskenazi, Joe. (2009). "Shakedown +20: Remembering the Loma Prieta Quake of 1989. Today's Edition: Mama Mia." SF Weekly. October 7, 2009. Online: http://blogs.sfweekly.com/thesnitch/2009/10/ shakedown_20_remembering_the_b.php. Accessed October 2012.

Federal Highway Administration. (2010). "Fact Sheet 16 - States Across the Country Implement Accelerated Bridge Construction." Publication No. FHWA-HOP-11-006. Washington, D.C.: U.S. Department of Transportation. Online: http://www.ops.fhwa.dot.gov/wz/practices/factsheets/ factsheet16/index.htm. Accessed October 2012.

Federal Highway Administration. (2010). "FHWA Bridge Conference Spotlights Opportunities and Successes in Accelerated Bridge Construction." Publication No. FHWA-HRT-10-017. Washington, D.C.: U. S. Department of Transportation. Online: http://www.fhwa.dot.gov/publications/ focus/10sep/01.cfm. Accessed August 2012.

Federal Highway Administration. (2009). "Accelerated Bridge Construction Picks Up Steam." Innovator: Accelerating Innovation for the American Driving Experience. Volume 2, Issue 11, February/March 2009. Publication No. FHWA-HIF-09-032. Washington, D.C.: U.S. Department of Transportation. Online: http://www.fhwa.dot.gov/hfl/innovator/pdfs/issue11.pdf. Accessed October 2012.

Federal Highway Administration. (2006). "Rapid Bridge Construction: How to Get There." 2006 Concrete Bridge Conference Workshop. Washington, D.C.: U. S. Department of Transportation. Online: http://www.fhwa.dot.gov/bridge/prefab/pbesreport.cfm. Accessed October 2012.

Housner, George W., \& Charles C. Thiel, Jr. (1990). Competing Against Time: Report of the Governor's Board of Inquiry on the 1989 Loma Prieta Earthquake. Earthquake Spectra, 6(4), pp.681-711.

Holombo, J., M. J. N. Priestley, F. Seible. (2000). “Continuity of Precast Prestressed Spliced-Girder Bridges Under Seismic Loads." PCI Journal. Volume 45, Number 2, March-April 2000, pp. 40-63.

International Federation of Structural Concrete. (2007). Seismic Bridge Design and Retrofit - Structural Solutions. (Volume 39). Lausanne, Switzerland: FIB.

lowa Department of Transportation. (2012). "U.S. 6 bridge over Keg Creek." Ames, lowa: lowa Department of Transportation. Online: http://www.iowadot.gov/us6KegCreek/projectinfo.html. Accessed December 2012. 
Kam, Weng Yuen and Stefano Pampanin. (2011). General Building Performance in the Christchurch CBD: a contextual report. Christchurch, New Zealand: University of Canterbury. Online: http://www.dbh.govt.nz/UserFiles/File/Reports/quake-contextual-report-canterbury-uni.pdf. Accessed October 2012.

NCHRP (2011). "Application of Accelerated Bridge Construction Connections in Moderate-to-High Seismic Regions." NCHRP Report 698. Washington, D.C.: Transportation Research Board.

Priestley, M. J. N., F. Seible, and G. M. Calvi. (1996). Seismic Design and Retrofit of Bridges. New York: John Wiley \& Sons, Inc.

Sanders, David H. (2002). "Example 2: Dapped-end T-beam supported by an inverted T-beam." Examples for the Design of Structural Concrete with Strut-and-Tie Models. Farmington Hills, Michigan: American Concrete Institute ( $\mathrm{ACl})$.

SEAOC. (2010). "Seismic Design of Concrete Parking Structure Ramps." Structure. July, 2010. Seismology Committee, Structural Engineers Association of California. Online: http://www.structuremag.org/ article.aspx?articlelD=1096. Accessed October 2012.

Shoup, Lilly, Nick Donohue, and Marissa Lang. (2011). The Fix We're In For: The State of Our Nation's Bridges. Washington, D.C.: Transportation for America.

Snyder, R.M., J. Vander Werff, Z. J. Thiemann, S. Sritharan, J. Holombo. (2011). Seismic Performance of an I-Girder to Inverted-T Bent Cap Connection, Final Report. Sacramento, California: Caltrans; and Ames, lowa: lowa State University.

Sritharan, S., J. Vander Werff, R. E. Abendroth, W. G. Wassef, L. F. Greimann. (2005). "Seismic Behavior of a Concrete/Steel Integral Bridge Pier System," Journal of Structural Engineering. Volume 131, Issue 7.

Stover, Carl W. and Jerry L. Coffman. (1993). Seismicity of the United States. Washington, D.C.: U.S. Geological Survey, United States Government Printing Office.

Thiemann, Zachary J. (2009). Pretest 3-D finite element analysis of the girder-to-cap-beam connection of an inverted-tee cap beam designed for seismic loadings. Masters degree thesis. Ames, lowa: lowa State University.

USGS. (2012). United States Geological Survey. Washington, D.C.: United States Geological Survey (USGS). Online: www.usgs.gov. Accessed October 2012.

USGS. (2005). U.S. Geological Survey Fact Sheet 068-03, Monitoring Earthquake Shaking in Buildings to Reduce Loss of Life and Property. Washington, D.C.: USGS. Online: http://pubs.usgs.gov/ fs/2003/fs068-03/. Accessed October 2012. 
USGS. (1999). USGS Online Publications Directory, Oakland. Washington, D.C.: USGS. Online: http://pubs.usgs.gov/dds/dds-29/web_pages/oakland.html. Accessed October 2012.

USGS. (1971). U.S. Geological Survey Photographic Library. Washington, D.C.: USGS. Online: http://libraryphoto.cr.usgs.gov/cgi-bin/show_picture.cgi?ID=ID.\%20Kachadoorian,\%20R.\%20\%20\% 20125c\&SIZE=medium. Accessed December 2012.

Vander Werff, Justin and Sri Sritharan. (2012). "Seismic Load Distribution between Girders in Integral Bridges." 2012 PCl Convention and National Bridge Conference. October 2012. Nashville, Tennessee: Precast Concrete Institute (PCI). 


\section{CHAPTER 2. LITERATURE REVIEW OF ABC IN SEISMIC REGIONS}

\subsection{Introduction}

Significant effort has been devoted to researching the seismic behavior of bridges, especially in the last couple decades as the utilization of capacity design principles have been increasingly recognized to provide dramatic increase in performance in seismic events. This chapter examines the current state of the art regarding research and work related to seismic bridge engineering. Specific areas of interest in the literature review conducted for this research work include accelerated bridge construction in seismic regions, connections for precast and segmental construction in seismic regions, girder load distribution due to vertical and lateral loading, and vertical seismic ground motion effects.

\subsection{Accelerated Bridge Construction in Seismic Regions}

\subsubsection{Background}

Accelerated bridge construction $(A B C)$ is being increasingly promoted and pursued by departments of transportation all across the country. Increased transportation demand related to economic and population growth is fueling the desire for rapid construction of bridge projects. Also, the need for improvements to the aging transportation infrastructure throughout the United States has increased the urgency for fast and efficient construction techniques. While brief searches related to almost any of the state departments of transportation across the country will yield some references to $A B C$ methods, states that the FHWA specifically cites as having undertaken significant ABC work include Utah, Florida, New York, Virginia, lowa, Washington State, Louisiana, Texas, and South Carolina (FHWA, 2009 and 2010).

In the few years since the FHWA study mentioned above, interest and work related to $A B C$ implementation has continued to increase. $A B C$ 's current relevance in bridge engineering is evident in the Bridge Engineering Handbook, Second Edition: Construction and Maintenance (Chen and Duan, 2014). An entire chapter in this updated handbook is devoted to $A B C$. This reference states that $A B C$ "using streamlined engineering processes and prefabricated elements and systems (PBES) demonstrated its worth through several pilot projects and is being accepted as an innovative practice in today's construction environment" (Chen and Duan, 2014). 


\subsubsection{Use of $A B C$ in Seismic Regions}

While much information has been published related to the use of accelerated bridge construction, the main focus of this study is its implementation in seismic regions. Although the use of $A B C$ techniques in seismic regions has been limited, considerable research work in the past several years has been devoted to adapting $A B C$ methods to meet the structural requirements for seismic regions.

The Transportation Research Board has put forth a concerted effort to promote the use of $A B C$ techniques in seismic regions. NCHRP Report 698 (Marsh et al., 2011), the culmination of a 2011 study, provides a literature review of the connections and systems that are currently in use or being studied for use in $A B C$. The review focused on connections for particular locations (pile to pile cap connections, connections between column segments, substructure to superstructure connections, for example) as well as connections for particular force transfer mechanisms (grouted ducts, integral connections, hybrid connections, etc.) The study rated the various connections using several different categories, including readiness for implementation, potential time savings, potential performance, construction risk, seismic performance, inspectability, and durability. Suggested research from this study includes work related to integral connections that form part of the load path for longitudinal seismic loading. Examples of particular areas of research include looking at flush-soffit cap beam type bridges where longitudinal post-tensioning may or may not be used and innovative connecting approaches beyond those currently in use for cap beams.

Ou et al. (2007) conducted an analytical study investigating the use of segmental columns for seismic regions. This study focused on a column detail that, at the time, had been primarily implemented in regions of low seismicity such as Florida, Texas, North Carolina, Virginia, and New Jersey. Using first a simplified analytical model incorporating a stat pushover approach followed by a detailed three-dimensional finite-element model and associated parametric study, this work investigated the appropriateness of a similar detail for high seismic regions such as California. Notable conclusions from this work included: (1) the simplified model for static pushover analysis provided a simple tool for the seismic design of segmental precast unbonded posttensioned columns, and (2) the 3D FE model was capable of predicting the experimental cyclic behavior of segmental columns with good accuracy. This work was continued when Ou et al. (2010) conducted an experimental study. The test setup utilized vertical actuators for gravity load and a horizontal actuator for lateral load as shown 
in Figure 2.1 to test four large-scale specimens. The study showed that the proposed columns performed well seismically, having significant ductility and good hysteretic behavior. Joint opening between the segments was found to contribute significantly in the drift and thus necessary to consider in design of similar systems for seismic regions.

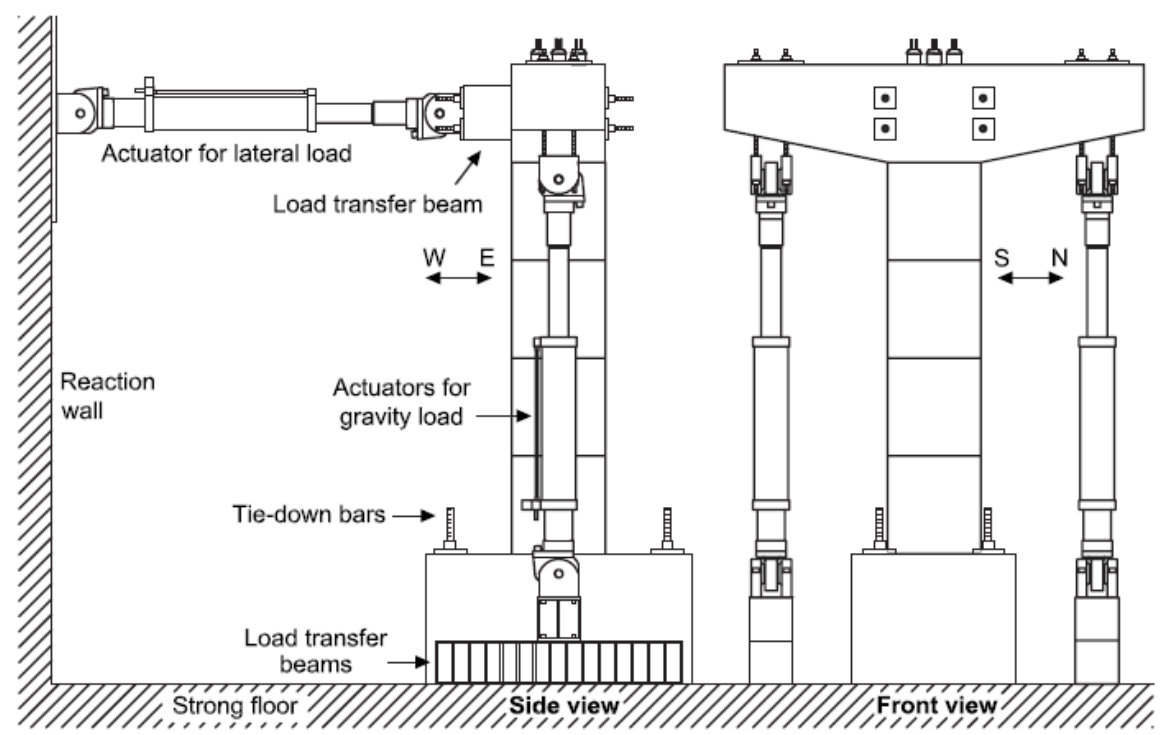

Figure 2.1. Segmental column test setup (Ou et at., 2010)

The Washington State Department of Transportation (WSDOT) is actively working to increase implementation of $A B C$ in seismic regions. A 2010 TRB article explains WSDOT's effort to develop practice and implementation of ABC (Kyaleghi, 2010).

\subsection{Connections for Segmental Construction in Seismic Regions}

Already in the early 2000's, NCHRP was conducting studies on connections between segmental elements to encourage the implementation of ABC techniques. NCHRP 519 (Miller et al., 2004) recommends details and specifications for the design of continuity connections for precast concrete girders, including examples illustrating the design of four precast girder types made continuous for live load. The intent of the study was to recommend connections that would achieve structural continuity and thus provide integral (moment and shear resistant) connections since traditional approaches to segmental construction often conservatively approximate segmental connections to be pins (i.e. simply supported). This study proposed several revisions to the AASHTO LRFD Bridge Design Specifications 
related to the following: (1) the definition of continuous precast/prestressed concrete bridges, (2) timedependent material properties and analysis methods for continuous precast/prestressed concrete bridges, (3) effect of girder age on the connection continuity, (4) more realistic treatment of cracking effects in connection continuity, (5) design limits for service and strength limit states, (6) clarification of negative moment connection specifications, (7) possibilities for positive moment continuity connections, and (8) detailing requirements.

"Modeling of Jointed Connections in Segmental Bridges" (Veletzos and Restrepo, 2010) presents a segment joint modeling approach as a first step toward accurately estimating the seismic response of the superstructure joints due to input ground motions. The approach combines complex continuum mechanics with a simplified model utilizing rotational springs, including nonlinear tendon-grout slip response. The study included validation from large-scale experiments.

Related to the study mentioned above, "Equivalent Unbonded Length for Modeling of Multistrand Tendons in Precast Segmental Construction" (Veletzos, 2014) presents results and conclusions from a large-scale experimental research program that investigated the debonding characteristics of multistrand tendons. This study concluded that tendon slip relative to grout is small in comparison with the slip between the duct and the surrounding concrete. The study also developed an equation to evaluate the equivalent unbounded length of multistrand tendons, intended to be directly applied to nonlinear modeling of the segment joint response.

\subsection{Girder Load Distribution in Integral Bridges}

\subsubsection{Background}

Advantages associated with integral bridges have led to increased implementation, but design recommendations for such structures continue to be limited in some critical areas. The distribution of lateral load among girders in the superstructure is a particular aspect of integral bridge design that has not been addressed adequately. AASHTO, the standard for bridge design in the United States, provides very little information related to the distribution of lateral seismic loads. Other design documents directed specifically towards seismic regions, such as Caltrans' Seismic Design Criteria (SDC, 2010) and Bridge Design Aids (BDA, 1995), contain helpful design recommendations but do not provide a detailed approach for seismic lateral load distribution. 
Various investigations over the past fifteen years have touched on seismic lateral load distribution in the superstructure of integral bridge systems. Holombo et al. (2000) briefly looked at lateral load distribution alongside other issues of interest related to seismic loading of precast concrete superstructures. National Cooperative Highway Research Program (NCHRP) Project 12-54 (Wassef et al. 2004, Sritharan et al. 2005, Vander Werff 2002), conducted jointly by lowa State University and Modjeski and Masters, Inc., also investigated lateral load distribution as part of a larger research effort examining seismic issues in bridges with steel superstructures. While these and other projects have raised the issues related to seismic lateral load distribution based on experimental data, we are not aware of any systematic studies that investigate the issue including confirmation from test data and formulation of design recommendations.

The investigations mentioned above primarily focused on examinations of the performance and sufficiency of bridge systems for high seismic regions. These studies utilized the construction and testing of large-scale experimental models of prototype integral bridge structures. The first test unit modeled a bridge with a 4-girder prestressed concrete superstructure (Holombo et al. 2000), using precast bulb-tee girders and referred to as the precast bulb-tee (PBT) model. The next two test units were based on bridges with 4-girder steel superstructures (Wassef et al. 2004), referred to as the steel pier cap (SPC) models. A more recent study by Caltrans investigated a test unit consisting of a 5-girder prestressed concrete superstructure (Snyder et al. 2011) including an inverted-tee bent cap is referred to as the inverted-tee bent cap (ITB) model. Fig. 1 provides views of the prototype structures for these investigations. The two SPC models were based on a similar prototype structure, and the PBT and ITB models were also based on a similar prototype structure, except for the number of girders. All of these tests had specific areas of focus; however, common areas of interest for each of the studies can be summarized as: (1) the design of a prototype bridge utilizing integral connection details capable of withstanding seismic loading, (2) the experimental validation of these details using large-scale test specimens, and (3) the formation of suitable seismic design recommendations based on the analytical and experimental findings.

\subsubsection{Current Design Practice}

The current AASHTO LRFD Bridge Design Specifications (2010) includes a well-established procedure for using distribution factors to appropriately distribute moment and shear due to vertical live loads to 
interior (Section 4.6.2.2.2b) and exterior (4.6.2.2.2d) girders with concrete decks. The distribution factors are based on the spacing, span, and longitudinal stiffness of the beams and the depth of the slab. The distribution factor approach has been shown to be reliable for vertical live load by many studies (Zokaie et al. 1991, Kim and Nowak 1997, Mabsout et al. 1999, Barr et al. 2001, and Cai 2005, for example). More recent work as part of NCHRP Project 12-26 has continued with the live load distribution factor approach while simplifying the equations (Mertz 2007).

Caltrans' current approach to vertical live load distribution primarily incorporates the recommendations from AASHTO. Certain special live loads are distributed using the Lanell distribution approach ("Concrete box girder live load distribution by Lanell for special loads" 1998). Also, Caltrans makes some slight modifications to the AAHSTO approach for one-cell and two-cell box girder bridges (California Amendments to AASHTO LRFD Bridge Design Specifications 2011). However, the basis of the overall approach continues to be related to the spacing, span, and section properties of the girders and deck. While this distribution approach is very appropriate for distributing service-level live loads, it is not necessarily analogous to the vertical load distribution that occurs when the bridge structure is exercised by large displacements and experiences considerable cracking due to a large seismic event. For this reason, we introduce a slightly different stiffness-based approach to vertical load distribution during large seismic loads later in this paper, to be used primarily in conjunction with a similar lateral load distribution model in determining seismic load paths through the superstructure.

Regarding lateral load distribution, Section 4.11.2 in the AASHTO Guide Specifications for LRFD Seismic Bridge Design (2009) states that the superstructure components and their connections "shall be designed to resist overstrength moments and shears of ductile columns." Section 8.10 in these guidelines goes on to address the capacity design of the superstructure for integral bent caps in reinforced concrete structures. These guidelines limit the distribution of the column overstrength moment to an effective width equal to the sum of the diameter of the column and the depth of the superstructure. This issue was discussed previously in Chapter 1, along with Caltrans' slight modification to AASHTO's approach. 


\subsection{Seismic Vertical Acceleration}

\subsubsection{Background}

Research and development related to structural behavior due to seismic acceleration has been extensive in the last 20 to 30 years. However, the vast majority of this work has focused on horizontal seismic acceleration. This focus makes sense, since the horizontal motion from earthquake events is largely responsible for much of the structural damage. Also, horizontal effects introduce an entirely new direction of action to a traditionally-designed structure, whereas vertical effects occur in the same direction as gravity and live load effects that are have traditionally been the primary focus in structural design. Furthermore, maximum vertical effects typically occur very early during an earthquake event, whereas maximum horizontal effects tend to come a bit later in the event; therefore, maximum vertical and horizontal effects do not typically occur simultaneously.

Despite reasonable justification for focusing on horizontal effects, interest in vertical seismic acceleration effects has increased in recent years. This interest has been generated in part by the simple observation that vertical effects have not been studied that much and therefore are not understood that well. This lack of understanding can lead to overly conservative approaches. For example, in certain Caltrans details, reinforcement is added to prevent failure due to vertical effects, without specific justification for including it. The reinforcement is included simply as a precaution, just in case vertical effects might cause a problem in the detail. Many designers realize that current approaches have little justification, so they desire to have a better understanding of the vertical acceleration effects so as to design for the more responsibly and perhaps more efficiently.

In addition, many engineers and scientists involved with structural seismic behavior became more interested in vertical seismic effects as a result of the 2011 earthquake in Christchurch, New Zealand. This earthquake produced amazingly high vertical accelerations, even though its moment magnitude was only moderate. The vertical accelerations were to be contributing factors in some of the structural failures that produced large amounts of destruction and some loss of life.

\subsubsection{Models that approximate geological (seismologic) observations}

Many recent studies have investigated vertical peak ground acceleration (PGA) and have compared magnitudes of peak vertical accelerations with peak horizontal accelerations. In 2012, Tezcan and Cheng 
presented a nonparametric approach to characterize vertical seismic effects. This approach was compared with a current empirical model for varying magnitude, distance, and local soil conditions. This reference states that it is common practice to set the ratio of vertical to horizontal spectrum $(\mathrm{V} / \mathrm{H})$ to $2 / 3$, but it is currently recognized that this practice is not always conservative. The analytical approach presented in this reference used magnitude, source-to-site distance, and shear wave velocity in the top $30 \mathrm{~m}$ of the soil profile. It then employs a support vector machines algorithm to analytically develop $\mathrm{V} / \mathrm{H}$ estimates; in short, as per the authors, this "algorithm learns the nonlinear relationship between a set of predictive variables and the $\mathrm{V} / \mathrm{H}$ ratio directly from ground motion data."

In 2011, a study by Bommer et al. developed a model for the prediction of $\mathrm{V} / \mathrm{H}$ ratios based on similar input as incorporated in Tezcan and Cheng's study. This model was developed from strongmotion accelerograms from the Middle East and Europe. Bommer et al. cite four current models for the prediction of V/H ratios based on magnitude, distance, and site class: Ambraseys et al. (1996), Kalkan and Bulkan (2004), Ambraseys and Douglas (2003), and Gulerce and Ambrahamson (2011). Bommer et al. cite major limitations to the first three models and developed their model using a similar approach to Gulerce and Abrahamson (2011). The model uses functional forms and regression analysis to estimate V/H ratios for PGA and 5\%-damped spectral accelerations up to a period of $3.0 \mathrm{~s}$. This study concluded that this approach provides a reasonable method to estimate the distribution of $\mathrm{V} / \mathrm{H}$ ratios of ground motions generated by shallow crustal earthquakes in the regions considered for the study. The approach is very similar to the method developed by Gulerce and Abrahamson (2011) for North American regions.

A Yang and Lee (2007) study documented the characteristics of vertical and horizontal ground motion during the earthquake in Niigata-ken Chuetsu, Japan, in 2004. This study showed that, for this data set, the ratio of peak vertical to horizontal acceleration was typically less than or equal to $2 / 3$, but for a few sites the ratio was higher than $2 / 3$ or even 1 . The study also concluded that the ratio between peak velocity and peak acceleration depends on site-to-source distance and site condition, with ratios increasing as the epicentral distance increased or the soil stiffness decreased. Another finding was that the vertical response spectra tend to display low frequency contents at distant sites and high frequency contents at hard sites, whereas the effects of site condition and distance seemed to be less significant for horizontal response spectra. The study also showed that the peak value of the average vertical response spectra was lower and occurred at a period of about one half the horizontal spectra. Finally, the study concluded that the $\mathrm{V} / \mathrm{H}$ ratio was strongly dependent on spectra frequency, site-to-source 
distance, and site condition, being significantly higher than $2 / 3$ at short periods and in the near-field region, and also exceeding $2 / 3$ at very long periods (greater than $5 \mathrm{~s}$ ).

The studies presented thus far focus on the $\mathrm{V} / \mathrm{H}$ ratio, where $\mathrm{V}$ is the magnitude of vertical PGA and $\mathrm{H}$ is the magnitude of horizontal PGA. However, very few of these investigations have compared the simultaneous magnitude of vertical and horizontal accelerations. One of the only studies that considered vertical accelerations and horizontal accelerations at the same time was a study by Ambraseys and Douglas (2000), along with a follow-up study in 2003. In fact, these studies mentioned the limitation of omitting consideration of simultaneous behavior, saying: "A major draw-back of the acceleration ratio ... for practical purposes is that in an earthquake the maximum ground or response accelerations in the vertical and horizontal direction occur at different times." In this study, extensive ground acceleration records from seismic events were used to develop an absolute vertical-tohorizontal spectral ratio, $\mathrm{q}_{\mathrm{s}}=\left(\mathrm{SA}_{\mathrm{v}} / \mathrm{SA}_{\mathrm{h}}\right)_{\max }$. Here, $\mathrm{SA}_{\mathrm{v}}$ and $\mathrm{SA}_{\mathrm{h}}$ are peak values of vertical and horizontal acceleration, adjusted for distance and site effects. This is comparable to the common V/H ratio. However, the study also developed a simultaneous vertical to horizontal spectral ratio, $q_{i}=u_{t t, v}\left(t_{\max }\right) / S A_{h}$, where $u_{t t, v}$ is the vertical response acceleration at time $t_{\max }$, and $t_{\max }$ is the time at which the peak horizontal acceleration occurs. Figure 2.2 is a reproduction from the study which compares the absolute ratio (top set of curves) with the simultaneous ratio (bottom set of curves). For each set of curves, the solid line is for all earthquakes, the dashed line is for normal motion, the dashed line is for thrust motion, and the dash-dot line is for strike-slip motion. While the predicted absolute ratio for all earthquakes is between 0.3 and 0.4 for periods higher than $0.3 \mathrm{~s}$, the predicted simultaneous ratio for all earthquakes is close to 0.1 for the same range, significantly lower. This difference indicates the unlikelihood of vertical and horizontal peaks occurring simultaneously. Also, in a follow-up study in 2003, Ambraseys and Douglas mention that "the spectral response of the vertical acceleration and the attenuation of its spectral ordinates with magnitude and distance differ in amplitude and shape from those of the horizontal." 


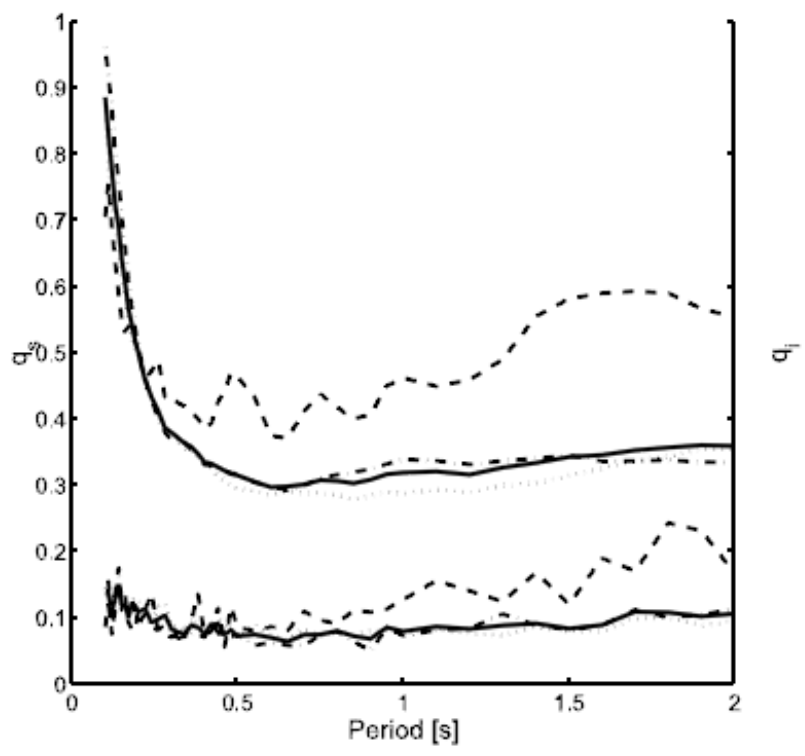

Figure 2.2 Comparison of $q_{s}$ and $q_{i}$

However, especially for locations in close proximity to the fault, the peak vertical acceleration can happen occur almost simultaneously with the peak horizontal acceleration. Consider Figure 2.3, below for example, taken from Silva (1997). This figure shows acceleration time histories recorded for the 1994 Northridge earthquake (on top, at the Pacoima Dam-downstream site), and for the 1989 Loma Prieta earthquake (on bottom, at the Corralitos site). Both of these locations were within $8 \mathrm{~km}$ of the fault responsible for the event, and the figures show that the vertical acceleration peaks (shown as the middle record for both) occurs almost simultaneously with the horizontal peaks; in fact, the horizontal and vertical components are very similarly shaped throughout each record. Likely of significance related to this behavior is that both sites were rock sites. It seems that for rock sites that are close to faults, horizontal and vertical demands may be expected to similar and simultaneous. This behavior for the rock sites is seen to contrast with acceleration data from two close ( $9 \mathrm{~km}$ or less distance from fault) soil sites from the Northridge event in Figure 2.4 (see next page), also from Silva. Both of these soil sites show short-period motion significantly affecting the vertical acceleration prior to the large horizontal motions; thus, the highest $\mathrm{V} / \mathrm{H}$ ratios occur prior to the peak horizontal acceleration. 


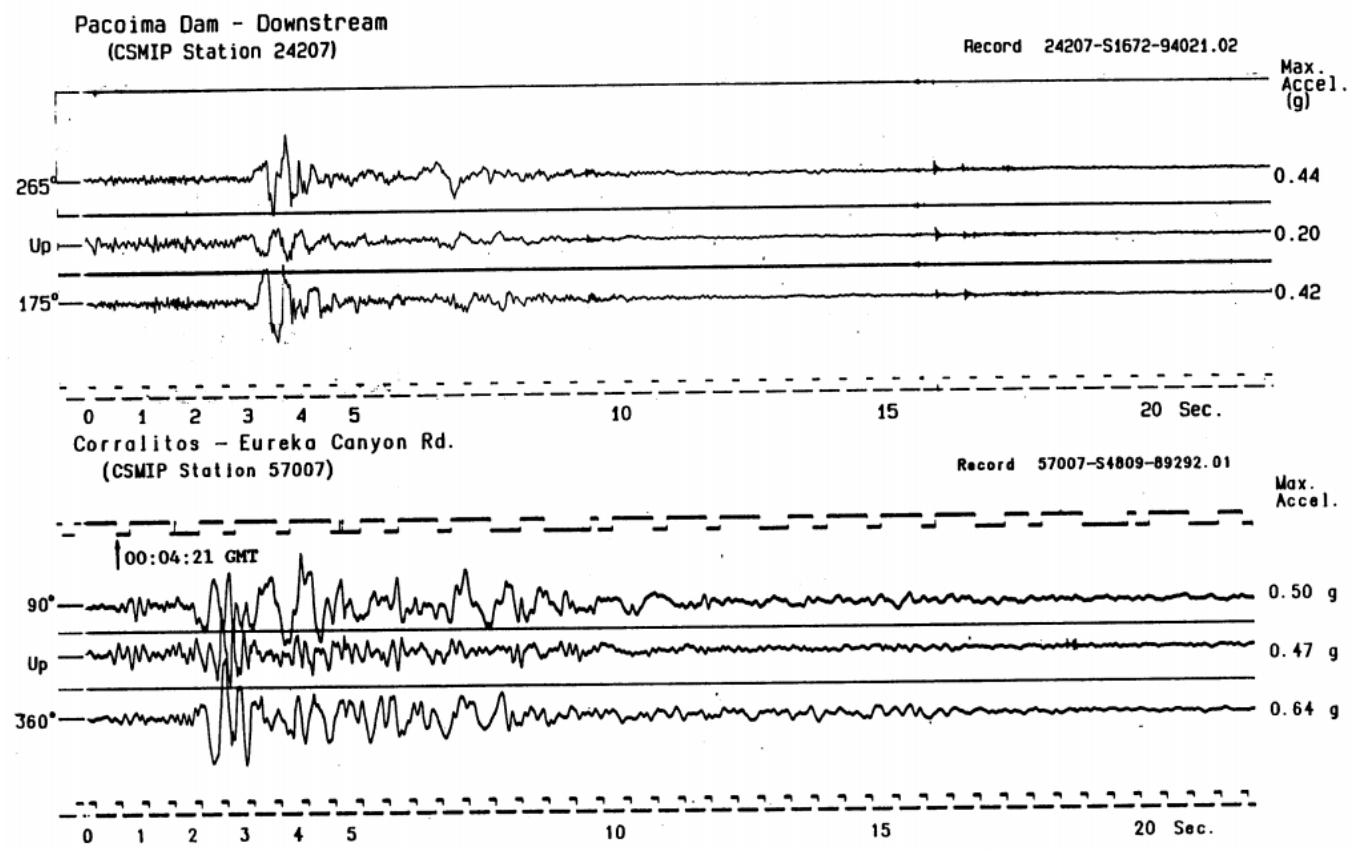

Figure 2.3. Horizontal and vertical component acceleration time histories on rock sites for the 1994 Northridge earthquake (top) and the 1989 Loma Prieta earthquake (bottom)

While not reproduced here, additional investigation by Silva from the Northridge and Loma Prieta events showed that, at greater distances from the fault, both rock and soil sites behave more like the short-distance soil sites, exhibiting maximum vertical motions (and, consequently, large V/H ratios) related to short-period behavior prior to the occurrence of the peak horizontal ground motions.

In conclusion, regarding the simultaneous nature of peak vertical and horizontal motions, it appears that, for sites close to faults, relation of vertical and horizontal motion depends largely on soil type and the consequent propagation of the seismic waves through the various types of soil mediums, whereas for sites at greater distances, vertical peak behavior tends to occur prior to horizontal behavior, for both rock and soil sites. Further research on this topic would be beneficial. 


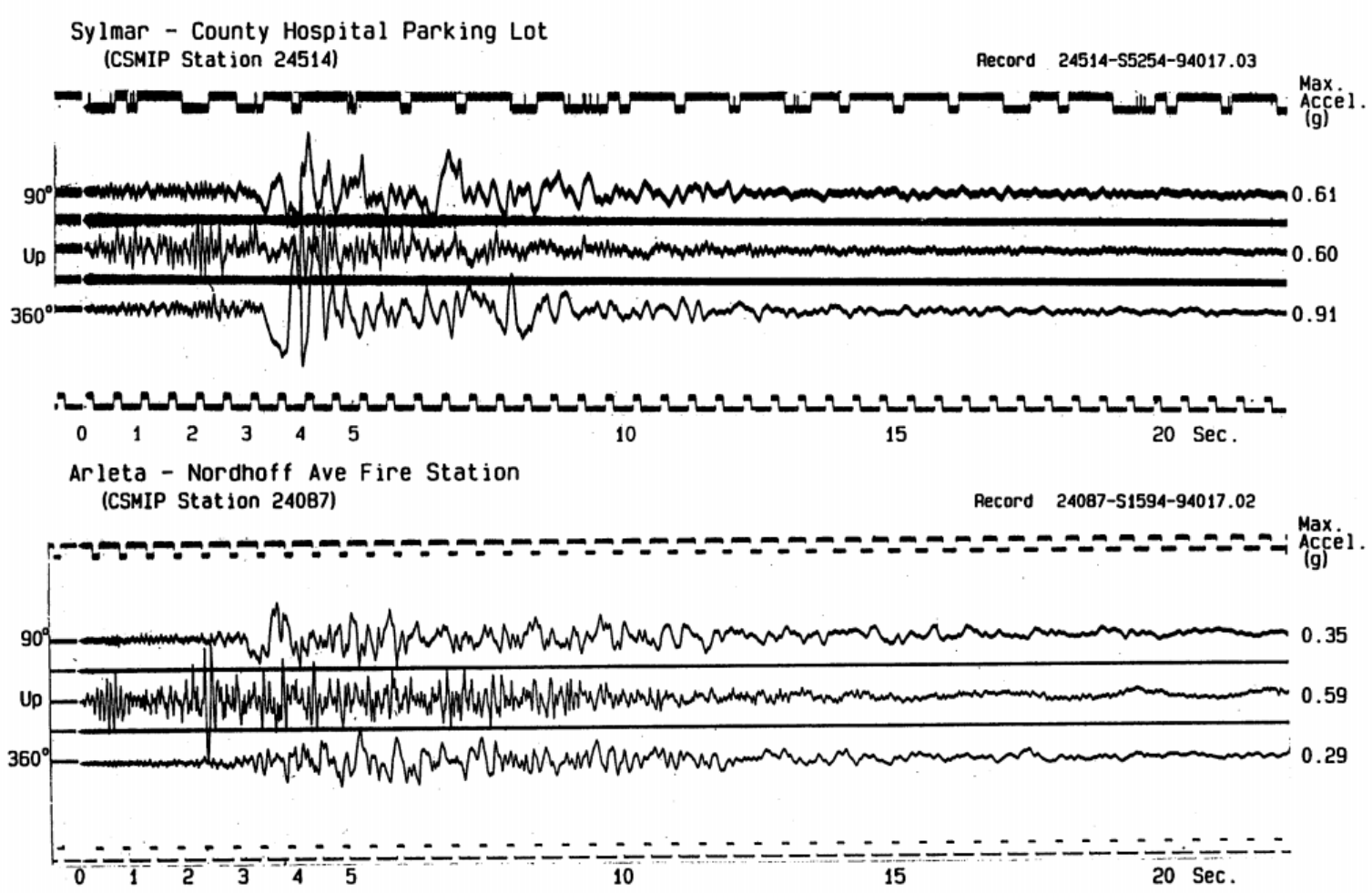

Figure 2.4. Horizontal and vertical component acceleration time histories recorded during the Northridge earthquake

The oft-cited number for the $\mathrm{V} / \mathrm{H}$ ratio (note that this ratio is commonly reported as $\mathrm{V} / \mathrm{H}$, which is the inverse of the ratio mentioned in the question) is $2 / 3$, is mentioned in the following recently accessed sources: Tezcan and Cheng, 2012; Bommer et al., 2011; Yang and Lee, 2007; Ambraseys and Douglas, 2003; and Ambraseys and Douglas, 2000. The 2003 Ambraseys and Douglas study, which replicates the figure provided above from their 2000 study, reports that the mean ratios for strike-slip and normal events are 0.73 and 0.61 , respectively, and hence are quite close to the commonly accepted ratio of $2 / 3$.

Papazoglou and Elnashai (1996) provide an interesting compilation of data from a few notable events related to vertical acceleration that occurred prior to the time of the study. These events include the Northridge, California quake on January 17, 1994, where a vertical acceleration of $1.18 \mathrm{~g}$ and V/H ratio of 1.79 were observed; and the Kobe, Japan quake on January 17, 1995, where observations included a vertical acceleration of $0.33 \mathrm{~g}$ and $\mathrm{V} / \mathrm{H}$ ratio of 1.21 . [Also note that one of the vertical acceleration data points reported by Ambraseys and Douglas (2000) for the Kobe quake was 0.57g.] It does not appear that there are any documented vertical accelerations higher than the acceleration of 
$2.2 \mathrm{~g}$ that was recorded during the Christchurch, New Zealand quake (New Zealand Journal of Geology and Geophysics, 2012).

A sizeable amount of data is available for the two recent mega-quakes, Chile in 2010 with a magnitude of 8.8 (Boroschek et al., 2010) and Japan in 2011 with a magnitude of 9.1 (Kalkan and Sevilgen, 2011). For the Chile event, one reporting station recorded a peak vertical acceleration of $0.702 \mathrm{~g}$ with a peak horizontal acceleration of $0.564 \mathrm{~g}$, for a $\mathrm{V} / \mathrm{H}$ ratio of 1.24 . One other station from the Chile event recorded a vertical acceleration of $0.398 \mathrm{~g}$ and a peak horizontal acceleration of $0.402 \mathrm{~g}(\mathrm{~V} / \mathrm{H}$ $=0.99$ ), but most of the stations reported $\mathrm{V} / \mathrm{H}$ ratios well below 1 . For the Japan event, accessing data from 273 reporting stations and comparing recorded vertical and horizontal accelerations, one station recorded $0.406 \mathrm{~g}$ vertical PGA with $0.374 \mathrm{~g}$ horizontal PGA (note that this is the resultant of the peaks in the two horizontal directions), for a $\mathrm{V} / \mathrm{H}$ ratio of 1.09 . The average $\mathrm{V} / \mathrm{H}$ ratio for the reporting stations from the Japan event was 0.41. A final note on the Japan data is that the maximum horizontal PGA reported from these stations was $2.699 \mathrm{~g}$, and the vertical PGA recorded at that station was 1.88 , for a $\mathrm{V} / \mathrm{H}$ ratio of 0.70 at the location of largest recorded acceleration.

In summary, it appears that from this limited data, it is not that uncommon for vertical PGA values to exceed horizontal PGA values in large seismic events, as it occurred during about half of the largescale events that had data available. However, it should also be noted that these occurrences seem to be at only a small fraction of the stations that are affected by a particular seismic event; in other words, even in earthquakes that have reported $\mathrm{V} / \mathrm{H}$ values higher than 1 , it usually only happens in a very small portion of the area affected by the overall quake. It is well-documented that the larger $\mathrm{V} / \mathrm{H}$ ratios tend to occur at short periods in the near-source distance range (see, for example Silva, 1997).

\subsection{References}

AASHTO. (2011). "US 6 Keg Creek Bridge." America's Transportation Awards. Washington D.C: AASHTO. Online: http://www.americastransportationaward.org/Default.aspx?ContentID=250. Accessed October 2012.

AASHTO. (2010). LRFD Bridge Design Specifications, $5^{\text {th }}$ Edition. Washington, D.C.: AASHTO.

AASHTO. (2009). Guide Specifications for LRFD Seismic Bridge Design. Washington, D.C.: AASHTO.

Ambraseys, N. N., Simpson, K. A., and Bommer, J. J. (1996). "Prediction of Horizontal Response Spectra in Europe." Earthquake Engineering and Structural Dynamics. 25, 371-400. 
Ambraseys, N., and Douglas, J. (2000). "Reappraisal of the effect of vertical ground motions on response," Engineering Seismology and Earthquake Engineering, ESEE Report No. 00-4, August 2000.

Ambraseys, N. N., and Douglas, J. (2003). "Near-field horizontal and vertical earthquake ground motions," Soil Dynamics and Earthquake Engineering, 23(1), 1-18.

Barr, P., Eberhard, M. O., and Stanton, J. (2001). "Live-load distribution factors in prestressed concrete girder bridges." Journal of Bridge Engineering, 6(5), 298-306.

Bommer, J. J., Akkar, S., and Kale, O. (2011). "A Model for Vertical-to-Horizontl Response Spectral Ratios for Europe and the Middle East." Bulletin of the Seismological Society of America, 101(4), pp. 17831806, August 2011.

Boroschek, R., Soto, P., León, R. (2010), "Registros del Terremoto del Maule, Mw=8.8, 27 de febrero de 2010", RENADIC 10/05, October 2010. http://www.renadic.cl, https://terremotos.ing.uchile.cl

Cai, C. S. (2005). "Discussion on AASHTO LRFD Load Distribution Factors for Slab-on-Girder Bridges." Practice Periodical on Structural Design and Construction, 10(3), 171-176.

Caltrans. (1995). Bridge Design Aids. Sacramento, California: California Department of Transportation (Caltrans). Online: http://www.dot.ca.gov/hq/esc/techpubs/manual/bridgemanuals/bridge-designaids/bda.html. Accessed August 2012.

Caltrans. (2010). "Caltrans Precast Concrete Committee Update." Presented at the 2010 Caltrans/PCMAC/Consultants Bridge Workshop, Nov. $3^{\text {rd }}$, 2010. Online: http://www.precastconcrete.org/seminars/2010/2010-09.pdf. Accessed December 2012.

Caltrans. (2010). Seismic Design Criteria, Version 1.6. Sacramento, California: Caltrans. Online: http://www.dot.ca.gov/hq/esc/earthquake_engineering/SDC_site/2010-11-

17_SDC_1.6_Full_Version_OEE_Release.pdf. Accessed August 2012.

Caltrans. (2011). Bridge Design Practice Manual. Sacramento, California: Caltrans. Online: http://www.dot.ca.gov/hq/esc/techpubs/manual/bridgemanuals/bridge-design-practice/bdp.html. Accessed August 2012.

Caltrans. (2012). Seismic Retrofit Program. Sacramento, California: Caltrans. Online: http://www.dot.ca.gov/hq/paffairs/about/retrofit.htm. Accessed October 2012.

Caltrans Seismic Advisory Board, J. Penzien, Chairman. (2003). The Race to Seismic Safety, Protecting California's Transportation System. Submitted to the Director, California Department of Transportation. 
Chen, W. F. and Lian Duan. (2014). Bridge Engineering Handbook, Second Edition: Construction and Maintenance. Boca Raton, Florida: CRC Press.

Cook, William D. and Denis Mitchell. (1988). "Studies of Disturbed Regions Near Discontinuities in Reinforced Concrete Members." ACI Structural Journal. Volume 85, Issue 2, March 1988. Farmington Hills, Michigan: American Concrete Institute (ACI).

Eskenazi, Joe. (2009). "Shakedown +20: Remembering the Loma Prieta Quake of 1989. Today's Edition: Mama Mia." SF Weekly. October 7, 2009. Online: http://blogs.sfweekly.com/thesnitch/ 2009/10/shakedown_20_remembering_the_b.php. Accessed October 2012.

Federal Highway Administration. (2012). "ABC/PBES Costs." Prefabricated Bridge Elements and Systems. Washington, D.C.: U.S. Department of Transportation. Online: http://www.fhwa.dot.gov/ everydaycounts/technology/bridges/pbeswebinartraining/s2_m4.cfm. Accessed December 2012.

Federal Highway Administration. (2010). "Fact Sheet 16 - States Across the Country Implement Accelerated Bridge Construction." Publication No. FHWA-HOP-11-006. Washington, D.C.: U.S. Department of Transportation. Online: http://www.ops.fhwa.dot.gov/wz/practices/factsheets/ factsheet16/index.htm. Accessed October 2012.

Federal Highway Administration. (2010). "FHWA Bridge Conference Spotlights Opportunities and Successes in Accelerated Bridge Construction." Publication No. FHWA-HRT-10-017. Washington, D.C.: U. S. Department of Transportation. Online: http://www.fhwa.dot.gov/publications/focus/ 10sep/01.cfm. Accessed August 2012.

Federal Highway Administration. (2009). "Accelerated Bridge Construction Picks Up Steam." Innovator: Accelerating Innovation for the American Driving Experience. Volume 2, Issue 11, February/March 2009. Publication No. FHWA-HIF-09-032. Washington, D.C.: U.S. Department of Transportation. Online: http://www.fhwa.dot.gov/hfl/innovator/pdfs/issue11.pdf. Accessed October 2012.

Federal Highway Administration. (2006). "Rapid Bridge Construction: How to Get There." 2006 Concrete Bridge Conference Workshop. Washington, D.C.: U. S. Department of Transportation. Online: http://www.fhwa.dot.gov/bridge/prefab/pbesreport.cfm. Accessed October 2012.

Gulerce, Z., and Abrahamson, N. N. (2011). "Site-specific spectra for vertical ground motion," Earthquake Spectra, 27(4).

Housner, George W., \& Charles C. Thiel, Jr. (1990). "Competing Against Time: Report of the Governor's Board of Inquiry on the 1989 Loma Prieta Earthquake." Earthquake Spectra, 6(4), pp.681-711.

Holombo, J., M. J. N. Priestley, F. Seible. (2000). “Continuity of Precast Prestressed Spliced-Girder Bridges Under Seismic Loads.” PCI Journal. Volume 45, Number 2, March-April 2000, pp. 40-63. 
International Federation of Structural Concrete. (2007). Seismic Bridge Design and Retrofit - Structural Solutions. (Volume 39). Lausanne, Switzerland: FIB.

lowa Department of Transportation. (2012). "U.S. 6 bridge over Keg Creek." Ames, lowa: lowa Department of Transportation. Online: http://www.iowadot.gov/us6KegCreek/projectinfo.html. Accessed December 2012.

Kalkan, E., and Sevilgen, V. (2011). "March 11, 2011 M9.0 Tohoku, Japan Earthquake," USGS, Accessed online: http://nsmp.wr.usgs.gov/ekalkan/Tohoku/index.html.

Kalkan, E. and Gulkan, P. (2004). "Empirical attenuation equations for vertical ground motion." Earthquake Spectra, 20(3), 853-882.

Kam, Weng Yuen and Stefano Pampanin. (2011). General Building Performance in the Christchurch CBD: a contextual report. Christchurch, New Zealand: University of Canterbury. Online: http://www.dbh.govt.nz/UserFiles/File/Reports/quake-contextual-report-canterbury-uni.pdf. Accessed October 2012.

Kim, S. and Nowak, A. S. (1997). "Load distribution and impact factors for I-girder bridges." Journal of Bridge Engineering, 2(3), 97-104.

Kyaleghi, Bijan. "Washington State Department of Transportation Plan for Accelerated Bridge Construction" (2010). Transportation Research Record: Journal of the Transportation Research Board. Volume 2200, pages 3-11.

Khaleghi, B., Schultz, E., Seguirant, S., Marsh, L., Haraldsson, O., Eberhard, M., \& Stanton, J. (2012). "Accelerated bridge construction in Washington State: From research to practice." $\mathrm{PCl}$ Journal, 57(4).

Mabsout, M. E., Tarhini, K. M., Frederick, G. R., and Kesserwan, A. (1999). "Effect of multilanes on wheel load distribution in steel girder bridges." Journal of Bridge Engineering, 4(2), 88-106.

Mattock, Alan H. (2012). "Strut-and-Tie Models for Dapped-End Beams." Concrete International. Volume 34, Issue 2, February 2012. Farmington Hills, Michigan: American Concrete Institute (ACI).

Mattock, A. H. (1979). "Design and Behavior of Dapped-End Beams." PCl Journal. Volume 24, No. 6. Chicago, Illinois: Prestressed Concrete Institute (PCI).

Mertz, D. (2007). NCHRP Report 592: Simplified Live Load Distribution Factor Eq.s, Transportation Research Board (TRB), Washington, D. C. 
Miller, R. A., Castrodale, R. Mirmiran, A., and Hastak, M. (2004). Connection of Simple-Span Precast Concrete Girders for Continuity, NCHRP Report 519. Transportation Research Board: Washington, D.C.

Motaref, Sarira. (2011) Seismic Response of Precast Bridge Columns with Energy Dissipating Joints. Dissertation, University of Nevada, Reno.

National Cooperative Highway Research Program (NCHRP). (2012). "2012 Domestic Scan on ABC Connections: Findings and Recommendations." Summary Report of the NCHRP 20-68A - US Domestic Scan Program. Online: www.abc.fiu.edu/wp.../Summary-Report-Presentation_AKB.pptx. Accessed December 2012.

NCHRP (2011). "Application of Accelerated Bridge Construction Connections in Moderate-to-High Seismic Regions." NCHRP Report 698. Washington, D.C.: Transportation Research Board.

Ou, Y. C., M. Chiewanichakorn, A. J. Aref, G. C. Lee (2007). "Seismic Performance of Segmental Precast Unbonded Post-tensioned Concrete Bridge Columns." Journal of Structural Engineering, 133(11), 1636-1647. ASCE.

Ou, Yu-Chen; Ping-Hsiung Wang; Mu-Sen Tsai; Kuo-Chun Chang; George C. Lee (2010). "Large-Scale Experimental Study of Precast Segmental Unbonded Posttensioned Concrete Bridge Columns for Seismic Regions." Journal of Structural Engineering, 136(3), 255-264. ASCE.

Papazoglou, A. J., and Elnashai, A. S. (1996). "Analytical and field evidence of the damaging effect of vertical earthquake ground motion," Earthquake Engineering and Structural Dynamics, Volume 25, 1109-1137.

Priestley, M. J. N., F. Seible, and G. M. Calvi. (1996). Seismic Design and Retrofit of Bridges. New York: John Wiley \& Sons, Inc.

Sanders, David H. (2002). "Example 2: Dapped-end T-beam supported by an inverted T-beam." Examples for the Design of Structural Concrete with Strut-and-Tie Models. Farmington Hills, Michigan: American Concrete Institute ( $\mathrm{ACl})$.

SEAOC. (2010). "Seismic Design of Concrete Parking Structure Ramps." Structure. July, 2010. Seismology Committee, Structural Engineers Association of California. Online: http://www.structuremag.org/ article.aspx?articleID=1096. Accessed October 2012.

Shoup, Lilly, Nick Donohue, and Marissa Lang. (2011). The Fix We're In For: The State of Our Nation's Bridges. Washington, D.C.: Transportation for America.

Silva, W. J. (1997). "Characteristics of vertical strong ground motions for applications to engineering design." Proc. Of the FHWA/NCEER Workshop on the Nationall Representation of Seismic Ground 
Motion for New and Existing Highway Facilities, I.M. Friedland, M.S Power and R. L. Mayes eds., Technical Report NCEER-97-0010.

Snyder, Richard. (2010). Seismic performance of an I-girder to inverted-t bent cap bridge connection. Masters degree thesis. Ames, lowa: lowa State University.

Snyder, R.M., J. Vander Werff, Z. J. Thiemann, S. Sritharan, J. Holombo. (2011). Seismic Performance of an I-Girder to Inverted-T Bent Cap Connection, Final Report. Sacramento, California: Caltrans; and Ames, lowa: lowa State University.

Sritharan, S., J. Vander Werff, R. E. Abendroth, W. G. Wassef, L. F. Greimann. (2005). "Seismic Behavior of a Concrete/Steel Integral Bridge Pier System," Journal of Structural Engineering. Volume 131, Issue 7.

Stover, Carl W. and Jerry L. Coffman. (1993). Seismicity of the United States. Washington, D.C.: U.S. Geological Survey, United States Government Printing Office.

Tezcan, J., and Cheng, Q. (2012). "A nonparametric characterization of vertical ground motion effects." Earthquake Engineering and Structural Dynamics. 41(3): 515-530, March 2012.

Thiemann, Zachary J. (2009). Pretest 3-D finite element analysis of the girder-to-cap-beam connection of an inverted-tee cap beam designed for seismic loadings. Masters degree thesis. Ames, lowa: lowa State University.

USGS. (2012). United States Geological Survey. Washington, D.C.: United States Geological Survey (USGS). Online: www.usgs.gov. Accessed October 2012.

USGS. (2005). U.S. Geological Survey Fact Sheet 068-03, Monitoring Earthquake Shaking in Buildings to Reduce Loss of Life and Property. Washington, D.C.: USGS. Online: http://pubs.usgs.gov/ fs/2003/fs068-03/. Accessed October 2012.

USGS. (1999). USGS Online Publications Directory, Oakland. Washington, D.C.: USGS. Online: http://pubs.usgs.gov/dds/dds-29/web_pages/oakland.html. Accessed October 2012.

USGS. (1971). U.S. Geological Survey Photographic Library. Washington, D.C.: USGS. Online: http://libraryphoto.cr.usgs.gov/cgi-bin/show_picture.cgi?ID=ID.\%20Kachadoorian,\%20R.\%20\%20\% 20125c\&SIZE=medium. Accessed December 2012.

Vander Werff, Justin and Sri Sritharan. (2012). "Seismic Load Distribution between Girders in Integral Bridges." 2012 PCl Convention and National Bridge Conference. October 2012. Nashville, Tennessee: Precast Concrete Institute (PCI). 
Vander Werff, Justin, Rick Snyder, Sri Sritharan, and Jay Holombo. (2011). "Seismic Performance of an Inverted-Tee Bridge Test Model with Precast Girders." 2011 PCl Convention and National Bridge Conference. October 2011. Salt Lake City, Utah: Precast Concrete Institute (PCI).

Veletzos, M. and J. Restrepo. (2014) "Equivalent Unbonded Length for Modeling of Multistrand Tendons in Precast Segmental Construction." ASCE Journal of Bridge Engineering. 19(1), 101-109.

Veletzos, M. J., \& Restrepo, J. I. (2010). Modeling of jointed connections in segmental bridges. ASCE Journal of Bridge Engineering, 16(1), 139-147.

Yang, J., and Lee, C. M. (2007). "Characteristics of vertical and horizontal ground motions recorded during the Niigata-ken Chuetsu, Japan Earthquake of 23 October 2004," Engineering Geology, 94(12), 50-64, October 2007.

Zokaie, T., Osterkamp, T. A., and Imbsen, R. A. (1991). NCHRP Report 12-26/1: Distribution of Wheel Load on Highway Bridges, TRB, Washington, D. C. 


\section{CHAPTER 3. A COST-EFFECTIVE INTEGRAL BRIDGE SYSTEM WITH PRECAST I-GIRDERS FOR SEISMIC APPLICATION}

A paper to be submitted to the $P C l$ Journal

J. R. Vander Werff ${ }^{1}$, R. Snyder ${ }^{2}$, S. Sritharan ${ }^{3}$, and J. Holombo ${ }^{4}$

\subsection{Abstract}

To promote accelerated bridge construction in seismic regions, a large-scale experimental investigation was conducted to examine the seismic sufficiency of precast concrete members in integral bridge superstructures. Such structures are not commonly used in high seismic regions, due to lack of design guides and overly conservative design approaches. A half-scale, 17.8-m (58.5-ft) long test unit modeling a portion of a prototype bridge incorporating a concrete column, I-shaped precast concrete girders, and an inverted-tee concrete cap beam has been used to experimentally verify that precast concrete members utilizing accelerated construction techniques can be used in integral superstructures and provide excellent seismic performance. The experimental work was also used to compare and contrast an as-built girder-to-cap connection detail with an improved detail. The results show that the as-built detail in existing bridges will satisfactorily resist positive and negative seismic moments and allow plastic hinges to develop at the column tops, even though this was not the original design intent. However, the improved detail is recommended for new bridges to avoid potential deterioration of the girder-to-cap connection.

\subsection{Introduction}

Accelerated bridge construction $(A B C)$ is increasingly being pursued and promoted across the United States. Many states are dealing with aging transportation infrastructure along with increased transportation demand due to continuing economic and population growth (ASCE, 2013). Rapid construction of bridge projects to meet these needs is increasingly beneficial (Chen and Wuan, 2014).

\footnotetext{
${ }^{1}$ Assistant Professor; Engineering, Dordt College, Sioux Center, lowa

${ }^{2}$ Senior Engineer; SRF Consulting Group, Minneapolis, Minnesota

${ }^{3}$ Wilson Engineering Professor; Civil, Construction, and Environmental Engineering, lowa State University, Ames, lowa

${ }^{4}$ Senior Bridge Engineer; T.Y. Lin International, San Diego, California
} 
Similarly to the rest of the country, the California Department of Transportation (Caltrans) is interested in the benefits that $A B C$ techniques can provide, provided that seismic issues can be satisfactorily addressed. Caltrans' desire to improve and increase the possibilities of $A B C$ methods are highlighted in its “ABC Strategic plan" (2008a) and the related "Lessons Learned” report (2008b).

The obvious primary benefit to the incorporation of $A B C$ methods is the reduction of on-site construction time, along with the associated mitigation of long traffic delays. A common way to accomplish decreased time in the field is to utilize prefabricated components as much as possible. By using prefabricated elements, such as precast concrete members instead of cast-in-place concrete sections, certain additional secondary benefits are realized including the elimination of the need for falsework and an overall improvement in quality control by relocating production from unpredictable field conditions into a controlled shop environment.

Even though $A B C$ methods have notable advantages, the incorporation of such techniques in moderate-to-high seismic regions has been slowed because of the poor performance of precast structures, primarily buildings, in previous earthquake events. In fact, current bridge data from Caltrans shows that cast-in-place concrete accounts for over 70 percent of the material in bridge projects, while precast concrete accounts for around 5 percent (Hida, 2012). The vulnerability of precast structures has been largely due to inadequate performance of the connections and failing to ensure satisfactory load paths. Precast concrete structures were observed to experience connection failures, especially in buildings, in past seismic events including the Loma Prieta earthquake in 1989 (Housner and Thiel, 1990) and the Northridge earthquake in 1994 (SEAOC, 2010).

Increased opportunities to incorporate $A B C$ techniques and associated benefits will be realized if precast connections can be developed that are viable to implement in the field, do not significantly increase cost, and are able sustain large seismic demands. Capacity design is the most common approach in designing for earthquake loads. Using this approach, structures are designed to exhibit ductile behavior in certain locations that are specifically detailed to accommodate sufficient inelastic action while maintaining strength. These specially detailed regions are commonly referred to as plastic hinges. When a large seismic event occurs, the plastic hinge regions undergo inelastic deformation while the remainder of the structure continues to experience elastic behavior even when subjected to high 
seismic demand. By incorporating this design philosophy, structures can be economically designed to accommodate large seismic lateral displacements and absorb the earthquake energy imparted to the structure in the form of hysteretic energy dissipation without collapsing and endangering the structure's occupants.

In bridges, the plastic hinge regions are generally restricted to the column ends to prevent significant damage to the bridge superstructure including the deck and allow easy inspection following a seismic event. The design of the bridge superstructure is critical, because it must have sufficient strength to maintain elastic behavior while allowing plastic hinge formation in the columns. The girder-to-cap connections in particular require careful attention for integral superstructure demands, where the girders are designed to have moment capacity across the cap beam. Integral designs are especially advantageous in seismic regions, since the moment continuity in the superstructure above the column bents provides a possible plastic hinge location in the column just below the cap beam. The development of girder-to-cap connections that facilitate rapid construction techniques in the field and provide sufficient shear and moment continuity for integral connections in high seismic regions will provide greater opportunity to utilize precast concrete members and their associated benefits.

\subsection{Research Significance}

To promote the use of precast concrete and $A B C$ methods in seismic regions, the work detailed here was undertaken to accomplish two primary objectives. First, an existing inverted-tee cap beam concept has been utilized to facilitate precast dapped-end girders, but current Caltrans recommendations do not consider this detail to have sufficient moment capacity to be an integral connection under high seismic loading. Large-scale experimental testing of the existing detail could shed light on the connection's seismic capability, and perhaps lead to better recommendations for its future implementation. Second, the development of an improved girder-to-cap connection detail that reliably provides an integral superstructure connection would be very beneficial in promoting the cost-effective use of precast concrete and cost-effective accelerated construction methods in seismic regions.

\subsection{A Precast Bridge System for Seismic Regions}

One of Caltrans' preferred precast sections is the California I-Girder (Ma, 2008). A detail that has been utilized by Caltrans to facilitate the use of such I-girders is the inverted-tee bent cap concept, 
shown in Figure 3.1. This system is well-suited for $A B C$ implementation because its configuration allows quick installation of girders. It is typically implemented with cast-in-place columns and cast-in-place inverted-tee cap beams. Once the cap beam is positioned, the ledge on each side of the cap beam stem works well to support the dapped end of precast girders. The girder dapped ends can subsequently be integrated with the cap beam by the use of a cast-in-place diaphragm and appropriate connection reinforcement. Finally, the cast-in-place bridge deck can be placed over the completed superstructure.

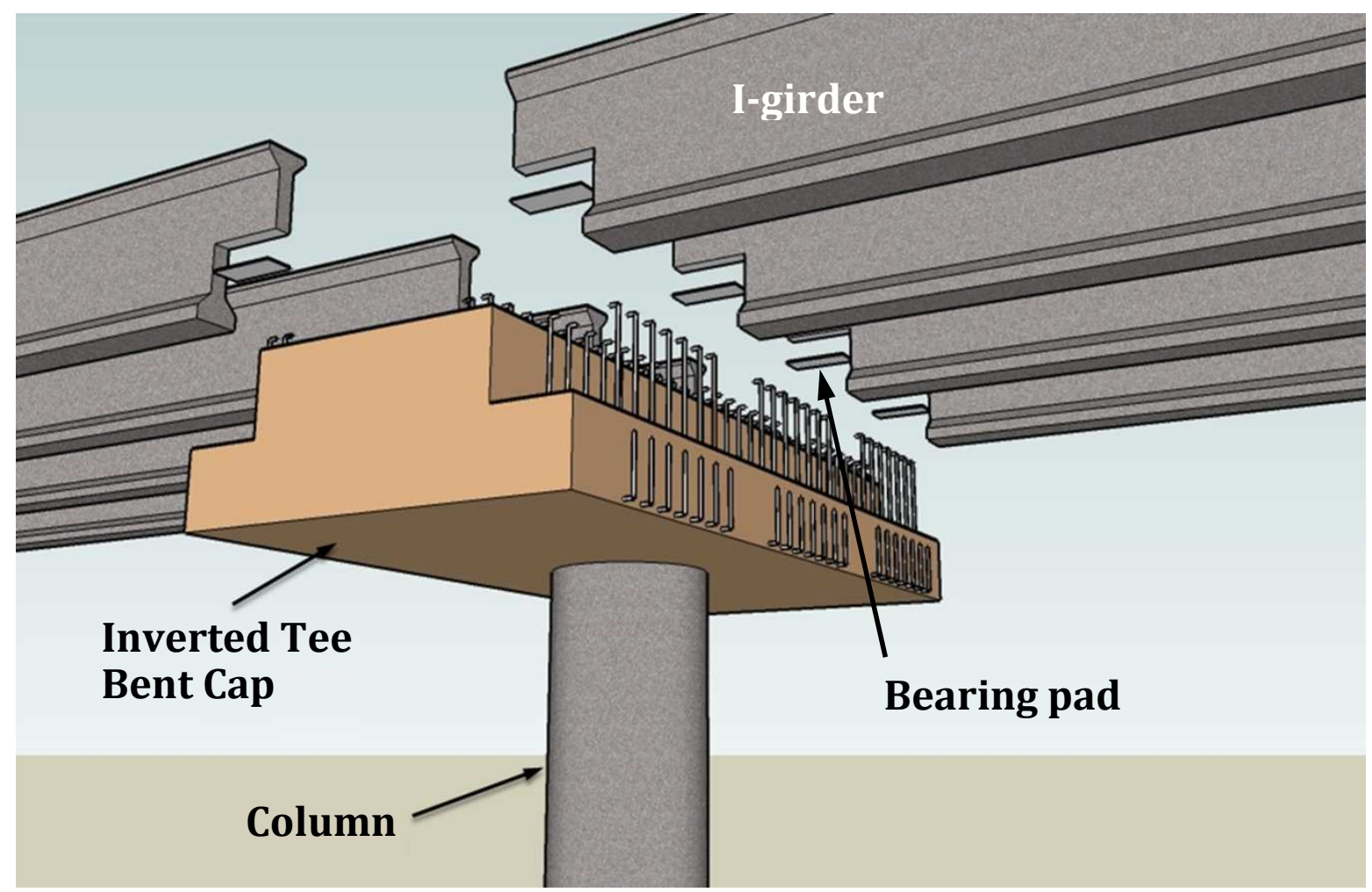

Figure 3.1. Inverted-tee bent cap concept

Where the inverted-tee bent cap concept has been utilized by Caltrans, the superstructure has been designed according to current design recommendations (Caltrans, 2010b; Caltrans, 1995). The current recommendations anticipate the degradation of the positive moment connection due to large seismic displacements and the loss of tension continuity in the girder lower flange connection region. Therefore, the recommendations stipulate that the cap-to-girder connection be regarded as a connection with zero moment resistance under seismic loading. Regarding this connection as a "pin" under seismic loading has undesirable ramifications. Figure 3.2 provides a simple statics analysis for the base moment of the column, depending on whether the girder-to-cap connection is pinned or fixed. Figure 3.2a shows that, 
with pinned superstructure connections, the substructure moment at the base of the column is $\mathrm{HL}$, where $\mathrm{H}$ is the horizontal seismic design load and $\mathrm{L}$ is the column length. The analysis shown in Figure $3.2 \mathrm{~b}$ assumes that the capacity of the plastic hinges at the top and bottom of the column will be equal, resulting in a total superstructure moment and substructure moment of $\mathrm{H} / 2$ as shown. The moment connections in the superstructure provide an additional plastic hinge location and also significantly reduce the substructure moment, allowing the foundation cost to be reduced.

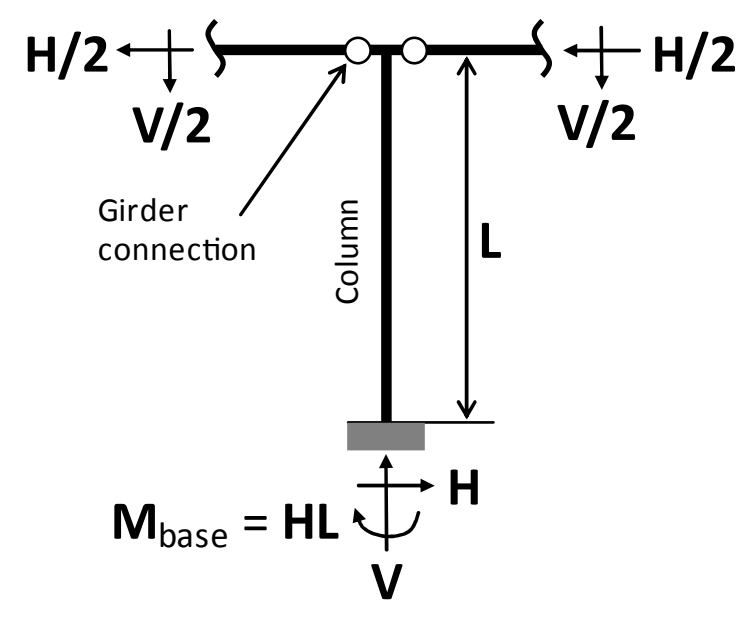

a. Pinned girder-to-cap connection

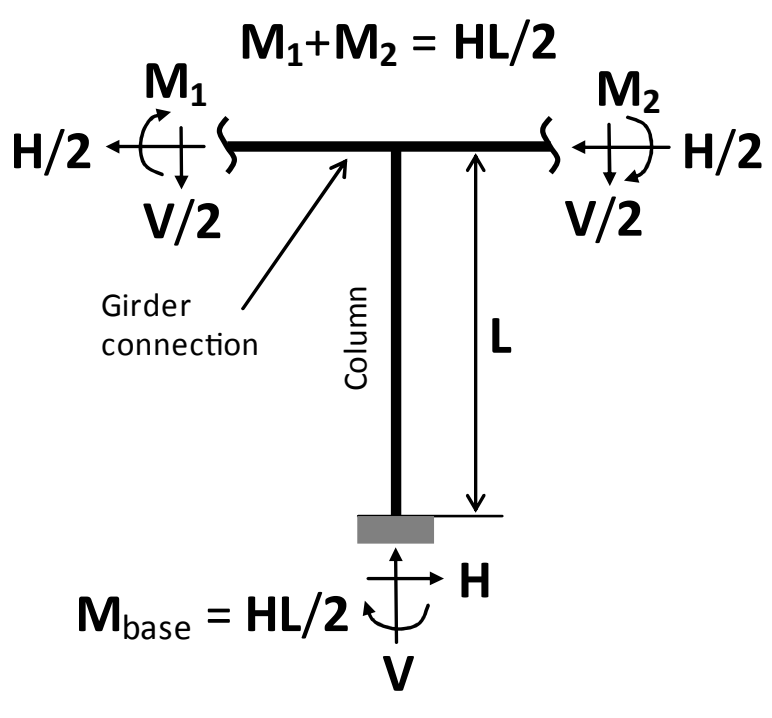

b. Fixed girder-to-cap connection

Figure 3.2. Influence of girder connection on column seismic moment demand

Even with these design limitations imposed on the girder-to-cap connection, the inverted-tee concept has been utilized because of the benefits of using precast concrete girders over cast-in-place options. Development of girder-to-cap connections that provide full moment resistance will offer the possibility of incorporating the design approach presented in Figure $3.2 \mathrm{~b}$, resulting in a more competitive solution to cast-in-place concrete and enhancing the opportunity to incorporate $A B C$ methods in high seismic regions. In addition, total cost benefits for precast structures such as reducing traffic impact and improving worker safety are not integrated into the construction cost of the bridge but are important advantages of such approaches. 


\subsection{Prototype Bridge}

To formulate the experimental plan, a prototype bridge utilizing the inverted-tee concept was developed as shown in Figure 3.3. The four-span bridge incorporated reinforced concrete columns in single-column bents, concrete inverted-tee cap beams, and five precast, prestressed, I-shaped concrete girders per span. The prototype bridge was designed by a design team from PBS\&J (currently Atkins) in San Diego, California, and independently confirmed by a research team at lowa State University. The design was based on AASHTO LRFD Bridge Design Specifications, Third Edition (2003) with Interims and California Amendments (2006b) following the guidelines from the Caltrans Bridge Design Aids (1995), Caltrans Bridge Design Specifications (2003), and Caltrans Seismic Design Criteria, version 1.5 (2006a). The design utilized Caltrans' deepest standard I-girder section along with a five-girder superstructure and single column bents to develop maximum demand in the cap and connection region. Detailed information and design calculations for the prototype bridge can be found in Theimann (2009).

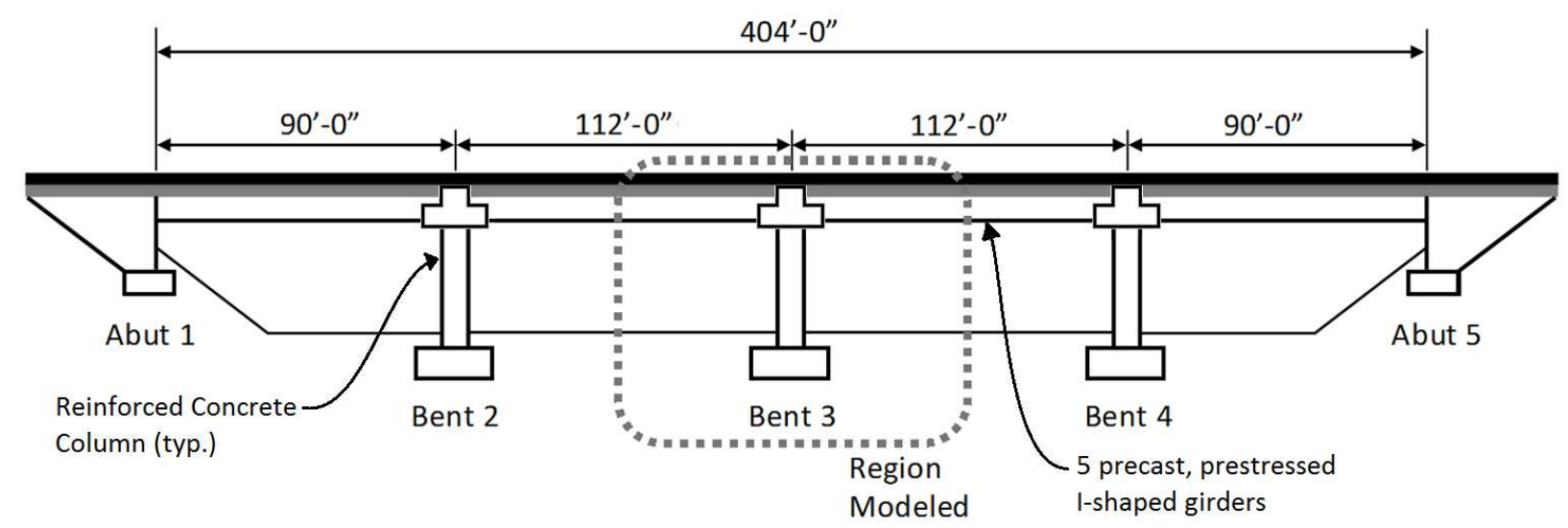

a. Longitudinal elevation

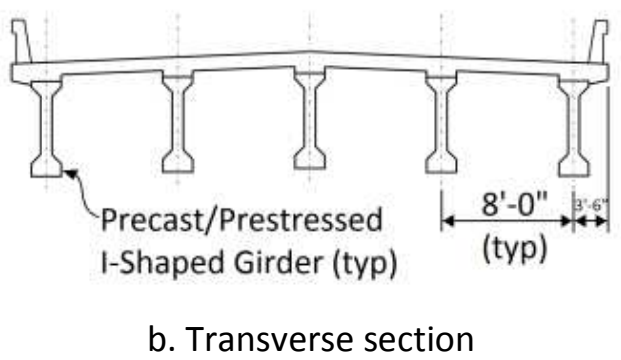

Figure 3.3. Prototype integral bridge structure 


\subsection{Experimental Investigation}

The experimental investigation was designed to determine the seismic behavior of the bridge system and to carefully investigate and quantify the girder-to-cap connection performance. The experimental work was divided into two phases. The primary purposes for Phase I were to: (1) confirm the validity of the overall system for high seismic regions, (2) determine the capability of the girder-tocap connections to maintain elastic superstructure action up to high seismic displacements (i.e., the sufficiency of the girder connections to provide adequate resistance to develop plastic hinges in the column), and (3) compare and contrast the existing Caltrans girder-to-cap connection detail with an improved detail. The primary purpose of Phase II was to exercise the girder-to-cap connections to realize their full potential by applying connection demands beyond what would be permitted by the typical overstrength capacity of the column plastic hinge region.

\subsubsection{Test Unit Details}

The girder-to-cap connection that has been previously been utilized by Caltrans for the inverted-tee system is shown in Figure 3.4a, referred to here as the "as-built" connection detail. This detail utilizes dowel bars that pass through ducts in the webs of the precast girders near their dapped ends. After the girders are placed on the corbel of the inverted-tee, the dowel bars are grouted into place in the girder webs, and a cast-in-place concrete diaphragm is used to encase the dapped end and dowel bars, thus achieving connection continuity. 


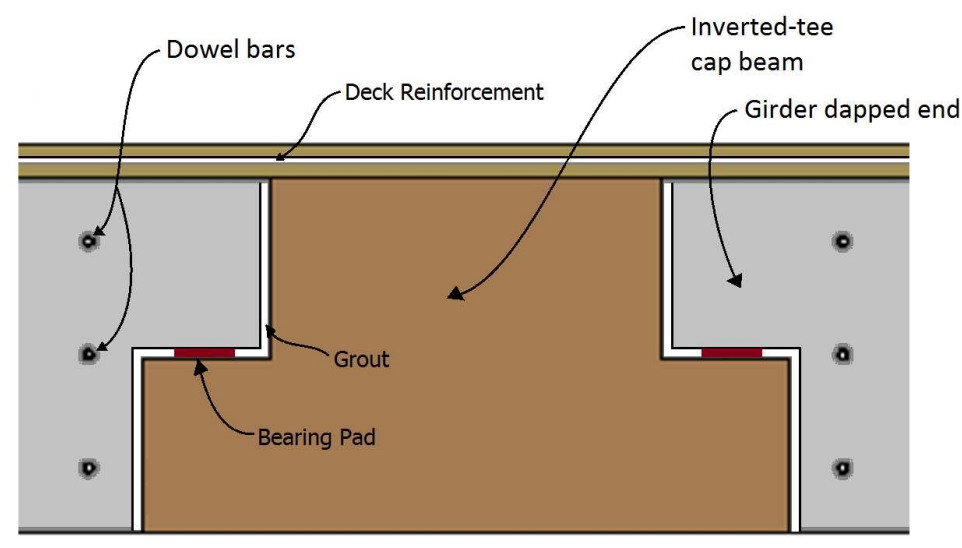

a. As-built detail

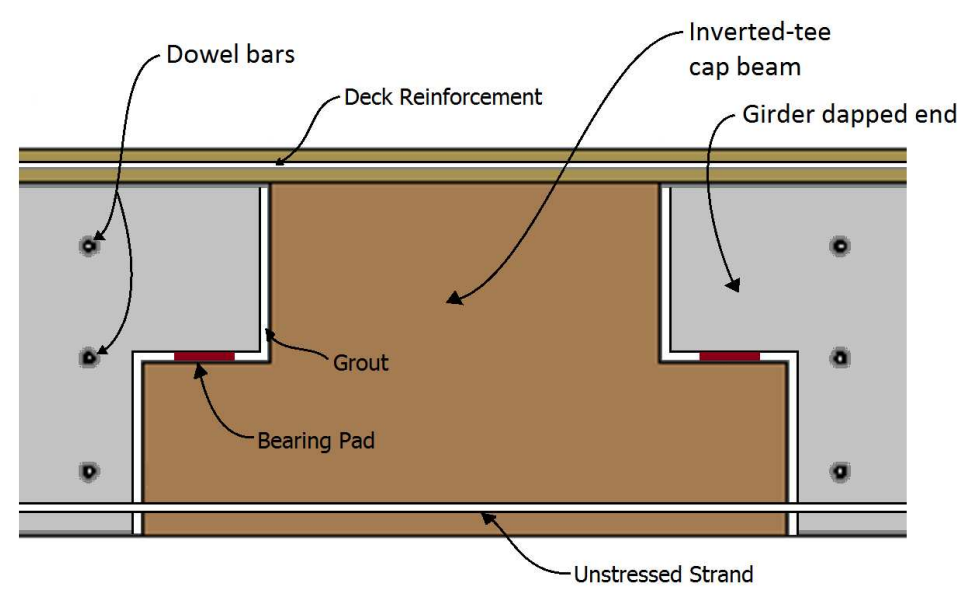

b. Improved detail

Figure 3.4. Girder-to-cap connection concepts

For the detail to maintain its integral performance during seismic loading, it needs to successfully transfer vertical shear as well as positive and negative moments. Downward vertical shear in the as-built detail is easily transferred from the girder dapped end to the cap beam corbel, due to the direct support configuration of the dapped end on the corbel. The as-built detail also has significant negative moment capacity, because the deck reinforcement provides tension continuity across the girder-to-cap joint. The dowel bars provide some resistance to upward shear and positive moment loading that could occur during a large seismic event. However, since the detail includes no tension continuity near the girder bottom flange, Caltrans currently anticipates rapid degradation of the girder-to-cap connection region will commence under high positive moment action. Therefore, Caltrans recommendations currently 
require that it be treated as a pin connection when subjected to seismic loading. One of the objectives in the experimental investigation was to determine whether Caltrans' current treatment of the existing detail is overly simplistic. While the detail would deteriorate when subjected to large seismic displacements, the diaphragm, dowel bars, deck, and reinforcement would continue to provide measurable shear and moment strength. The load mechanisms that exist in this partially deteriorated state are difficult to pinpoint; thus, experimental work to enhance understanding of these mechanisms and more fully quantify their behavior would be beneficial to the design process and implementation of this detail.

In addition to more fully quantifying the as-built detail, an additional objective was to develop an improved detail that would provide a more predictable load mechanism to supply the necessary shear and moment capacity. The main limitation with the as-built detail is the lack of positive moment tension continuity. To address this deficiency, the improved detail incorporates unstressed strands to provide tension continuity between the girder bottom flange and the cap beam corbel, as shown in Figure 3.4b. The strands are run through ducts in the bottom flange of the precast girder and continue across the girder-to-cap interface into aligning ducts in the cap beam. After the strands are placed, they are grouted in place to provide anchorage in the girder and cap. This connection detail has the same negative moment and vertical shear capabilities as the as-built detail, but it has the added benefit of positive moment and additional shear resistance across the connection interface provided by the addition of the grouted unstressed strands.

\subsubsection{Test Unit Configuration}

The large-scale experimental test unit was developed to investigate the overall system performance and to compare and contrast the capability of the as-built and improved connections. A schematic representation of the test configuration, along with a photograph, is provided in Figure 3.5. The test unit was designed at a 50 percent dimensional scale of the prototype structure. It modeled the full fivegirder width of the prototype on both sides of Bent 3, with the girder length extending approximately to the mid-span of the girders on either side of the column, as shown by the dashed region in Figure 3.3a. The termination of the girders at the location representing the prototype mid-span resulted in support locations at the approximate girder inflection points under horizontal seismic loading. Hold-downs were utilized to properly simulate the effects of gravity load in the girder-to-cap connection region; these 
hold-downs were located at the approximate girder inflection points during the service-load-only condition, with load application occurring in two stages as detailed in the next section. Two pairs of horizontal actuators, one at each end of the test unit, were used to apply quasi-static horizontal seismic loads, and pairs of vertical actuators at each end were used to provide vertical support and to accommodate the column growth expected due to the formation of plastic hinges without introducing additional load to the superstructure. This type of support was accomplished by programming the vertical actuator control based on the predicted column growth at various horizontal displacement levels, following the procedure outlined by Holombo et al. (1998).

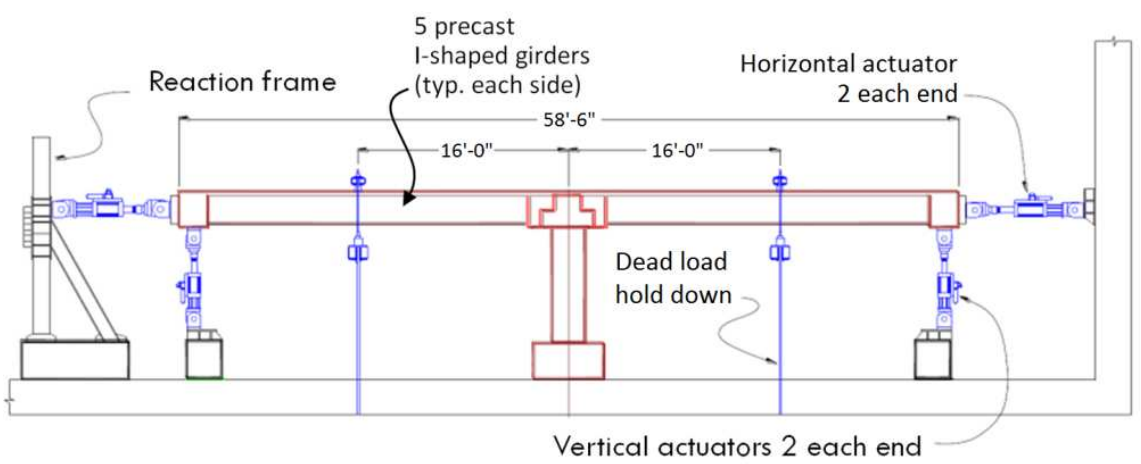

a. Schematic of Phase I configuration

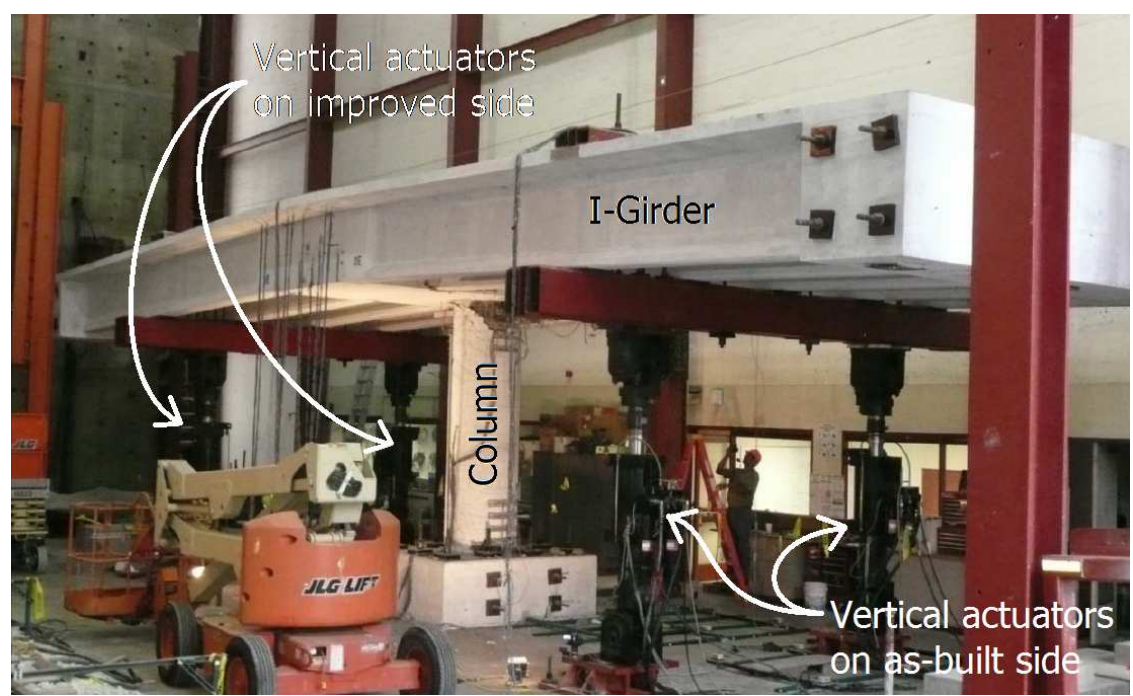

b. Photograph of Phase II configuration

Figure 3.5. Inverted-tee test unit 
In order to test both the as-built and improved connections without building two test units, the five girders on one side of the inverted-tee cap beam were connected using the as-built detail, while the improved detail was used for the girder-to-cap connection of the five girders on the opposite side of the cap beam. Figure 3.6a provides a cross-sectional view through the connection region, showing the improved detail on the left and the as-built detail on the right. Both details utilized dowel bars passing through the precast girder web and anchored in a cast-in-place concrete diaphragm surrounding the connection region. The only difference between the two connections was that unstressed posttensioning strands were included in the improved connection, running continuously through ducts in the bottom flange of the girder and into ducts in the cap beam corbel. These strands were grouted in place after being positioned. In a prototype bridge utilizing this detail, the strands would run through the cap beam and continue into the girder on the far side of the cap beam, but since the improved connection was modeled only on one side of the test unit, the strands from the improved connection were terminated and anchored on the far side of the cap beam.

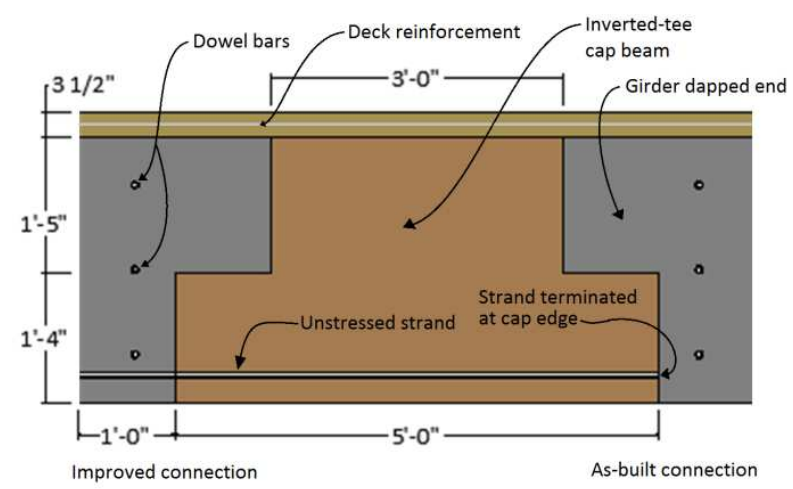

a. Section through cap beam connection region

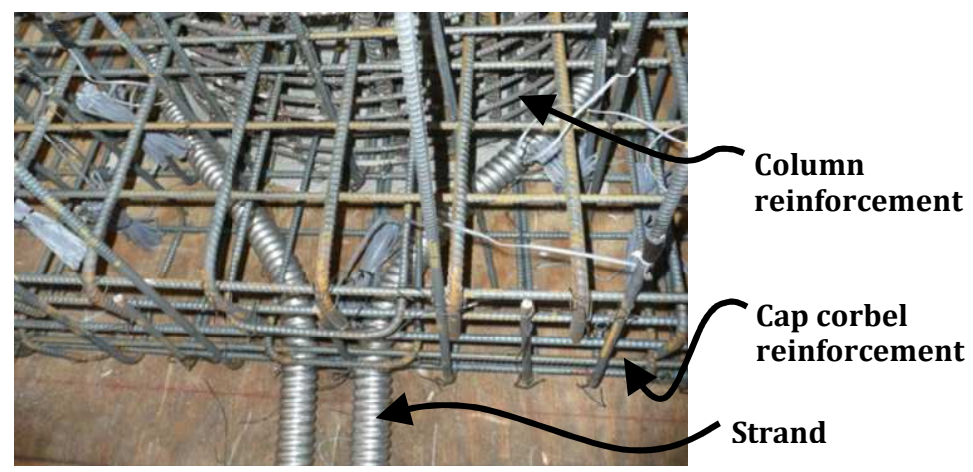

b. Photograph of center girder connection prior to concrete placement

Figure 3.6. Test unit girder-to-cap connection detail 
Figure 3.6b provides a photograph of the cap connection region for the center girder. The five-girder configuration results in the center girders attaching to either side of the cap beam adjacent to the cap beam-to-column connection. Because of this connection proximity, the strand ducts in the cap beam for the center girder improved connection were curved around the column connection region. While the introduction of these curves was a concern in terms of feeding the strand through the ducts and successfully grouting after placement, it did not pose any challenges during construction.

\subsubsection{Construction}

Construction of the test unit was completed at the Charles Lee Powell Laboratories at the University of California, San Diego. In order to make the test unit as close to an actual inverted-tee bridge as possible, typical field construction practices and techniques were incorporated into the test unit construction. The footing and column were constructed first, and temporary shoring was erected around the column to support the construction of the inverted-tee cap beam. Figure 3.7 shows the cap beam atop the column prior to girder placement. The girders were fabricated offsite at a precast concrete production facility. Typical methods were used in the girder construction process; however, engineered wire mesh was used to provide the transverse reinforcement in the girder. The wire mesh was incorporated to validate its use in place of traditional transverse reinforcement in precast girders. After the girders were delivered to the laboratory, temporary shoring was used to support them in position on the cap beam, as shown in Figure 3.8. The strands for the improved connection were then properly positioned through the cap beam ducts and grouted in place. The temporary shoring was also used to aid in the construction of the diaphragm in the connection region. 


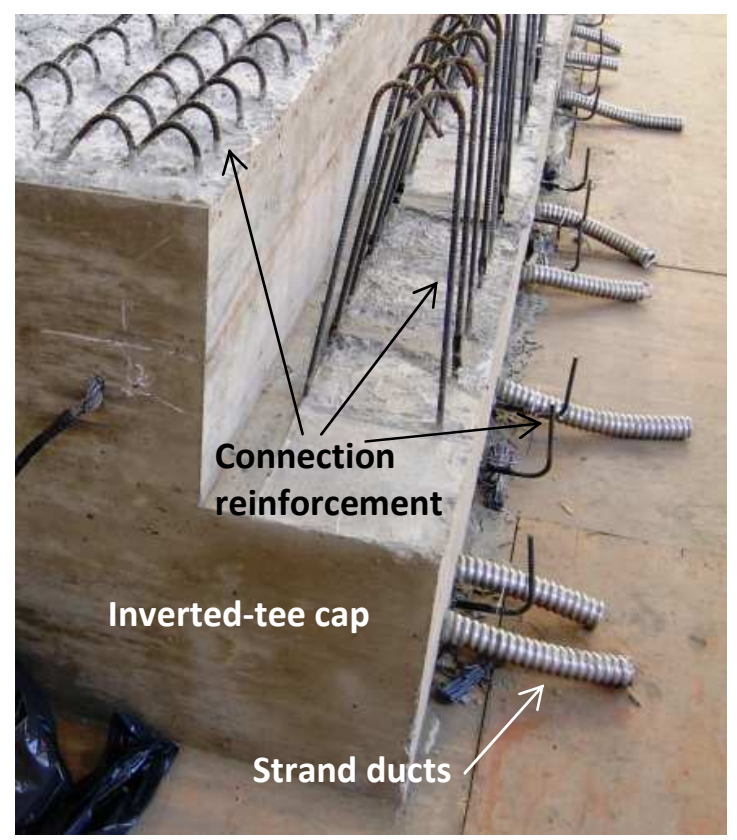

Figure 3.7. Inverted-tee cap beam prior to girder placement

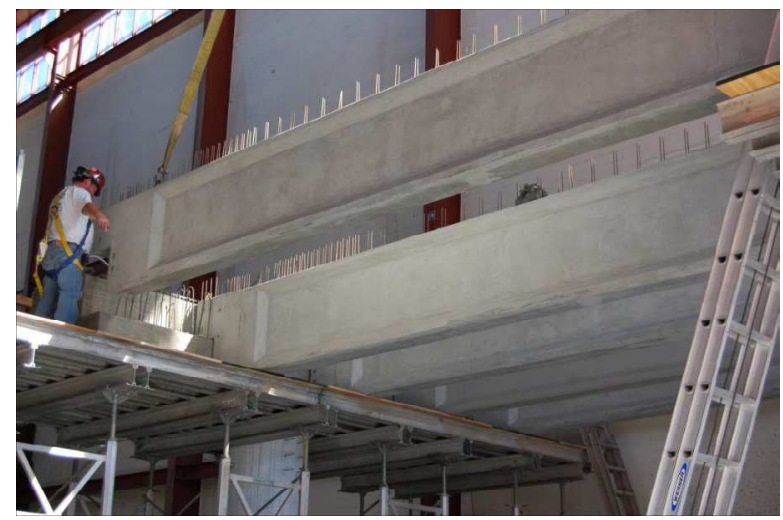

(a) Installing as-built girders

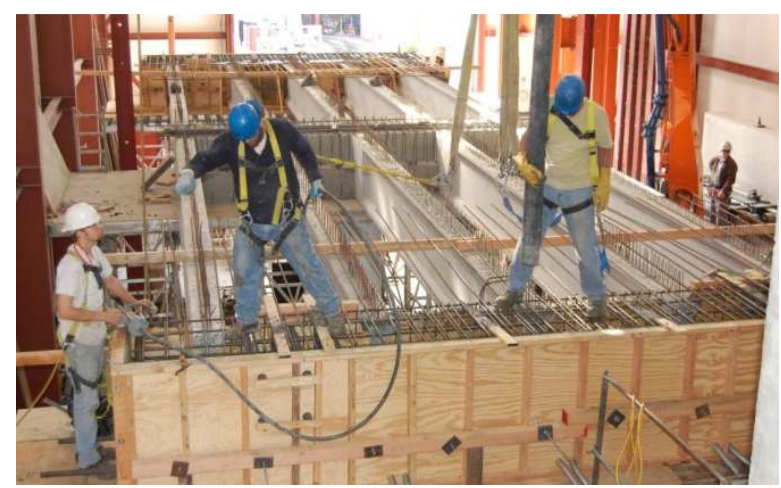

(c) Casting an abutment

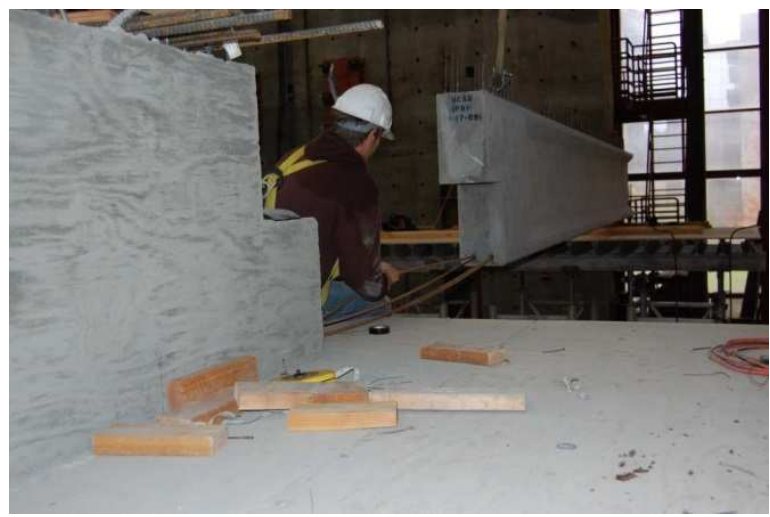

(b) Installing strand for improved girders

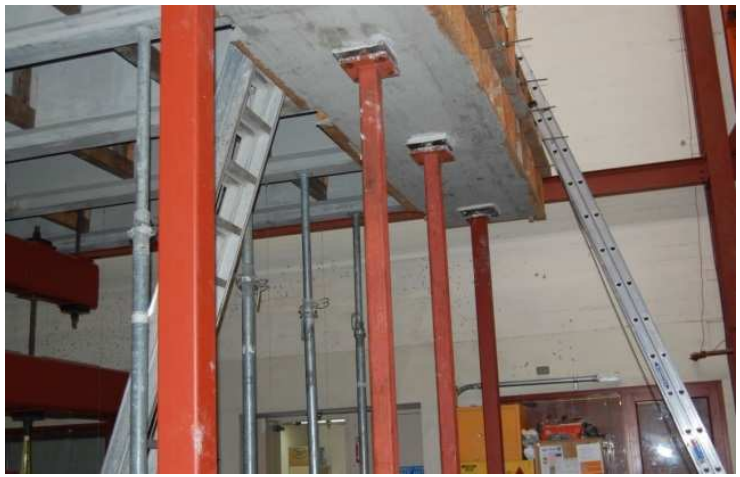

(d) Temporary abutment support

Figure 3.8. Photographs of construction 
To provide temporary stability to the system, the concrete in the lower third of the diaphragm was placed without fully constraining the girder ends and prior to applying the Stage 1 hold-down forces to each girder simulate additional girder self-weight. Following the Stage 1 load application, the diaphragm concrete placement was completed, and the abutment and deck concrete was placed. After the hardening of the deck concrete, the Stage 2 hold-down load was applied to each span to simulate the additional weight of parapets and wearing surface that would be added to the prototype structure following deck concrete placement.

\subsubsection{Staged Loading to Simulate Prototype Gravity Effects}

The test configuration was designed to provide stress simulation of the prototype girder-to-cap connection region. To accomplish this simulation, the progression of the prototype connection load transfer capabilities during construction needed to be replicated as closely as possible. For the field construction of the prototype structure, the girders would be set in place without moment restraint prior to the diaphragm placement. The casting and subsequent curing of the diaphragm concrete in the girder-to-cap connection would then create a moment connection. The initial loads between the girders and cap beam prior to diaphragm casting are transferred as if the girders are simply-supported. However, after placement of the diaphragm, the loads between the girders and cap are transferred through a moment connection. Since the test unit did not model the full length of the girders prior to diaphragm placement or the parapet and wearing surface loads that would be added after deck and diaphragm placement, the vertical load simulations were introduced in a staged process to properly simulate the connection fixity during each stage of the loading process.

The moment profile comparison of the prototype and the test unit at Stage 1 (dead loads prior to connection moment capacity) and Stage 2 (additional dead loads after the connection moment capacity is developed) in Figure 3.9 shows how the hold-down forces were used to accurately simulate the moments in the connection region. Similar comparisons were conducted to ensure proper simulation of the shear in the connection region but, for brevity, are not included here. The Stage 1 loads (33.4 kips per girder) were applied individually to each girder, since they were simulating additional girder selfweight load that would be present prior to deck placement. The Stage 2 loads (45.2 kips per girder), however, were applied using a spreader beam across the test unit deck, since these loads were 
simulating loads such as deck, wearing surface, and parapet that would be present after deck placement.

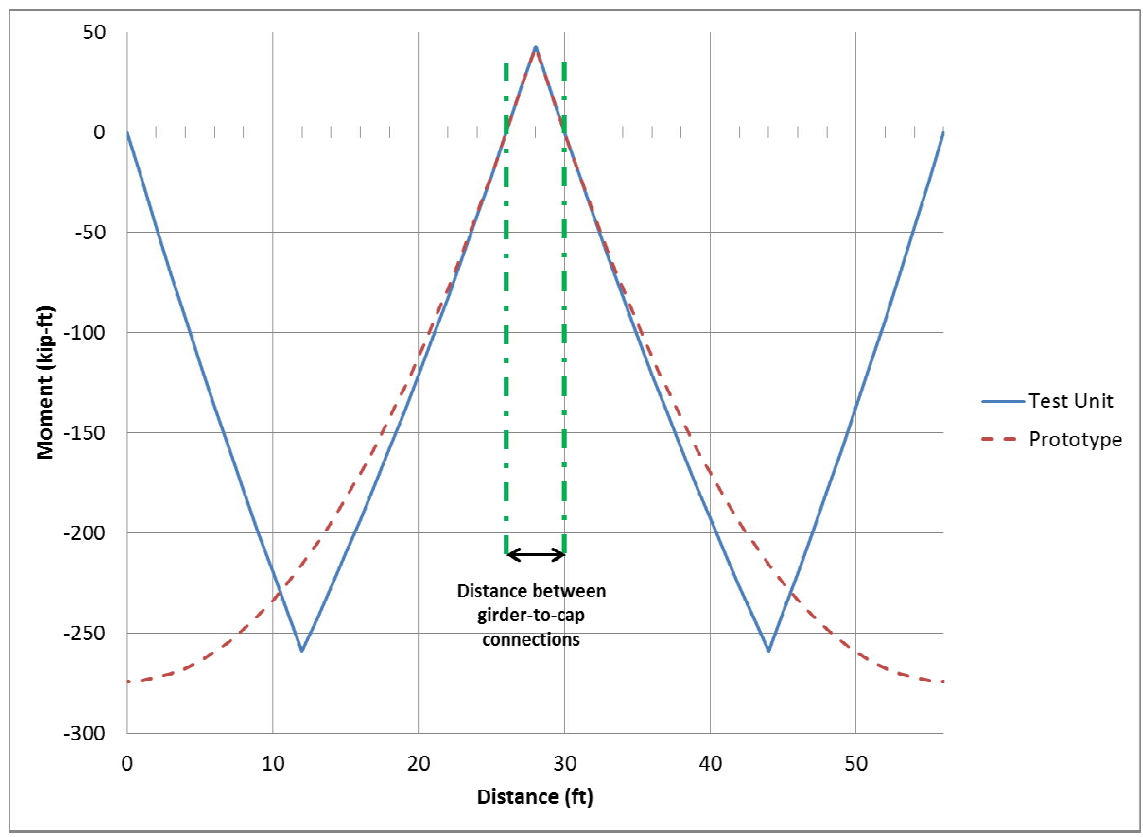

a. Stage 1 loading

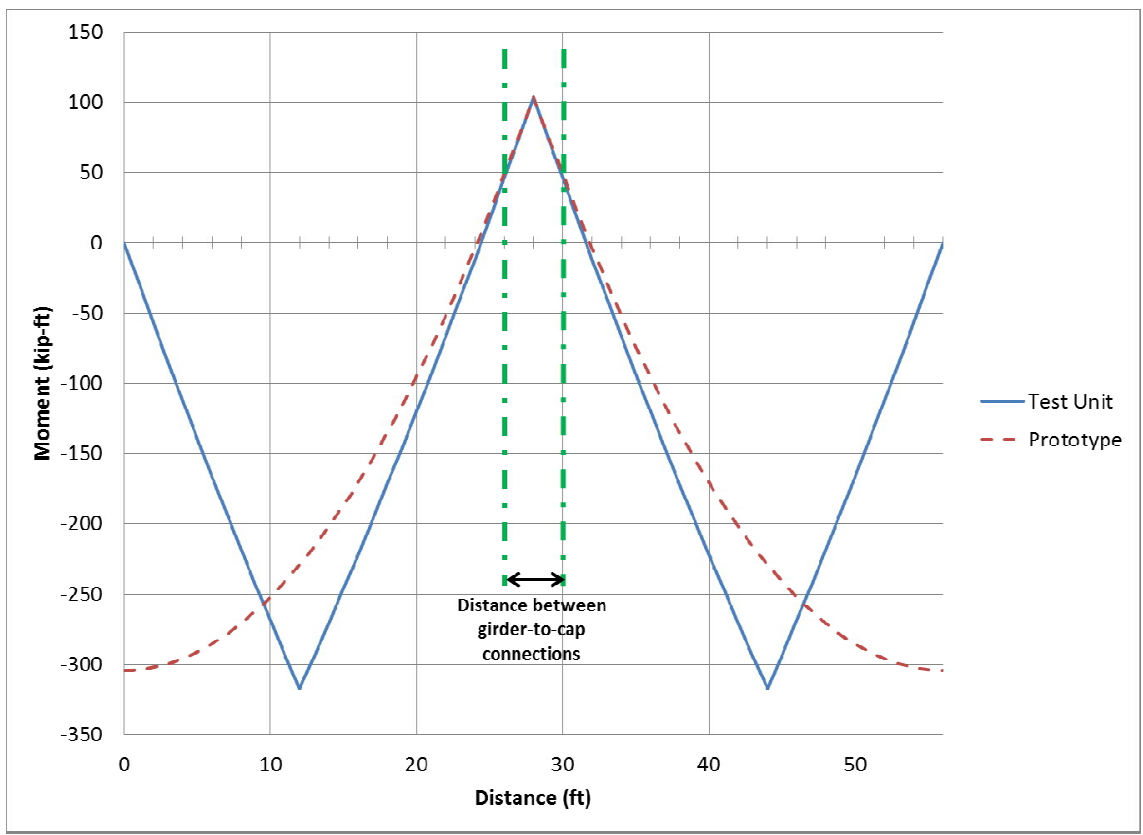

b. Stage 2 loading

Figure 3.9. Comparison of prototype and test unit moment profiles during stage loading (test unit scale) 


\subsubsection{Seismic Load Protocol}

The portion of the test unit load protocol planned to simulate the horizontal seismic effects was deemed "Phase I." A cyclic quasi-static load process was planned to simulate the effects of horizontal earthquake loads, as shown in Figure 3.10. Single load cycles would be used to apply loads using the horizontal actuators under force control at peaks of $\pm 0.25 F_{y}, \pm 0.5 F_{y}$, and $\pm 0.75 F_{y}$, where $F_{y}$ was the estimated first yield strength of the system. (First yielding in the column longitudinal reinforcement was expected to occur simultaneously at the top and bottom column ends.) The remainder of the test was conducted using the horizontal actuators under displacement control, using three fully reversed quasistatic displacement cycles at system ductility levels varying from $\mu_{\Delta}=1.0$ to $\mu_{\Delta}=10.0$.

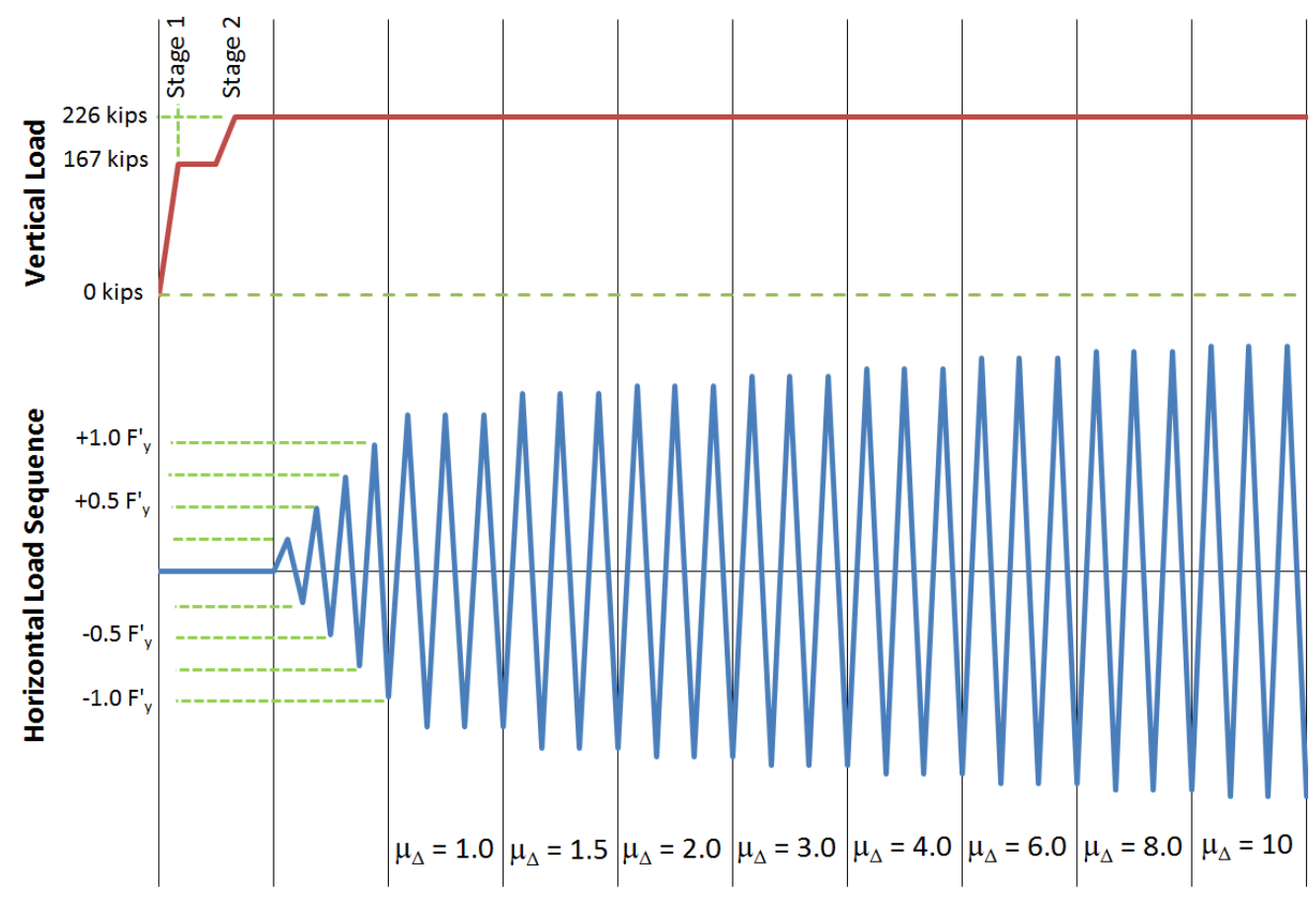

Figure 3.10. Phase I load sequence

\subsection{Experimental Investigation: Phase I}

Primary purposes for Phase I included: (1) confirming the validity of the overall system for high seismic regions, (2) determining the capability of the girder-to-cap connections to maintain elastic superstructure action up to high seismic displacements (i.e., the sufficiency of the girder connections to provide adequate resistance to develop plastic hinges in the column), and (3) comparing and contrasting the existing Caltrans girder-to-cap connection detail with an improved detail. 


\subsubsection{General Summary of the Test Unit Performance}

The Phase I test was initially conducted under force-control, using the horizontal actuators to excite the superstructure. The test switched to horizontal displacement control after establishing the idealized yield displacement for the test unit based on yielding of the column longitudinal bars. General observation of the displacement-control portion of the testing in Phase I indicated excellent seismic behavior. Figure 3.11a shows the column during the Phase I testing. Plastic hinges were developed at both the base of the column above the footing and at the top of the column just below the cap beam, indicating successful performance of the superstructure. The successful superstructure performance was notable, since it contradicted Caltrans' current treatment of the as-built connection as having limited moment resistance at high seismic displacements.

Overall, the structure achieved a displacement ductility of 10 , corresponding to 7 inches of total horizontal displacement in each direction. At this displacement level, several column longitudinal bars had buckled, and confinement failure was beginning to occur. Both the improved and as-built connections between the cap beam and girders behaved as fixed connections and did not show signs of significant damage or degradation. Fairly extensive flexural cracking was observed across the width of the deck, indicating that the diaphragm action of the deck had engaged all of the girders in resisting the column seismic moment. The seismic load distribution among the girders is investigated in depth in Vander Werff and Sritharan (2014). 


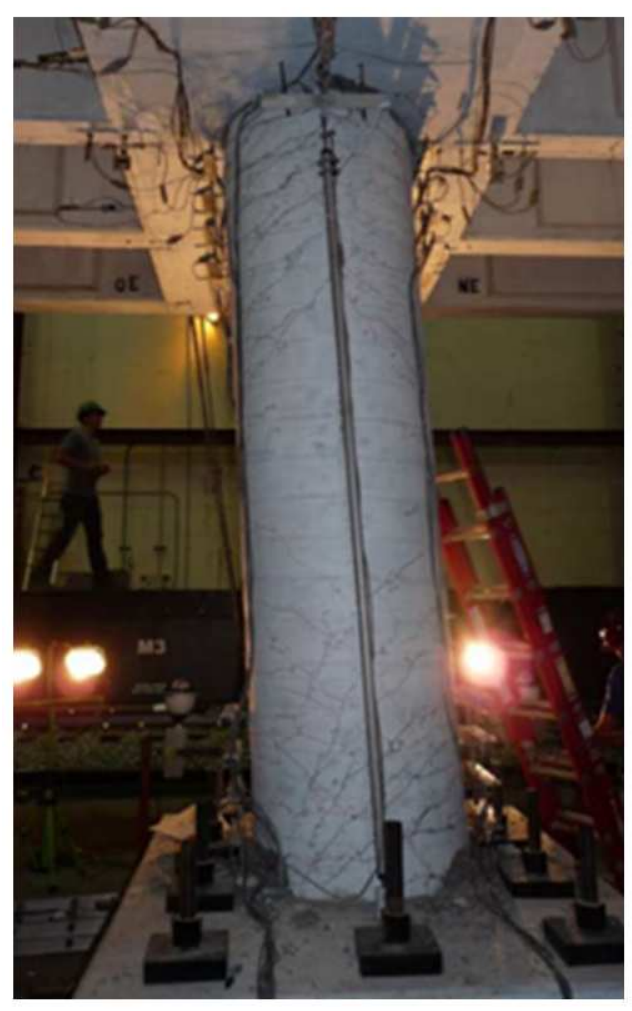

a. Column at $180 \mathrm{~mm}$ lateral displacement (displacement ductility +10.0)

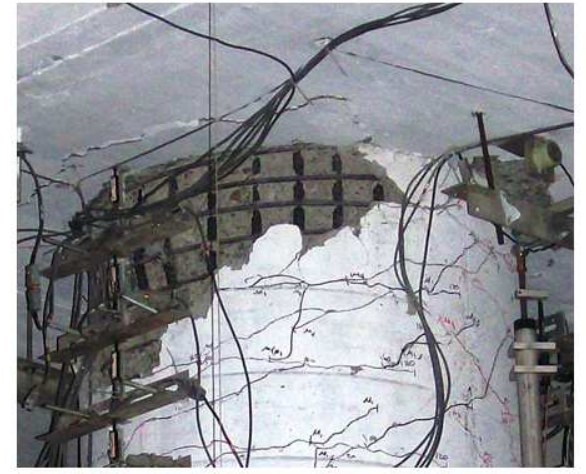

b. Buckled bars in the column top plastic hinge region

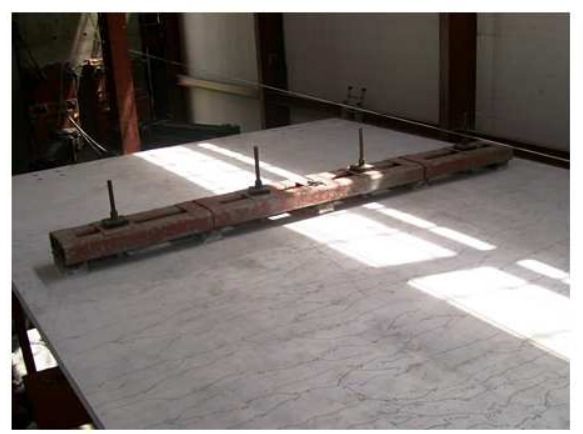

c. Flexural cracking across the entire deck width

Figure 3.11. Test unit photographs during and after Phase I testing

\subsubsection{Force-Displacement Response}

The force-displacement response of the test unit, shown in Figure 3.12, is indicative of excellent seismic performance, as strength retention was maintained all the way to $\pm 8.0 \mu_{\Delta}$. Also, while longitudinal bar buckling and beginning of confinement loss occurred at $\pm 10.0 \mu_{\Delta}$, significant strength still remained in the system. This strength exhibits the ability of the system to continue carrying gravity load even at very large seismic displacements. 


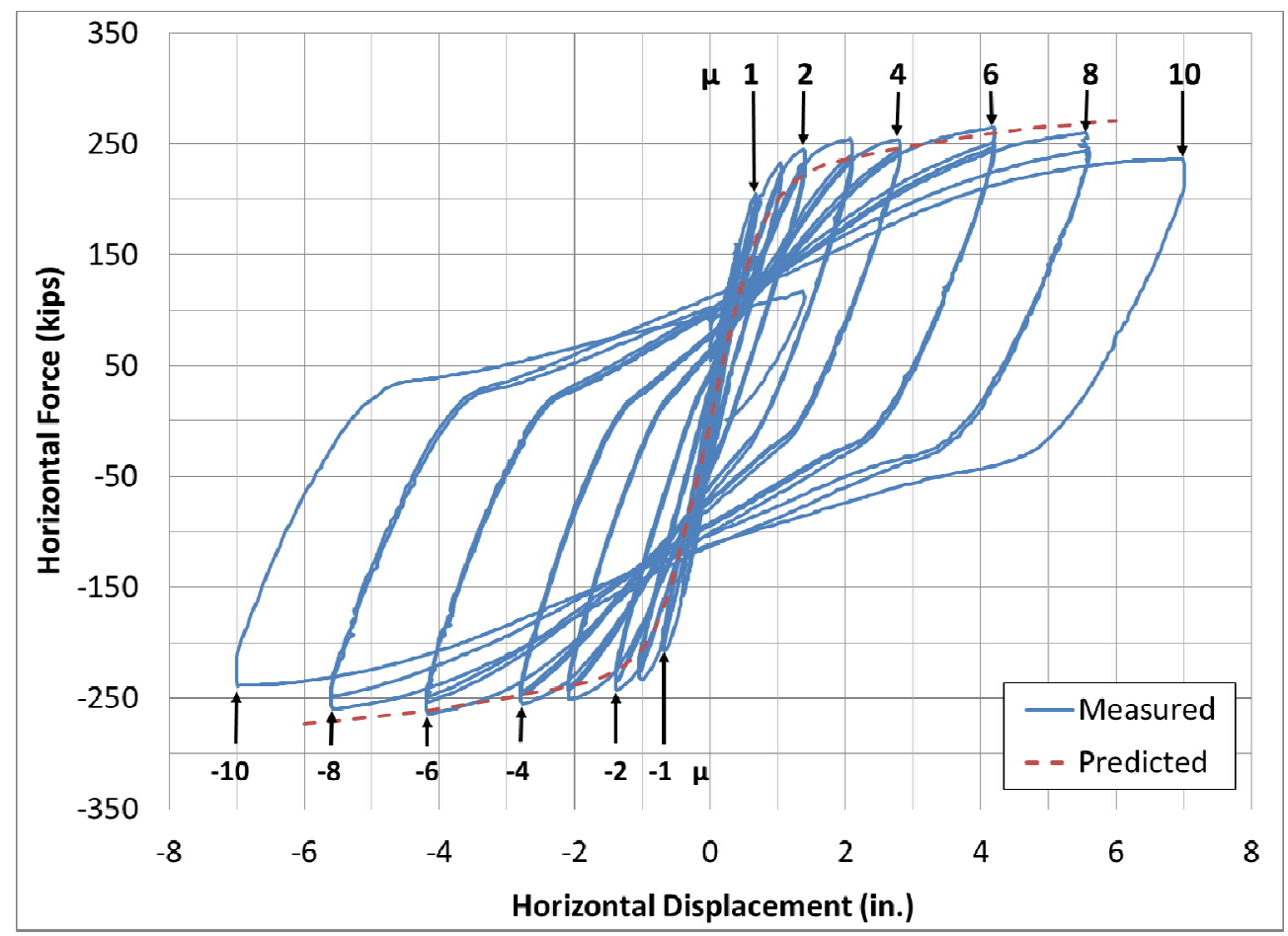

Figure 3.12. Horizontal force-displacement response for system test unit

\subsubsection{Analytical Comparison}

The analytical investigation incorporated a finite element model (FEM) analysis and an associated grillage analysis. Details of the FEM are provided in Theimann (2010); in summary, three-dimensional FEMs at both prototype and test unit scales were created to analyze the superstructure behavior. The behavior of the girder-to-cap connections and the interaction between the girders across the superstructure were of particular interest in this analysis. Since the FEM work focused on the superstructure behavior, a grillage analysis was also conducted to investigate the generalized behavior of the prototype and predict the response of the test unit. The grillage model (detailed in Snyder et al., 2011) included a column with nonlinear elements at top and bottom to model the plastic hinge behavior. The elements in the grillage superstructure were modeled to incorporate findings from the FEM work. In particular, the FEM results were used to introduce the slipping and friction force transfer effects in the girder-to-cap connection region to the grillage model. The grillage model was used primarily to predict the force-displacement response of the test unit and to investigate the load distribute between the girders in the superstructure. The grillage results are shown along with the experimental results later in this paper. 
The force-displacement predictions from the grillage model, also shown in Figure 3.12, compared favorably to the experimental horizontal force-displacement response of the superstructure, which is shown in There is slight variation at the small displacements, which is attributed to the use of a cracked effective stiffness for both the column and superstructure sections in the grillage model, rather than the actual gross values for the elastic region of the test. However, the results converged more closely at higher levels of displacement as more of the test unit began to soften due to the development of cracks and yielding of longitudinal reinforcement.

\subsubsection{Connection Response}

Investigation of the behavior of the girder-to-cap beam connections was a primary area of interest, verifying in particular whether the superstructure remained elastic while allowing the column plastic hinges to fully develop. Visual observations during Phase I indicated that the superstructure did indeed remain elastic, as plastic hinges were developed in the column and no significant spalling, bar buckling, or other failure indicators were observed in the superstructure. Data gathered during Phase I testing was used to validate these observations. Figure 3.13 shows dowel bar strains measured in the as-built and improved connections for the center girder at peak displacements producing negative moment in the connection region. The maximum measured strain in the as-built connection was approximately 900 $\mu \varepsilon$, and the maximum measured strain in the improved connection was approximately $1000 \mu \varepsilon$. Both of these values are well below the yield strain (approximately $2000 \mu \varepsilon$ ) of the dowel bars. Also, the dowel bar strain magnitudes from peak displacements producing positive moment in the connections (not shown in the figure) were observed to be roughly half the magnitude of the strains under negative moment loading. The relatively low strain magnitude observed in all the dowel bars indicates that the dowel bar behavior remained elastic throughout the Phase I test for both the as-built and improved connection details. 


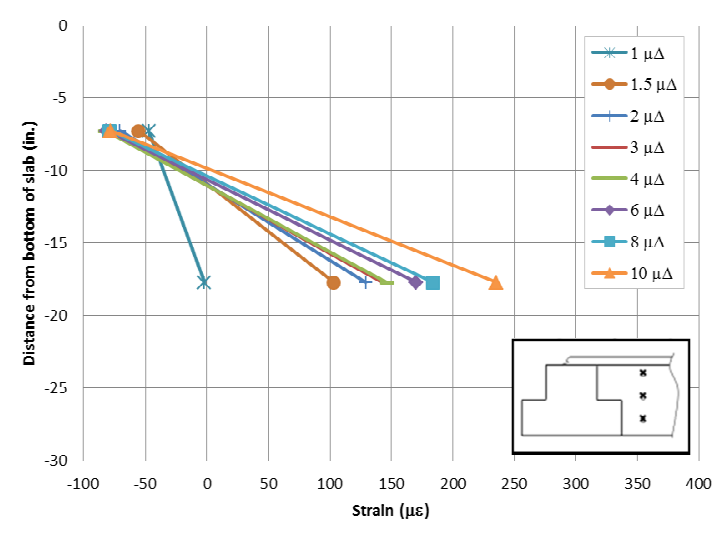

a. As-built connection (positive peaks)

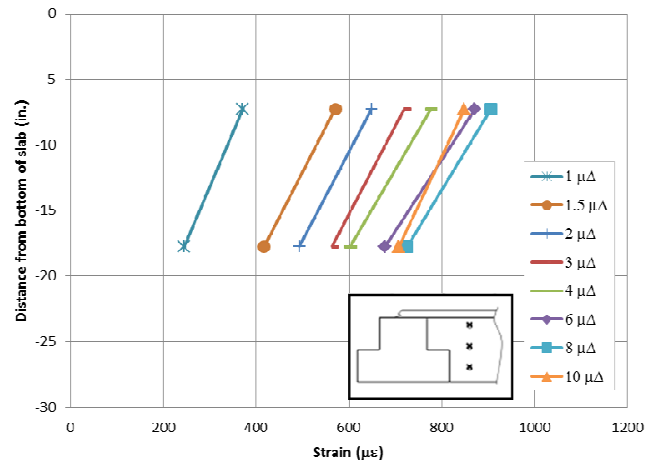

c. As-built connection (negative peaks)

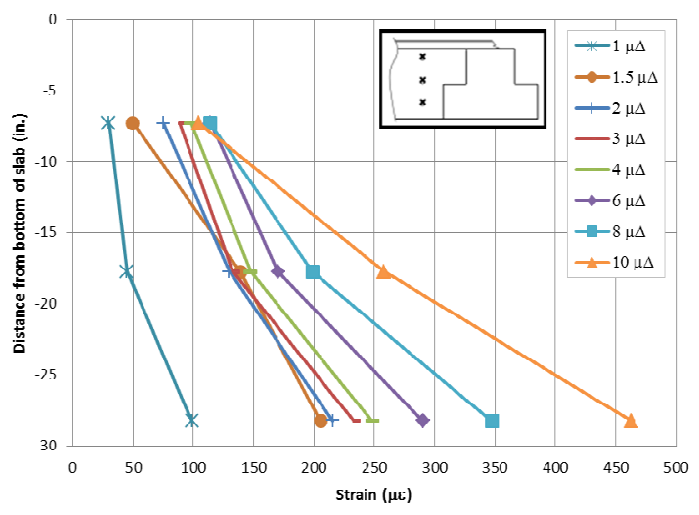

b. Improved connection (positive peaks)

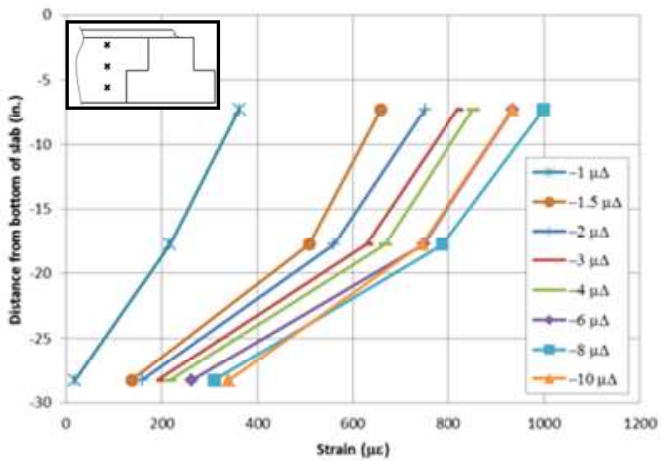

d. Improved connection (negative peaks)

Figure 3.13. Dowel bar strains at peak displacements

The improved connection implemented unstressed strands for positive moment continuity that were not included in the as-built detail. An interesting observation related to the dowel bar data presented above is that the dowel bar strains in the improved connection are not decidedly lower than the dowel bar strains in the as-built connection, as might be expected if some of the positive moment tension load is diverted from the dowel bars to the strands. Strain data from the strands in the improved connections of one exterior and two intermediate girders are shown in Figure 3.14. All the strands seem to have been slightly engaged already at low displacements, but all exhibited a noticeable increase in engagement when the superstructure was displaced to $1.5 \mu_{\Delta}$ (1.0 in.). This sudden magnitude increase corresponds closely to the point in the test where noticeable opening of the girder-cap interface of the improved connection was first observed. The opening at this point was an indication that the concrete tensile capacity was fully lost, producing significant load transfer to the strands. The dowel bar strain profiles from the improved connection (Figure 3.13b,d) above also show the largest incremental 
increase between displacements steps $1.0 \mu_{\Delta}$ and $1.5 \mu_{\Delta}$. This behavior indicates that the dowel bars and unstressed strand act in concert to transfer the positive moment tension load, rather than the unstressed strand diverting a considerable portion of the action away from the dowel bars. The combination of the dowel bars and unstressed strand provides a viable mechanism for resisting large positive moment action.

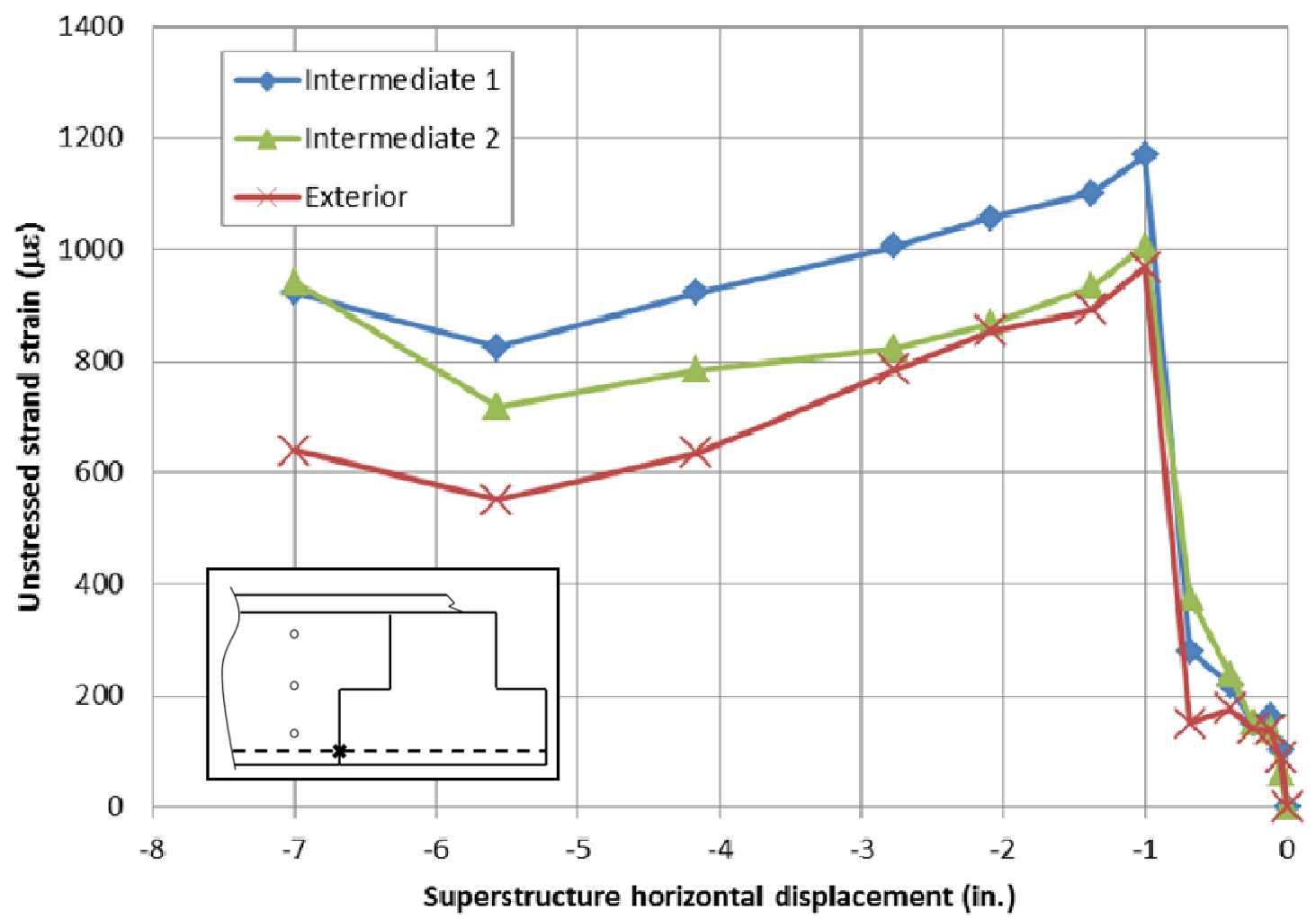

Figure 3.14. Unstressed strand strains in exterior and intermediate girders at peak displacements producing positive moment in the improved connection region

The relative behavior of the gap between the girder bottom flange and the adjoining edge of the diaphragm provides further insight into the difference between the improved and as-built connection behaviors. Figure 3.15 compares the dowel strains plotted as a function of this gap data for both the improved and as-built connections at positive-moment-direction peak load conditions. Comparing both sets of data along the vertical axis confirms the similarity in dowel bar strain magnitude for the improved and as-built connections. However, the comparison along the horizontal axis reveals noticeably larger displacements in the as-built connection, showing that the unstressed strand in the 
improved connection was effective in reducing the gap opening under positive moment loading. Similar to the data above, this data shows that while the unstressed strand did not decrease the dowel bar strain, it certainly improved the performance of the connection.

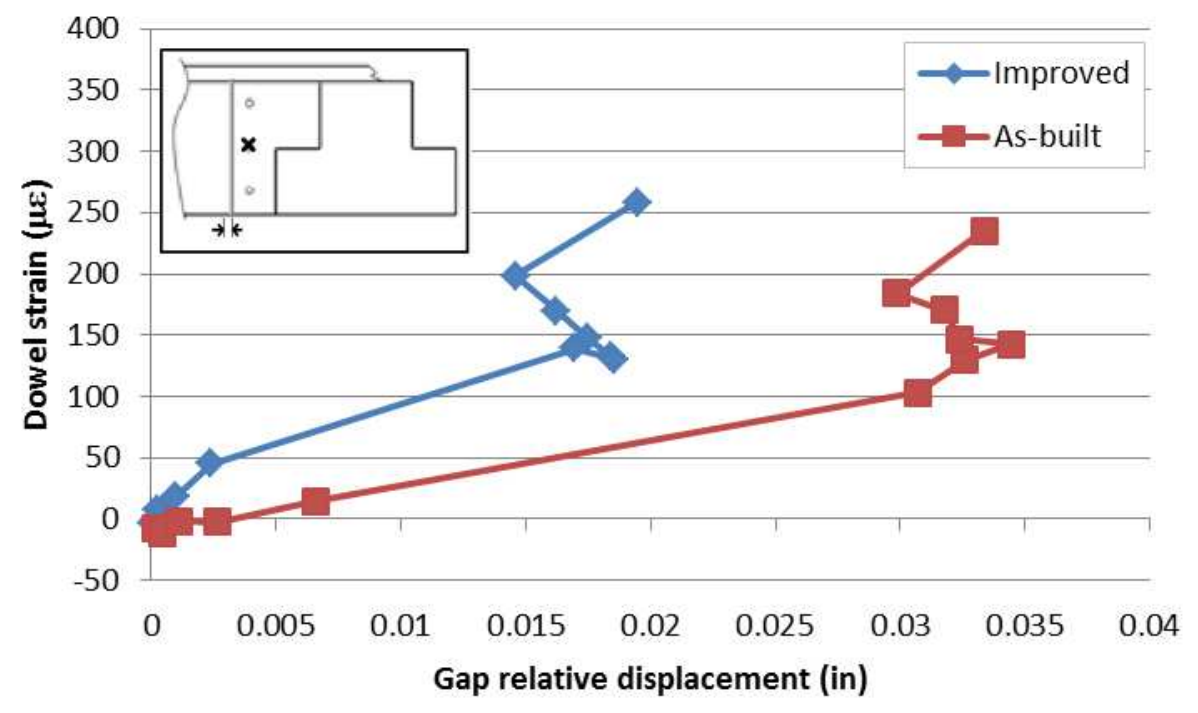

Figure 3.15. Gap opening at the bottom girder-to-diaphragm interface (Phase I)

Strains measured in the deck reinforcement, which acted as the primary tension reinforcement for the connections under negative moment loading, were also used to investigate the superstructure behavior. A primary finding was that the deck strains clearly exhibited the engagement of all five girders in resisting the column moment, from the early load stages all the way through to the overstrength moment. More details on this topic can be found in Vander Werff and Sritharan (2014).

\subsection{Experimental Investigation: Phase II}

Since the superstructure, including the connection, maintained elastic response in the Phase I test, a subsequent experimental test phase was conducted. The purpose of this phase, deemed "Phase II," was to fully exercise the girder-to-cap connections and further quantify their behavior. The configuration of the Phase II test was similar to the Phase I configuration shown earlier in Figure 3.5, except that the girder tie-downs were removed and the vertical actuators were moved to the tie-down locations. A photograph of the Phase II test configuration was provided in Figure 3.5b. 


\subsubsection{Load Protocol}

For Phase II, the relocated vertical actuators were used as the primary control mechanism, while the horizontal actuators were configured to remain at zero-load to retain horizontal stability in the test unit without affecting the load condition. Figure 3.16 provides the load protocol used with the vertical actuators. The actuators were initially adjusted under load control to establish the initial condition, matching the endpoint of the Phase I test and corresponding with the left edge of the sequence shown in Figure 3.16. Displacement control was then used to apply small incremental vertical displacements at the actuator locations down to $1.5 \mathrm{in}$. below the initial girder positions (producing negative moment in the connection regions) and then up to 1.0 in. above the initial girder positions (producing positive moment in the connection regions). The vertical displacements were applied to both sides of the test unit simultaneously. The initial displacement control sequence was used to establish test procedure and ensure specimen performance without going beyond load levels produced during Phase I. Following the initial sequence, the primary displacement sequence utilized three cycles per displacement level, as shown in Figure 3.16, up to a maximum displacement of 6.0 in. downward and 3.0 upward on each side of the test unit.

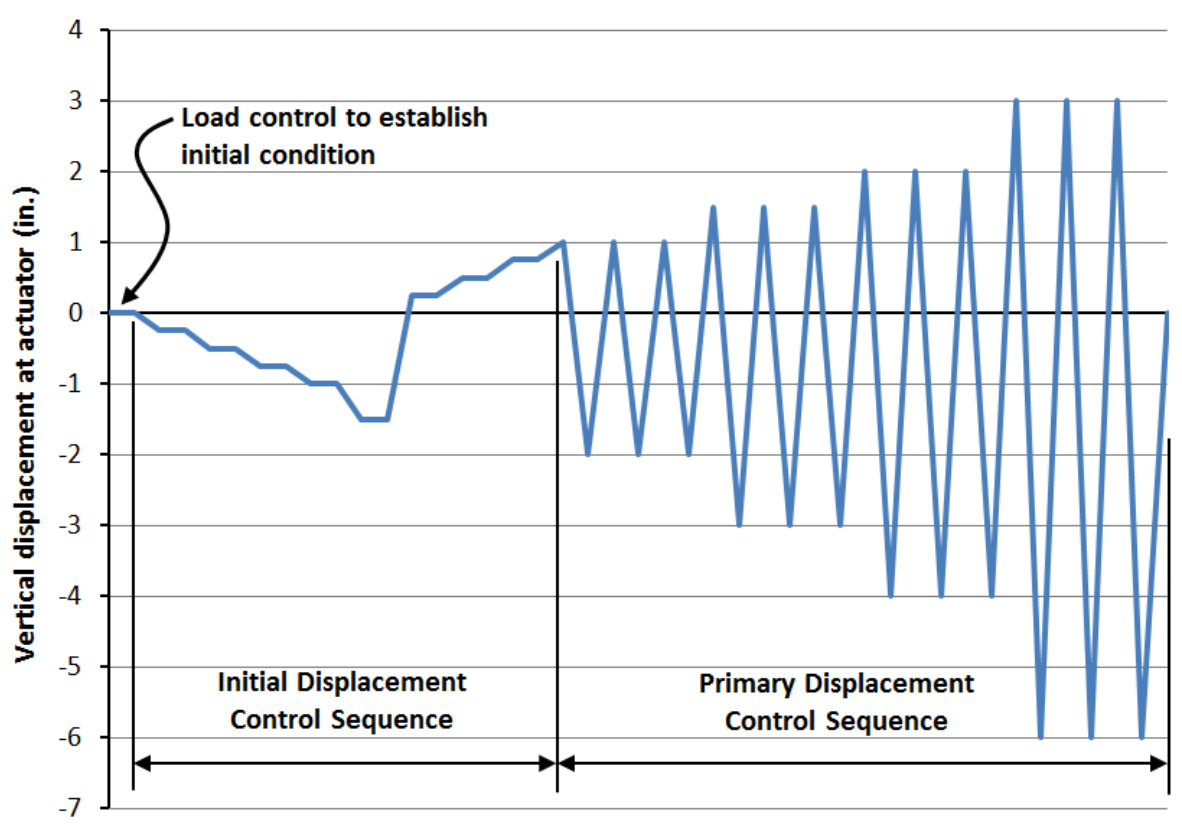

Figure 3.16. Test unit Phase II load sequence 


\subsubsection{General Observations}

The primary observation during the Phase II portion of the experimental test was the contrast in performance between the as-built connections and the improved connections. Throughout the test, the improved connections exhibited virtually no signs of damage, whereas the as-built connections in all five girders experienced a significant amount of deterioration in the interface regions between the girders and the diaphragm.

At a displacement of +0.5 in., the as-built connection was already subjected to a moment approximately $27 \%$ greater than the maximum positive moment achieved during the Phase I test. At a displacement of +0.75 in., the improved connection side remained essentially unchanged, but the asbuilt side began to exhibit significant degradation. The gap between the girder bottom flanges and the cap beam widened to approximately 0.2 in., and the 1 -in. thick grout along the bottom interface between the girders and cap had begun to separate and fall off, as shown in Figure 3.17a. Cracks in the diaphragm concrete indicative of the girder bottom dowel bar trying to pull out were observed on the as-built connection side. At +1.0 -in. displacement, the as-built connection continued to exhibit interface grout spalling, significant crack opening and bottom flange girder pullout, and a significant crack between the underside of the deck and the top of the diaphragm that indicated a connection separation. The improved connection remained essentially unchanged.

The higher displacement cycles continued to show the trend of increased deterioration on the asbuilt side with little change on the improved side. Eventually, the as-built connection deteriorated to the point of behaving as essentially a pin connection under positive-moment loading. Figure $3.17(b, c)$ shows the deterioration of the as-built connections at large positive displacements. The pin behavior of the asbuilt connection and the plastic hinge formed at the top of the column during Phase I prevented any further testing to increase the positive moment in the improved connection to the point of ultimate failure. Based on the force-displacement plots for the structure at a downward displacement of 6.0 in., both connection details seemed to have additional negative moment capacity. However, when the structure was cycled to an upward displacement of 3.0 in., a $42 \%$ drop in strength was observed, indicating that the as-built connection had already reached its ultimate capacity. Visual observations, including significant damage and pullout of the girders, seemed to confirm this data indication, so the 
behavior of the as-built connection was deemed to have been adequately captured, and the test was terminated.

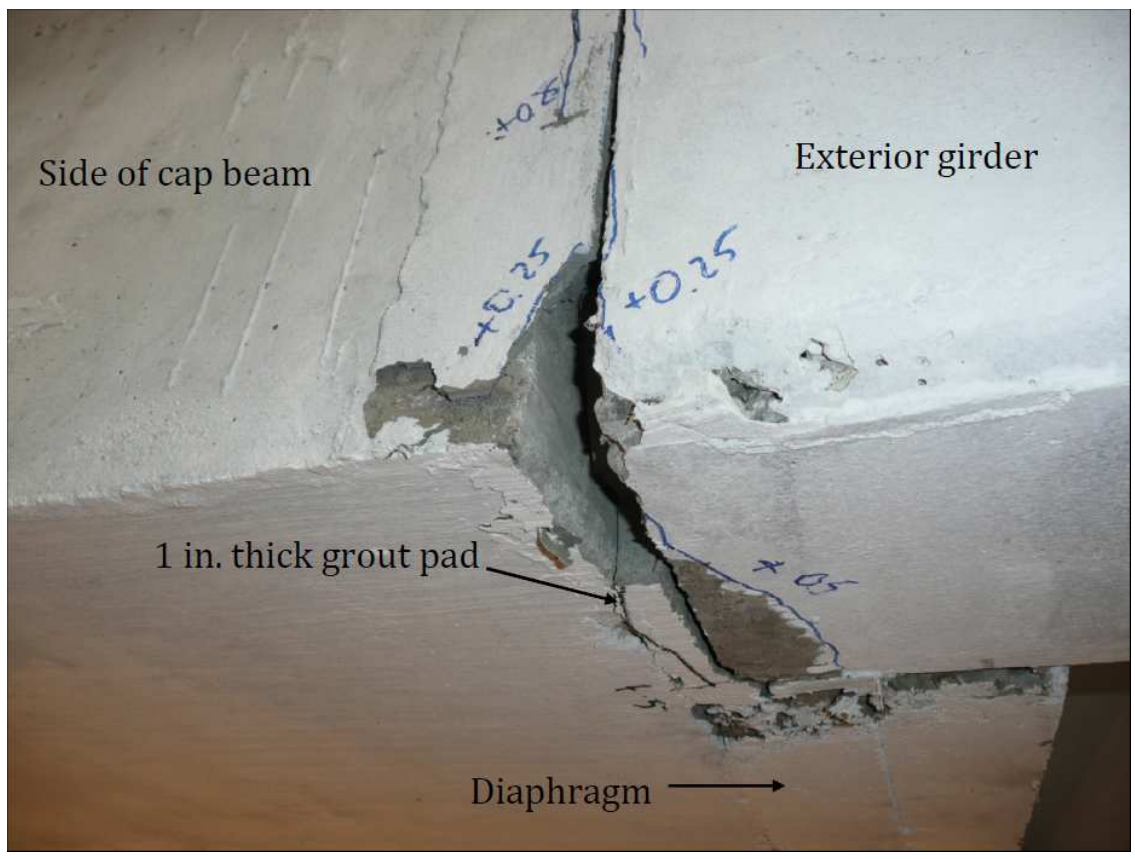

a. Partially spalled grout pad at as-built girder-to-cap interface at +0.75 -in. displacement

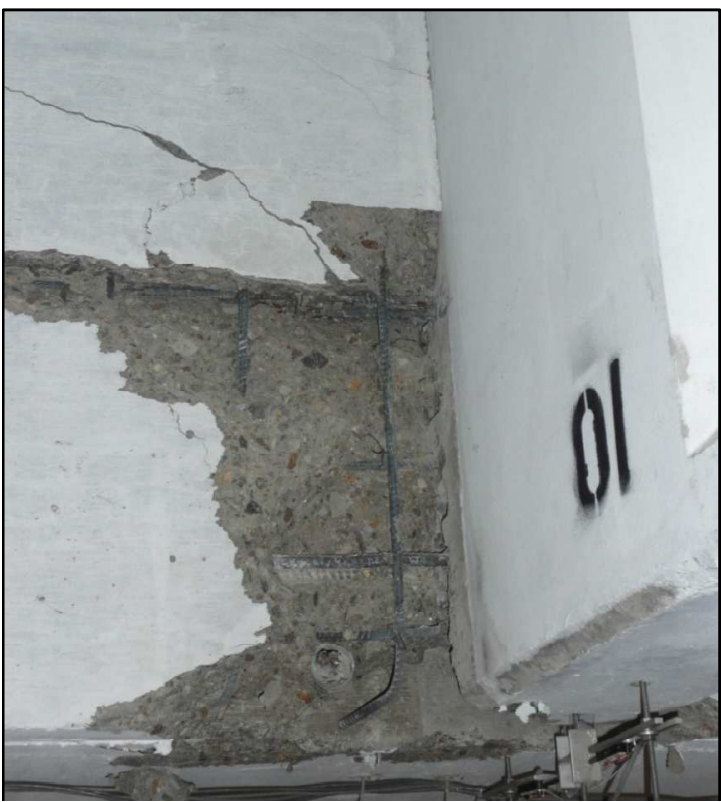

b. Deterioration of as-built connection

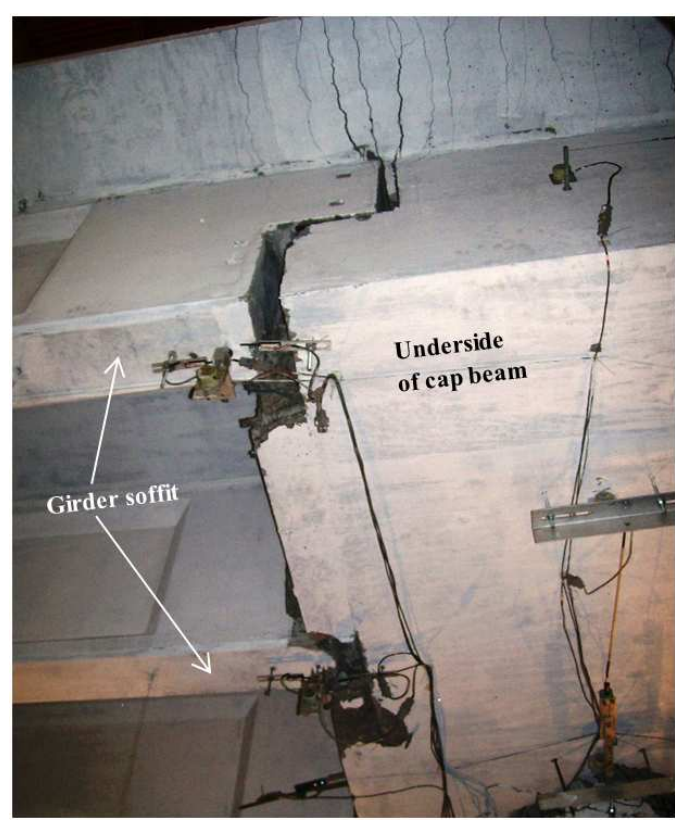

c. Opening of as-built connection under large positive-moment displacement

Figure 3.17. As-built connection region during the latter stages of Phase II testing 


\subsubsection{Force-Displacement Response}

The configuration of the Phase II test made it challenging to isolate the behavior of the improved and as-built sides of the test unit, as initial observation of the test raw data seemed to indicate inelastic behavior of both the improved and as-built connections. However, a careful analysis of the data was subsequently conducted, taking into account the experimental rotations, column load, horizontal actuator load, and vertical loads from both sides. This analysis was used to determine the total moment on the two sides, independent of each other. This modified data, shown in Figure 3.18, provides a much clearer picture of the test unit behavior and reveals distinctly different performance for the improved and as-built connections, particularly under positive moment excitation.

In Figure 3.18a, the behavior of the as-built and improved connections when subjected to positive moment is seen to be decidedly different. While the as-built connection showed significant strength deterioration at displacements higher than 0.75 -in., the improved connection was not subjected to relative displacements (adjusted to account for girder rotation) higher than approximately 0.35 in., and the response was essentially linear and elastic. Both connections demonstrated reserve positive moment strength well beyond the maximum demand experienced under horizontal seismic loading, shown by the dashed line on the figure. However, the as-built connection clearly experienced a loss in stiffness at loading above the maximum horizontal demand whereas the improved connection performance remained elastic.

Figure $3.18 \mathrm{~b}$ provides a comparison of the negative moment behavior of the two connections. The improved connection exhibited a slight increase in performance over the as-built connection. The relative displacement difference between the improved and as-built connections at the large displacements is likely due to the loss of the grout pad in the as-built connection. The difference in negative moment performance between the improved and as-built connections is seen to be much less pronounced than for the positive moment behavior. This similarity is not surprising, since the deck reinforcement provides the primary tension transfer mechanism for the two connections, and both connections utilized the same deck reinforcement detail. Both connections exhibited excellent negative moment performance, resisting moments that were 2.5 to 3.0 times higher than the maximum demand realized under horizontal seismic loading. 


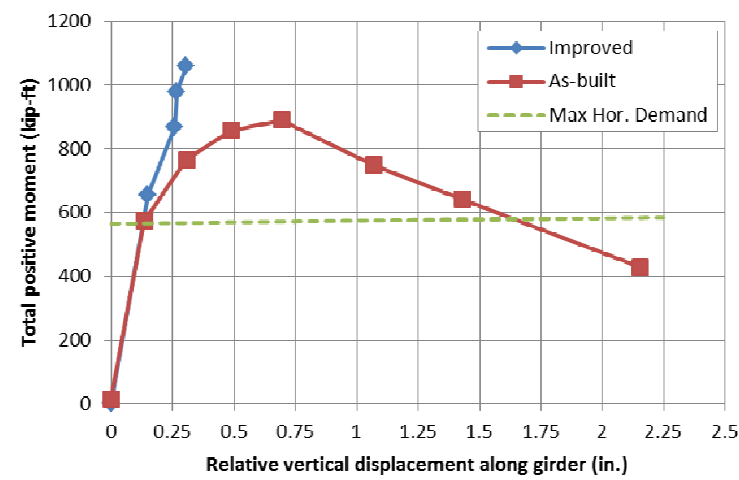

a. Positive moment in girder-to-cap connection

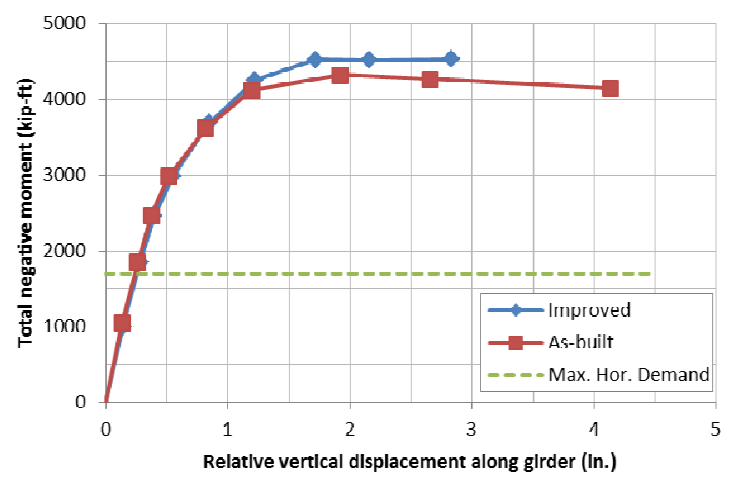

b. Negative moment in girder-to-cap connection

Figure 3.18. Comparison of as-built and improved connection moment behavior

\subsubsection{Behavior of Connection Details}

The similarity of the dowel bar behavior in the improved and as-built connection during Phase I was noted above. However, the gap relative displacement data from Phase I indicated improved behavior for the improved connection. Figure 3.19 shows the same data from Phase II, and it reveals that the improved connection's superior performance is even more pronounced for this phase. The gap relative displacement is considerably larger for the as-built connection. In addition, the magnitudes of dowel bar strain are seen to be lower in the improved connection. Both these observations show the benefit of the unstressed strand, even more apparent here for the large loads and displacements during Phase II than previously during Phase I.

Figure 3.20 shows the strains measured on these dowel bars at the peak displacements for the duration of the Phase II test. The behavior under displacements producing negative connection moment was very similar for both the as-built and improved connections. For displacements producing positive connection moment, a notable difference was measured between the as-built and improved dowel bars. The as-built connection exhibited quickly increasing strains at positive displacements of $1.0 \mathrm{in}$. and higher, whereas the improved connection strain plateaued at that displacement level. The engagement of the unstressed strands in the improved connection prevented the dowel bar load to increase in the improved connection at high displacements, whereas the dowel bar in the as-built connection continued to experience increase in load until it yielded at a girder displacement of 1.5 to $2.0 \mathrm{in}$. These data indicate that the dowel bars are engaged in the improved connection, even though the addition of the strand provides significant positive-moment tension continuity. Although the unstressed strand 
considerably improves the connection performance, the combined mechanism of the dowel bars and the unstressed strand provide the positive moment tension resistance.

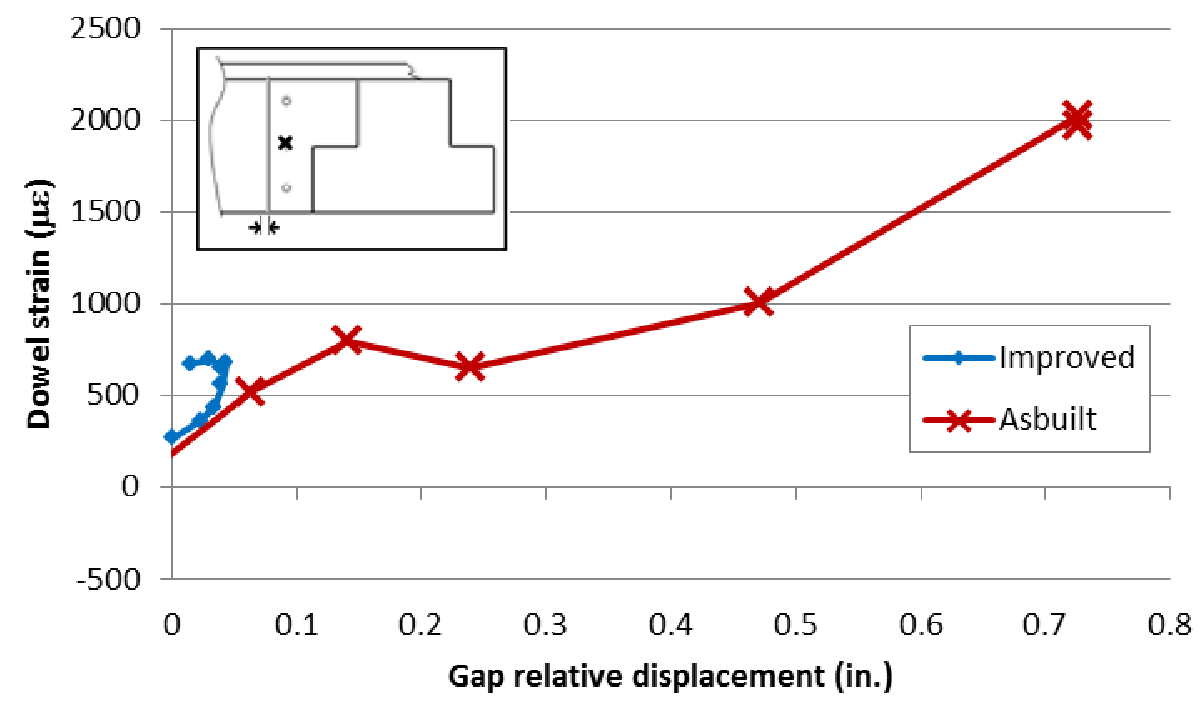

Figure 3.19. Gap opening at the bottom girder-to-diaphragm interface (Phase II)

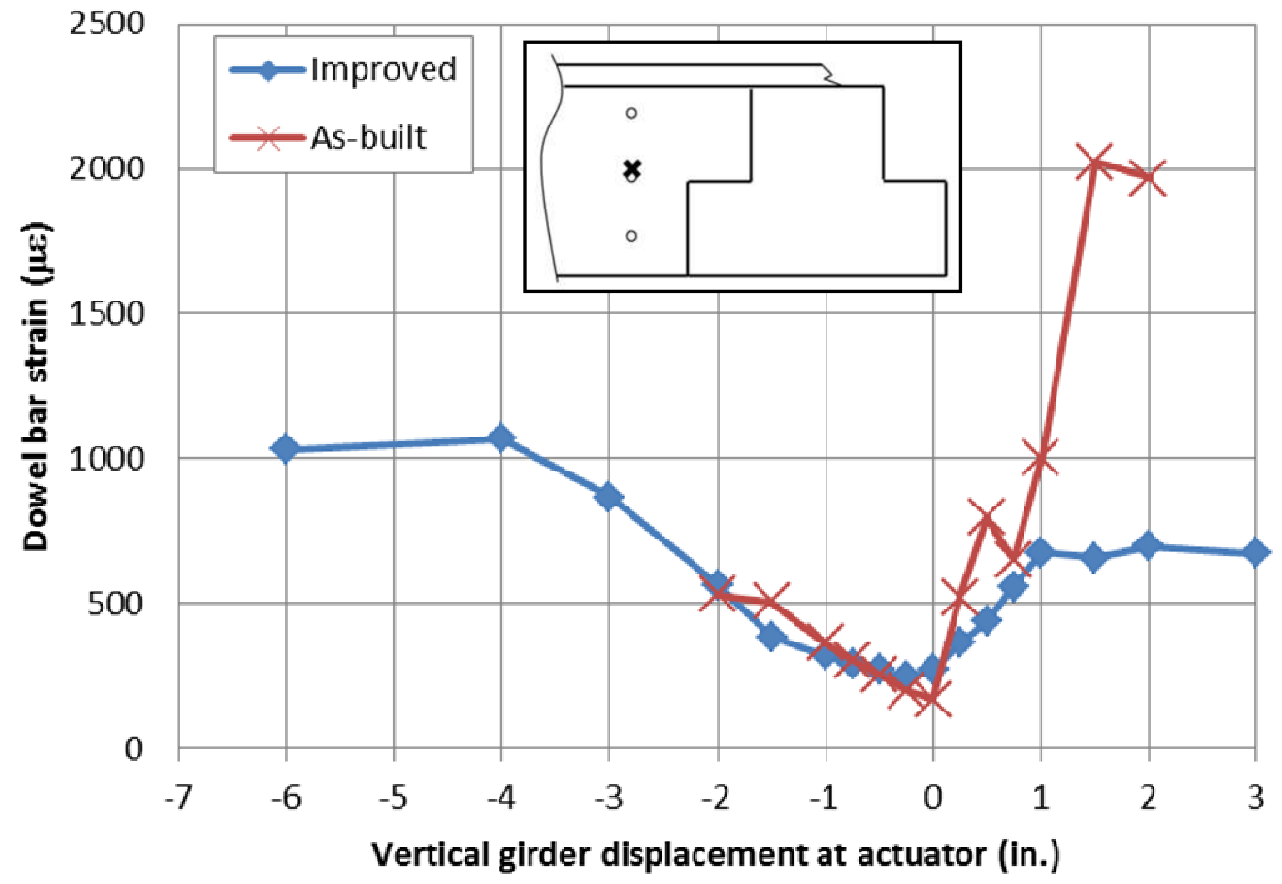

Figure 3.20. Dowel bar strains in center girder mid-level bars at peak displacements 
Strains on the unstressed strands in the improved girder-to-cap connections were also used to investigate the connection behavior. Figure 3.21 shows measured strains at peak positive displacements (producing positive connection moment) on the strands at the interface between the cap beam and the intermediate and exterior girders (no data were available for the center girder). The yield strain for the strand, based on a yield stress of $230 \mathrm{ksi}$, was $7930 \mu \varepsilon$, so the total strain values for the entirety of the test remained well below this level. The strains exhibit a trend of gradual increase during the initial portion of the Phase II test and then are seen to plateau for girder displacements ranging from 0.75 in. to $1.5 \mathrm{in}$. However, for the large vertical displacements, the trends diverge, with one intermediate girder showing an increase in strain, while the other intermediate girder and the exterior girder show a decrease in strain. This divergent behavior occurs during the same portion of the test for which the dowel bars on the improved connection side showed consistent behavior. One hypothesis for this observation is that the significant deterioration occurring on the as-built side of the test unit during the high displacement portion of the Phase II test produced inconsistent load paths through the superstructure, and consequently resulted in uneven load transfer in the girders. Overall, the strands were certainly effective in working with the dowel bars to provide a positive moment tension mechanism, but further testing to investigate the strand behavior at large displacements would be helpful in fully quantifying the improved connection detail.

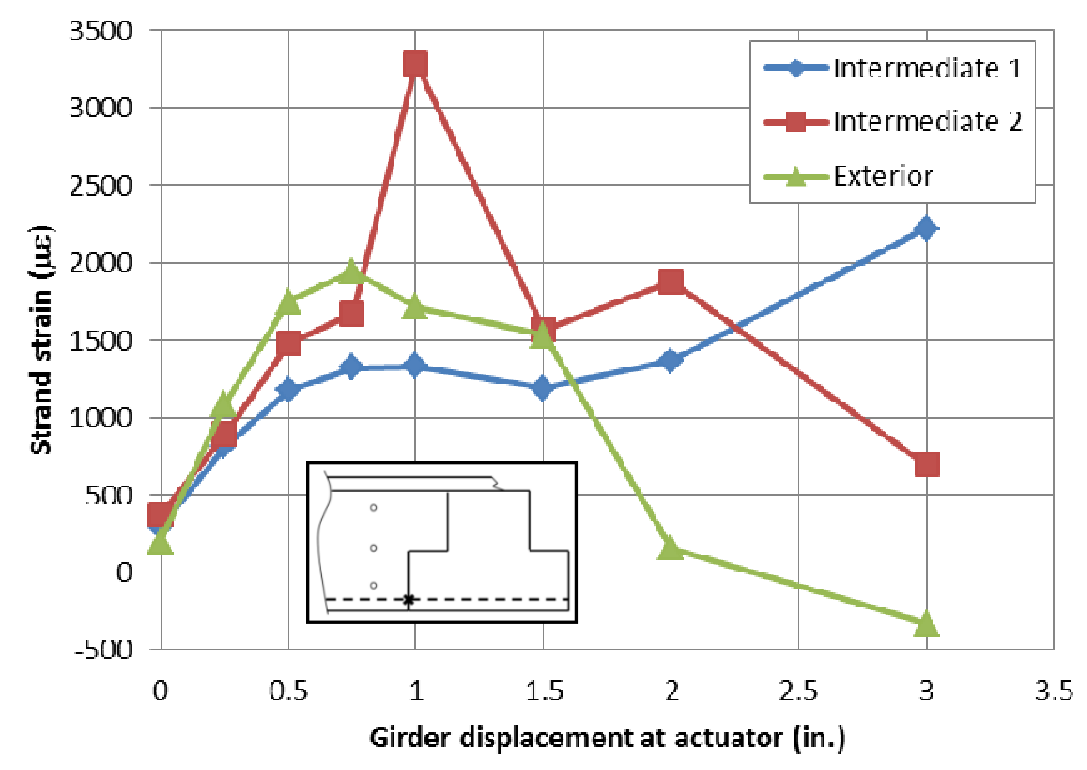

Figure 3.21. Unstressed strand strains at interface of cap beam to intermediate and exterior girders at peak positive displacements 


\subsection{Conclusions}

Details that facilitate the use of $A B C$ methods in high seismic regions are increasingly desirable. In particular, the inverted-tee cap beam offers an excellent possibility for using precast concrete components in bridge superstructures susceptible to high seismic loads, provided that the girder-to-cap connection region is properly addressed. The work in this study has shown that connections that are sufficient for high seismic load are feasible and can be used in concert with precast girders to provide an excellent $A B C$ alternative.

Based on this research study, the following specific conclusions can be drawn:

1. The improved connection detail, which incorporated unstressed strands for positive moment continuity, provided excellent performance during Phase I loading simulating gravity and full horizontal seismic conditions. The improved connection remained elastic throughout Phase I testing and exhibited noticeably lower relative displacement at the girder-to-cap beam interface than an as-built connection detail that did not include the unstressed strands.

2. The superior performance of the improved connection was even more apparent during Phase II loading which produced maximum connection shear and moment conditions in the connection region that were approximately double the expected maximum demand from the gravity and full horizontal seismic condition. The improved connection remained elastic and produced maximum relative interface displacement that was only $6 \%$ of the corresponding displacement in the as-built connection detail.

3. The column overstrength moment was distributed to all the girders in the superstructure, including the exterior girders. This load distribution already occurred in the girder-to-cap connection region immediately adjacent to the cap.

4. Although it did not perform as well as the improved connection, the as-built connection was successful in behaving as a fully continuous connection during the Phase I loading simulating gravity and full horizontal seismic conditions. It maintained elastic behavior for the duration of the Phase I test, although its relative displacements at the girder-to-cap interface were larger than for the improved connection.

5. The as-built connection deteriorated considerably when subjected to the Phase II load sequence that exercised the connection beyond the gravity and full horizontal seismic condition. While the 
as-built connection produced a positive moment resistance that was over $50 \%$ higher than the expected gravity and full seismic condition, it did not maintain this resistance at large vertical girder displacements.

6. The cap beam-diaphragm-girder connection in existing bridges that contain the as-built connection detail can be expected to act as an integral connection, rather than degrading to a pin connection during seismic loading as per current recommendations. Retrofits of such bridges should ensure that the top of the column can develop a plastic hinge and contain adequate confinement reinforcement, along with ensuring that the column shear resistance is sufficient in light of the plastic hinge formation at the column top.

7. The combination of the inverted-tee girder and I-girder connection was demonstrated to be a viable $A B C$ system. Constructability of the detail was straightforward, and adequate seismic performance was demonstrated. Both the as-built and improved connection details successfully transferred shear forces and did not allow vertical unseating or collapse of the superstructure, even when subjected to very high superstructure vertical forces and displacements.

8. The unstressed strand in the improved connection considerably reduced the girder-to-cap beam gap opening and maintained elastic behavior of the connection. However, it did not drastically reduce the dowel bar strains, except for at very high displacements. The results demonstrate that the unstressed strand and dowel bars work together to form a viable positive moment tension load transfer mechanism.

9. Wire mesh reinforcement was demonstrated to be an acceptable detail in precast girders in lieu of standard reinforcing bars.

\subsection{References}

AASHTO. (2003). AASHTO LRFD Bridge Design Specifications, Third Edition. American Association of Safety and Highway Transportation Officials (AASHTO), Washington, D. C.

ASCE. (2013). 2013 Report Card for America's Infrastructure. American Society of Civil Engineers (ASCE), Reston, Virginia.

Caltrans. (1995). Bridge Design Aids. California Department of Transportation (Caltrans), Sacramento, CA.

Caltrans. (2003). Bridge Design Specifications. Caltrans, Sacramento, CA. 
Caltrans. (2006). Seismic Design Criteria, Version 1.5. Caltrans, Sacramento, CA.

Caltrans. (2006). Interims and California Amendments to AASHTO LRFD Bridge Design Specifications. Caltrans, Sacramento, CA.

Caltrans. (2008). "Accelerated Bridge Construction Applications in California: A Lessons Learned Report." Version 1.1, August 2008, Caltrans, Sacramento, CA.

Caltrans. (2008). "Caltrans ABC Strategic Plan: Development of Practice and Policy for Future Bridge Projects." Version 1.1, August 2008, Caltrans, Sacramento, CA.

Caltrans. (2010). "Caltrans Precast Concrete Committee Update." 2010 Caltrans/PCMAC/Consultants Bridge Workshop, Nov. 3, 2010, Caltrans, Sacramento, CA.

Caltrans. (2010). Seismic Design Criteria, Version 1.6. Caltrans, Sacramento, CA.

Chen, W. F. and Lian Duan. (2014). Bridge Engineering Handbook, Second Edition: Construction and Maintenance. Boca Raton, Florida: CRC Press.

Computers and Structures, Inc. (CSI). (2008). SAP2000 V14, CSI, University of California-Berkeley, Berkeley, CA.

Dassault Systemes Simulia Corporation. (2008). ABAQUS v6.8. Providence, RI.

Hida, S. (2012). “California Department of Transportation's Next Generation Bridges." Fourth KwangHua Forum, Shanghai, China. Accessed online: http://risedr.tongji.edu.cn/4th_KwangHua_Forum/downfile/PS_2/Sue_Hida.pdf.

Housner, George W., \& Charles C. Thiel, Jr. (1990). Competing Against Time: Report of the Governor's Board of Inquiry on the 1989 Loma Prieta Earthquake. Earthquake Spectra, 6(4), pp.681-711.

Ma, J. (2008). "California Precast Bridge Design Overview." $15^{\text {th }}$ Annual Caltrans/PCMAC Bridge Seminar, Sacramento, California. Accessed online: http://www.precastconcrete.org/seminars/2008/200805.pdf.

SEAOC. (2010). "Seismic Design of Concrete Parking Structure Ramps." Structure. July, 2010. Seismology Committee, Structural Engineers Association of California (SEAOC), Sacramento, CA.

Snyder, R., Vander Werff, J., Thiemann, Z., Sritharan, S., Holombo, J. (2011). Seismic Performance of an IGirder to Inverted-T Bent Cap Connection, Final Report, Caltrans, Sacramento, CA, and lowa State University (ISU), Ames, IA. 
Sritharan, S., Bromenschenkel, R., Vander Werff, J., Peggar, R. (2013). "Two Alternate Connections for Integral Precast Concrete Girder Bridges in Seismic Regions," Seventh National Seismic Conference on Bridges and Highways, Oakland, CA.

Thiemann, Z. J. (2009). "Pretest 3-D finite element analysis of the girder-to-cap-beam connection of an inverted-tee cap beam designed for seismic loadings." M. S. thesis, ISU, Ames, IA.

Vander Werff, J., Sritharan, S. (2014). "Girder Load Distribution for Seismic Design of Integral Bridges." Journal of Bridge Engineering, American Society of Civil Engineers (ASCE), 10.1061/(ASCE)BE. 19435592.0000641. 


\section{CHAPTER 4. PRECAST CONNECTIONS DESIGNED FOR ABC IN SEISMIC REGIONS}

A paper to be submitted to the ASCE Journal of Structural Engineering

J. R. Vander Werff ${ }^{1}$, R. Peggar ${ }^{2}$, S. Sritharan ${ }^{3}$, and R. Bromenschenkel ${ }^{4}$

\subsection{Abstract}

The behavior of critical connections between prefabricated elements in bridges utilizing accelerated construction methods $(A B C)$ continues to be of utmost interest. Some of these connections will experience excessively high demand in regions that are susceptible to high seismic load. This paper presents a large-scale experimental study that investigated seismic performance of the connection between precast concrete I-shaped girders and a concrete inverted-tee cap beam using two different details. The ability of the girder-to-cap connection to successfully resist positive-moment and the corresponding shear under combined gravity and seismic effects was of particular interest. The possibility of connection failure due to increased demand resulting from vertical seismic acceleration was also investigated.

This study utilized a half-scale test unit and replicated a portion of a typical inverted-tee cap beam, along with two $10.7 \mathrm{~m}$ (35 ft) long girders with unique connection details and split bridge decks so each detail could be tested individually. Both connection details were improvements to an existing detail for precast dapped-end girders and inverted-tee cap beams that has been used by the California Department of Transportation (Caltrans). Both connections relied on deck reinforcement as the primary tension-transfer mechanism for negative moment. For positive moment tension transfer, one connection utilized unstressed grouted strands to provide continuity between the girder bottom flange and the cap beam. The other connection implemented a group of large-diameter transverse dowel bars located in the lower portion of the girder that were placed inside looped strands cast in the cap beam

\footnotetext{
${ }^{1}$ Assistant Professor; Engineering, Dordt College, Sioux Center, lowa

${ }^{2}$ Research Assistant; Civil, Construction, and Environmental Engineering, lowa State University, Ames, lowa

${ }^{3}$ Wilson Engineering Professor; Civil, Construction, and Environmental Engineering, lowa State University, Ames, lowa

${ }^{4}$ Senior Bridge Engineer; Division of Engineering Services, California Department of Transportation (Caltrans), Sacramento, California
} 
and subsequently encased in a cast-in-place diaphragm. Both connections exhibited excellent seismic performance, remaining elastic up to load levels well in excess of what would be required to develop a column plastic hinge with due consideration to vertical acceleration effects. Both connections were subjected to large girder displacements in order to fully quantify their performance. The resistance provided by both connections in both the negative and positive moment directions was two to three times larger than maximum expected horizontal seismic demand, showing that each connection could successfully resist significant vertical acceleration in addition to maximum expected horizontal effects.

\subsection{Introduction}

Many regions in the United States are experiencing increased transportation demand along with aging transportation infrastructure. Consequently, innovative methods to improve and expedite construction of this infrastructure are in high demand. A primary approach that states across the country are implementing to keep up with continually increasing transportation infrastructure needs is accelerated bridge construction $(A B C)$. $A B C$ methods seek to incorporate prefabricated elements as much as possible to decrease field construction time. Such methods have been widely employed in the U.S. in states like Texas, Florida, and Utah for more than a decade [see Federal Highway Administration (FWA), 2004; National Cooperative Highway Research Program (NCHRP), 2011; Stanton et al., 2006; and Matta et al., 2005 for example].

The primary benefit to incorporating $A B C$ techniques is the reduction of field construction time. Reduced construction time leads directly to other benefits including the mitigation of long traffic delays and total public cost associated with long-term detours. Also, secondary benefits include elimination of the use of concrete falsework and an overall improvement in quality control, due to increased use of precast concrete members rather than cast-in-place concrete sections.

Despite the advantages of $A B C$, such methods have been difficult to implement in moderate-to-high seismic regions because of the poor seismic performance of the connections established between precast components. Recent information indicates that over 70 percent of the material currently in use in bridges in the state of California is cast-in-place concrete (Hida, 2012). Structural failures in relatively recent events in California such as the Loma Prieta earthquake in 1989 (Housner and Thiel, 1990) and 
the Northridge earthquake in 1994 (SEAOC, 2010) confirmed the vulnerability of connections in precast concrete construction.

The California Department of Transportation (Caltrans) has embarked on an effort to develop precast connections that are suitable for earthquake loads and thus pave the way for increased implementation of $A B C$ methods in seismic regions [see for example Caltrans' "ABC Strategic plan" (2008a) and the related "Lessons Learned" report (2008b)]. An existing detail that has been used by Caltrans for precast girder connections that offers promise for providing sufficient seismic resistance incorporates a concrete inverted-tee cap beam and precast dapped-end I-shaped girders. Figure 4.1 shows a schematic of this concept. Attaching the girder dapped end to the inverted-tee ledge provides a configuration that allows quick installation of the girders. A cast-in-place diaphragm in the connection region can provide connection continuity at the girder-to-cap interface.

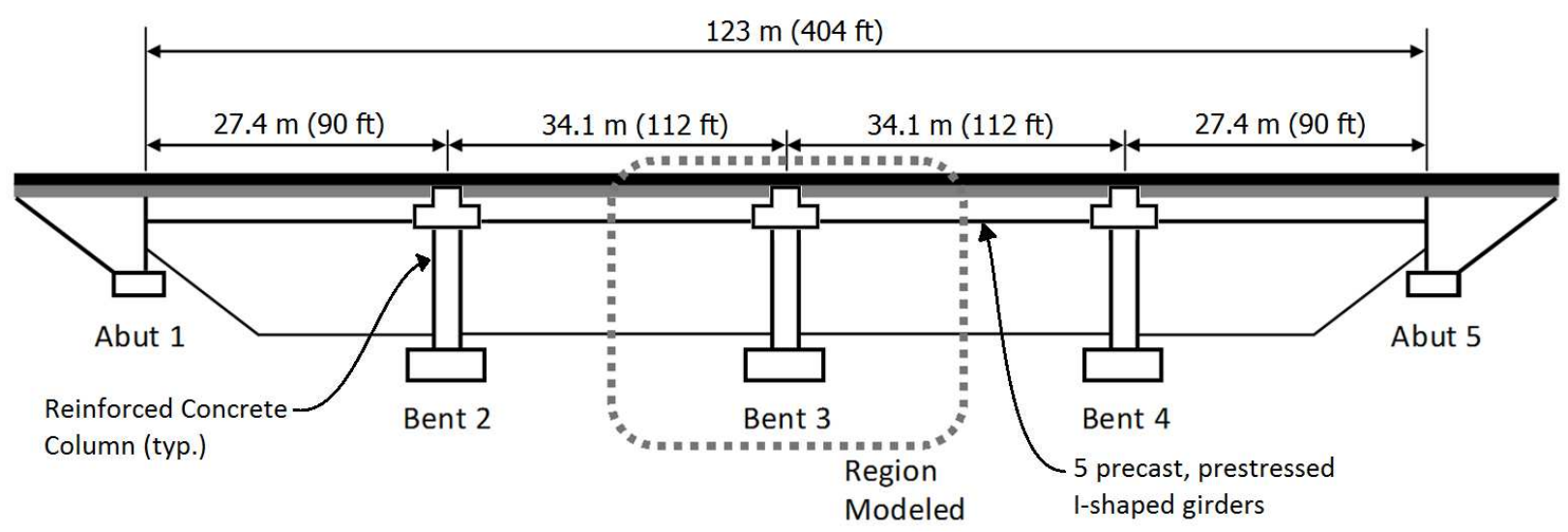

Figure 4.1. Prototype bridge utilizing the inverted tee system

However, the existing detail (referred to as the "as-built" detail) has two main drawbacks that have prevented it from being widely used in California and other seismic regions. First, while a cast-in-place bridge deck and reinforcement running over the girder-to-cap connection can provide reliable tension continuity for negative moment, the connection does not provide positive moment continuity in the reverse direction. Thus, when subjected to positive moment during an earthquake event, the connection is not well suited for large moment resistance. Consequently, the use of this detail reduces the possibility of a plastic hinge in the column just below the cap beam, making the bridge design less cost competitive. The development of a girder-to-cap connection detail with moment continuity will 
greatly increase the usefulness of the inverted-tee concept in seismic regions and provide an excellent opportunity to utilize $A B C$ techniques.

A second limitation of the connection is related to vertical acceleration effects. The current Caltrans Seismic Design Criteria (SDC) stipulates, in Section 2.1.3, "For Ordinary Standard bridges where the site peak ground acceleration is $0.6 \mathrm{~g}$ or greater, an equivalent static vertical load shall be applied to the superstructure to estimate the effects of vertical acceleration" (Caltrans, 2013). The SDC in Section 7.2.2 requires that this vertical load is to be $25 \%$ of the dead load, applied upward and downward. In addition, SDC Section 7.2.2 also stipulates that, if vertical acceleration must be considered, longitudinal side mild reinforcement in the girders must be capable by means of shear friction of resisting $125 \%$ of the dead load shear at the interface with the cap beam. This requirement exists to protect against potential shear failures should the bottom of the girder attempt to open in a seismic event; however, it has been disadvantageous with respect to the inverted-tee and precast girder system because of the need to include mild reinforcement running continuously between the girder and the cap beam. Thus, the research detailed in this paper intends to illustrate that extending unstressed strands from the girder to the bent cap provides sufficient shear resistance in the connection with adequate capacity to resist vertical acceleration effects. Such work will verify that the inverted-tee and precast girder system is a robust and economically advantageous option for implementing accelerated construction.

To further investigate the use of the inverted tee system in seismic regions, a joint study was completed in 2010 (see Snyder et al., 2011, and Chapter 3 of this dissertation) which sought to quantify the seismic performance of the as-built connection detail. The 2010 study established an improved connection better equipped to handle seismic demands efficiently and also verified the validity of the system for seismic regions. The work from the 2010 study showed the benefit in continuing to investigate and develop precast girder-to-cap beam connections for $A B C$ methods, leading to the study detailed in this paper. Broadly, this study is intended to promote the use of $A B C$ by developing connections that enable cost-effective $A B C$ methods in seismic regions. To accomplish this broad goal, the work has been focused on conceptualizing two girder-to-cap beam connections for precast members and experimentally verifying them for gravity and horizontal seismic loading while also considering potential impact from vertical acceleration. 


\subsection{Brief summary of the system test}

The system test conducted by Snyder et al. (2011) and detailed in Chapter 3 of this dissertation utilized a $50 \%$-scale test unit to simulate the region around the center bent of the prototype bridge shown in Figure 4.1. The test unit, shown in Figure 4.2, incorporated five girders approximately $28 \mathrm{ft}$ long on each side of the inverted tee cap beam, along with a single-column bent, to model the portions of the center span of the prototype between the approximate horizontal seismic inflection points. The cap beam region of the test unit, shown in cross-section in Figure 4.2b, was designed to incorporate the as-built connection detail along with an improved connection detail. The as-built connection incorporated three dowel bars that were encased in the cast-in-place concrete diaphragm following girder placement. However, for the improved connection detail, unstressed prestressing strands were run through ducts in the bottom flange of the girder and the bottom of the cap beam. These strands provided tension continuity for positive moment in the girder-to-cap connection, thus supplementing the negative moment tension continuity provided by the deck reinforcement.

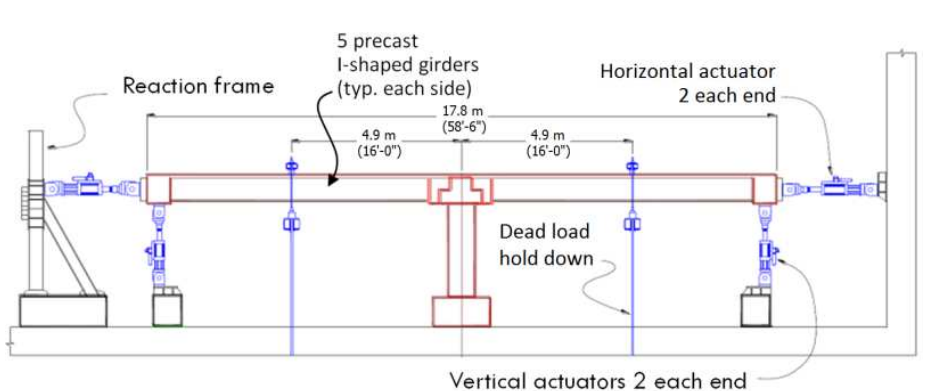

a. Test configuration

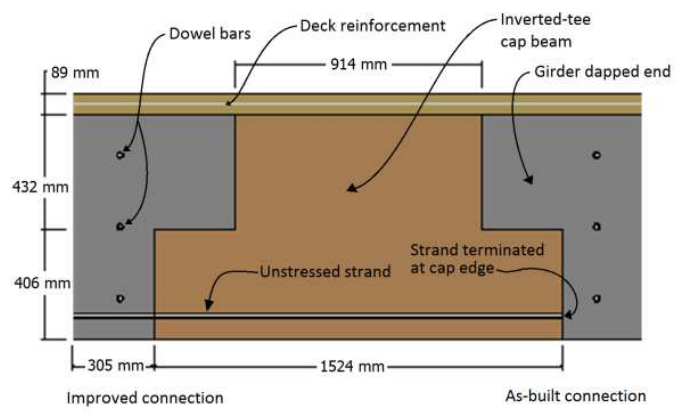

b. Girder-to-cap connection detail

Figure 4.2. System test unit

In Phase I of the system test, the test unit superstructure was subjected to cyclic horizontal loads and displacements in the longitudinal direction to simulate horizontal seismic action. Expectations from the test, based on analytical predictions including finite element and grillage analyses, included: (1) good overall system seismic performance, (2) similar negative moment capacity for both the as-built and improved connections, (3) positive moment capacity and vertical shear capacity for the as-built connection that would be sufficient to develop the column overstrength moment, and (4) increased positive moment capacity for the improved connection. The horizontal force-displacement response envelopes from this phase of testing, for both the push and pull directions, is provided in Figure 4.3. As 
the figure shows, the system maintained strength up to high ductility levels. Plastic hinges were successfully formed in both the top and bottom of the column. Also, although the different connection details employed on the two sides of the cap beam meant that connection flexural stiffnesses would vary for the push and pull directions, the figure shows that both connections produced very similar system performance for this phase of testing. Overall, the test clearly demonstrated the suitability of the system for high seismic regions.

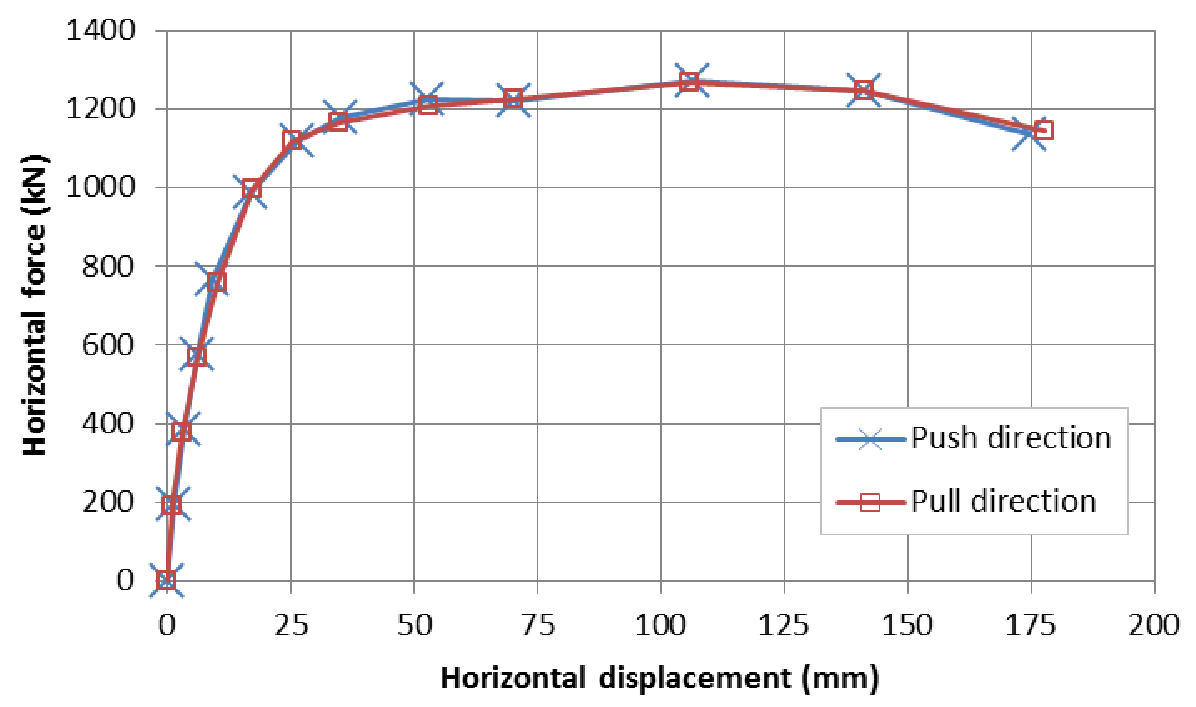

Figure 4.3. Horizontal force-displacement response envelope from system test Phase I

Phase II of the system test was designed to fully exercise the as-built and improved connection details. In this phase of testing, the horizontal actuators were used only to provide stability. The vertical

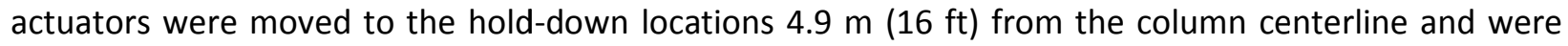
used to subject the superstructure to large vertical forces and displacements, also subjecting the girderto-cap connections to large shear and moment demands. Figure 4.4 provides the peak moment values for both the improved and as-built details in both the positive and negative moment directions. In the negative moment direction, the performance of both the as-built and improved connections was similar, with slightly more strength exhibited by the improved connection. This similarity was not surprising, since the deck reinforcement provided the tension transfer mechanism for both connections. In the positive moment direction, however, the as-built connection performed noticeably poorer than the improved connection. In fact, deterioration of the as-built connection ended up dictating the end of the 
experimental test; once the positive moment continuity of the as-built connection was lost, the test unit configuration prevented the development of larger moments in the improved connection. Despite the loss in stiffness in the as-built connection, Figure $4.4 \mathrm{~b}$ shows that its positive moment strength was considerably higher than the maximum demand during the seismic test, thus indicating its sufficiency in providing an integral connection and allowing plastic hinge formation in the column.

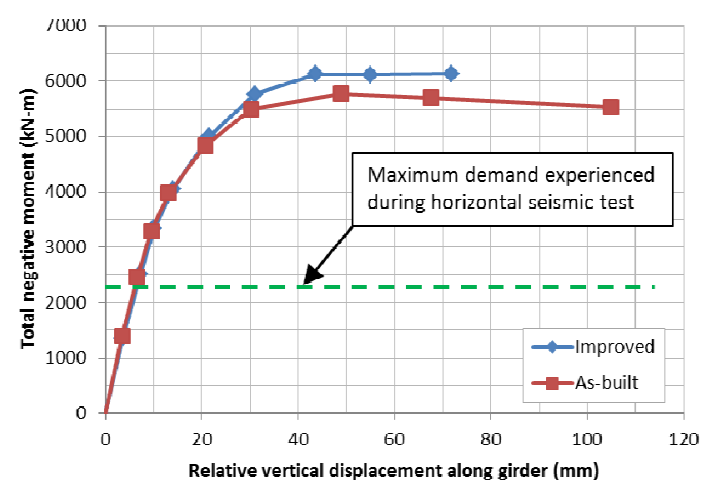

a. Negative moment in girder-to-cap connection

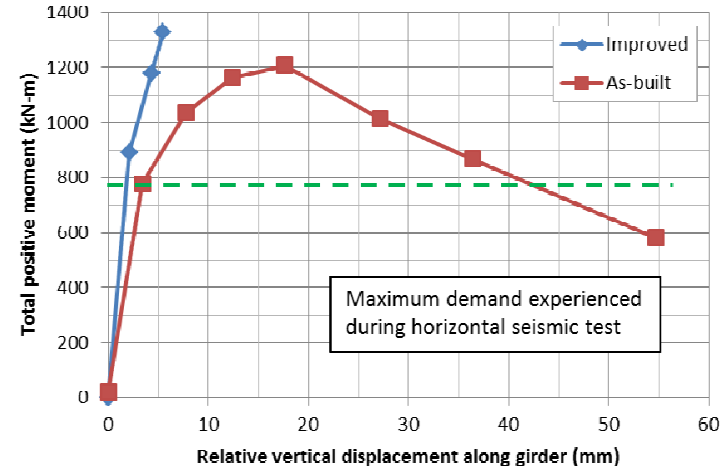

b. Positive moment in girder-to-cap connection

Figure 4.4. Moment-displacement behavior of system test unit due to peak vertical loads

\subsection{Experimental configuration}

\subsubsection{General description}

To fully quantify the behavior of the improved connection incorporated in the system test, a $50 \%$ scale component test of the connection region was devised to experimentally verify the connection detail without re-creating the whole bridge system. Figure 4.5 provides a three-dimensional representation of the connection test configuration. The test unit, which was designed to provide the opportunity to fully exercise two different girder-to-cap connection details independently from each other, consisted of a single column, footing, and cap beam, along with two I-girders. To appropriately model the composite girder section behavior, a bridge deck was included in the test unit. However, the deck was split between the two girders as shown in the figure to allow the two connection details to be tested separately. 


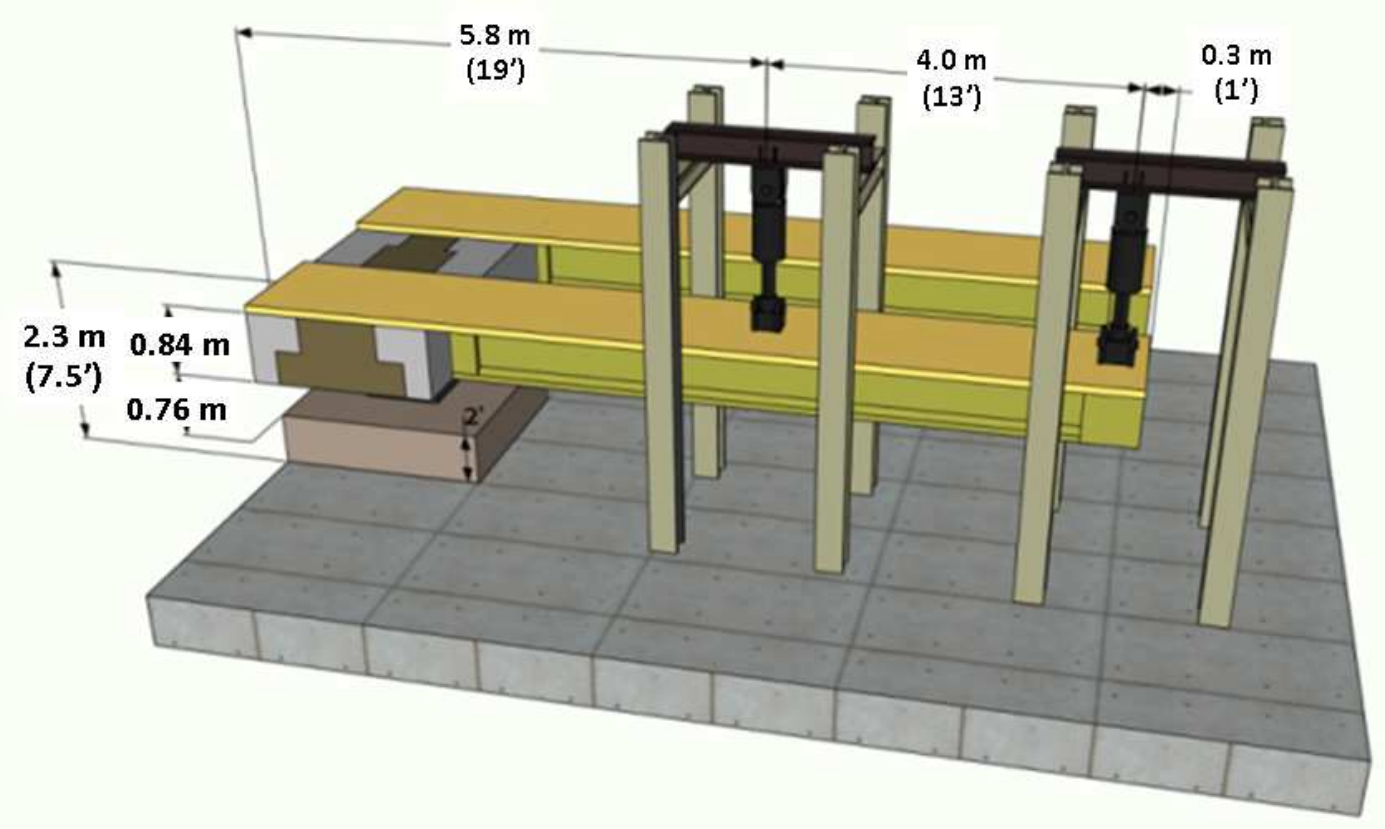

Figure 4.5. Connection test configuration concept

\subsubsection{Cap beam and column design}

A secondary objective of the connection test was to offer proof of concept for implementing a precast cap beam. The field implementation of such a concept could decrease onsite construction time and be well-suited for $A B C$ methods. To be used as a precast element, the cap beam was designed with ducts in the column region as shown in Figure 4.6a. These ducts were designed to align with the column longitudinal bars; thus, after the cap beam was precast, it was simply set in place on top of the column, with the column longitudinal bars (shown in Figure 4.6b) extending up into the cap beam ducts. The ducts were then filled with high-strength grout $\left[\mathrm{f}_{\mathrm{c}}{ }_{\mathrm{c}}=46 \mathrm{MPa}(6700 \mathrm{psi})\right.$ at 7 days] to securely anchor the cap beam to the column.

In a prototype structure, the girder-to-cap connection would be expected to remain elastic, even when subjected to the highest seismic demands, since elastic superstructure behavior is critical for successful performance following capacity design principles that localize inelastic deformations in the column plastic hinge regions. In this test setup, however, the intent was to fully exercise and quantify the girder-to-cap connections well beyond their elastic limit. Therefore, the test unit cap beam was expected to be subjected to torsional loads well beyond those that would be experienced by a cap beam 
in a prototype structure. To account for the additional torsion, longitudinal ducts were added to the cap beam as shown in Figure 4.6a to provide the opportunity to add torsional capacity during the latter stages of testing by introducing post-tensioning. Additional steel was also added in the non-connection side of the cast-in-place diaphragm to further increase the cap's torsional resistance.

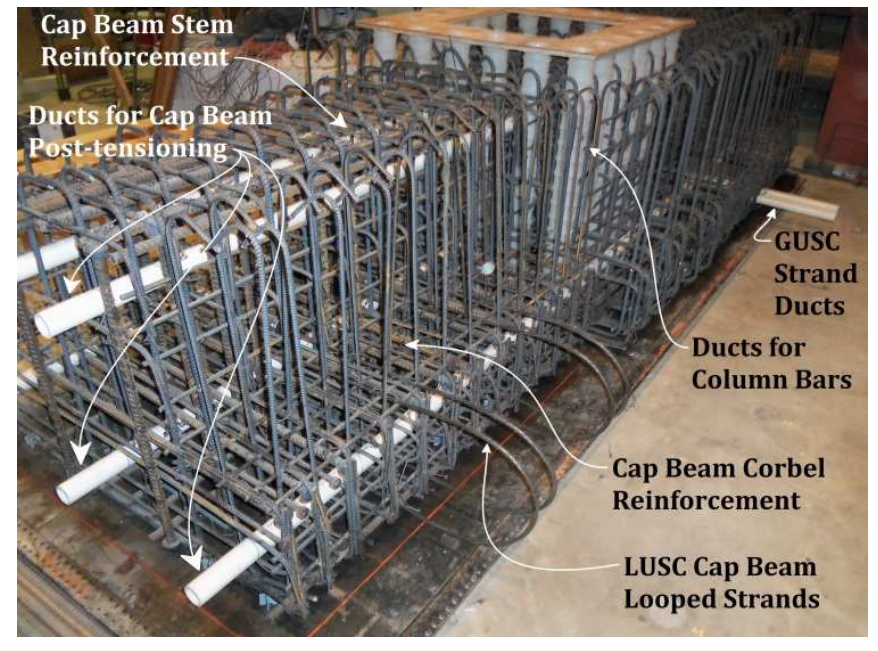

a. Cap beam prior to casting concrete

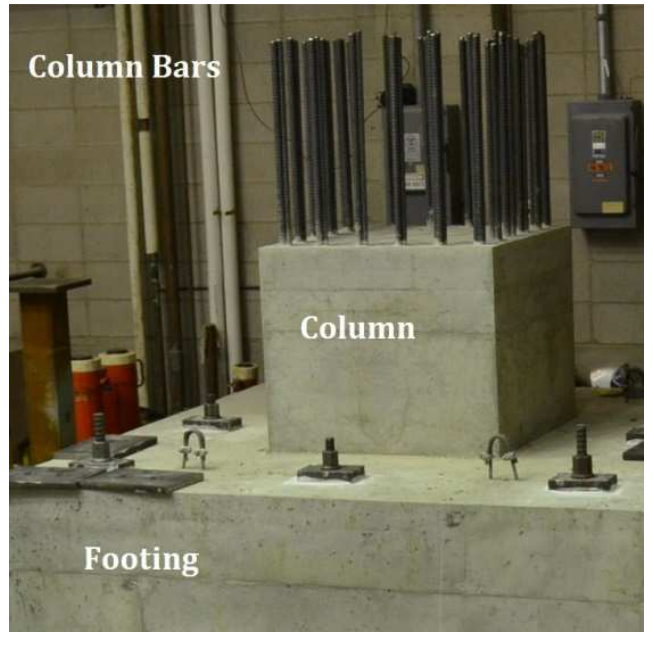

b. Column and footing prior to cap beam placement

Figure 4.6. Connection test construction photographs

Since the girder-to-cap connection negative moment capacity was significantly higher than the positive moment capacity, the design cap beam torsion was related to the predicted negative moment connection performance. To determine this design torsion, the maximum expected negative girder-toconnection moment was estimated assuming yielding of the deck steel as the failure mechanism. The tributary area of deck steel contributing to the connection behavior was estimated as $5160 \mathrm{~mm}^{2}(8.0$ $\left.\mathrm{in}^{2}\right)$, and the moment arm was conservatively estimated as $813 \mathrm{~mm}$ (32.0 in), based on the distance from the center of the deck steel to the top of the girder lower flange. Therefore, the expected moment was calculated as:

$$
M_{\text {exp }}=A_{s} f_{y} j=\left(5160 m^{2}\right)(414 \mathrm{MPa})(813 \mathrm{~mm})=1737 \mathrm{kN}-\mathrm{m}(1280 \mathrm{kip}-\mathrm{ft})
$$

This moment was increased by $10 \%$ to determine the design torsional load in the cap beam to be 1910 $\mathrm{kN}-\mathrm{m}$ (1408 kip-ft). The torsional capacity of the cap beam without post-tensioning was determined using the approach from Priestley et al. (1996) to be $472 \mathrm{kN}-\mathrm{m}$ (348 kip-ft); this calculation was verified 
by comparing it with the $\mathrm{ACl}$ (2011) approach which yielded very similar results. Priestley's approach was then used to determine the additional torsional capacity of the cap beam utilizing post-tensioning and incorporating the contribution of the mild reinforcement. Post-tensioning was accomplished using six DYWIDAG bars capable of carrying $356 \mathrm{kN}$ (80 kips) each, and the mild steel provided an additional clamping force of 1677 kN (377 kips). Continuing with Priestley's approach, the combined clamping force of $3812 \mathrm{kN}$ (857 kips) was calculated to increase the torsional capacity of the cap to $2120 \mathrm{kN}-\mathrm{m}$ (1564 kip-ft), sufficiently larger than the predicted design torsional load.

For configuration simplicity, the test column was designed to be square, since the column itself was not part of the test specimen and was not intended to represent a prototype bridge structure. The

column was designed to remain elastic up to the ultimate capacity of the girder-to-cap beam connection. A design moment value of $1910 \mathrm{kN}-\mathrm{m}$ (1408 kip-ft) was established for the column. This design value was based on the same predicted performance of the connection in the negative moment direction that was used in the cap beam design above. The predicted axial load in the column was determined to be $231 \mathrm{kN}$ (52 kips), based on the girder, cap beam, and column weight and the expected actuator test loads. Using the ACl (2011) interaction approach, the required area of steel for the column was determined to be $19230 \mathrm{~mm}^{2}\left(29.8 \mathrm{in}^{2}\right)$. To accommodate the precast cap beam connection, sixty \#22M (\#7 U.S.) bars were chosen to provide a total steel area of $23230 \mathrm{~mm}^{2}$ (36.0 $\mathrm{in}^{2}$ ). These bars were arranged in bundles of three around the perimeter the column so they could easily be inserted into the ducts of the precast cap beam.

\subsubsection{Grouted Unstressed Strand Connection (GUSC) detail}

One of the girder-to-cap connection details implemented in the connection test was a duplicate of the improved connection in the previous system test. Since this connection concept incorporated unstressed strands positioned in the girder bottom flange and the lower region of the cap beam and then grouted in place, it was referred to as the Grouted Unstressed Strand Connection (GUSC). The GUSC detail duplicated the improved connection from the system test, including the dowel bars from the as-built connection but relying primarily on the deck reinforcement for negative moment tension continuity and the unstressed strands for positive moment continuity (see Figure 4.7a). In the system test, the unstressed strand was run through ducts extending through the girder bottom flange for the entire longitudinal girder length, as shown in Figure 4.7b. However, strand testing after the system test 
indicated that terminating the strand a certain distance from the connection region would provide sufficient anchorage to develop the full tension capacity of the strand. Thus, for the GUSC detail in the connection test, the strand ducts were fluted out from the girder bottom flange $3.0 \mathrm{~m}$ from the girdercap interface at the test unit scale, as shown in Figure 4.7c.

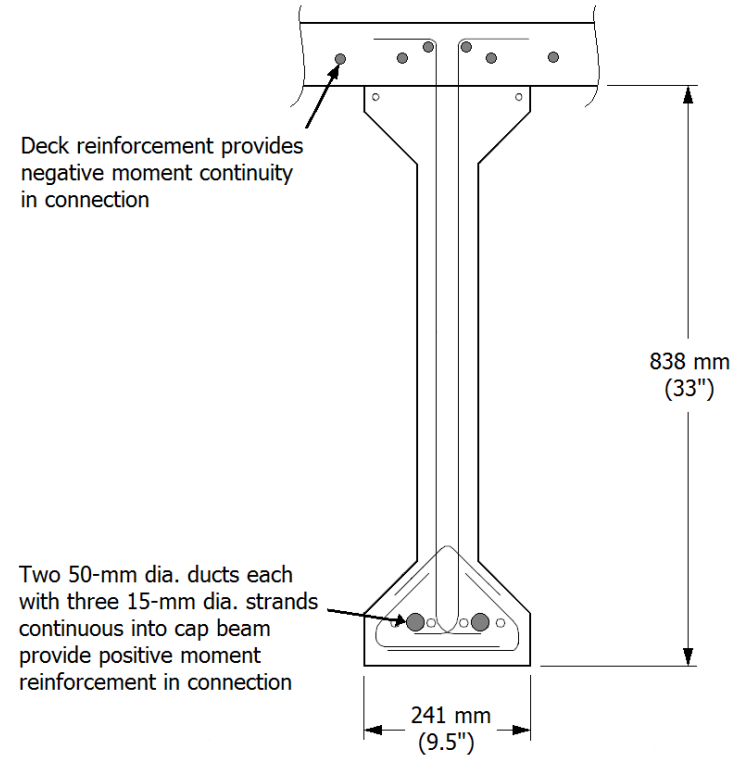

a. Location of connection reinforcement

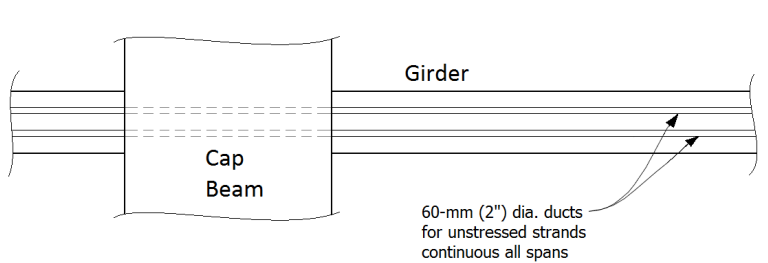

b. Continuous strands in girder bottom flange

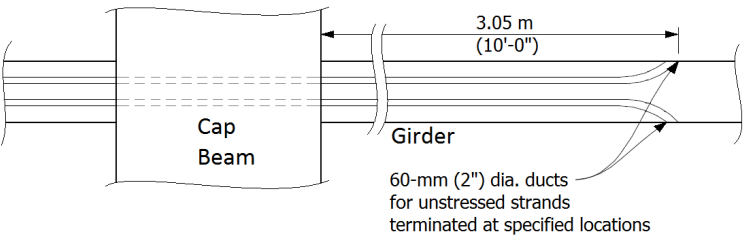

c. Anchorage of strands beyond connection region

Figure 4.7. Reinforcement in grouted unstressed strand connection (GUSC) (test unit scale)

\subsubsection{Looped Unstressed Strand Connection (LUSC) detail}

A schematic view of the second girder-to-cap connection detail investigated in the connection test is shown in Figure 4.8. This detail was referred to as the Looped Unstressed Strand Connection (LUSC). Moment continuity in this connection was accomplished by enlarging and relocating the dowel bars to the lower portion of the girder and extending them through continuous looped unstressed strands that 
extended out from the cap beam ledge. The desired tension load path at the bottom of the girder was completed by additional unstressed strand cast into the girder. These additional girder strands were intended to provide confinement of the dowel bars passing through the girder by looping around the dowel bar blockouts. The blockouts were filled with grout to ensure bond between the girder and dowels. The entire region was again encased by a cast-in-place concrete diaphragm, similar to the GUSC detail. The positive moment continuity in the LUSC detail was different from the GUSC detail in that the LUSC detail utilized an offset path of continuous longitudinal steel between the girder bottom flange and the cap beam. While this load path may have been slightly less straightforward than the tension continuity provided in the GUSC detail, the LUSC had the advantage of not requiring precise alignment of strand ducts during field assembly like the GUSC specimen. Looped strands that protrude from the cap beam ledge on either side of the girder provided ample clearance as they wrapped around the Theaded dowel bars that ran through the girder and formed a link with added strand in the girder. A shear friction mechanism between the dowel bars and the looped strands was expected to be the primary path for positive moment tension load transfer. As for negative moment continuity, there was little difference in the LUSC and GUSC concepts, since the deck reinforcement provided the principle negative moment tension continuity for both details. Additional information on the design concepts for both the GUSC and LUSC details is provided in Sritharan et al. (2013).

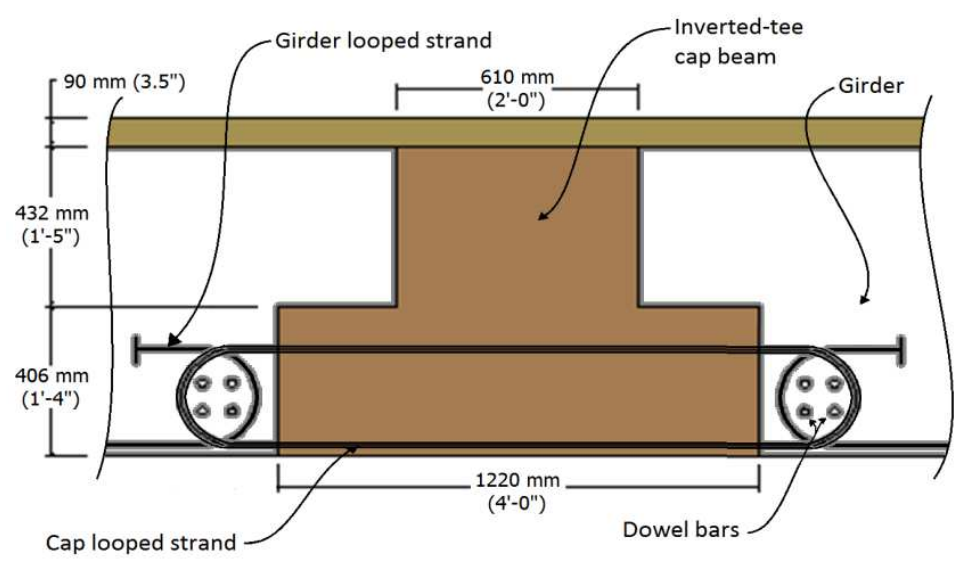

Figure 4.8. Looped unstressed strand connection (LUSC) (test unit scale)

\subsubsection{Girder, diaphragm, and deck design}

The girders were designed to model the largest standard California I-girder and coincided with the girders that had been previously used in the system test. Modifications were made to the girder ends 
according to each connection detail. For the GUSC, ducts were been added to the bottom flange of the girder as shown previously in Figure 4.7. For the LUSC, four looped strands were attached to an anchor plate and ducts were positioned the girder to allow placement of the dowel bars as shown in Figure 4.8.

The diaphragm was designed to duplicate the system test configuration, representative of the diaphragm that would be utilized in a prototype structure utilizing this system. However, on the side of the diaphragm opposite the girders, additional mild reinforcement was included in the cap beam longitudinal direction to increase the cap beam torsional capacity, described in detail earlier.

The bridge deck was split into two separate portions with a gap between the two girders so that each girder and connection could be exercised independently. The width of the bridge deck above each girder was 1435 mm (4'-8 1/2"), based on AASHTO's recommended tributary width (AASHTO, 2012). The reinforcement incorporated in the deck was a duplication of the reinforcement utilized in the system test, which was representative of the deck reinforcement in the prototype bridge.

\subsubsection{Load protocol}

The main objective in loading the test unit was to simulate the prototype shear and moment in the girder-to-cap connection region for conditions simulating gravity and horizontal seismic loading along with consideration for vertical acceleration effects. Since both connection details are intended for use in a bridge configuration similar to the system test unit, analytical predictions (for example Snyder, 2010 and Theimann, 2010) and experimental results from the system test provided helpful data in determining a suitable load protocol. The system test study was used to establish test-scale values of $125 \mathrm{kN}$ (28 kips) and -141 kN-m (-104 kip-ft) for the gravity-only shear and moment, respectively, as shown in Table 4.1. The system test results were also used to establish the column overstrength moment due to horizontal seismic loading that the bridge superstructure would be required to resist. Lateral load distribution results from the system test as well as other similar large-scale experimental studies were used to determine comparable shear and moment magnitudes that would be experienced in the individual girder connections. A detailed explanation of this lateral load distribution work is found in Vander Werff and Sritharan (2014). Resulting shear and moment values, in both the positive and negative directions, are shown in the second row of Table 4.1 for the load scenario that includes gravity load and full horizontal seismic load in either longitudinal direction. 
Table 4.1. Proposed connection test load protocol

\begin{tabular}{|c|c|c|c|c|}
\hline \multirow{2}{*}{$\begin{array}{l}\text { LOADING } \\
\text { PROTOCOL }\end{array}$} & \multicolumn{2}{|c|}{ Negative Shear and Moment } & \multicolumn{2}{|c|}{ Positive Shear and Moment } \\
\hline & Shear, kN (kips) & Moment, kN-m (kip-ft) & Shear, kN (kips) & Moment, kN-m (kip-ft) \\
\hline Gravity Only & $142(32)$ & $114(84)$ & 0 & 0 \\
\hline $\begin{array}{l}\text { Gravity }+100 \% \text { Seismic } \\
\text { No vertical acceleration }\end{array}$ & $160(36)$ & $438(323)$ & $93(21)$ & $230(170)$ \\
\hline $\begin{array}{c}\text { Gravity }+100 \% \text { Seismic } \\
+0.25 \text { g Vertical } \\
\text { Acceleration }\end{array}$ & $191(43)$ & $475(350)$ & $107(24)$ & 239 (176) \\
\hline $\begin{array}{l}\text { Percentage increase } \\
\text { from gravity/horizontal }\end{array}$ & $19 \%$ & $8 \%$ & $14 \%$ & $4 \%$ \\
\hline $\begin{array}{l}\text { Gravity }+100 \% \text { Seismic } \\
\quad+0.5 \mathrm{~g} \text { Vertical } \\
\text { Acceleration }\end{array}$ & $222(50)$ & $510(376)$ & $120(27)$ & $248(183)$ \\
\hline $\begin{array}{l}\text { Percentage increase } \\
\text { from gravity/horizontal }\end{array}$ & $39 \%$ & $16 \%$ & $29 \%$ & $8 \%$ \\
\hline $\begin{array}{c}\text { Gravity }+100 \% \text { Seismic } \\
+\quad 1.0 \mathrm{~g} \text { Vertical } \\
\text { Acceleration } \\
\end{array}$ & $285(64)$ & 582 (429) & $147(33)$ & $294(217)$ \\
\hline $\begin{array}{l}\text { Percentage increase } \\
\text { from gravity/horizontal }\end{array}$ & $78 \%$ & $33 \%$ & $57 \%$ & $28 \%$ \\
\hline
\end{tabular}

The other aspect of seismic loading that the connection test was designed to investigate was vertical ground motion. The Caltrans SDC mild side reinforcement requirement for vertical acceleration shear mentioned in Section 4.2 is a major impediment to implementation of the inverted-tee cap and dappedend girder system, because there is no room on the bottom flange of the girder to include this additional steel. In addition, recent earthquakes (especially the 2011 Christchurch, New Zealand, event) raised awareness of the susceptibility of structures to vertical acceleration effects (Kam and Pampanin, 2011). Observations during the system test had indicated that the GUSC detail had sufficient shear capacity to meet the vertical acceleration demands without including additional reinforcement, and the LUSC detail was expected to behave similarly. Thus, a main goal of the connection test was to subject the connection details to simulated vertical acceleration load and verify that the connections could be implemented without including the additional reinforcement required by the current Caltrans SDC (2013). To accomplish this objective, the load protocol as shown in Table 4.1 was developed to include simulated vertical acceleration effects in the connection region in addition to the expected shear and moment demand from gravity and horizontal seismic loading. 
Since the performance of the girder-to-cap connection was the primary focus of the test, the goal of the load protocol was to properly simulate the shear and moment in the connection region rather than duplicate the shear and moment along the entire length of the girders. Therefore, with the test setup introduced earlier in Figure 4.5, the two actuators [one located $3.05 \mathrm{~m}$ (10 ft) from the connection and a

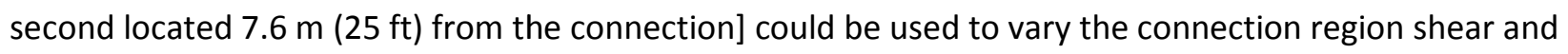
moment appropriately. To illustrate this approach, Figure 4.9 provides the shear and moment diagrams for the gravity-only simulated condition shown in row 1 of Table 4.1. While the shear and moment values along the length of the girder vary due to the concentrated loads introduced by the actuators, the connection shear and moment values are properly simulated. By varying both actuator loads in both directions as needed, any desired shear and moment values could be developed in the connection of the test unit.

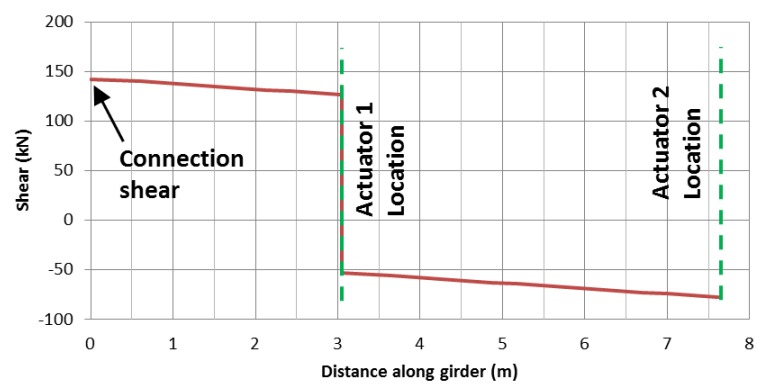

a. Shear diagram

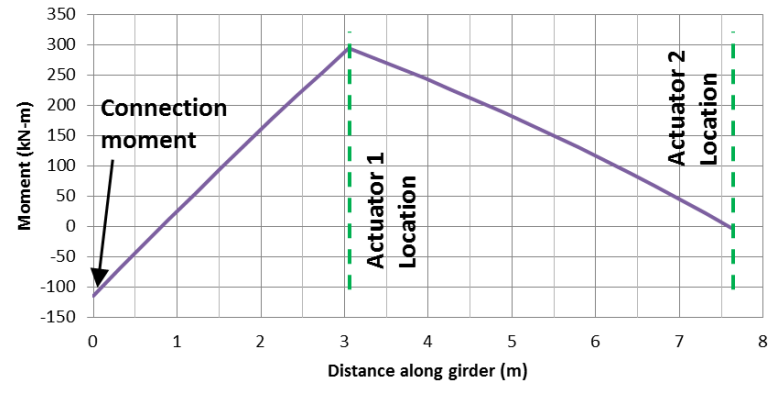

b. Moment diagram

Figure 4.9. Test unit girder shear and moment diagrams at gravity simulation condition

Once the target values were established, a cyclic load protocol was developed to incrementally reach the target peaks. The protocol was divided into three phases. Phase I incorporated cyclic loading to reach the full gravity-plus-horizontal-seismic load condition. Phase II included gravity and horizontal seismic but also added the effects of increasing magnitudes of vertical acceleration, applied as pseudostatic loads based on the scaled prototype mass. Finally, Phase III utilized large forces and displacements to fully exercise the girder connections. Figure 4.10 shows the connection moment for the load sequence in each of the three phases. Note that these figures have been adjusted to represent the actual loads used during testing, rather than the planned loads prior to testing. The corresponding connection shear followed a very similar pattern to the connection moment, so the shear load sequence figures are omitted for brevity. 


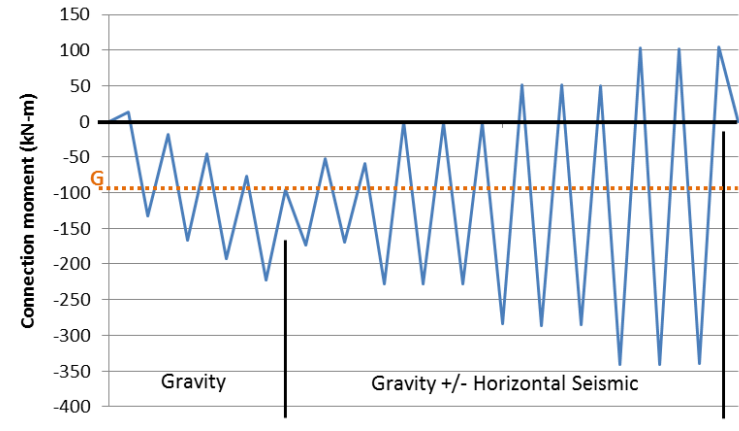

a. Phase I (Gravity and horizontal seismic load)

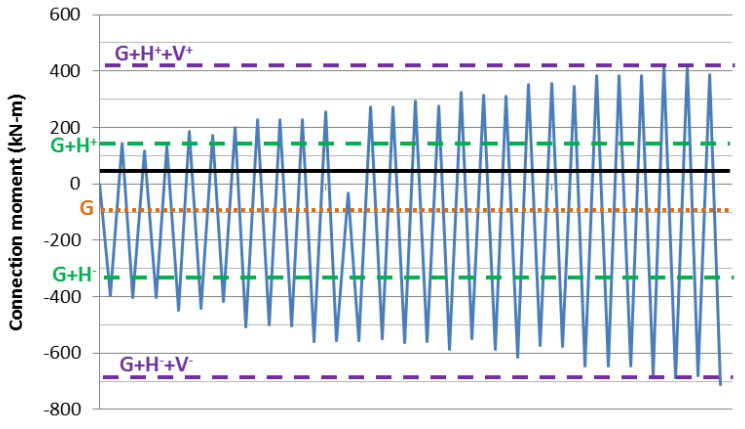

b. Phase II (Gravity, horizontal seismic, and vertical acceleration load)

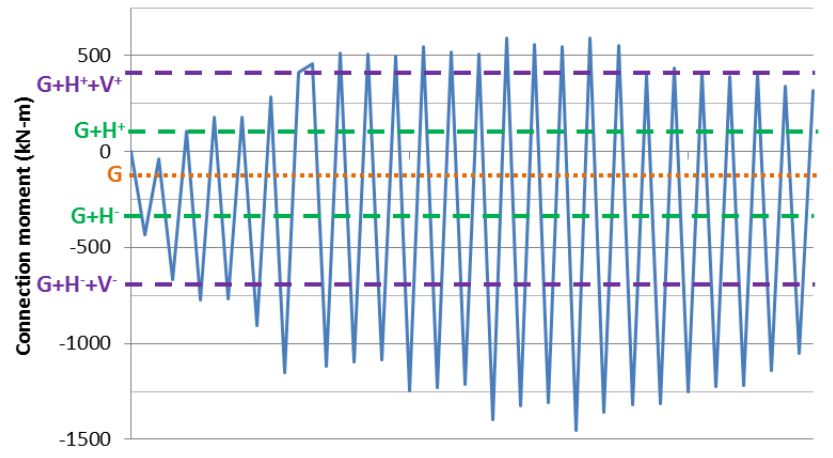

C. Phase III (Displacement control)

Figure 4.10. Load protocol for connection test of GUSC detail

\subsubsection{Construction}

Construction of the test unit was completed in the structural laboratory of lowa State University (ISU). Traditional cast-in-place concrete methods were used for the footing and column. The cap beam was also constructed as a separate unit at ISU to demonstrate the viability of using precast cap beams as part of $A B C$. Figure 4.6, shown previously, provides photographs of the cap beam prior to concrete placement and the column/footing assembly prior to cap beam placement. For the column-to-cap connection, the sixty \#22M (\#7 U.S.) column longitudinal bars (in bundles of 3) were extended to approximately the top of the cap beam, but the column concrete was cast only to the bottom surface of the cap beam. In the cap beam, corrugated ducts were positioned to match the column longitudinal bar locations. This detail allowed the cap beam to be easily set in place and positioned by lining it up with the column bars and sliding it down. Once positioned, the cap-to-column interface was filled using highstrength fiber-reinforced grout $\left[f^{\prime}{ }_{c}=61 \mathrm{MPa}(8900 \mathrm{psi})\right.$ at 7 days] and the ducts were filled with highstrength grout without fibers $\left[f^{\prime}{ }_{c}=46 \mathrm{MPa}(6700 \mathrm{psi})\right.$ at 7 days] to complete the connection. Steel fibers 
with $19 \mathrm{~mm}$ (0.75 in.) length were included in the cap-to-column interface grout, using a volumetric fiber-to-grout ratio of 0.015 , because of the cyclic tension and compression load that the interface would experience, but they were excluded from the ducts for ease of grout placement. The specific fibers and quantities used were based on results from previous successful tests. The completed columncap assembly is shown in Figure 4.11a.

The precast girders were constructed by Andrews Prestressed Concrete in Clear Lake, lowa, and shipped to ISU. The girders were positioned on the cap beam and supported at the free end by temporary steel formwork as shown in Figure 4.11b. Dowel bars were placed through the girders and into the diaphragm region according to each connection detail. For the GUSC, the four unstressed strands were run through the girder and cap beam by simply aligning the girder and cap beam and sliding the strands through. The quantity of strands was chosen by designing them to resist the tension produced by the positive moment that would be expected to develop in the connection under full seismic conditions. The strands were then grouted in place, after which they were anchored against the back side of the cap beam using standard anchorage chucks. Although previous component testing had indicated that the grout alone would provide sufficient strand anchorage, the chucks were included as a precaution to allow continuation of the test in the event of bond anchorage failure. The load at one of the anchorage points was monitored during the test to determine whether the grout alone was sufficient to anchor the strand.

High-strength grout $\left[\mathrm{f}_{\mathrm{c}}{ }_{\mathrm{c}}=88 \mathrm{MPa}(12.7 \mathrm{ksi})\right.$ at 7 days] was used to complete the interface between the girders and cap beam. Because of the cyclic nature of the connection load under seismic conditions, steel fibers were incorporated into the grout mix in the same manner as for the column-to-cap interface. Once the girder-cap interface was established, the formwork for the diaphragms on the front and back sides of the cap beam was erected. In addition, the formwork for the two split decks was erected by using temporary girder brackets on each side of the two girders; this formwork is shown in Figure 4.11c. After placement of the diaphragm and deck concrete and removal of the formwork, the test actuator frames were positioned over the GUSC girder and the two actuators were attached as shown in Figure 4.11d. After testing the GUSC detail, the frames and actuators were repositioned over the LUSC girder for testing of that connection detail. Concrete strengths for the girders, cap beam, and diaphragm are provided in Table 4.2. 


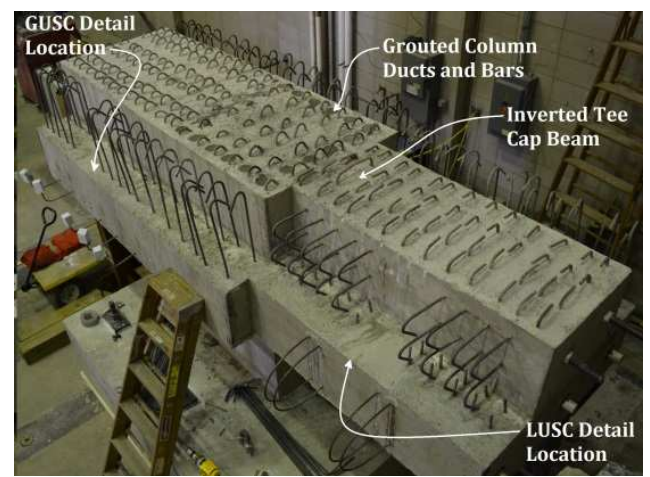

a. Cap beam prior to girder, diaphragm and deck placement

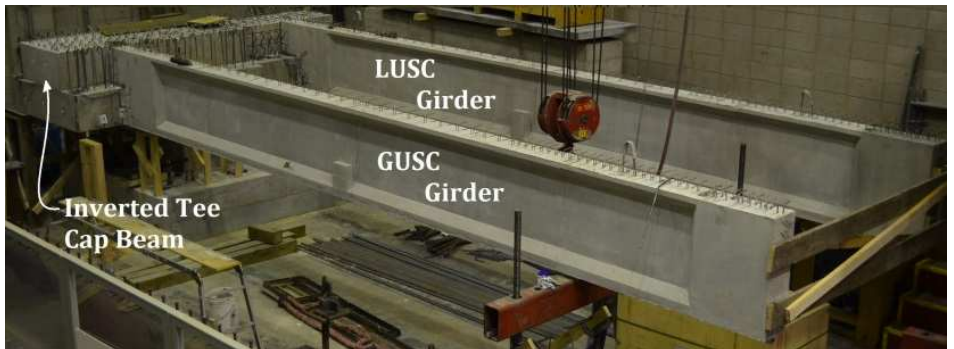

b. Girders prior to diaphragm and deck placement

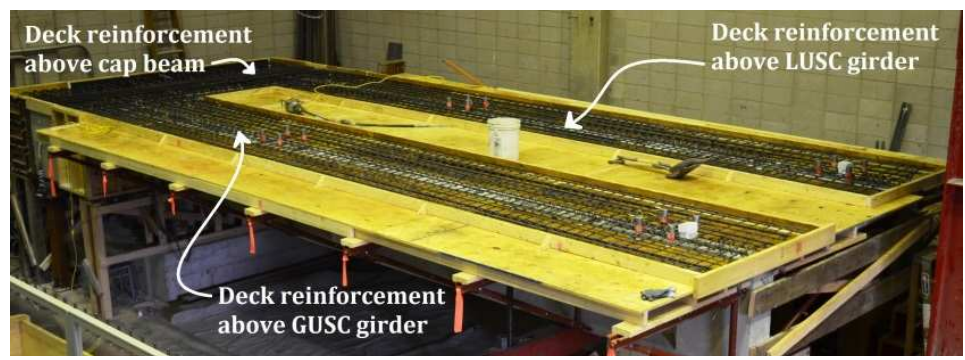

c. Deck formwork and reinforcement

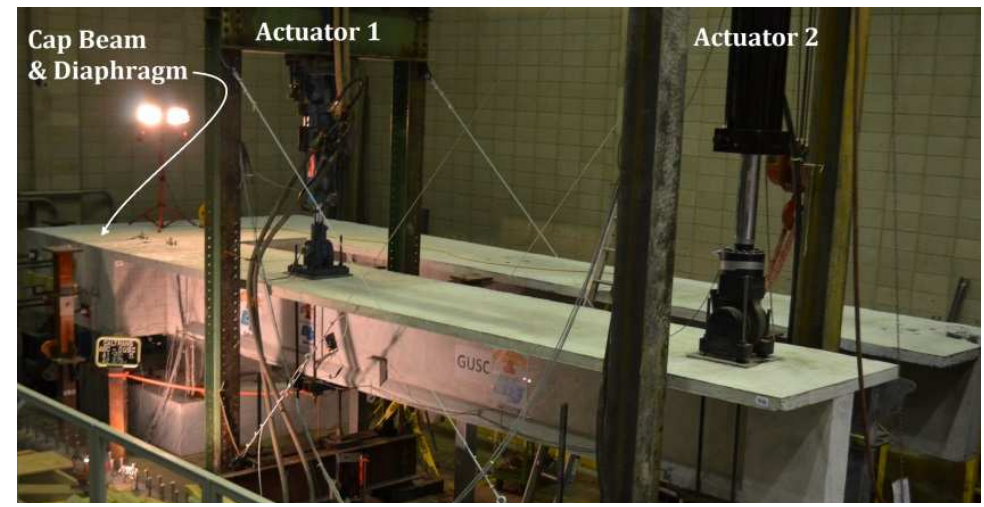

d. Completed test unit and load frames

Figure 4.11. Construction and test configuration photographs

Table 4.2. Test unit concrete strengths

\begin{tabular}{|c|c|c|c|}
\hline Component & $\begin{array}{c}\text { 7-day strength, } \\
\text { MPa (psi) }\end{array}$ & $\begin{array}{c}\text { 28-day strength, } \\
\text { MPa (psi) }\end{array}$ & $\begin{array}{c}\text { Test day strength, } \\
\text { MPa (psi) }\end{array}$ \\
\hline Cap beam corbel & $33(4750)$ & $41(5918)$ & $48(7005)$ \\
\hline Cap beam stem & $25(3653)$ & $32(4704)$ & $39(5618)$ \\
\hline Girder & Not recorded & $70(10,200)$ & Not recorded \\
\hline Deck \& Diaphragm & $30(4319)$ & Not recorded & $38(5460)$ \\
\hline
\end{tabular}




\subsubsection{Instrumentation}

Approximately 100 strain gages were installed on the reinforcement in the test unit. These strain gages were positioned to investigate the cap beam, girder, deck, diaphragm, and column performance, with a focus on the behavior of the connection region. In addition, approximately 30 external displacement transducers were utilized during each of the connection tests to record the test unit movement and deformation.

Both the GUSC and LUSC details were instrumented with LED position indicators, as shown in Figure 4.12. The data from these indicators enabled the determination of the relative displacement of the girder compared to the face of the diaphragm. Since positive moment performance in particular was of interest, the LED data was used to look at the relative movement of the girder bottom flange and thus provide an indication of how much slip was occurring between the girder and the cap beam.

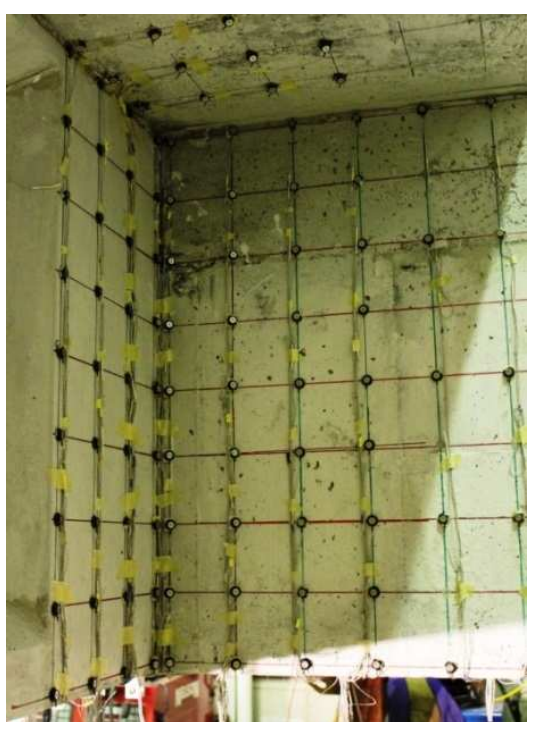

Figure 4.12. LED indicators to record position during experimental testing

\subsection{Experimental results}

\subsubsection{Overall connection behavior}

Both the GUSC and LUSC details performed very well during the experimental testing. Both exhibited elastic behavior for positive moment magnitudes considerably higher than the expected demand at the full horizontal seismic condition. In fact, for both details the elastic behavior continued to magnitudes approximately 1.25 times higher than the demand expected at full horizontal seismic load plus 1.0-g vertical acceleration. Figure 4.13 shows the connection moment history for both tests plotted 
as functions of vertical displacement at the Actuator 2 location (see Figure 4.11c). In these plots, "H" signifies the maximum expected horizontal seismic demand based on the column overstrength moment and "V" signifies the demand expected from 1.0-g magnitude vertical acceleration. These plots are helpful in identifying the magnitude of moment demand generated during the tests. Both connections demonstrated elastic behavior up to positive connection moment magnitudes near $400 \mathrm{kip}-\mathrm{ft}$, almost 2.4 times higher than the expected full horizontal seismic positive moment of $170 \mathrm{kip}-\mathrm{ft}$, and almost double the full horizontal plus 1.0-g vertical condition of $215 \mathrm{kip}-\mathrm{ft}$. The plots also clearly demonstrate elastic moment behavior in both connections up to magnitudes considerably higher than expected seismic demands, including both horizontal and vertical effects. In addition, the plots show that both connections exhibited considerable ductility for both positive and negative moment response.

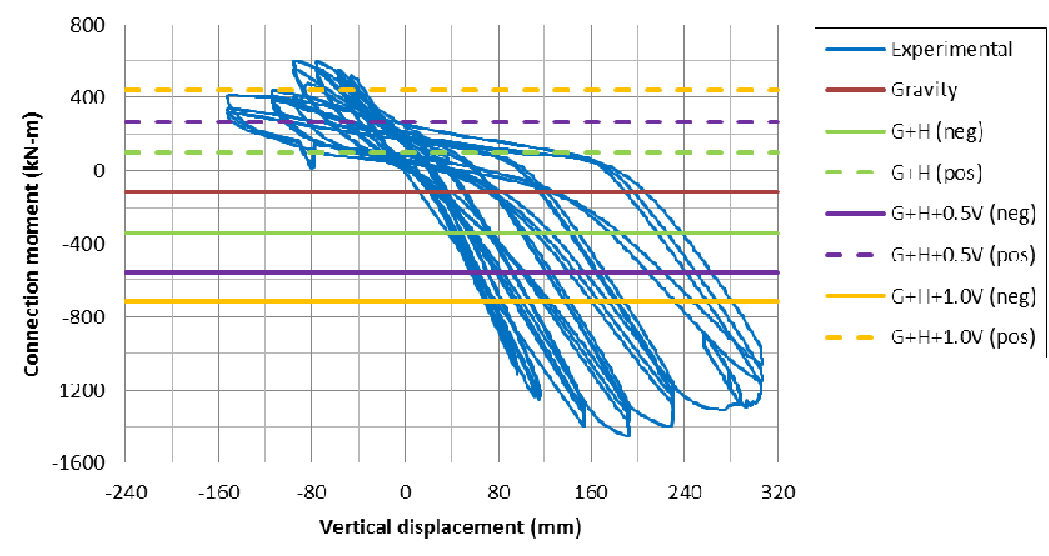

a. GUSC test

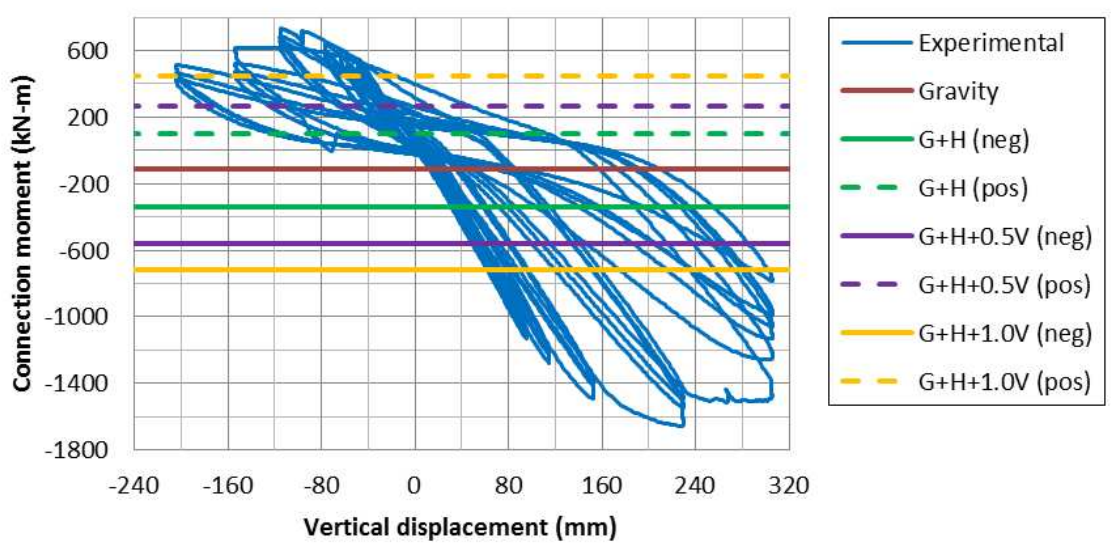

b. LUSC test

Figure 4.13. Recorded connection moment as a function of vertical displacement at the far actuator 
Figure 4.14 shows the connection shear at the first load/displacement peaks during the GUSC test (a very similar pattern was used for the LUSC test) plotted as a function of connection moment. The initial portion of the boxed pattern shows the load incrementally advancing to the full gravity condition. Then the remainder of the boxed pattern extending to higher shear values and larger negative moment values shows the negative shear and moment conditions advancing through horizontal seismic and into large vertical acceleration simulations. The diamond patterns show the conditions associated with positive moment during the horizontal seismic simulation initially and concluding with the larger vertical acceleration simulations. The " $x$ " and triangle patterns show the large force/displacement conditions that were not simulations of any specific prototype conditions but rather were intended to fully exercise and quantify the connection behavior.

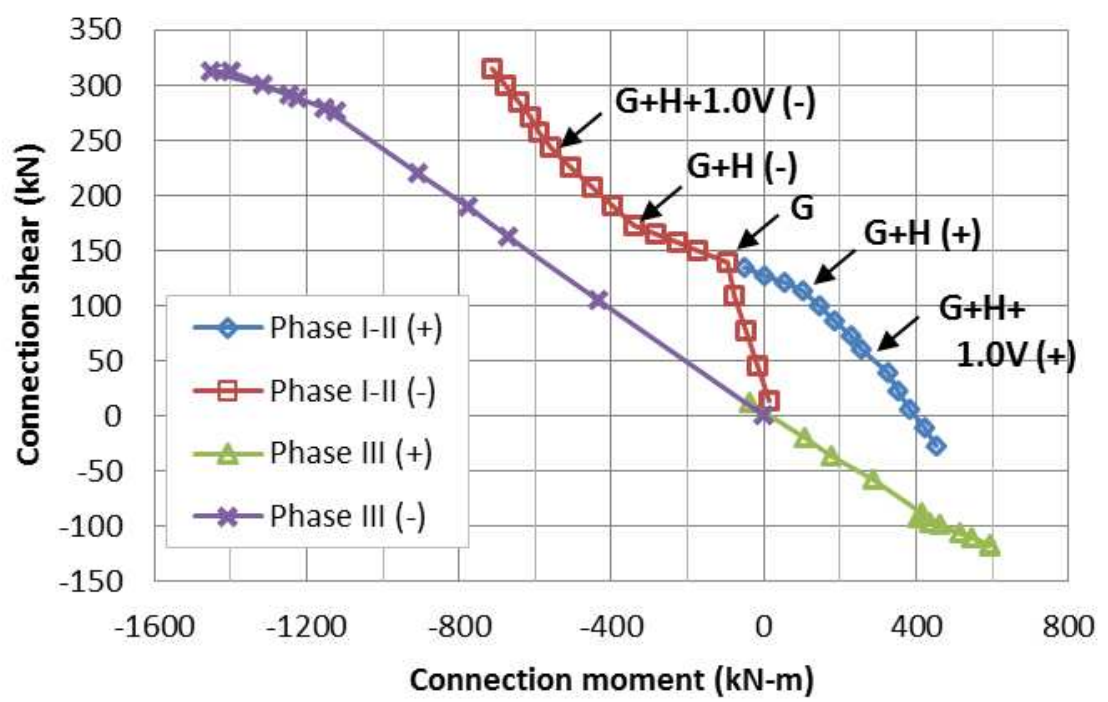

Figure 4.14. Connection shear resistance in GUSC

\subsubsection{Failure mechanisms}

The concrete in the connection region of the GUSC detail remained largely intact for the duration of testing. The primary failure mechanism of the connection was the fracture of one of the connection strands. Figure 4.15 provides a view looking straight up into the connection region at the girder-to-cap interface under the maximum positive moment displacement. The strand on the right in the photograph is seen to have remained intact, while the strand on the left fractured. The photograph also shows that, 
even at this extreme stage of the test, the grout pad between the girder vertical face and the cap beam girder face remained in place, held by the unstressed strand.

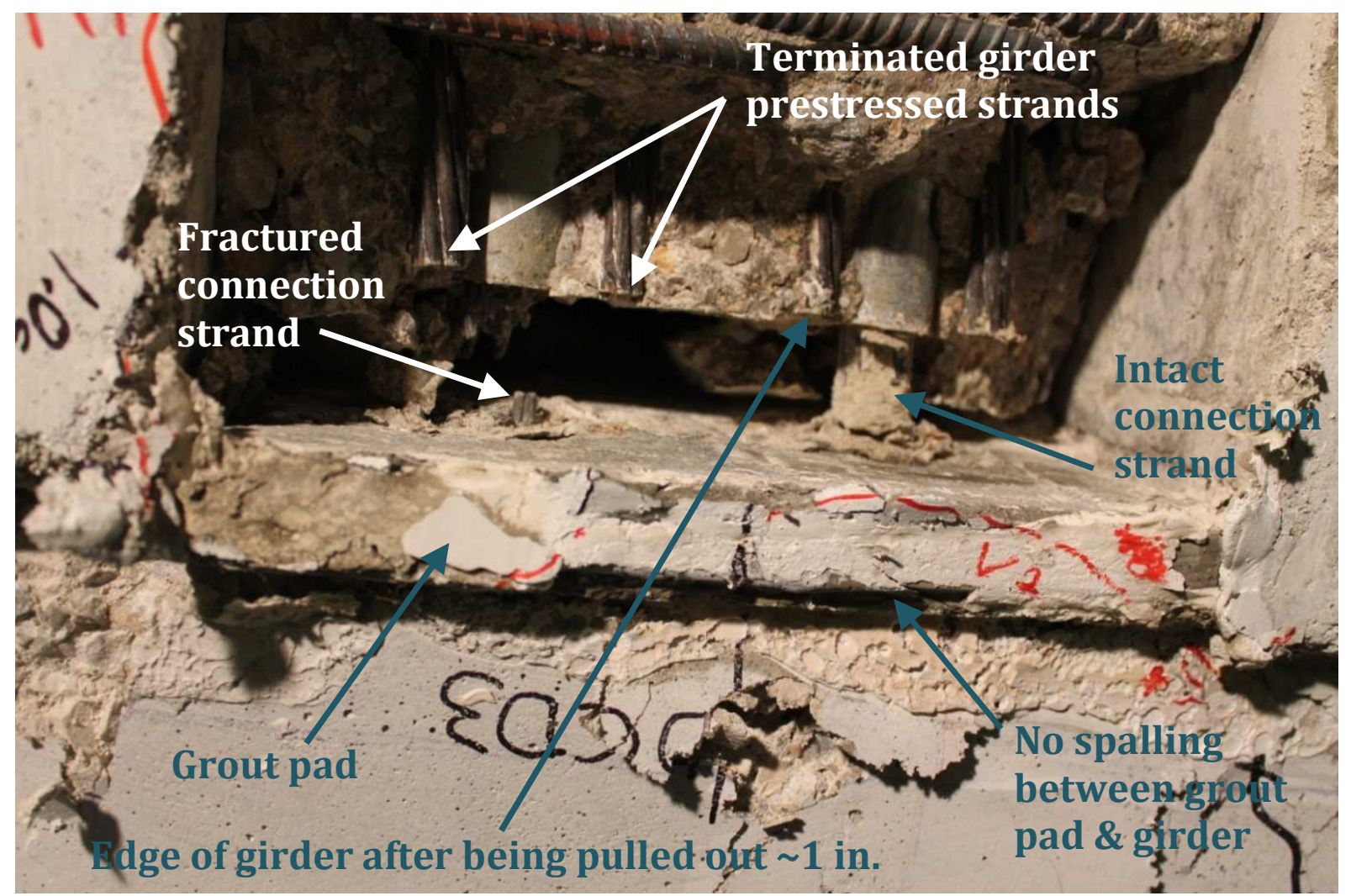

Figure 4.15. GUSC girder-cap interface during peak positive-moment displacement (looking up)

Fracture of the strand as the primary failure mechanism is significant for a couple of reasons. First, its fracture indicated that the grout on both sides of the interface (in the cap beam as well as in the girder bottom flange) provided sufficient anchorage to fully develop the strength of the strand. As mentioned earlier, a load cell was used to monitor the behavior of the strand at the back side of the cap beam. This monitoring revealed that, for the duration of the test, no load was transferred at the strand's anchorage point; thus, the grout/strand bond in the cap beam was sufficient to completely anchor the strand. Second, the fracture of the strand under positive moment loading indicated that the strand played a significant frictional role in providing positive moment connection capacity, as per the design intent. 
The positive moment failure mechanism in the LUSC detail was not quite as straightforward as the GUSC detail. Observations at the conclusion of the LUSC test indicated that the failure of the connection under positive moment loading was related to the interaction of the diaphragm concrete, the looped strands, and the dowel bars. At the highest displacement cycles of Phase III loading, a clearly defined crack and separation of the diaphragm around the dowel bars was observed, as shown in Figure 4.16.

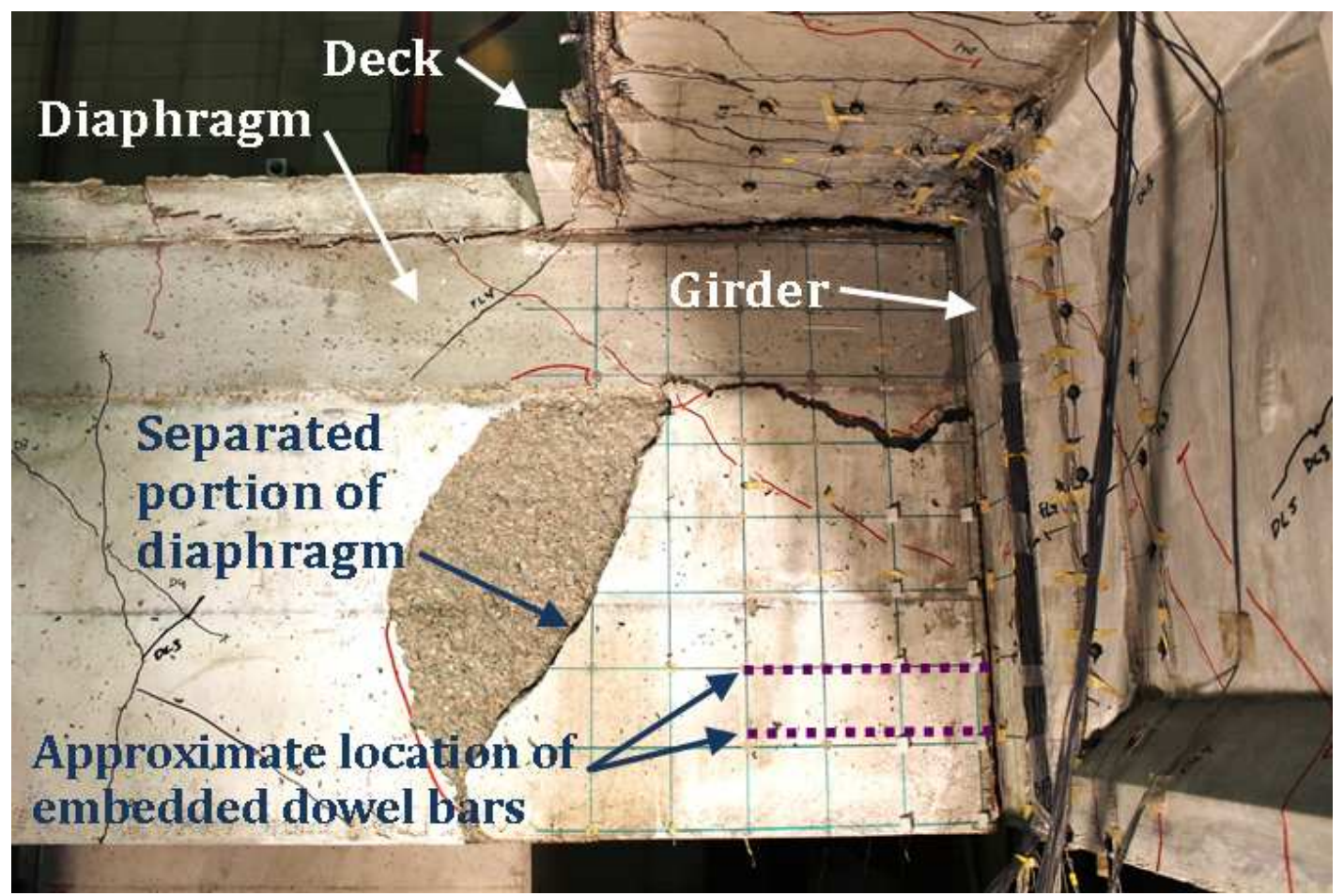

Figure 4.16. Condition of the diaphragm of LUSC detail at peak positive (upward) girder displacement of 4.5 in. at Actuator 2

\subsubsection{Behavior of the connection interface}

The LED indicators introduced in Section 0 were used to investigate the relative displacement between the girder and diaphragm at their interface. The results of the analysis for both details are provided in Figure 4.17. Both details exhibited similar relative displacement tendencies. The relative displacements in the GUSC are slightly higher than for the LUSC. The slightly lower stiffness of the GUSC connection in the positive moment direction can be attributed to the positive moment tension mechanism. In the GUSC, the unstressed strand is primarily responsible for tension transfer, so as it elongates elastic it allows slight movement at the girder-to-cap interface. In the LUSC detail, on the 
other hand, the tension continuity is provided by the interaction of the dowel bars, strands, and concrete, thus resulting in less elastic movement prior to reaching the connection ultimate capacity.

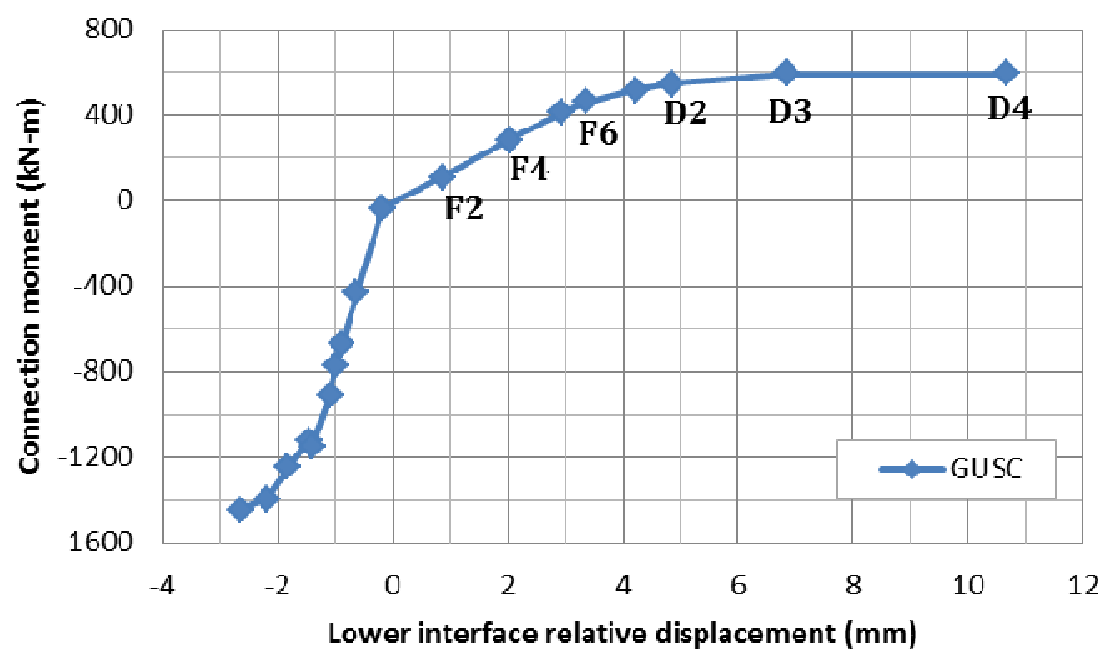

a. GUSC detail

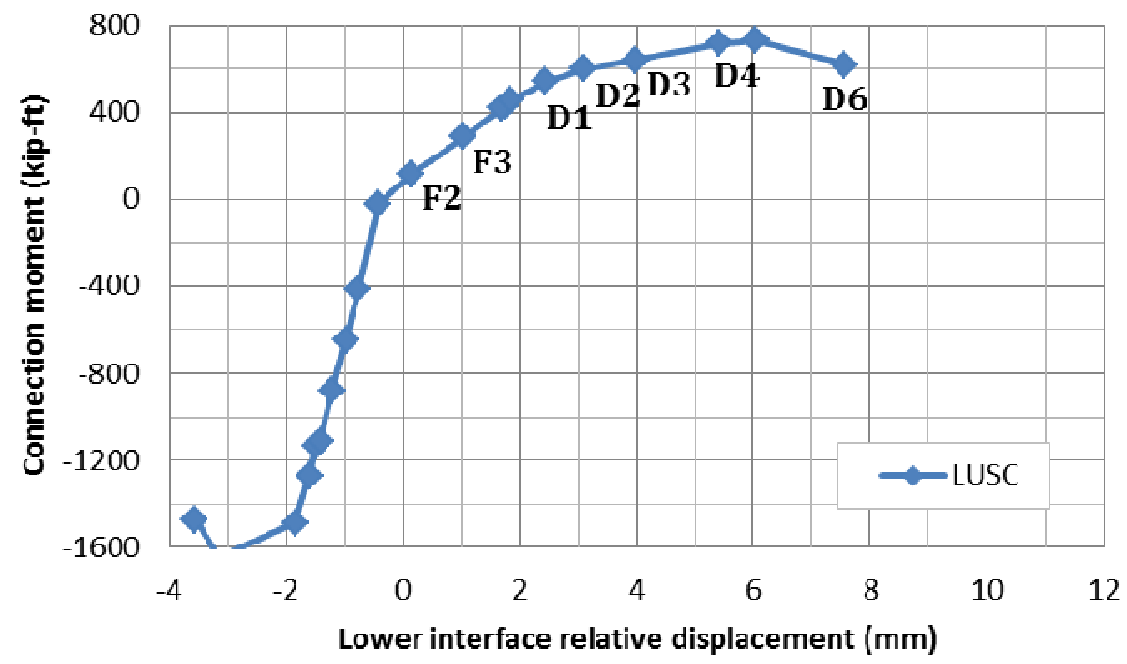

b. LUSC detail

Figure 4.17. Relative displacement of lower interface between girder and diaphragm

\subsubsection{Performance of the GUSC detail}

Strain gages were used to monitor the strain in the unstressed strands throughout the GUSC test. Figure 4.18a provides strain values from near the connection interface in one of the strands for the positive moment peak conditions for most of the Phase III portion of the test. The dowel bars that were 
duplicated from the as-built connection also contributed to the connection performance; Figure 4.18b provides these strain values for the same peak conditions as in Figure 4.18a. The labels by the points on each curve in Figure 4.18a indicate the corresponding load/displacement peak; the points labeled as " $F$ " were the peaks from the force-control portion of Phase III, whereas the points labeled as " $D$ " were the peaks from the displacement-control portion.

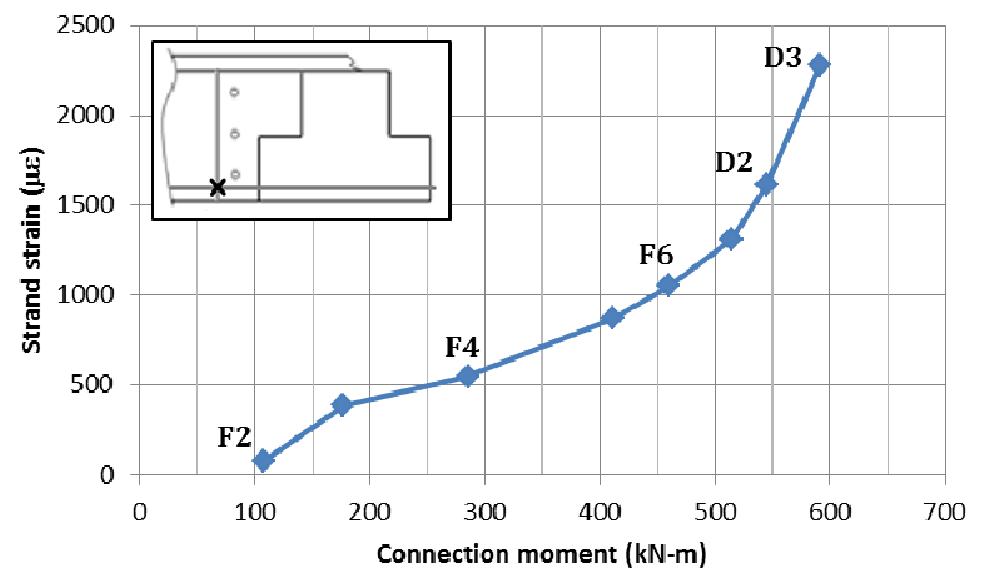

a. Unstressed strand strain for positive moment peaks

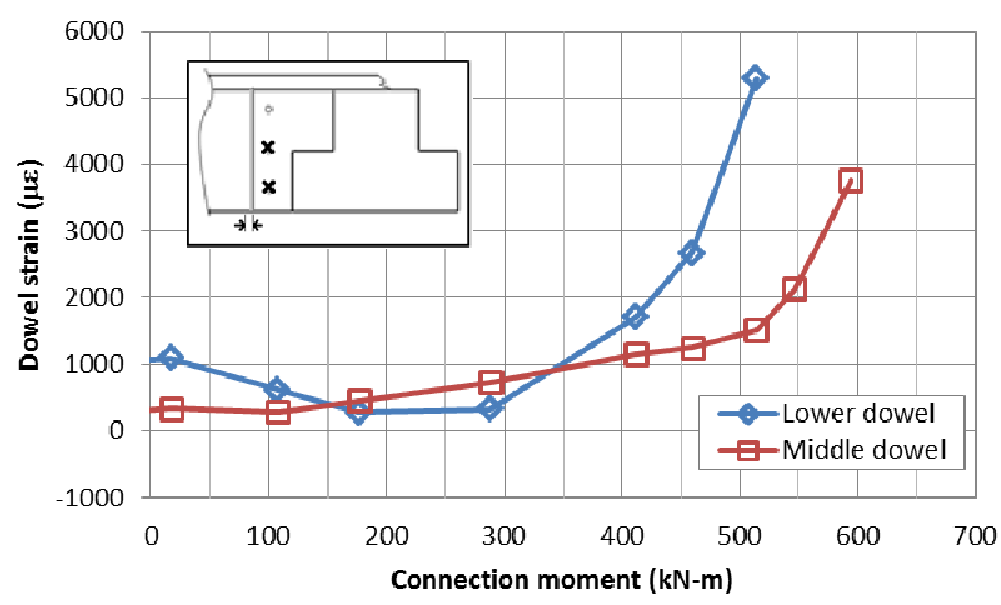

b. Dowel bar strain for positive moment peaks

Figure 4.18. Performance of unstressed strand and dowel bars in GUSC detail

The increase in slope in Figure 4.18a at high moments shows that the strands carried a greater portion of the load when the connection was subjected to large moments and displacements. Therefore, it can be inferred that another positive moment transfer mechanism was contributing significantly in the 
lower load portions of the test, but as the moment increased the strand was required to contribute more to resist the required demand. The other primary mechanisms in the GUSC detail that could contribute to resisting positive moment tension were shear friction between the diaphragm concrete and the general confinement and restraint provided by the diaphragm concrete. Figure 4.18b offers insight into the dowel bar and diaphragm mechanism. These plots show the measured strains in the lower and middle dowel bars at peak displacements producing positive moment in the connection. The dowel bar strains here exhibit a similar trend to the strand strain presented above. The data indicates that the dowel bars and unstressed strand act in concert to resist positive moment tension, and this combined mechanism picks up more load under high displacements as the ability of the concrete to provide confinement and anchorage lessens.

Figure 4.19 presents the strand strain as a function of the relative displacement measured at the lower interface of the girder and diaphragm. The linear behavior of the strand strain here indicates two important behaviors. First, the strand strain is directly related to the gap opening (relative interface displacement); thus, the strand is a primary contributor in the performance of the connection. The strand provides a successful tension load path to significantly improve the positive moment performance of the connection detail and maintain a linear tendency in the separation of the girder from the cap beam and diaphragm. Second, these data confirm the successful anchorage of the strand in the girder and cap beam, since the relative displacement of the connection shows no indication of irregularity in the relationship between the strand strain and location. Any slipping occurring in the anchorage regions of the strands would affect the relationship at the interface, so these data match the strand load cell data mentioned earlier in confirming the successful anchorage of the strand.

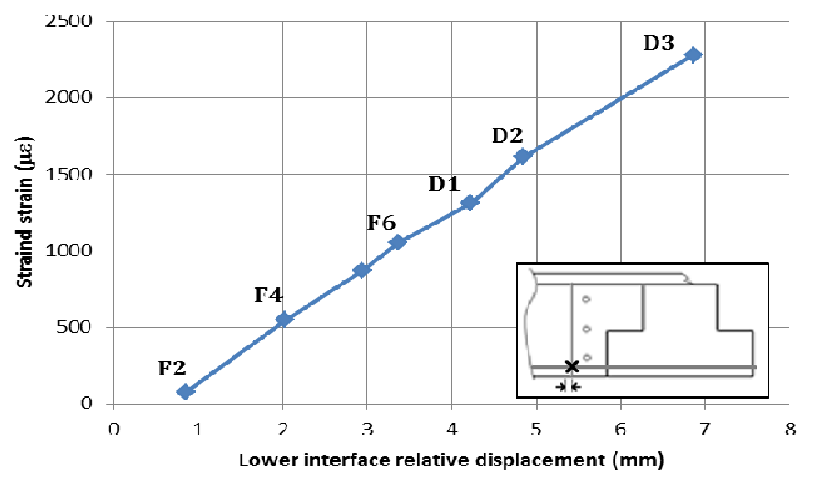

Figure 4.19. Strand strain related to relative interface displacement 


\subsubsection{Performance of the LUSC detail}

Because of the complexity of the positive moment tension transfer mechanism in the LUSC detail, data from the dowel bars, diaphragm looped strands, and girder looped strands were investigated and compared to quantify the connection performance. Figure 4.20 shows measured strain in one of the four dowel bars near the girder web plotted as a function of the relative displacement of the girder lower flange and the diaphragm. The positive relative displacements correspond with positive moment loading and are of primary interest. These data reveal a regular and linear trend throughout the Phase III test. The uniformity of this relationship suggests that the dowel bars are indeed a primary contributor in the positive moment performance of the LUSC detail. Another notable observation is that the maximum strain of $1783 \mu \varepsilon$ measured in the dowel bars was noticeably lower than the approximate yield strain of $2300 \mu \varepsilon$. The relatively low strain demand indicates that the dowel bar size (\#6 bars in the test unit) could be reduced without affecting the connection performance; however, additional investigation would be helpful prior to developing a specific design recommendation.

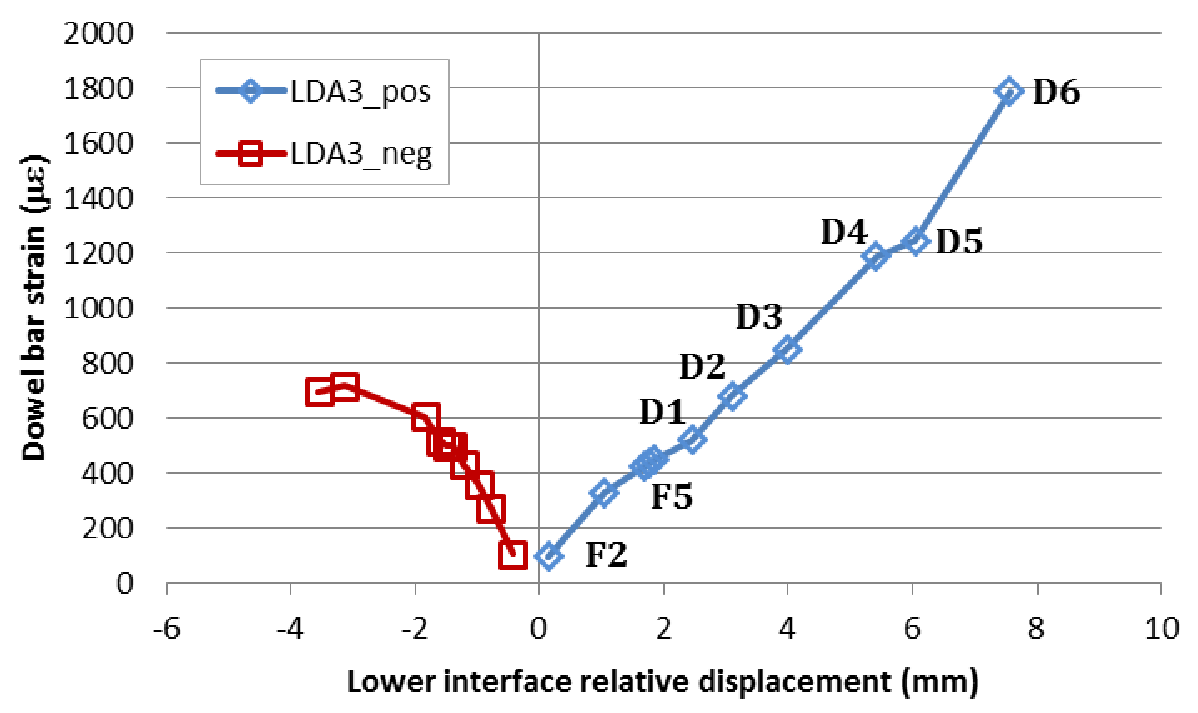

Figure 4.20. LUSC dowel bar strain as a function of interface relative displacement

Confinement for the dowel bars was expected to be provided by the looped strands in the diaphragm and girder. Figure 4.21a shows how this mechanism performed in the diaphragm; this figure presents the diaphragm looped strand strain at peak displacements as a function of the dowel bar strain. This relationship is again relatively linear throughout the test. The regularity of this relationship 
suggests that the diaphragm loops were an important component in the successful positive moment behavior of the connection detail. The strain history of the relationship between the looped strand strain and dowel bar strain throughout the test, plotted in Figure 4.21b, also confirms the regular relationship between the two. While there is relaxation in the strain as the load reverses, the pattern is quite uniform throughout the test and indicates regular interaction between the looped strands and the dowel bars.

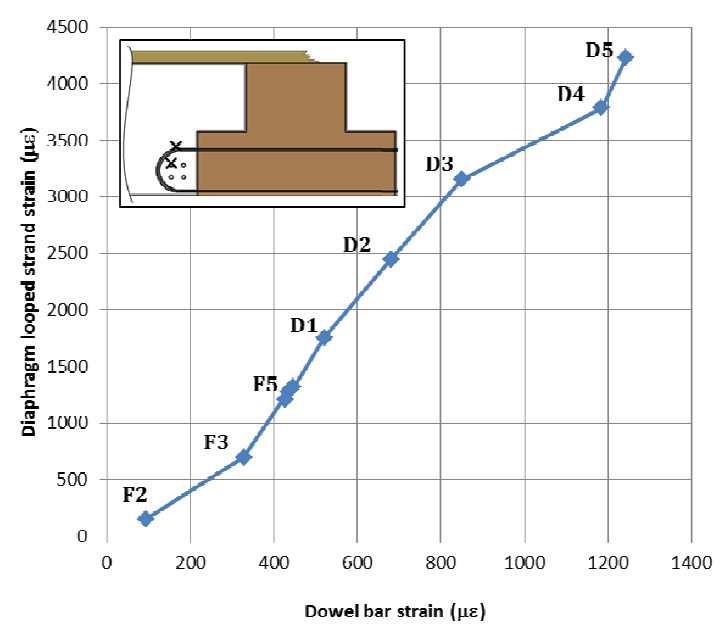

a. Peak positive moment displacements

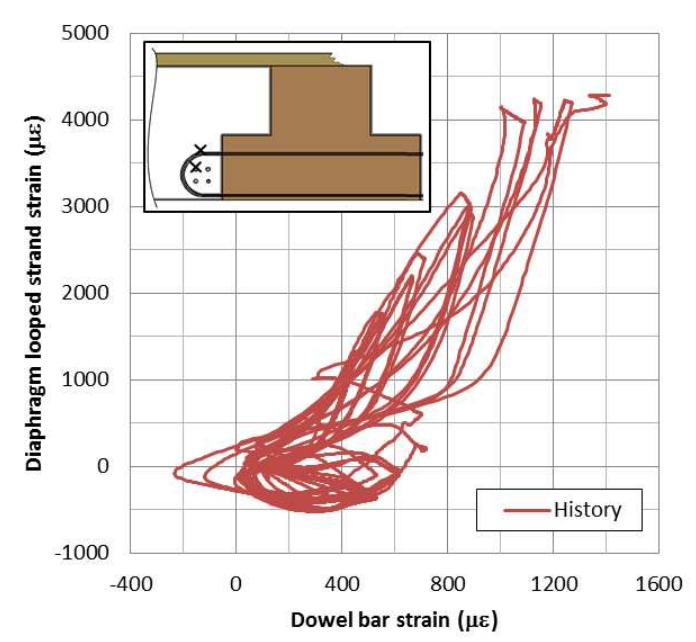

b. Strain history

Figure 4.21. LUSC looped strand strain as a function of dowel bar strain

One more observation from Figure 4.21 is that the maximum diaphragm looped strand strain was around $4300 \mu \varepsilon$, significantly lower than the strand yield strain of $7900 \mu \varepsilon$. In a detail based on this design concept, the looped strand could likely be reduced without compromising the connection performance.

The interaction of the dowel bars with the girder looped strands was also crucial to successful positive moment connection performance. Figure 4.22a shows the strain at peak displacements in the girder looped strand plotted as a function of dowel bar strain. This figure is strikingly similar to Figure 4.21a, indicating the girder strands were similarly engaged in the force transfer and also similarly equipped to perform as intended. Likewise, Figure $4.22 \mathrm{~b}$ is very similar to Figure $4.21 \mathrm{a}$, verifying a regular relationship between the girder looped strand and the dowel bar strain. The final similarity of the girder loops to the diaphragm loops was the strain magnitudes, as the maximum girder strand strain 
is noticeably lower than the yield strain. Similar to the diaphragm loops, these loop strands could likely be reduced without significantly altering the performance of the connection.

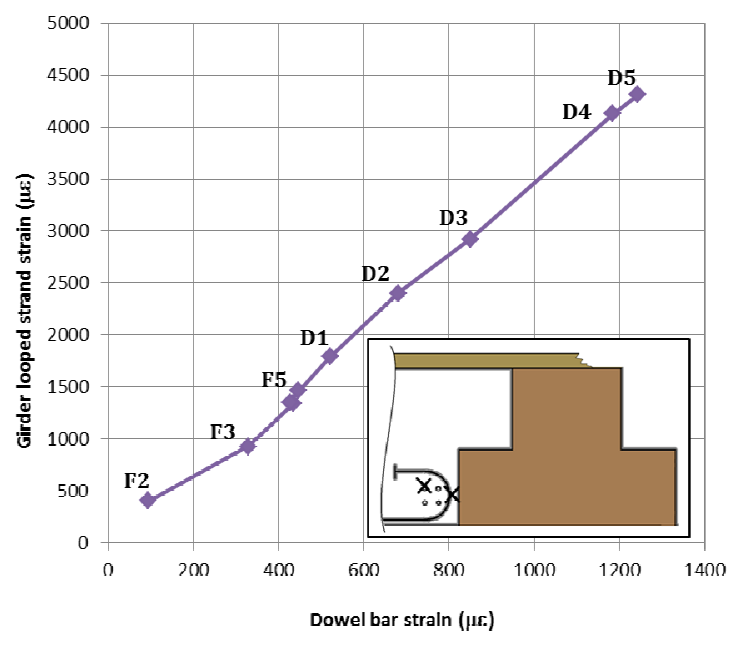

a. Peak positive moment displacements

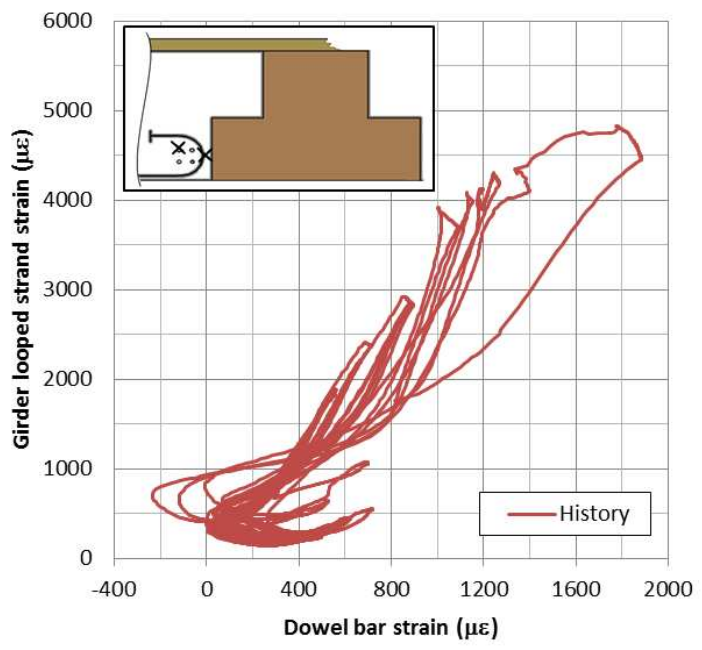

b. Strain history

Figure 4.22. LUSC girder looped strain as a function of dowel bar strain

\subsection{Preliminary design recommendations}

\subsubsection{GUSC Detail}

The primary design question to be addressed in the GUSC detail is how to size the unstressed strands to be sufficient for the tension demand that will occur under maximum positive moment loading. As discussed in Section 4.5.4, data revealed that the unstressed strands and dowel bars worked together to provide positive moment tension continuity; as the strand strain increased, the dowel bar strain also increase in a relatively linear manner. Therefore, a suggested design approach is to use the tension capacity of the strand as a starting point, since this capacity is simple to determine based on the strand strength and cross-sectional area. Once the strand tension capacity is determined, the correlated positive moment resistance of the strand can be determined. Then the positive moment resistance contribution from the dowel bars can be determined using the strand moment capacity along with an appropriate factor. The total positive moment capacity can then be compared to the maximum expected positive moment demand in the connection, based on column overstrength moment and vertical acceleration effects. 
For the test unit GUSC detail, four 3/8 in. diameter 7-wire strands were used $\left(A_{\text {strand }}=0.085\right.$ in $\left.^{2}\right)$, with $\mathrm{F}_{\mathrm{ut}}=270 \mathrm{ksi}$. Assuming a moment lever-arm distance of $33 \mathrm{in}$. (approximated as the distance from the center of the bridge deck to the center of the strands) the moment capacity of the four GUSC strands can be estimated to be $252 \mathrm{kip}-\mathrm{ft}$. The maximum positive moment demand generated in the GUSC detail was 436 kip-ft; therefore, an additional moment capacity of 184 kip-ft was produced in the combined strand and dowel mechanism. Based on these numbers, the combined strand and dowel mechanism provided a positive moment resistance approximately 1.7 times greater than the positive moment capacity of the strands alone. If this factor is incorporated into the design recommendation for the strand, the strand moment capacity can be calculated as:

$$
\mathrm{M}_{\text {strand }}=1.7 \mathrm{~N} \mathrm{~A}_{\text {strand }}\left(0.8 \mathrm{Fut}_{\mathrm{ut}}\right) \mathrm{j}_{\mathrm{s}}
$$

where $\mathrm{N}$ is the number of unstressed strands that provide continuity between the girder bottom flange and the cap beam, $A_{\text {strand }}$ is the cross-sectional area of a single strand, $F_{u t}$ is the tensile strength of the strand, and $j_{s}$ is the moment-arm distance of the strand mechanism which can be approximated as the distance between the center of the strands and the center of the bridge deck. This approach assumes that the dowel bars are sized sufficiently to remain intact and contribute to the positive moment tension mechanism. Additional investigation would be beneficial in confirming this recommended design approach and further quantifying the contribution of the dowel bars in the positive moment performance of the connection.

\subsubsection{LUSC Detail}

For the LUSC detail, examination of the experimental results indicated that the dowel bars, diaphragm looped strands, and girder looped strands all played a significant role in providing positive moment capacity. In addition, the diaphragm and girder looped strand demand was observed to be directly related to dowel bar demand. Thus, a suggested design approach is to size the dowel bars sufficiently using a shear friction approach that considers the tendency of the girder bottom flange and dowel bars to pull away from the cap and diaphragm when the connection is subjected to positive moment. Since the looped strands in both the girder and diaphragm act primarily as confinement mechanisms in restraining the dowel bars, these strands can then be sized based on the dowel bar design. 
For the test unit LUSC detail, four \#19 (metric) dowel bars were chosen based on past experience and recommendations. The test data revealed that the strain in these dowel bars remained well below yield for the entirety of the test. If an appropriate shear friction approach had been used in sizing the dowel bars, they may have been able to be sized more efficiently. The looped strands in the test unit LUSC detail were sized to provide a force ratio of approximately 1.0 between the strand and the dowel bars using the following relationship:

$$
\text { F.R. }=1.0=\left[N_{\mathrm{ls}} A_{\mathrm{ls}} F_{\mathrm{utls}}\right] /\left[\mathrm{N}_{\mathrm{db}} A_{\mathrm{db}} F_{\mathrm{ydb}}\right]
$$

where F.R. is the force ratio, $\mathrm{N}_{\mathrm{ls}}$ and $\mathrm{N}_{\mathrm{db}}$ are the number of looped strands per side and dowel bars, respectively, $A_{l s}$ and $A_{d b}$ are the cross-sectional areas of single looped strands and dowel bars, respectively, $F_{u t s}$ is the tensile strength of the looped strands, and $F_{y d b}$ is the yield strength of the dowel bars. Since the strain magnitudes in the looped strands in the LUSC detail were observed to be below yield by a fractional value similar to the dowel bar reserve capacity, the test results indicate that the force ratio of 1.0 is appropriate. However, further investigation into using shear friction to size the dowel bars and the force ratio to size the strand is recommended to validate this preliminary proposed design approach.

\subsection{Conclusions}

The previous system test confirmed the validity of the inverted-tee cap beam and dapped-end Igirder system for seismic regions. The subsequent connection test, detailed here, has allowed further development and quantification of two particular girder-to-cap connection details for this system. One connection detail, the grouted unstressed strand connection (GUSC), utilizes unstressed strand to improve the positive moment tension continuity between the girder and cap beam. The second detail, the looped unstressed strand connection (LUSC), utilizes dowel bars that are confined by looped strands to provide a similar improvement in positive moment tension continuity between the girder and the cap beam. The following list provides specific conclusions that have been made as a result of this connection investigation:

1. The GUSC detail provides sufficient moment and shear resistance for integral bridge designs in high seismic regions. The detail remained elastic for negative moment demand as high as 3.6 
times the maximum expected gravity and horizontal seismic demand and for positive moment demand as much as 4 times the maximum expected gravity and horizontal seismic demand.

2. The LUSC detail also provides sufficient moment and shear resistance for integral bridge designs in high seismic regions. Its negative and positive moment resistance was determined to be 4 times as high and 4.5 times as high, respectively, of expected negative and positive moment demands due to gravity and maximum horizontal seismic demand.

3. Both details were sufficient for simulated gravity and seismic loads that included significant vertical acceleration contribution. Both connections were subjected to demands that included simulated vertical acceleration in excess of $1.25-\mathrm{g}$ before exhibiting any inelastic tendencies.

4. The successful performance of both details when subjected to vertical acceleration effects confirms that the Caltrans SDC requirement of including additional girder side mild reinforcement is unnecessarily conservative for these details. While this requirement is intended to guarantee sufficient shear connection performance when the connection is subjected to vertical acceleration demands, both connections demonstrated shear capacities considerably higher than the vertical acceleration demands without the inclusion of the additional mild steel.

5. The use of grouted, unstressed strand is a viable way to transfer the positive moment tension in

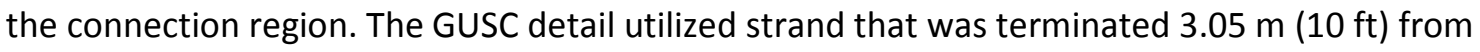

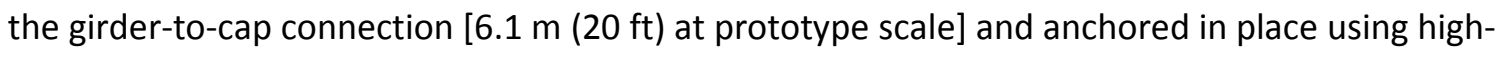
strength grout pumped into the strand ducts. The eventual failure mechanism of the detail was the fracture of the strand at the girder-to-cap interface, verifying that the grout provided sufficient anchorage to fully develop the strength of the strand.

6. In the GUSC detail, the dowel bars that are similar to the existing Caltrans detail act with the unstressed strand in the girder lower flange; each mechanism resists a portion of the connection moment. Preliminary findings from this test indicate that the combined dowel bar and strand mechanism increases the positive moment resistance by about 1.7 over what would be expected in the strand mechanism alone. Proposed design recommendations for the GUSC detail should take the combined dowel bar and strand mechanism into account, but additional investigation would be helpful to further quantify the performance of this mechanism and develop final design recommendations.

7. In the LUSC detail, the interaction between the dowel bars in flexure and the looped strands in confinement tension provides a viable positive moment tension transfer mechanism. A shear 
friction model considering the positive moment tension in the dowel bar region can be used to size the dowel bars. Subsequently, a force ratio of 1.0 between the dowel bar capacity and looped strand capacity can be used to size the looped strand. Further investigation is recommended to more fully quantify the dowel bar and looped strand behavior and finalize the design recommendations for this detail.

\subsection{References}

AASHTO. (2012). AASHTO LRFD Bridge Design Specifications, $6^{\text {th }}$ Edition. Washington, D.C.: American Association of State Highway and Transportation Officials (AASHTO).

ACl. (2011). Building Code Requirements for Structural Concrete (ACl 318-11). Farmington Hills, Michigan: American Concrete Institute (ACI).

Caltrans. (2013). Seismic Design Criteria, Version 1.7. Caltrans, Sacramento, CA.

Caltrans, (2008), "Accelerated Bridge Construction Applications in California: A Lessons Learned Report." Version 1.1, August 2008, Caltrans, Sacramento, CA.

Caltrans. (2008). "Caltrans ABC Strategic Plan: Development of Practice and Policy for Future Bridge Projects." Version 1.1, August 2008, Caltrans, Sacramento, CA.

FHWA Accelerated Bridge Construction Technologies. (2004). Federal Highway Administration, US Department of Transportation, Washington D.C.

Hida, S. (2012). "California Department of Transportation's Next Generation Bridges." Fourth KwangHua Forum, Shanghai, China. Accessed online: http://risedr.tongji.edu.cn/4th_KwangHua_Forum/downfile/PS_2/Sue_Hida.pdf.

Housner, George W., \& Charles C. Thiel, Jr. (1990). “Competing Against Time: Report of the Governor's Board of Inquiry on the 1989 Loma Prieta Earthquake." Earthquake Spectra, 6(4), pp.681-711.

Kam, Weng Yuen and Stefano Pampanin. (2011). General Building Performance in the Christchurch CBD: a contextual report. Christchurch, New Zealand: University of Canterbury. Online: http://www.dbh.govt.nz/UserFiles/File/Reports/quake-contextual-report-canterbury-uni.pdf. Accessed October 2012.

Matta, F., Nanni, A., Galati, N., Ringelstetter, T. E., Bank, L. C., Oliva, M. G., and Jones, S. N. (2005). Prefabricated modular GFRP reinforcement for accelerated construction of bridge deck and rail system. In Proc., FHWA Accelerated Bridge Construction Conference (pp. 129-134). 
NCHRP. (2011). "Application of Accelerated Bridge Construction Connections in Moderate-to-High Seismic Regions." NCHRP Report 698. Washington, D.C.: Transportation Research Board.

Priestley, M. J. N., Seible, F. and Calvi, G. M. (1996). Seismic Design and Retrofit of Bridges. New York: John Wiley \& Sons, Inc.

SEAOC. (2010). "Seismic Design of Concrete Parking Structure Ramps." Structure. July, 2010. Seismology Committee, Structural Engineers Association of California (SEAOC), Sacramento, CA.

Snyder. R. M. (2010). "Seismic performance of an I-girder to inverted-T bent cap bridge connection." M. S. thesis, lowa State University (ISU), Ames, IA.

Snyder, R., Vander Werff, J., Thiemann, Z., Sritharan, S., Holombo, J., (2011), Seismic Performance of an I-Girder to Inverted-T Bent Cap Connection, Final Report, Caltrans, Sacramento, CA, and lowa State University (ISU), Ames, IA.

Sritharan, S., Bromenschenkel, R., Vander Werff, J., \& Peggar, R. (2013). Two alternate connections for integral precast concrete girder bridges in seismic regions. In Proceedings of the Seventh National Seismic Conference on Bridges \& Highways. Oakland, CA.

Stanton, J., Eberhard, M., \& Steuck, K. (2006). Rapid construction details for bridges in seismic zones. In Proceedings of the 22nd US-Japan Bridge Engineering Workshop. Seattle, WA.

Thiemann, Z. J. (2009), "Pretest 3-D finite element analysis of the girder-to-cap-beam connection of an inverted-tee cap beam designed for seismic loadings." M. S. thesis, ISU, Ames, IA.

Vander Werff, J., Sritharan, S. (2014). "Girder Load Distribution for Seismic Design of Integral Bridges." ASCE Journal of Bridge Engineering, May 2014, DOI: 10.1061/(ASCE)BE.1943-5592.0000641. 


\section{CHAPTER 5. GIRDER LOAD DISTRIBUTION FOR SEISMIC DESIGN OF INTEGRAL BRIDGES}

A paper published in the ASCE Journal of Bridge Engineering

(May 2014, DOI: 10.1061/(ASCE)BE.1943-5592.0000641)

J. R. Vander Werff ${ }^{1}$ and S. Sritharan ${ }^{2}$

\subsection{Abstract}

Current seismic design practice related to integral bridge girder-to-cap beam connections allows little or no lateral seismic load to be distributed beyond the girders immediately adjacent to the column. However, distribution results from several large-scale tests have shown that the distribution of column seismic moment typically engages all the girders. An approach utilizing simple stiffness models to predict distribution in integral bridge structures is presented in detail; distribution predictions based on grillage analyses are also compared. The experimental results and the analytical results from the stiffness and grillage models show that current design methods related to vertical load distribution are sufficiently accurate. However, when applied to the distribution of lateral load, similarly-obtained results reveal that current design practice does not appropriately account for the amount of load that is distributed beyond the girders adjacent to the column to the non-adjacent girders. The current practice leads to excessive girder-to-cap connection reinforcement, increased girder depth, unnecessarily high seismic mass, and increased construction cost. Finally, this paper makes recommendations for more appropriate distribution of seismic lateral load in integral bridge superstructures.

\subsection{Introduction}

Integral bridges have several advantages over non-integral configurations. These advantages, which have been well-documented in recent years (Snyder et al. 2011, Maruri and Petro 2005, Wassef et al. 2004), have led to increased implementation of integral configurations, but design recommendations for such structures continue to be limited in some critical areas. The distribution of lateral load between girders in the superstructure is a particular aspect of integral bridge design that has not been addressed

\footnotetext{
${ }^{1}$ Assistant Professor; Engineering, Dordt College, Sioux Center, lowa

${ }^{2}$ Wilson Engineering Professor; Civil, Construction, and Environmental Engineering, lowa State University, Ames, lowa
} 
adequately. Common bridge design recommendations such as the AASHTO standards (AASHTO 2010; AASHTO 2009) provide very little information on the distribution of lateral seismic loads. Common standards used in seismic regions, such as Seismic Design Criteria (SDC, 2006) and Bridge Design Aids (BDA, 1995) from the California Department of Transportation (Caltrans) also do not provide a detailed approach for seismic lateral load distribution.

Investigations over the past fifteen years have explored seismic lateral load distribution in the superstructure of integral bridge systems. Holombo et al. (2000) briefly looked at lateral load distribution alongside other issues of interest related to use of precast concrete superstructures in seismic regions. National Cooperative Highway Research Program (NCHRP) Project 12-54 (Wassef et al. 2004, Sritharan et al. 2005, Vander Werff 2002) investigated lateral load distribution as part of a research effort examining seismic issues in bridges with steel superstructures and concrete substructures. These projects and others have mentioned the issues related to seismic lateral load distribution based on experimental data. However, the authors are not aware of any studies that systematically investigate seismic lateral load distribution using comparisons of experimental test data and predictive analytical models to formulate improved design recommendations.

The investigations mentioned above primarily focused on the performance and sufficiency of bridge systems for high seismic regions. The studies utilized the construction and testing of large-scale experimental models of prototype integral bridge structures. The first test unit modeled a bridge with a 4-girder prestressed concrete superstructure (Holombo et al. 2000), using precast bulb-tee girders. This test unit is referred to as the precast bulb-tee (PBT) model. The next two test units were based on bridges with 4-girder steel superstructures (Wassef et al. 2004). These units are referred to as the steel pier cap (i.e., SPC1 and SPC2) models. A more recent study by Caltrans investigated a test unit consisting of a 5-girder prestressed concrete superstructure (Snyder et al. 2011) including an inverted-tee bent cap. This unit is referred to as the inverted-tee bent cap (ITB) model. Figure 5.1 provides schematic details of the prototype structures for these investigations. All of the tests had specific areas of focus; however, common areas of interest can be summarized as: (1) the design of a prototype bridge utilizing integral connection details capable of withstanding seismic loading, (2) the experimental validation of these details using large-scale test specimens, and (3) the formation of suitable seismic design recommendations based on the analytical and experimental findings. This paper compiles the load 
distribution results from these experimental tests and compares them with predictions from grillage and simple stiffness models.

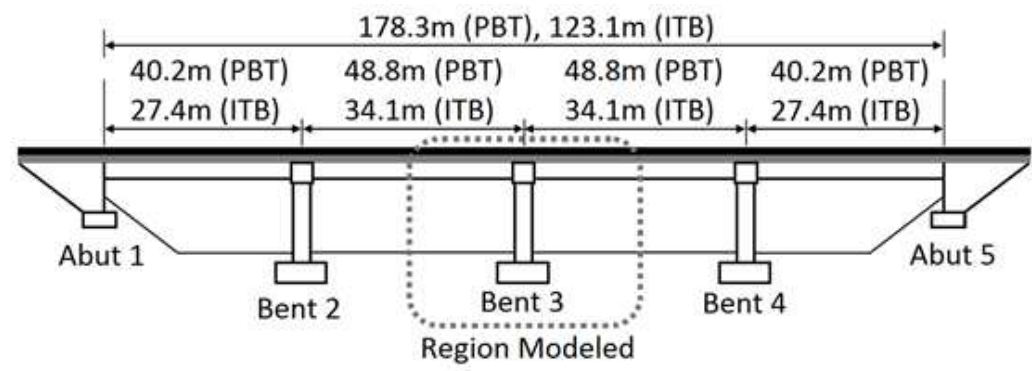

a. PBT and ITB studies, longitudinal elevation

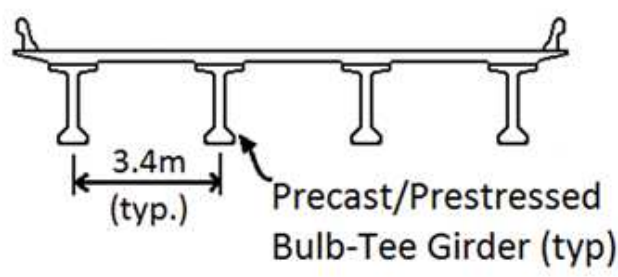

b. PBT study, transverse section

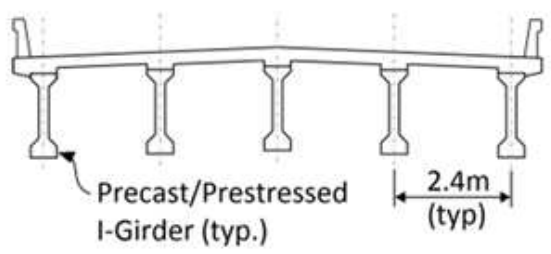

c. ITB study, transverse section

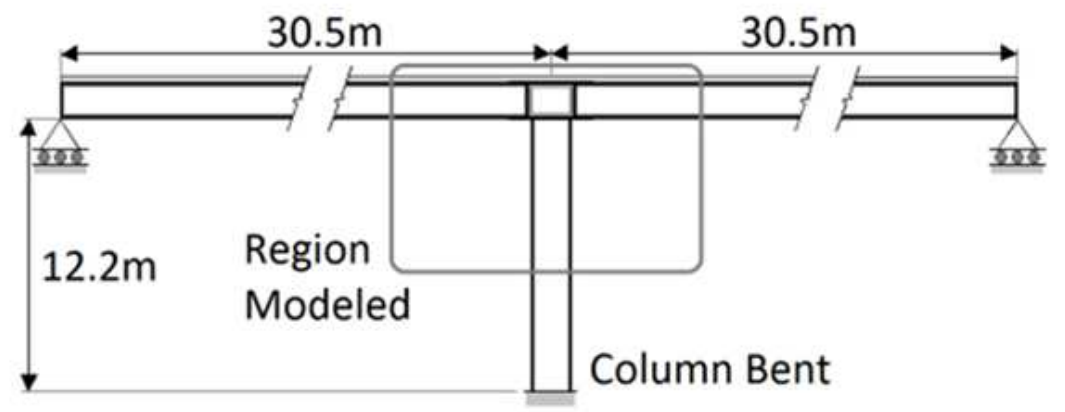

d. SPC study, longitudinal elevation

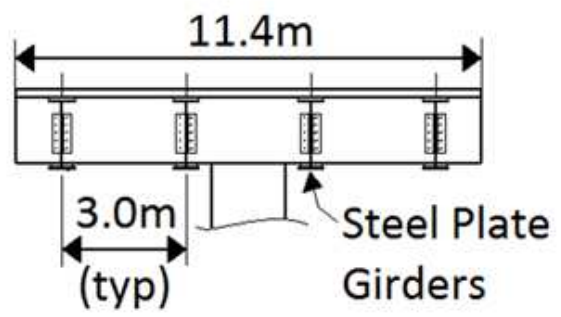

e. SPC study, transverse section

Figure 5.1. Prototype structures used for the integral bridge investigations 


\subsection{Current Design Practice}

The current AASHTO LRFD Bridge Design Specifications (2010) includes a well-established procedure for using distribution factors to distribute moment and shear due to vertical loads to interior and exterior girders with concrete decks (Section 4.6.2.2.2). The distribution factors are based on the spacing, span, and longitudinal stiffness of the beams and the depth of the slab. The distribution factor approach has been shown to be reliable for vertical live load by many studies (Zokaie et al. 1991, Kim and Nowak 1997, Mabsout et al. 1999, Barr et al. 2001, and Cai 2005, for example). Recent work as part of NCHRP Project 12-26 has continued with this approach while simplifying the equations (Mertz 2007).

Caltrans' current approach to vertical live load distribution incorporates the recommendations from AASHTO. While slight variations are made for special situations (see "Concrete box girder live load distribution by Lanell for special loads" 1998, or California Amendments to AASHTO LRFD Bridge Design Specifications 2011, for example), the basis of the approach continues to be spacing, span, and section properties of the girders and deck. This approach is appropriate for distributing service-level live loads. However, it is not analogous to the vertical load distribution that occurs when the bridge structure is exercised by large displacements and experiences considerable cracking due to a large seismic event. Also, the AASHTO distribution factors are primarily intended for girder design. However, a primary focus of seismic load distribution, particularly in conjunction with the ever-increasing use of segmental construction and accelerated bridge construction, is the design of the connections. Therefore, a stiffness-based approach to vertical load distribution during large seismic displacements is introduced later in this paper. This approach is primarily intended for use in conjunction with a similar lateral load distribution model in determining seismic load paths through the superstructure.

Regarding lateral load distribution, Section 4.11.2 in the AASHTO Guide Specifications for LRFD Seismic Bridge Design (2009) stipulates the superstructure components and their connections "shall be designed to resist overstrength moments and shears of ductile columns." Section 8.10 in these guidelines goes on to address the capacity design of the superstructure for integral bent caps in reinforced concrete structures. These guidelines limit the distribution of the column overstrength moment to an effective width equal to the sum of the diameter of the column and the depth of the superstructure. This stipulation is graphically summarized in Figure 5.2. The practical conclusion of this requirement is that the column overstrength moment can rarely, if ever, be distributed to the exterior 
girders in a system utilizing a single-column bent. The AASHTO guidelines do not allow the distribution of any portion of the column overstrength moment to the exterior girders for any of the four prototype structures considered in this study.

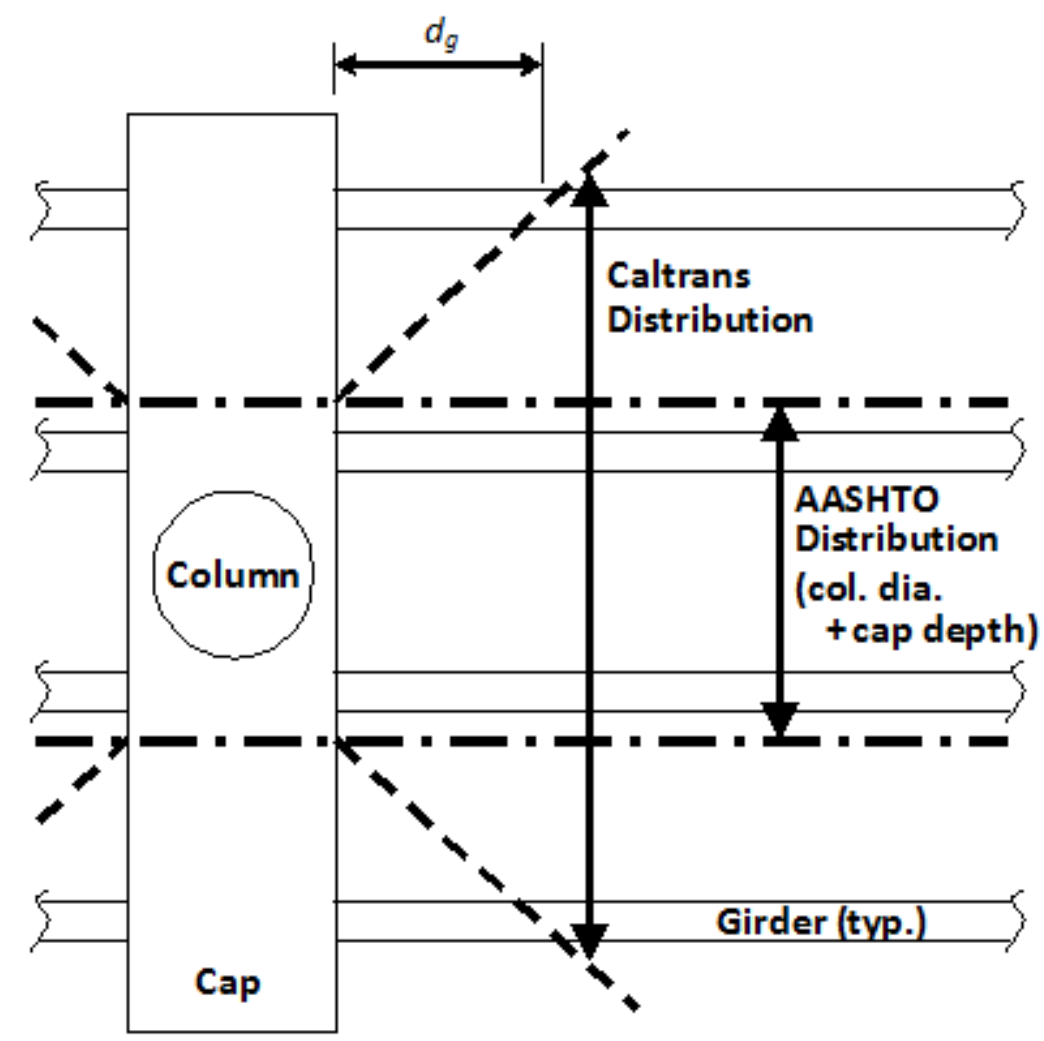

Figure 5.2. Distribution of column overstrength moment to girders (plan)

Focusing on Caltrans' approach to lateral load distribution, Chapter 5 of Caltrans' BDA (1995) offers no information in the BDA related to lateral load distribution. Section 7.2 in Caltrans' SDC follows the AASHTO recommendations for lateral distribution, while additionally recommending "the effective superstructure width can be increased at a $45^{\circ}$ angle [in plan] as [the distance increases] from the bent cap until the full section becomes effective." This modification is shown in Figure 5.2. This stipulation does not allow the distribution of the lateral load to the exterior girders at the cap-to-girder connection for all the prototype structures considered in this study and all similar integral bridge configurations. However, lateral load distribution would be permitted in regions where the longitudinal distance from the cap beam exceeds the girder spacing, identified in Figure 5.2 as $d_{g}$. 


\subsection{Analytical Approaches}

Detailed analytical models of integral bridge superstructures such as those incorporating a finite element analysis (FEA) can be helpful in understanding load distribution between girders. The bridge superstructure, including girders and cap beam, can be modeled using FEA, and the model can be used

to investigate load paths of both vertical load and horizontal seismic effects using the column overstrength moment (applied as a torsional load in the cap beam) through the superstructure. While a FEA can provide helpful results, they are typically cumbersome and time-consuming. A slightly simpler approach is to utilize a grillage model analysis (GMA). A GMA approach utilizes line elements for girder and cap beam elements, simplifying the modeling process while still providing opportunity to investigate the load paths through the superstructure. A third analysis approach uses member-stiffness-based calculations to approximate the distribution of gravity and seismic loads; this model is referred to as a simple stiffness model (SSM). The following sections provide an in-depth look at the analytical models used in this load distribution investigation.

\subsubsection{SSM Background}

The difference in load direction between vertical and horizontal loads produces differences in load transfer through a bridge superstructure. Vertical loads moving through the superstructure into the column will be transferred as flexural loads in both the girders and the cap beam. However, the column overstrength moment resulting from seismic lateral loads will produce both torsional and flexural actions in portions of the superstructure. These actions will include torsional loads in the cap beam, positive flexural loads in the girders on one side of the cap beam, and negative flexural loads in the girders on the opposing side of the cap beam. To account for these stiffness differences, two different SSMs are used for a given prototype structure. The first SSM for each structure is used to determine the distribution of the vertical load among the girders in the superstructure. The second SSM for each structure is used to investigate the distribution of the column overstrength moment. While the actual distribution is a combination of both actions, the vertical and lateral distribution behavior is separated to simplify the analysis.

\subsubsection{SSM for Vertical Load}

Figure 5.3a provides a schematic diagram of the vertical load distribution concept. This concept is used to analyze how the self-weight of the bridge transfers from the superstructure into the column, or 
vice versa, as a way to isolate this load behavior from the lateral load transfer occurring from large seismic accelerations. As such, the vertical load SSM presented here is not analogous to the commonlyused AAHSTO live load distribution factors for vertical load discussed earlier. The SSM is developed by estimating the appropriate stiffness of each of the individual elements, assuming rigid connections between the girder and cap, and developing an overall load distribution model. Because typical bridge superstructures tend to be symmetrical, calculating the stiffness for only half of each specimen is usually appropriate, as long as a suitable boundary condition is incorporated at the specimen centerline as shown in Figure 5.3b.

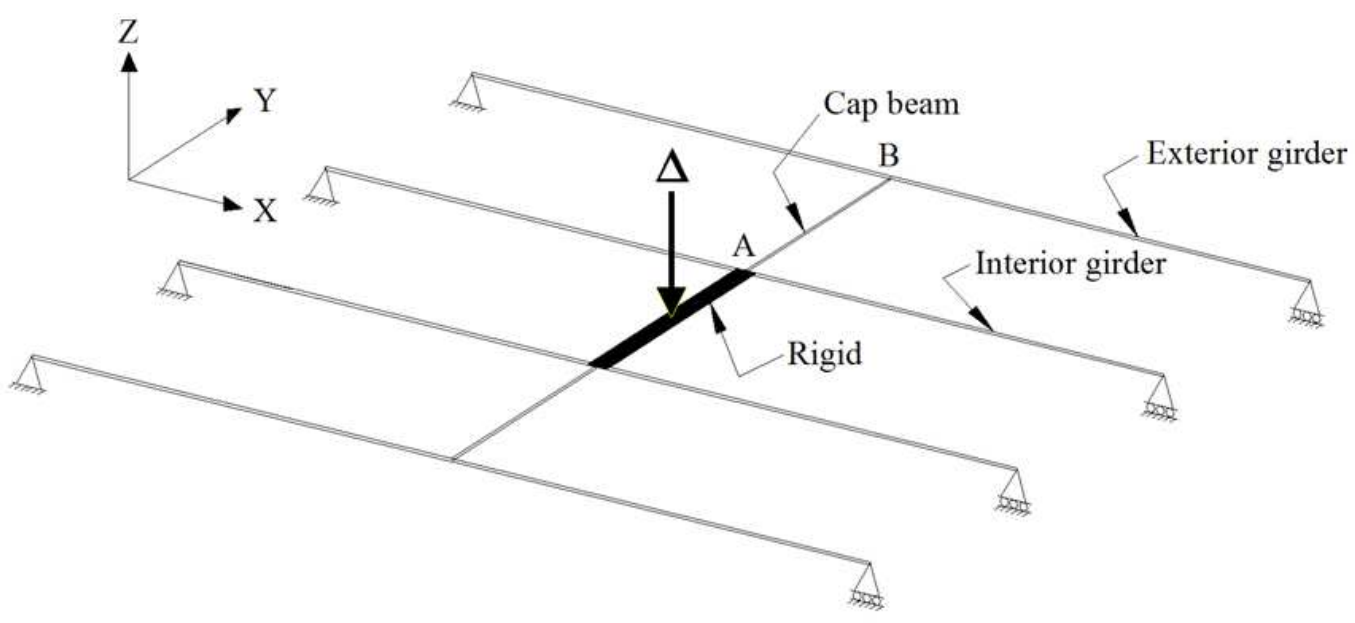

a. Overall schematic of specimen superstructure

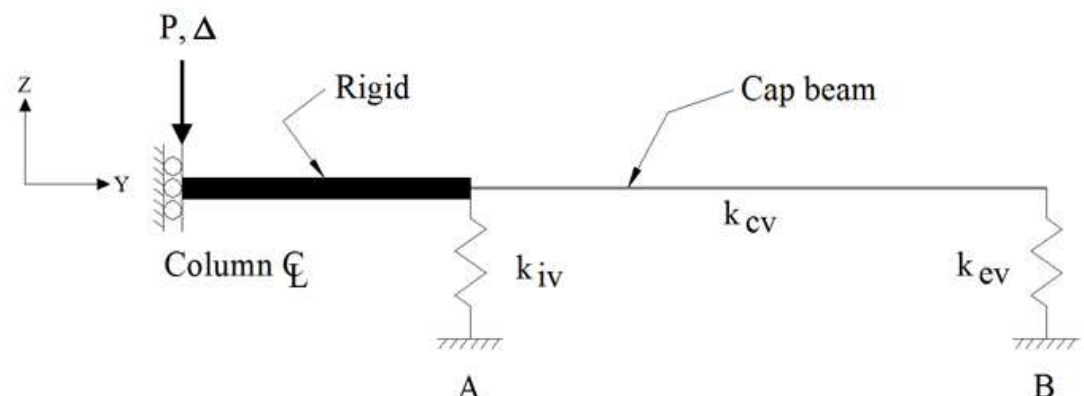

b. For development of vertical load distribution simple stiffness model (SSM)

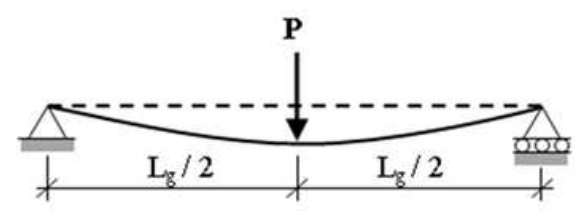

c. For determination of local girder stiffness

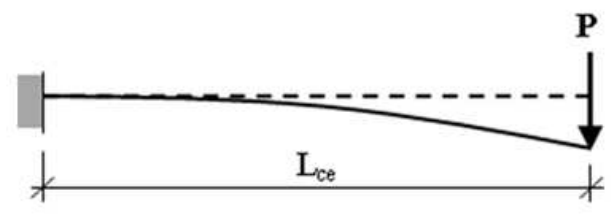

d. For determination of local cap beam stiffness

Figure 5.3. Vertical load distribution schematics 
The stiffness terms $k_{i v}$ and $k_{e v}$, for the interior and exterior girders, respectively, are defined as the magnitudes of flexural stiffness for the composite girder-deck sections, modeled as beams that are simply supported with concentrated vertical loads applied at their midspans, as shown in Figure 5.3c. Thus, using principles of basic mechanics, $\mathrm{k}_{\mathrm{iv}}$ and $\mathrm{k}_{\mathrm{ev}}$ can be determined using:

$$
\mathrm{k}=48 \mathrm{E}_{\mathrm{g}} \mathrm{l} / \mathrm{Lg}_{\mathrm{g}}^{3}
$$

where $E_{g}$ is the modulus of elasticity of the girder material, $l_{g}$ is the effective girder moment of inertia of either the interior or exterior girder, and $\mathrm{L}_{\mathrm{g}}$ is the girder span length. $\mathrm{I}_{\mathrm{g}}$ is based on the composite section of the girder and bridge deck, using cracked and uncracked concrete properties as appropriate. The resulting values of $k_{\mathrm{iv}}$ and $\mathrm{k}_{\mathrm{ev}}$ will likely not be equal because of the difference in tributary deck areas for the interior and exterior girders.

The cap beam flexural stiffness, $k_{c v}$, is determined by modeling the cap beam as a fixed-end cantilever beam with a concentrated vertical load applied at the free end as shown in Figure 5.3d, where the cantilever beam represents the portion of the cap beam between the interior girder and exterior girder. The relationship for $\mathrm{k}_{\mathrm{cv}}$ is:

$$
\mathrm{k}_{\mathrm{cv}}=3 \mathrm{El}_{\mathrm{c}} / \mathrm{L}_{\mathrm{ce}}
$$

where $E_{c}$ is the modulus of elasticity of the cap beam material, $I_{c}$ is the effective moment of inertia of the cap beam, and $L_{c e}$ is the length of the cap beam between the interior girder and the exterior girder.

An appropriate combined stiffness relationship can be developed by observing that, for a given configuration, the combined behavior of the various structural members will contribute to the resistance of a load in a manner either simultaneously parallel or sequentially in series with other individual member stiffness components. For example, referencing Figure $5.3 \mathrm{~b}$, the load $\mathrm{P}$, which is translated by the rigid center link, will be resisted in parallel by the flexural stiffness of the cap beam $\left(k_{c v}\right)$ and the flexural stiffness of Girder $A\left(k_{i v}\right)$, but the contribution of $k_{c v}$ from the cap beam will occur in series with the contribution from the flexural stiffness of Girder B ( $\left(k_{\mathrm{ev}}\right)$. The total stiffness of two components resisting a load in parallel is found by simply summing the two stiffness values. The total stiffness of two components resisting a load in series is found by dividing the product of the stiffness 
values by the sum of the stiffness values. Therefore, the equivalent stiffness, $k_{\text {vert }}$ for the scenario represented in Figure 5.3b is given by:

$$
k_{\text {vert }}=\left(k_{\mathrm{ev}} k_{\mathrm{cv}}\right) /\left(k_{\mathrm{ev}}+k_{\mathrm{cv}}\right)+k_{\mathrm{iv}}
$$

using the stiffness terms defined in Eqs. 5.1 and 5.2. The combined behavior of the external portion of the cap beam and the exterior girder, excluding the contribution of the interior girder, can be represented as:

$$
k_{e v+c v}=\left(k_{e v} k_{c v}\right) /\left(k_{e v}+k_{c v}\right)
$$

To determine the load distribution among the girders, the fractional relationships of appropriate stiffness terms are used to determine the fractional load expected in a particular girder. For example, for a symmetrical four-girder integral structure with stiffness terms determined as described above, the vertical load will be carried through two load paths (one through the interior girder and one through the cap beam and exterior girder). Therefore, the fractional load distribution to the interior girder is:

$$
D F_{\text {int }}=k_{\text {vert }} /\left(k_{\text {vert }}+k_{\text {evtcv }}\right)
$$

and the fractional load distribution to the exterior girder is:

$$
D F_{e x t}=k_{e v+c v} /\left(k_{v e r t}+k_{e v+c v}\right)=1-D F_{i n t}
$$

The accuracy of this approach depends on the appropriateness of the individual stiffness values used. Much work has been completed related to appropriate section properties to use for reinforced concrete sections, and some of this work has been devoted specifically to the behavior of reinforced concrete under seismic loading (see especially Priestley et al. 1996). In this study, since seismic behavior is of primary importance, composite section properties were determined assuming cracked concrete properties. Accordingly, the contribution of concrete on the tension side of the neutral axis was neglected in the determination of flexural section properties, following Priestley's approach. 


\subsubsection{SSM for Lateral Load}

The SSM for lateral load distribution can be used to determine the distribution of the column overstrength moment through the superstructure. A schematic of the horizontal load distribution concept is shown in Figure 5.4a. Symmetry again typically allows a half-model, as shown in Figure 5.4b. The column overstrength moment is represented here as a torsional load in the cap beam. The applicable stiffness values are $k_{i t}$ and $k_{\text {et }}$ (interior and exterior girder flexural stiffness) and $k_{c t}$ (cap beam torsional stiffness). The girder stiffness values are determined by the girder flexural behavior as shown in Figure 5.4c. Cracked and uncracked concrete properties are of particular interest in these stiffness values, since the bridge deck is in tension on one side of the cap beam and compression on the other side. Since the girders on each side of the cap beam act in parallel with each other, the girder stiffness values are:

$$
\mathrm{k}=3 \mathrm{E} \mathrm{I}_{\mathrm{gu}} /\left(\mathrm{L}_{\mathrm{g}} / 2\right)+3 \mathrm{E} \mathrm{I}_{\mathrm{gc}} /\left(\mathrm{L}_{\mathrm{g}} / 2\right)
$$

where $\mathrm{I}_{\mathrm{gu}}$ is the moment of inertia considering the deck concrete to be uncracked and $\mathrm{I}_{\mathrm{gc}}$ is the moment of inertia with cracked deck concrete. The torsional stiffness of the cap is determined based on the theoretical model shown in Figure 5.4d, resulting in:

$$
\mathrm{k}_{\mathrm{ct}}=\mathrm{GJ} / \mathrm{L} \mathrm{ce}
$$

where $G J_{c}$ represents the torsional rigidity of the cap beam. For the concrete cap beams in this study, the recommendation of Priestley et al. (1996) to use $0.05 \mathrm{~J}$ (where $\mathrm{J}$ is the polar moment of inertia) for cracked sections was used to determine $J_{c}$.

The resulting total stiffness value for the typical lateral load configuration, $k_{\text {lat, }}$ and stiffness value related to the cap and exterior girder contribution, $\mathrm{k}_{\mathrm{et}+\mathrm{ct}}$, are:

$$
\begin{gathered}
k_{\text {lat }}=\left(k_{e t} k_{c t}\right) /\left(k_{e t}+k_{c t}\right)+k_{i t} \\
k_{e t+c t}=\left(k_{e t} k_{c t}\right) /\left(k_{e t}+k_{c t}\right)
\end{gathered}
$$

and the lateral load distribution factors are: 


$$
\begin{gathered}
D F_{\text {int }}=k_{\text {lat }} /\left(k_{\text {lat }}+k_{\text {et+ct }}\right) \\
D F_{\text {ext }}=k_{\text {et }+c t} /\left(k_{\text {lat }}+k_{\text {et }+c t}\right)=1-D F_{\text {int }}
\end{gathered}
$$

These distribution factors can be used to estimate the fractional load distribution of the column overstrength moment to the interior and exterior girders, respectively.

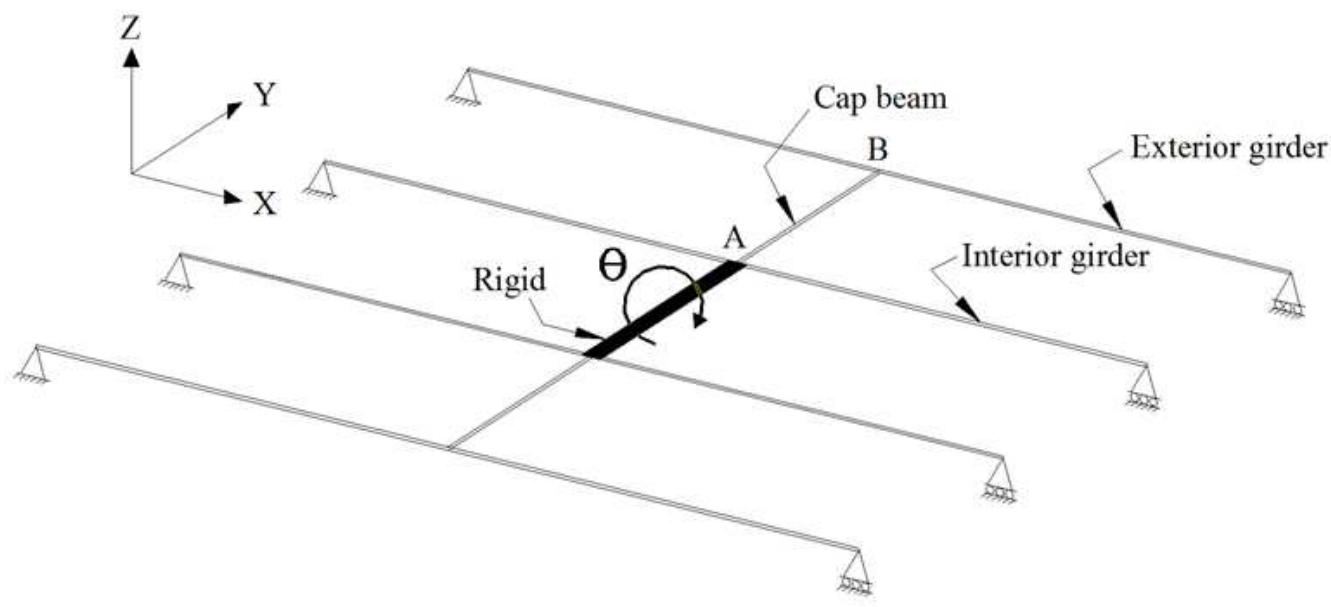

a. Overall schematic of specimen superstructure

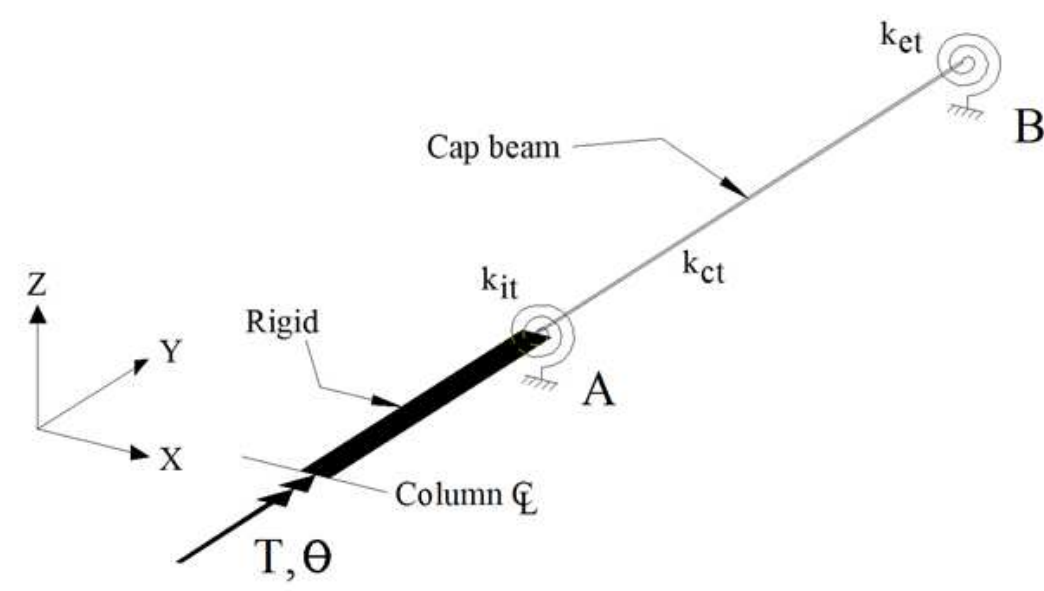

b. For development of lateral load distribution simple stiffness model (SSM)

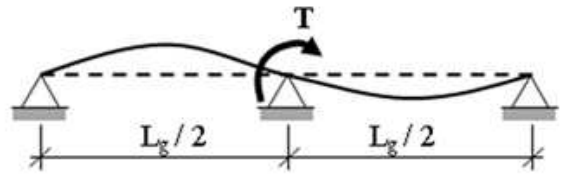

c. For determination of local girder stiffness

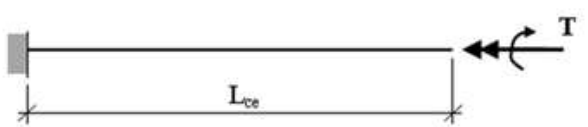

d. For determination of local cap beam stiffness

Figure 5.4. Lateral load distribution schematics 


\subsubsection{Grillage and FEA Models}

Grillage model analyses (GMAs) were conducted for each of the experimental studies considered in this work. The results from these GMAs are used for comparison with the SSM approach and the experimental results from each test unit. Figure 5.5 shows a schematic of the GMA used for the ITB model (Snyder et al. 2011). Member section properties for the line elements in this GMA are calculated using composite section properties, incorporating cracked or uncracked concrete properties similar to the approach described for the SSM calculations in the preceding section. Nonlinear springs are also incorporated in GMA, located in the plastic hinge regions of the reinforced concrete column. The spring behavior is defined by using appropriate analytical methods to determine moment-rotation behavior for the spring based on the predicted moment-curvature for the column section in the plastic hinge region (see Priestley et al. 1996, for example). Similar GMAs have been conducted for each of the test units used in this study. Information on the grillage model for the PBT study can be found in Holombo et al. (2000) and for the SPC study in Wassef et al. (2004).

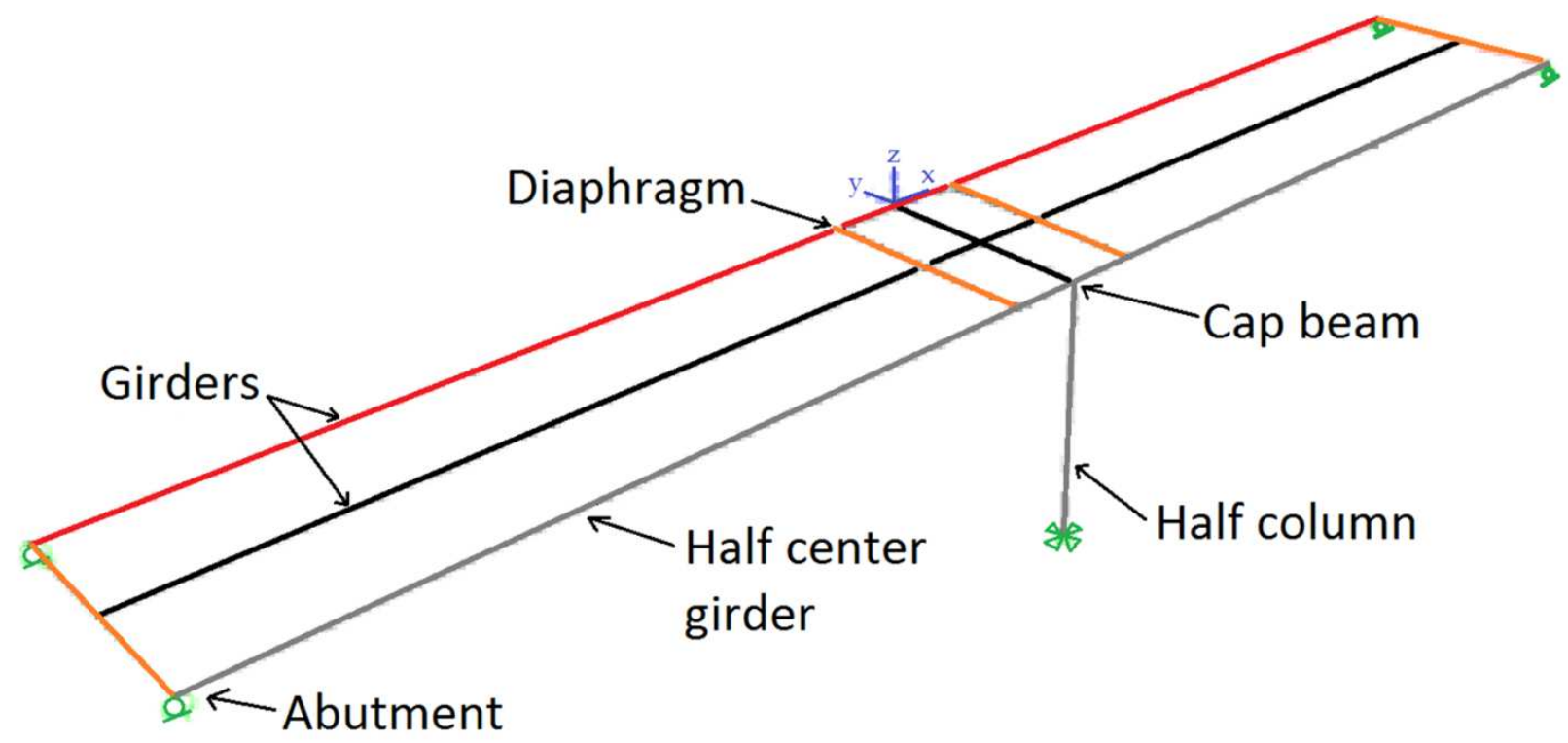

Figure 5.5. Grillage model for ITB test unit

All the GMAs included the contributions of the slab and diaphragm members to provide limited transverse continuity between girders. The deck and diaphragm contribution is at times observed to play a noticeable role in the load distribution among girders. The deck contribution in particular affects load distribution in the structures likely to experience degradation in the connections, since the 
connection deterioration produces variation in stiffness among the girders. When a stiffness difference exists among the girders, the deck contribution appears to play a larger role in transferring load from girder to girder. In the ITB study, a detailed FEA model was also developed in parallel with the GMA. Detailed information on this FEA work can be found in Theimann (2009). The FEA analysis results are not identical to the GMA results, but they confirm that inclusion of deck and diaphragm elements can affect the lateral load distribution results.

The stiffness-based SSM approach, described in the preceding section, is not well-suited to include the contribution of transverse elements such as deck and diaphragm. This limitation is a result of using stiffness values based on beam elements that are representative of individual, isolated girders. However, as will be seen in the results presented later, the SSM approach can still be a very serviceable option in predicting load distribution.

\subsection{Summary of Large-Scale Tests}

All the studies in this work included large-scale test units intended to examine and quantify system performance. All the test units modeled prototype structures utilizing an integral bent cap and a single reinforced concrete column. The prototype structures, presented earlier in Figure 5.1, were modeled experimentally to examine and quantify performance of the PBT, ITB, and SPC systems. Figure 5.6 shows the configuration for the ITB test unit. Detailed information on the test configuration and experimental results can be found in Holombo et al. (2000) for the PBT test, Sritharan et al. (2005) for the SPC tests, and Snyder et al. (2011) for the ITB test. 


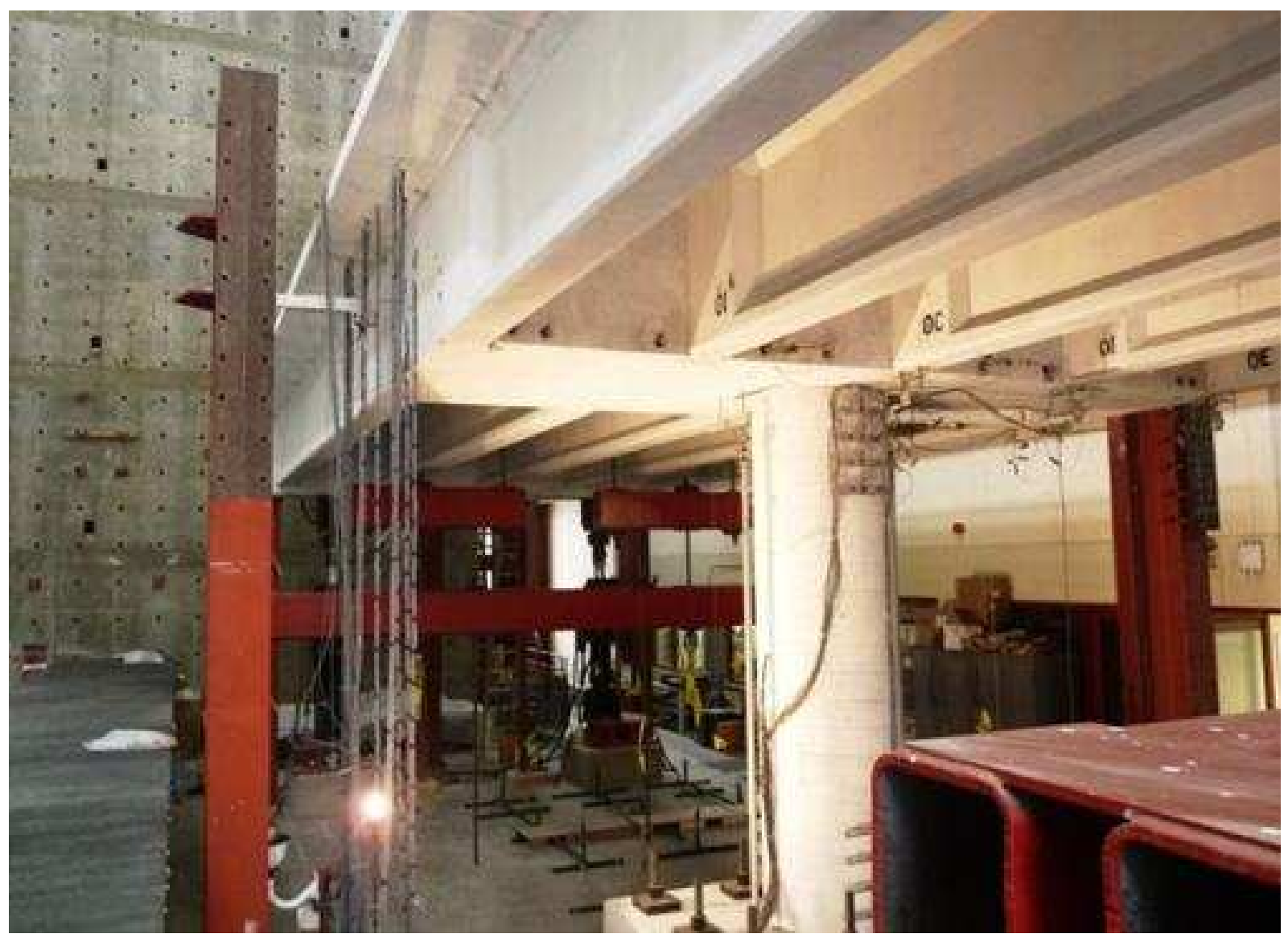

Figure 5.6. Test unit for ITB model

\subsubsection{PBT Test Unit}

The test unit for the PBT study was constructed as a 40-percent scale representation of a prototype bridge utilizing precast, prestressed concrete bulb-tee girders. The test unit modeled the prototype bridge from midspan to midspan of the two spans adjacent to the center bent. The test unit included the reinforced concrete column, the post-tensioned concrete cap beam, and portions of the girders extending across the cap beam to a scaled distance equivalent to the midspan of the prototype center spans. The load-displacement for the horizontal seismic loading is shown in Figure 5.7a. The test unit was observed to exhibit very good seismic behavior, retaining strength up to a lateral displacement ductility $\mu_{\Delta}=8$. 


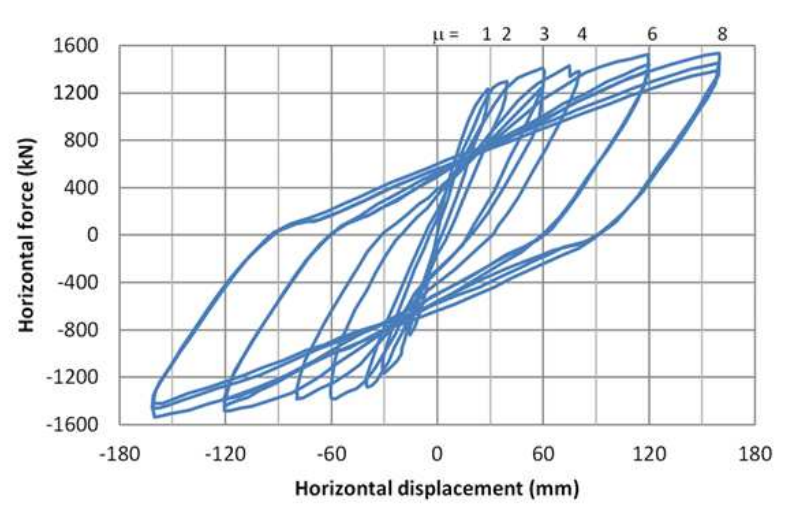

a. PBT test unit, data from Holombo et al. (2000)

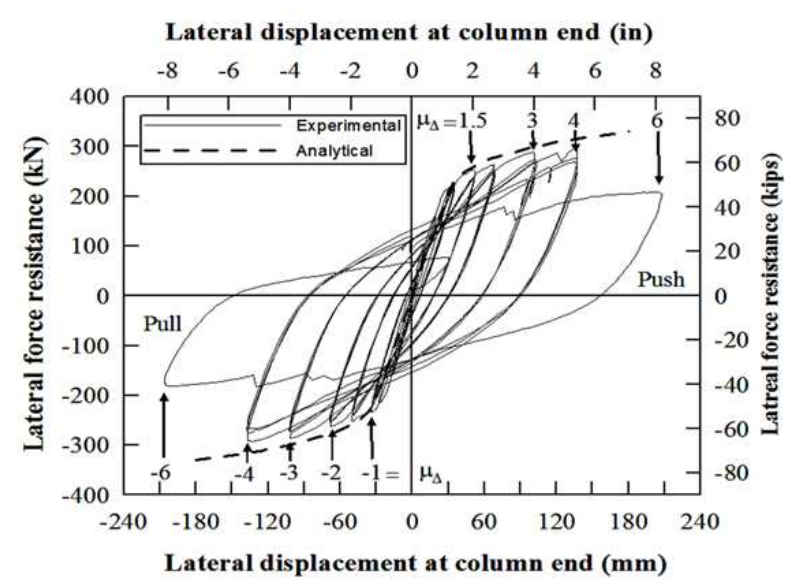

b. SPC1 test unit, Sritharan et al. (2005)

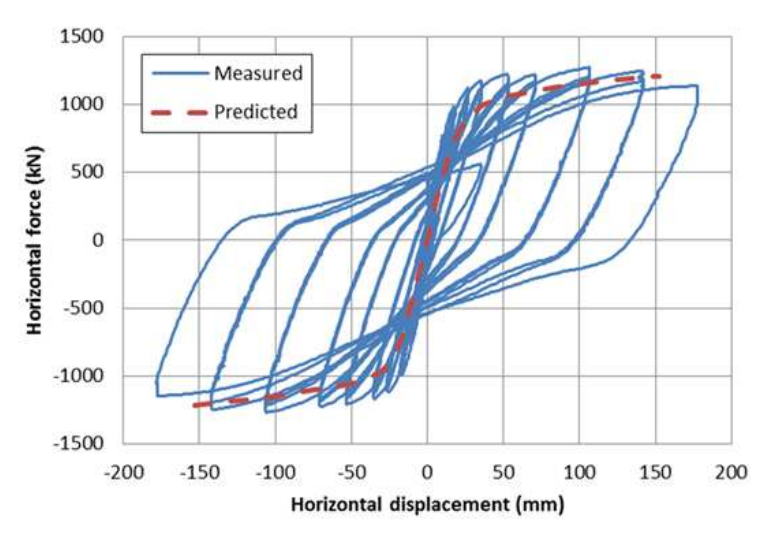

d. ITB test unit, Snyder et al. (2011)

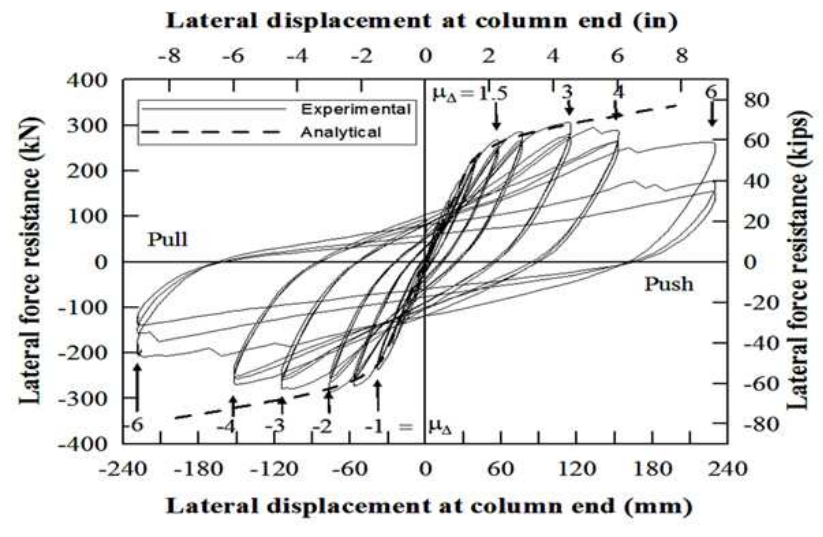

c. SPC2 test unit, Sritharan et al. (2005)

Figure 5.7. Horizontal load-displacement responses from experimental studies

\subsubsection{SPC Test Units}

Test units SPC1 and SPC2 were constructed for the NCHRP study. Both test units were similar, except SPC2 was designed and constructed with a reduced superstructure depth. The test units were built in an inverted configuration to simplify the laboratory setup and loading. These test units were one-third-scale representations of the region surrounding the center bent of a prototype bridge consisting of steel I-girders and a steel box-shaped cap beam. The test units included a reinforcedconcrete column, steel box beam pier cap, and steel girders extending to the midspan of the spans adjacent to the column. To account for the dead load in the inverted position, a vertical load was applied to the reinforced concrete column at its top (in the test orientation). 
Figure 5.7b and Figure 5.7c provide the load-displacement hysteresis behavior for SPC1 and SPC2 when subjected to simulated horizontal seismic loading. The test units were both observed to perform well. The superstructure in SPC1 exhibited elastic response throughout the duration of the test, and a plastic hinge was successfully formed in the column. The horizontal load test showed the structure to retain full strength up to target ductility, $\mu_{\Delta}=4$, and reduced strength with no stability failure up to ductility $\mu_{\Delta}=6$. Longitudinal bar buckling and subsequent fracture just below the cap beam was observed to be the primary failure mechanism. SPC2 also exhibited good overall seismic behavior. Stresses in the superstructure were observed to remain elastic throughout the horizontal test, and the structure also retained close to full strength up to ductility 4 , with significant strength, although reduced, at ductility 6 . The primary failure mechanism in SPC2 was the fracture of mechanical anchorage of the column longitudinal bars in the bridge deck near the cap beam.

Both SPC1 and SPC2 were subjected to service-level loading prior to the seismic loading. In these service level tests, vertical load and horizontal load were applied separately. Data from these tests, including girder strains and girder reactions, have been used to compile the results presented in the distribution comparisons later in this paper.

\subsubsection{ITB Test Unit}

The half-scale test unit for the ITB study modeled a portion of the reinforced concrete column, the cast-in-place concrete cap beam, and the central portion of the five precast concrete l-shaped girders on both sides of the cap beam. Two different integral connection details between the girders and cap beam were utilized, one on one side of the cap beam and the other on the opposite side. The first detail implemented a design that has already been used by Caltrans, referred to as the "as-built" connection. The connection detail on the other side of the cap beam was similar but incorporated an unstressed post-tensioning tendon to provide continuity for the positive-moment tension reinforcement through the connection. The tendon passed through the bottom flange of the girder and the cap beam corbel and then terminated on the far side of the cap beam. This connection is referred to as the "improved" connection. Although data was gathered from both the as-built and improved details, the data used in the distribution analysis presented in this paper are from only the improved connection portion of the test unit. The as-built data has been omitted since the improved connection configuration is likely more representative of future bridges based on this concept. 
Figure $5.7 \mathrm{~d}$ shows the load-displacement hysteresis for the test unit when subjected to simulated horizontal seismic loading. The system was observed to perform very well. The superstructure provided sufficient strength to successfully form plastic hinges in the column, and the structure maintained strength up to displacement ductility $\mu_{\Delta}=8$ with only minor strength loss at ductility $\mu_{\Delta}=10$. The loaddisplacement hysteresis and high displacement ductility attained by the test unit show that the girderto-cap connection performed well, remaining elastic while allowing full development of the column plastic hinges.

\subsection{Comparison of Analytical and Experimental Load Distributions}

\subsubsection{Vertical Load}

Using the approach described in the "Analytical Approaches" section, SSMs have been developed for each of the test units to investigate the distribution of the moment in the girders due to the vertical load. In addition, results from GMAs of each of the test units also have been used to look at the distribution of moment due to vertical load. Finally, the experimental results from each of the test units, summarized above, have been incorporated to further validate the analytical models.

Table 5.1 provides a compilation of the distribution of moment due to vertical load in the SPC and ITB test units, including experimental data, grillage model predictions, and SSM predictions. (The PBT test unit was not included in this comparison since corresponding experimental data was not available.) Also included in this table are the distribution ratios from AASHTO (2010), representing the current design recommendations. The design ratios included in this table are determined using the AASHTO specifications for live load distribution factors, even though these factors are not directly comparable to the results from the vertical SSM analysis as mentioned previously. 
Table 5.1. Vertical load distribution comparison

\begin{tabular}{|c|c|c|c|c|c|c|c|}
\hline \multirow{2}{*}{ Parameters } & \multicolumn{2}{|c|}{ SPC 1 } & \multicolumn{2}{c|}{ SPC 2 } & \multicolumn{3}{c|}{ ITB } \\
\cline { 2 - 8 } & Interior & Exterior & Interior & Exterior & Center & Intermediate & Exterior \\
\hline $\begin{array}{c}\text { Experimental } \\
\text { Ratio }\end{array}$ & 0.258 & 0.242 & 0.268 & 0.233 & 0.208 & 0.195 & 0.2 \\
\hline $\begin{array}{c}\text { Design Ratio } \\
\text { Design } \\
\text { Difference }\end{array}$ & 0.271 & 0.229 & 0.271 & 0.229 & 0.203 & 0.203 & 0.196 \\
\hline $\begin{array}{c}\text { Grillage } \\
\text { Ratio }\end{array}$ & 0.275 & $-5.0 \%$ & $1.1 \%$ & $-1.3 \%$ & $-2.4 \%$ & $4.1 \%$ & $-2.0 \%$ \\
\hline $\begin{array}{c}\text { Grillage } \\
\text { Difference }\end{array}$ & $6.5 \%$ & $-6.9 \%$ & $1.9 \%$ & $-2.2 \%$ & $1.4 \%$ & $12.3 \%$ & $-12.0 \%$ \\
\hline $\begin{array}{c}\text { SSM Ratio } \\
\text { SSM }\end{array}$ & 0.258 & 0.242 & 0.253 & 0.247 & 0.208 & 0.2 & 0.196 \\
\hline $\begin{array}{c}\text { SSM } \\
\text { Difference }\end{array}$ & $0.0 \%$ & $0.0 \%$ & $-5.4 \%$ & $6.2 \%$ & $0.0 \%$ & $2.6 \%$ & $-2.0 \%$ \\
\hline
\end{tabular}

The ratios for the experimental and analytical distributions reported in this table are determined on the basis of total load in all girders. Hence, for a five-girder structure, if each of the five girders would carry the same amount of load, the resulting ratio would be 0.20 for the center girder, 0.20 for each of the two intermediate girders, and 0.20 for each of the two exterior girders. The "difference" listed for each model in the table is the percentage difference between the analytical prediction and the experimental result.

The predictions in Table 5.1 from the design recommendations for live load distribution, the grillage analyses, and the SSM analyses all compare favorably with the measured experimental results. This favorable comparison is notable, since the design recommendation values are actually intended for live load distribution rather than for vertical load transfer during seismic loading. The values determined by current design recommendations for live load distribution vary a maximum of $5 \%$ from the experimental values. The SSM predictions are similar, with a maximum difference of $6.2 \%$. The largest discrepancy occurs in the grillage prediction for the ITB model, with a difference of approximately $12 \%$ in the predicted and experimental values for the intermediate and exterior girders.

\subsubsection{Horizontal Load}

For the lateral load SSMs, the approach presented in the "SSM for Lateral Load" section has been followed, except the model is altered slightly for the five-girder ITB structure. Because of the direct 
connection of the column, center girder, and cap beam, the general SSM approach is found to overestimate the load distribution to the center girder. Therefore, the predicted distribution of the load to the center girder is determined by comparing only the girder stiffness values and not the overall system stiffness values (resulting in a distribution of 0.20 to the center girder). Once the center girder distribution is predicted in this way, the SSM as presented is used to predict the intermediate and exterior girder distributions.

Results from the grillage model analyses of each of the test units have also been incorporated to predict the distribution of the lateral load moment. Experimental results from each of the test units are then compared to both the SSM and grillage analytical predictions along with the current design recommendations for lateral load distribution. Since none of the test units were subjected to horizontalload-only conditions, the horizontal-load-only experimental values have been determined by removing the vertical load contribution from the recorded strain or load data. This process has been accomplished by carefully identifying the zero-horizontal-load instances during each cycle of the horizontal load tests. The measured strains and displacements at these instances have been identified as vertical-load-only data. Subsequently, the vertical-load-only data has been found to be acceptably consistent throughout the lateral load test. Thus, for the portions of the test where lateral load was present, the vertical-loadonly data is used to bias the overall data and provide the horizontal-load-only data.

Table 5.2 lists the experimental values, analytical predictions, and current design recommendations for seismic lateral load only. The reported experimental distribution values have been established at the first peak displacements by comparing the strain increase in each girder as the lateral load was increased from zero to the load corresponding to the target displacement during each displacement half cycle. 
Table 5.2. Lateral load distribution comparison

\begin{tabular}{|c|c|c|c|c|c|c|c|c|c|}
\hline \multirow{2}{*}{ Parameters } & \multicolumn{2}{|c|}{ PBT } & \multicolumn{2}{c|}{ SPC 1 } & \multicolumn{2}{c|}{ SPC 2 } & \multicolumn{3}{c|}{ ITB } \\
\cline { 2 - 10 } & Interior & Exterior & Interior & Exterior & Interior & Exterior & Center & Interm. & Exterior \\
\hline $\begin{array}{c}\text { Experimental } \\
\text { Ratio }\end{array}$ & 0.334 & 0.166 & 0.333 & 0.167 & 0.350 & 0.150 & 0.205 & 0.239 & 0.158 \\
\hline $\begin{array}{c}\text { Design } \\
\text { Ratio }\end{array}$ & 0.5 & 0 & 0.5 & 0 & 0.5 & 0 & 0.333 & 0.333 & 0 \\
\hline $\begin{array}{c}\text { Design } \\
\text { Difference }\end{array}$ & $49.9 \%$ & $-100.0 \%$ & $52.1 \%$ & $-100.0 \%$ & $42.9 \%$ & $-100.0 \%$ & $62.4 \%$ & $39.3 \%$ & $-100.0 \%$ \\
\hline $\begin{array}{c}\text { GMA } \\
\text { Ratio }\end{array}$ & 0.344 & 0.156 & 0.360 & 0.140 & 0.349 & 0.151 & 0.228 & 0.212 & 0.174 \\
\hline $\begin{array}{c}\text { GMA } \\
\text { Difference }\end{array}$ & $2.9 \%$ & $-6.4 \%$ & $7.5 \%$ & $-19.3 \%$ & $-0.003 \%$ & $0.01 \%$ & $2.3 \%$ & $-12.7 \%$ & $9.2 \%$ \\
\hline $\begin{array}{c}\text { SSM } \\
\text { Ratio }\end{array}$ & 0.305 & 0.195 & 0.369 & 0.131 & 0.353 & 0.147 & 0.200 & 0.239 & 0.158 \\
\hline $\begin{array}{c}\text { SSM } \\
\text { Difference }\end{array}$ & $-9.5 \%$ & $17.1 \%$ & $9.8 \%$ & $-23.7 \%$ & $0.01 \%$ & $-1.7 \%$ & $-2.4 \%$ & $0 \%$ & $0 \%$ \\
\hline
\end{tabular}

As with the information in Table 5.1, the data in this table are reported on the basis of load ratio in each of the individual girders compared to the total load experienced in all girders. The first observation regarding these numbers is the striking dissimilarity of the design ratio numbers to the actual experimental values. Current design recommendations allow lateral load distribution among only the center and intermediate girders of the ITB structure, which is the only five-girder structure included in this investigation. However, an examination of the experimental data reveals that $15.8 \%$ of the lateral load was carried by each of the exterior girders, i.e., the two exterior girders together carried almost $32 \%$ of the total lateral load moment. The strains used to determine these distributions were measured directly above the connection interface and at a location approximately $450 \mathrm{~mm}$ along the girder from the connection interface. Caltrans' current recommendations would not allow distribution of the load to the exterior girders until reaching a distance of approximately $990 \mathrm{~mm}$ from the connection (the distance corresponding to $d_{g}$ in Figure 5.2 presented earlier). Hence, the measured distributions clearly show the distribution is happening sooner than the current recommended practice.

The data from the four-girder structures (PBT, SPC 1, and SPC 2) reveal even less correlation with the current design recommendations. For these structures, current design guidelines allow no distribution of lateral load to the exterior girders in the connection region; however, the experimental results show that $30 \%, 33 \%$, and $34 \%$ of the total lateral load moment is distributed to the exterior girders in the PBT, 
SPC 1, and SPC 2 test units, respectively. The results indicate that current design recommendations are overly conservative in confining the lateral load only to the interior girders adjacent to the column.

While the analytical predictions for each of the four structures considered have some discrepancy, the results from the SSMs and GMAs from all four of the structures compare better with the experimental results than the current design recommendations do. Looking at the GMAs, the maximum difference between the predicted ratios and the experimental ratios is 0.03 , whereas the design recommendations consistently differ from the experimental ratios by 0.15 or more. The SSMs also provide much better comparisons to the experimental results than current design predictions, with a maximum ratio discrepancy of about 0.04 . The experimental results validate the predictions of both the GMAs and SSMs, showing that large portions of the lateral load are indeed distributed beyond the girders immediately adjacent to the column.

\subsection{Lateral Load Distribution at Various Load Levels}

Data gathered from the SPC2 and ITB tests are helpful in investigating whether the lateral load distribution occurs consistently at low and high seismic load levels. Figure 5.8 shows the experimental load distribution for SPC2 for the peak conditions throughout the test, beginning at service load levels and continuing through several cycles of plastic deformation. The girder load distribution to the exterior girders is seen here to begin almost immediately, at the first recorded load level. The load level at this point of the test is only $0.25 \mathrm{~F}_{\mathrm{y}}$, with $\mathrm{F}_{\mathrm{y}}$ representing the lateral yield of the test unit. The exterior girders even at this early stage are carrying approximately 30 percent of the lateral load. Observed flexural cracking of the concrete across the entirety of the deck width prior to the $1.0 \mathrm{~F}_{\mathrm{y}}$ load level also indicates the engagement of all the girders in carrying the lateral load. The distribution to the exterior girders remains quite consistent throughout the duration of the load test. Thus, the SSM and GMA predictions for the superstructure are useful not only at high levels of seismic loading but also at service load levels. 


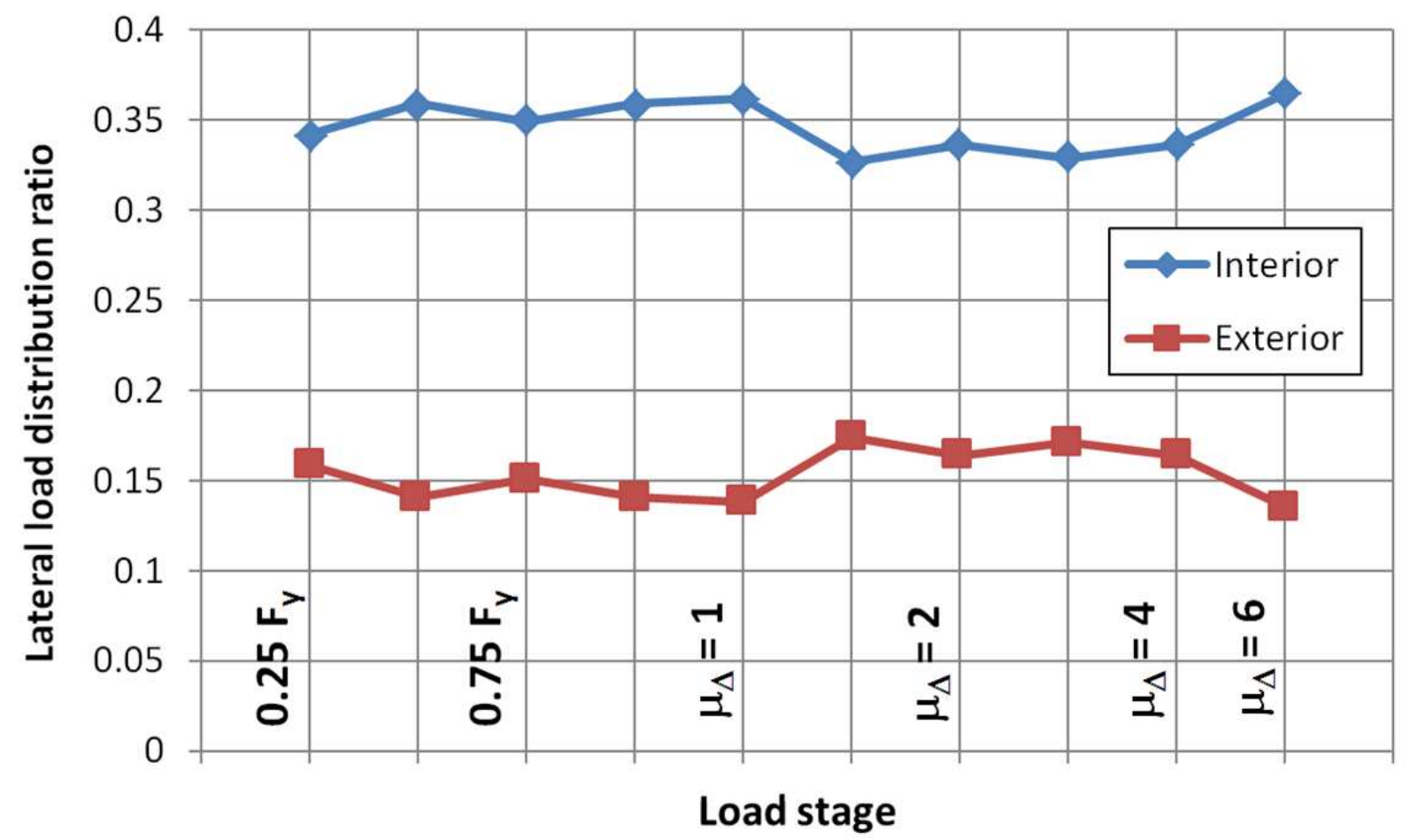

Figure 5.8. Experimental load distribution for SPC2

Figure 5.9 provides the load distributions at various load levels for the ITB test unit. These results show significant and relatively consistent distribution to all girders. The exterior girders are shown, at the very first peak load recorded, to individually carry 15 percent (30 percent combined) of the total lateral load. These results concur with the results from SPC2. Although there is a bit of irregularity in the distribution for the low loads, likely related to initial cracking and softening, significant distribution is observed at the early stages of loading followed by more uniform distribution for all of the higher peak conditions. 


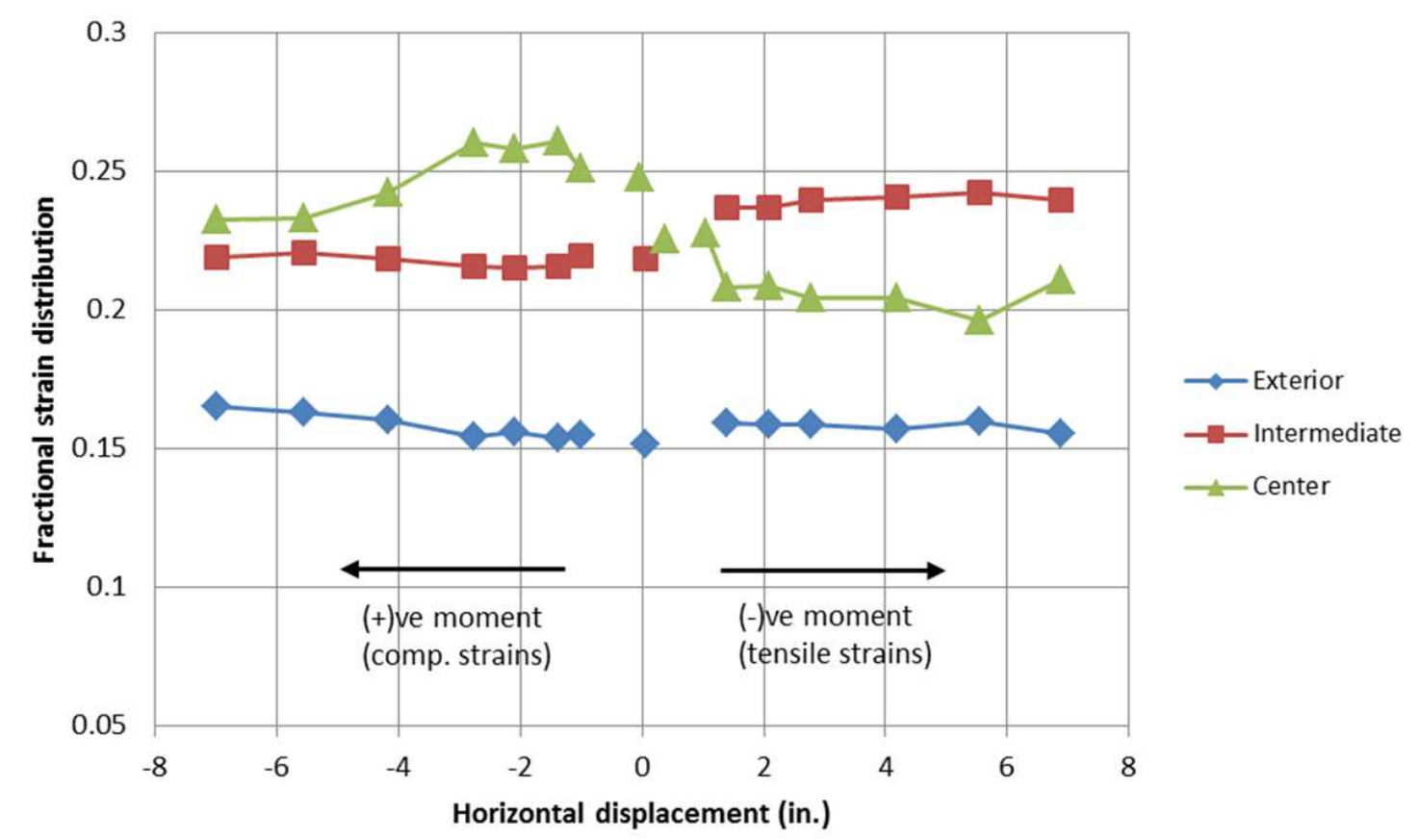

a. Peak displacements during entire Phase I test

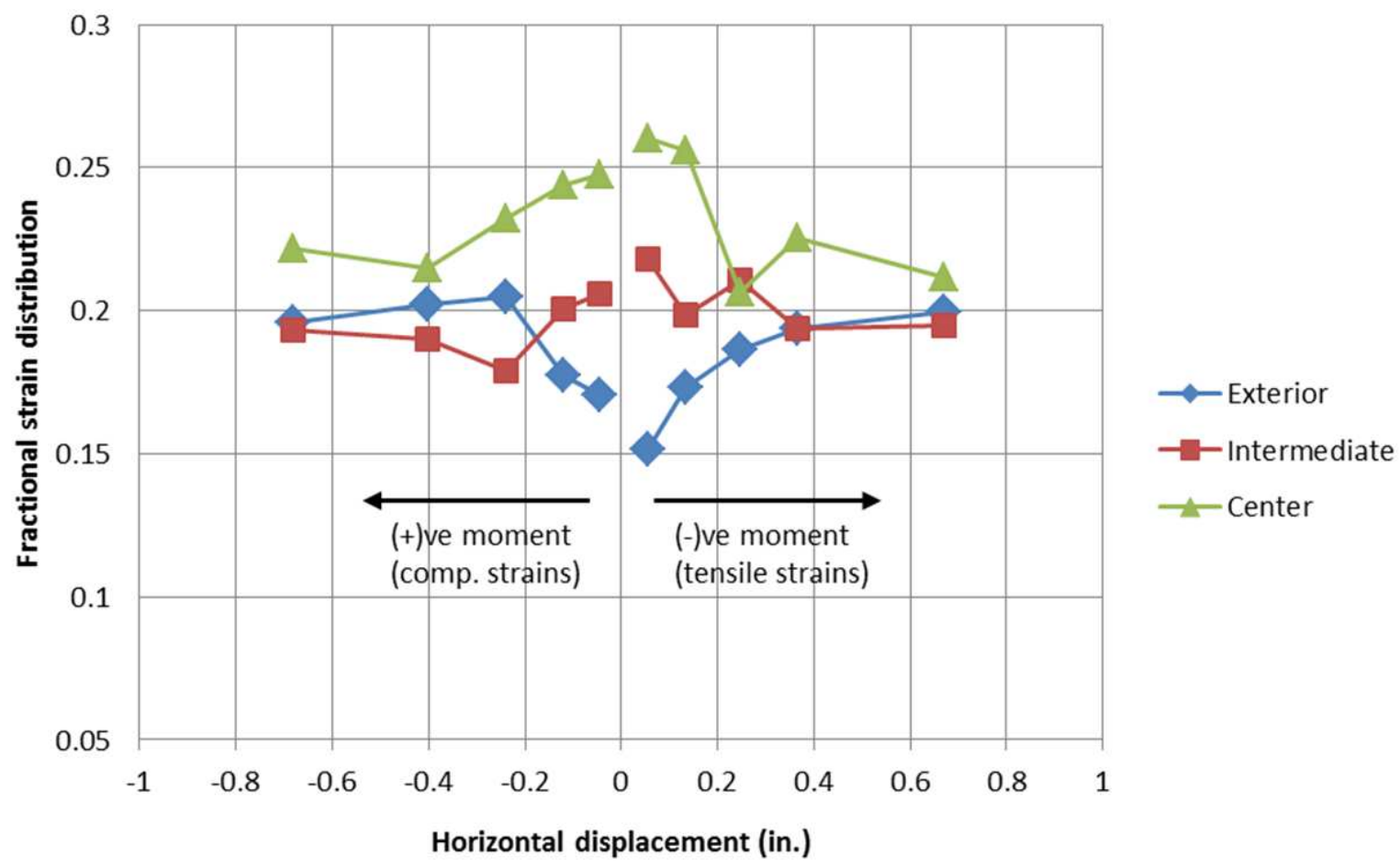

b. Peak displacements during low-load portion of Phase I test

Figure 5.9. Experimental load distribution for ITB test unit 


\subsection{Recommended Model for Lateral Load Distribution}

The work presented here shows the SSM is useful for predicting lateral load distribution for bridges with integral girder-to-cap connections. The SSM can provide a simple approach for determining more realistic lateral load distribution than the current design recommendations. Based on the SSM results presented previously, a suitable approach is to use the SSM prediction for all girders along with an appropriate variability margin. If $\alpha$ is introduced as a variability factor, and $D_{S S M}$ is defined as the girder distribution factors determined from Eqs. 5.11 and 5.12 as appropriate, the recommended distribution factor, $\mathrm{DF}_{\text {recom, }}$ can be defined as:

$$
\mathrm{DF}_{\text {recom }}=\alpha \mathrm{DF}_{\mathrm{SSM}}
$$

The variability factor, $\alpha$, is introduced to provide a safety margin since the simple model is not intended to be an exact representation of all the complexities of the real structure. Trial-and-error reveals that a value of 1.2 provides good results for the four structures in this study; similar studies could be used to further refine this variability factor. Using $\alpha=1.2$ and the interior fractional distribution values from Table 5.2 for each test unit, the recommended distributions for the interior girders in this study are $0.37,0.44,0.42$, and 0.29 , respectively, for the PBT, SPC1, SPC2, and ITB test units. The ratios of these recommended distributions to the measured experimental distributions range from 1.10 for the PTB test unit to 1.34 for the SPC1 test unit. The recommended distributions are shown graphically in Figure 5.10 ("Proposed") along with the current AASHTO/Caltrans approach ("Current") and compared with the experimental, GMA, and SSM predictions. Examining the data from the interior girders in the PBT test unit, the ratio of the current recommendation to the experimental distribution is 1.50 . However, the ratio of the proposed recommendation to the experimental distribution is 1.10 . Thus, when compared with current design recommendations, the SSM prediction for the PBT structure compares $40 \%$ more favorably with the experimental results. The improvements of the SSM model in distribution prediction for the SPC1, SPC2, and ITB structures are $17 \%, 22 \%$, and $19 \%$, respectively. 


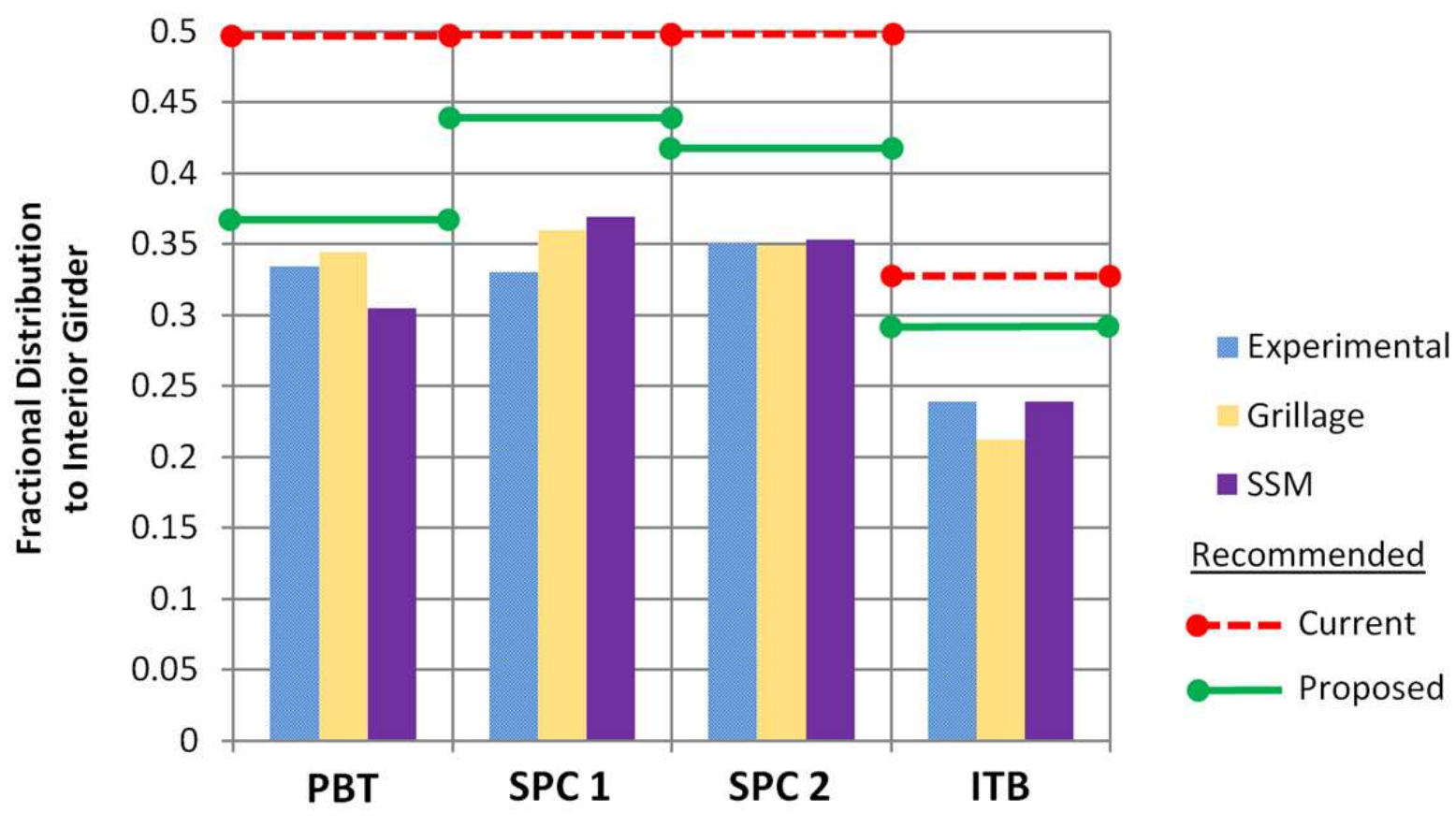

Figure 5.10. Distribution comparison for interior girder lateral load

\subsection{Conclusions}

This study focused on the development of simple stiffness models (SSMs) to predict seismic load distribution between girders in integral bridge superstructures. The conclusions drawn from this study are presented below:

1. Current practice and recommendations related to vertical distribution of dead load and vehicle live load are appropriate. Under high seismic horizontal displacements, the experimental girder strain values due to vertical load increase, but the vertical load distribution between girders remains relatively constant. Vertical load distributions determined using techniques such as the vertical simple stiffness model (SSM) and grillage model analysis (GMA) are shown to match well with current recommendations and experimental results.

2. Current practice and recommendations limit the distribution of column seismic overstrength moment-expected under horizontal seismic action longitudinally along the bridge-to the girders in the superstructure immediately adjacent to the column. Observed load distributions from large-scale tests confirm the girders that are not adjacent to the column consistently resist a significant amount of the column moment. 
3. Load predictions determined using the lateral load SSM compare favorably with more complex GMA techniques. The ratios of GMA interior girder distribution to SSM interior girder distribution are 1.10, 0.98, 0.99, and 0.89, for the PBT, SPC 1, SPC 2, and ITB structures, respectively. The largest difference between GMA and SSM predictions is for the ITB structure (a difference of 11.3\%), and in this instance the SSM prediction matches the experimental distribution almost exactly while the more complex GMA technique provides a poorer prediction.

4. The analytical predictions of lateral load distribution to the interior girders based on the SSM model average a difference of 5.0\% from the experimental distribution values, with a maximum difference of $9.8 \%$. The average percentage difference of the GMA predictions from the experimental values is $5.9 \%$, with a maximum difference of $12.7 \%$.

5. At very low levels of lateral load (as low as $0.25 \mathrm{~F}_{\mathrm{y}}$, with $\mathrm{F}_{\mathrm{y}}$ representing column yield due to lateral load), the test units consistently show at least $15 \%$ of the lateral load being distributed to the exterior girders. This distribution remains almost constant all the way to the maximum displacement ductility levels (as high as $\mu_{\mathrm{D}}=10.0$ ) experienced by each test unit.

6. Current design recommendations overestimate the lateral load distribution to the girders adjacent to the column by as much as $60 \%$. As described in Conclusion 4, the SSM approach provides significant improvement in the distribution predictions without implementing a more complex analytical approach. When using the SSM approach, a multiplier of 1.2 is recommended over the calculated distribution factor, based on the results from the four structures in this study. The design girder moment determined using the SSM approach is then expected to be $10 \%$ to $20 \%$ higher than the measured moment, a marked improvement over current recommendations. Improved distribution predictions will likely lead to shallower girders due to reduced demand in the connection region.

\subsection{Acknowledgements}

The large-scale tests which provided the data for this paper were made possible through funding from the California Department of Transportation (Caltrans) for the PBT and ITB units and the National Cooperative Highway Research Program (NCHRP) for the SPC units. The authors also wish to thank Jay Holombo, of T.Y. Lin International Group, Robert Abendroth, of lowa State University (ISU), and Ryan Staudt, former graduate student of ISU, for their contributions to this study. 


\subsection{References}

AASHTO Guide Specifications for LRFD Seismic Bridge Design. (2009). American Association of State Highway and Transportation Officials (AASHTO), Washington, D. C.

AASHTO LRFD Bridge Design Specifications, $5^{\text {th }}$ Edition. (2010). AASHTO, Washington, D. C.

Barr, P., Eberhard, M. O., and Stanton, J. (2001). "Live-load distribution factors in prestressed concrete girder bridges." Journal of Bridge Engineering, 6(5), 298-306.

Bridge Design Aids. (1995). California Department of Transportation, Sacramento, CA.

Cai, C. S. (2005). "Discussion on AASHTO LRFD Load Distribution Factors for Slab-on-Girder Bridges." Practice Periodical on Structural Design and Construction, 10(3), 171-176.

California Amendments to AASHTO LRFD Bridge Design Specifications - Fourth Edition. (2011). California Department of Transportation, Sacramento, CA, 4-34A.

Caltrans. (2006). Seismic Design Criteria (SDC), Version 1.4. California Department of Transportation (Caltrans), Sacramento, California.

"Concrete box girder live load distribution by Lanell for special loads." (1988). Bridge Memo to Designers, California Department of Transportation, Sacramento, CA.

Holombo, J. M., Priestley, J. N., Seible, F. (2000). "Continuity of Precast Prestressed Spliced-Girder Bridges Under Seismic Loads." PCl Journal, 45(2), 40-63.

Kim, S. and Nowak, A. S. (1997). "Load distribution and impact factors for I-girder bridges." Journal of Bridge Engineering, 2(3), 97-104.

Mabsout, M. E., Tarhini, K. M., Frederick, G. R., and Kesserwan, A. (1999). "Effect of multilanes on wheel load distribution in steel girder bridges." Journal of Bridge Engineering, 4(2), 88-106.

Maruri, R. and Petro, S. (2005). "Integral Abutments and Jointless Bridges (IAJB) 2004 Survey Summary." Proc., 2005 Integral Abutment and Jointless Bridges Conference (IAJB 2005), Federal Highway Administration (FHWA), Washington, D. C., 12-29.

Mertz, D. (2007). NCHRP Report 592: Simplified Live Load Distribution Factor Equations, Transportation Research Board (TRB), Washington, D. C.

Priestley, M. J. N., Seible, F., and Calvi, G. M. (1996). Seismic Design and Retrofit of Bridges, John Wiley and Sons, Inc., New York, NY. 
Snyder, R. M. (2010). "Seismic performance of an I-girder to inverted-T bent cap bridge connection." M. S. Thesis, lowa State University (ISU), Ames, IA.

Snyder, R. M., Vander Werff, J., Theimann, Z. J., Sritharan, S., and Holombo, J. (2011). Seismic Performance of an I-Girder to Inverted-T Bent Cap Connection, Final Report, Caltrans, Sacramento, CA, and ISU, Ames, IA.

Sritharan, S., Vander Werff, J., Abendroth, R. E., Wassef, W. G., Greimann, L. F. (2005). "Seismic Behavior of a Concrete/Steel Integral Bridge Pier System." Journal of Structural Engineering, 131(7), 10831094.

Theimann, Z. J. (2009). "3-D finite element analysis of the girder-to-cap beam connection on an invertedtee cap beam designed for seismic loadings." M. S. Thesis, ISU, Ames, IA.

Vander Werff, J. R. (2002). "Steel girder-concrete column integral bridges for seismic regions." M. S. Thesis, ISU, Ames, IA.

Wassef, W. G., Davis, D., Sritharan, S., Vander Werff, J. R., Abendroth, R. E., Redmond, J., and Greimann, L. F. (2004). NCHRP Report 527: Integral Steel Box-Beam Pier Caps, TRB, Washington, D. C.

Zokaie, T., Osterkamp, T. A., and Imbsen, R. A. (1991). NCHRP Report 12-26/1: Distribution of Wheel Load on Highway Bridges, TRB, Washington, D. C. 


\title{
CHAPTER 6. ANALYTICAL INVESTIGATION OF PRECAST GIRDER CONNECTIONS SUBJECTED TO SEISMIC MOTION INCLUDING VERTICAL ACCELERATION EFFECTS
}

\author{
A paper to be submitted to Engineering Structures
}

J. R. Vander Werff ${ }^{1}$ and S. Sritharan ${ }^{2}$

\subsection{Abstract}

Accelerated bridge construction ( $A B C$ ) methods offer many desirable characteristics compared to traditional bridge construction techniques. However, implementation of such methods, especially those that involve the use of precast concrete members, has been rare in seismic regions because of poor performance of connections between precast members in past seismic events. Two new connection details have been developed to provide integral connections between precast concrete I-shaped girders and precast or cast-in-place concrete inverted-tee cap beams. Experimental work has shown that these details are viable for seismic regions, but analytical work investigating the effects of time-history ground motions on the connections will be valuable to further validate the connections as useful details for advancing $A B C$ opportunities in seismic regions.

Several methods for incorporating vertical accelerations have been investigated in this analysis. These methods include applying constant vertical acceleration, incorporating vertical ground motion as a factor of recorded horizontal ground motion, and utilizing recorded vertical ground motion simultaneously with recorded horizontal ground motion. These analysis approaches provided opportunities to compare with experimental results and also critique current vertical acceleration design recommendations, such as those included in the California Department of Transportation's (Caltrans) Seismic Design Criteria (SDC). Conclusions related to the validity of the connection details, appropriateness of vertical acceleration analysis approaches, and current design recommendations related to vertical acceleration are presented in this paper.

\footnotetext{
${ }^{1}$ Assistant Professor; Engineering, Dordt College, Sioux Center, lowa

${ }^{2}$ Wilson Engineering Professor; Civil, Construction, and Environmental Engineering, lowa State University, Ames, lowa
} 


\subsection{Introduction}

Accelerated bridge construction $(A B C)$ methods are increasingly in vogue in the United States. Departments of Transportation around the country have been pursuing $A B C$ approaches for over a decade (NCHRP, 2011). ABC techniques rely on extensive prefabrication to minimize field construction time. Decreased time in the field results in reduced field cost, reduced public total cost because of reduced detour time, and improved quality by moving more of the construction process to a controlled shop environment.

One of the most common ways to accomplish $A B C$ is to utilize precast concrete elements in place of traditional cast-in-place concrete approaches. However, implementation of precast concrete in seismic regions is difficult because of the susceptibility of the connections. The last two major earthquake events in California (Loma Prieta in 1989 and Northridge in 1994) both exposed significant flaws in precast concrete connections, revealing the vulnerability of precast structures when subjected to large earthquake loads.

Bridge designs utilizing integral superstructure connections are implemented frequently in high seismic regions because of the desirable overall structural configuration they provide. The moment capacity provided in the girder-to-cap connections results in significant moment demand in the top of the columns when the structure is subjected to horizontal loading. Consequently, the column top can be detailed as a plastic hinge region for the high seismic displacement condition, providing additional energy absorption during large earthquake events. However, the difficulty of seismic-sufficient precast concrete connections, especially when attempting to provide significant moment capacity through the connection, means that the incorporation $A B C$ methods into integral superstructure designs in seismic regions is difficult.

Recognizing the vulnerability of precast connections under seismic loading, the California Department of Transportation (Caltrans) has implemented specific requirements for precast connections of integral elements. Section 7.2.3 of Caltrans' Seismic Design Criteria (2013) addresses specific precast girder requirements. While the current version acknowledges that precast spliced girders can be viable for integral superstructures, this type of system is still considered to be "nonstandard." Additionally, SDC calls for specific vertical acceleration requirements for superstructure 
connections, detailed in Section 7.2.2. Interest in vertical acceleration effects has heightened in recent years, especially following the devastating effects of vertical ground motion in the 2011 ChristChurch earthquake (Kam and Pampanin, 2011).

For integral superstructure connections suitable for $A B C$ techniques to be viable for seismic regions, they need to be shown to provide sufficient moment continuity to resist column overstrength moment along with sufficient shear capacity including vertical effects. Recent experimental work has been conducted to investigate two similar details for such capability. The overall concept was validated in a large-scale system test (Snyder et al., 2011) and two girder-to-cap connection details for use in such a system were tested in large-scale component tests (Sritharan et al., 2013). While the experimental results verified the sufficiency of the connection details using pseudostatic loading techniques, no analytical models that utilized ground motion time-history analyses for comparison with the experimental results had been completed. Thus, an analytical model utilizing OpenSees (2013) was developed to investigate the influence of vertical acceleration on the girder connections. This analytical work is presented in this paper.

\subsection{Vertical Acceleration Analytical Approaches}

The analytical model was developed in particular to investigate the moment and shear demands in integral bridge girder-to-cap connections under various earthquake load scenarios. Since the influence of vertical ground motion is a particular area of concern for such connections, special attention was given to appropriate methods for incorporating vertical acceleration effects into this analysis. Three approaches for modeling vertical ground motion were considered: (1) modeling the vertical acceleration as constant pseudostatic upward or downward force along the bridge superstructure, (2) using a timehistory analysis incorporating horizontal ground motion data from actual earthquake events and modeling the vertical acceleration as two-thirds the magnitude of the horizontal acceleration, and (3) using time-history ground motion data for both horizontal and vertical acceleration as recorded in actual earthquake events. All three of these approaches have been used in similar analytical efforts and are discussed in the following sections. 


\subsubsection{Constant Vertical Acceleration}

From a modeling standpoint, a simple way to incorporate vertical acceleration effects is to use a static force based on the structure's mass and the expected vertical acceleration. With this method the definition of the load is straightforward, the analysis tends to be stable, and the results are easily interpretable. The challenge with this method is using a meaningful vertical acceleration and associated constant force. Studies continue to investigate likely magnitudes of vertical acceleration during earthquake events, but regional effects like topography, soil type, and proximity to fault make such predictions very difficult.

\subsubsection{Vertical Acceleration as a Function of Horizontal Acceleration}

Much of the recent research effort related to vertical acceleration has focused on comparing magnitudes of peak ground acceleration (PGA) in the horizontal and vertical directions. A common practice is to use $2 / 3$ as the ratio of peak vertical to peak horizontal acceleration $(\mathrm{V} / \mathrm{H})$, but it is currently recognized that this practice is not always conservative. Because of the complexity of the relationship, many of the current efforts related to modeling vertical acceleration utilize numerical parametric approaches to develop $\mathrm{V} / \mathrm{H}$ estimates. These algorithms are developed to learn the nonlinear relationships between predictive variables and the $\mathrm{V} / \mathrm{H}$ ratio directly from the ground motion data, such as the study by Tezcan and Cheng (2012). Many other studies in the past couple of decades have proposed similar models using site and ground motion parameters, such as Gulerce and Ambrahamson (2011), Kalkan and Bulkan (2004), and Ambraseys and Simpson (1996).

These and similar studies have shown that the $\mathrm{V} / \mathrm{H}$ ratio is typically less than or equal to $2 / 3$. A study by Yang and Lee (2007) investigated the vertical and horizontal ground motion characteristics during the earthquake in Niigata-ken Chuetsu, Japan, in 2004. This study showed that V/H was typically less than or equal to $2 / 3$ for this data set, but for a few sites the ratio was as high as 1 . The study concluded that the $\mathrm{V} / \mathrm{H}$ ratio was strongly dependent on spectra frequency, site-to-source distance, and site condition. It showed that the $\mathrm{V} / \mathrm{H}$ ratio could be significantly higher than $2 / 3$ at short periods, in near-field regions, and at extremely long periods. 


\subsubsection{Horizontal and Vertical Ground Motion}

The studies mentioned above focus on the $\mathrm{V} / \mathrm{H}$ ratio, taking $\mathrm{V}$ as the magnitude of the vertical PGA and $\mathrm{H}$ as the magnitude of the horizontal PGA. The limitation of this method is that it utilizes the peak values from both the vertical and horizontal directions, but these peak values rarely occur at the same time. Thus, using the $\mathrm{V} / \mathrm{H}$ ratio to predict vertical ground motion based on horizontal ground motion is likely to be overly conservative. One of the only studies that considered simultaneous vertical and horizontal accelerations was conducted by Ambraseys and Douglas (2000), along with a follow-up study in 2003. These studies mentioned the limitation of omitting consideration of simultaneous behavior: " $\mathrm{A}$ major draw-back of the acceleration ratio...for practical purposes is that in an earthquake the maximum ground or response accelerations in the vertical and horizontal direction occur at different times."

However, in a couple significant earthquake events the peaks have been verified to occur at almost the same time, especially for near-fault rock sites. Figure 6.1a shows the ground motion for two such sites, the Pacoima Dam during the 1994 Northridge event and Eureka Canyon Road during the 1989 Loma Prieta Event. The peak vertical motion (middle line on both records) occurs at almost exactly the same time as the peaks in the two horizontal directions (top and bottom lines on both records). Interestingly, the near-fault non-rock sites do not show similar behavior, as indicated by the records in Figure $6.1 \mathrm{~b}$ that are also from the Northridge event. Comparing these records shows the difficulty of developing a one-size-fits-all approach to predicting vertical acceleration based on horizontal ground motion. 


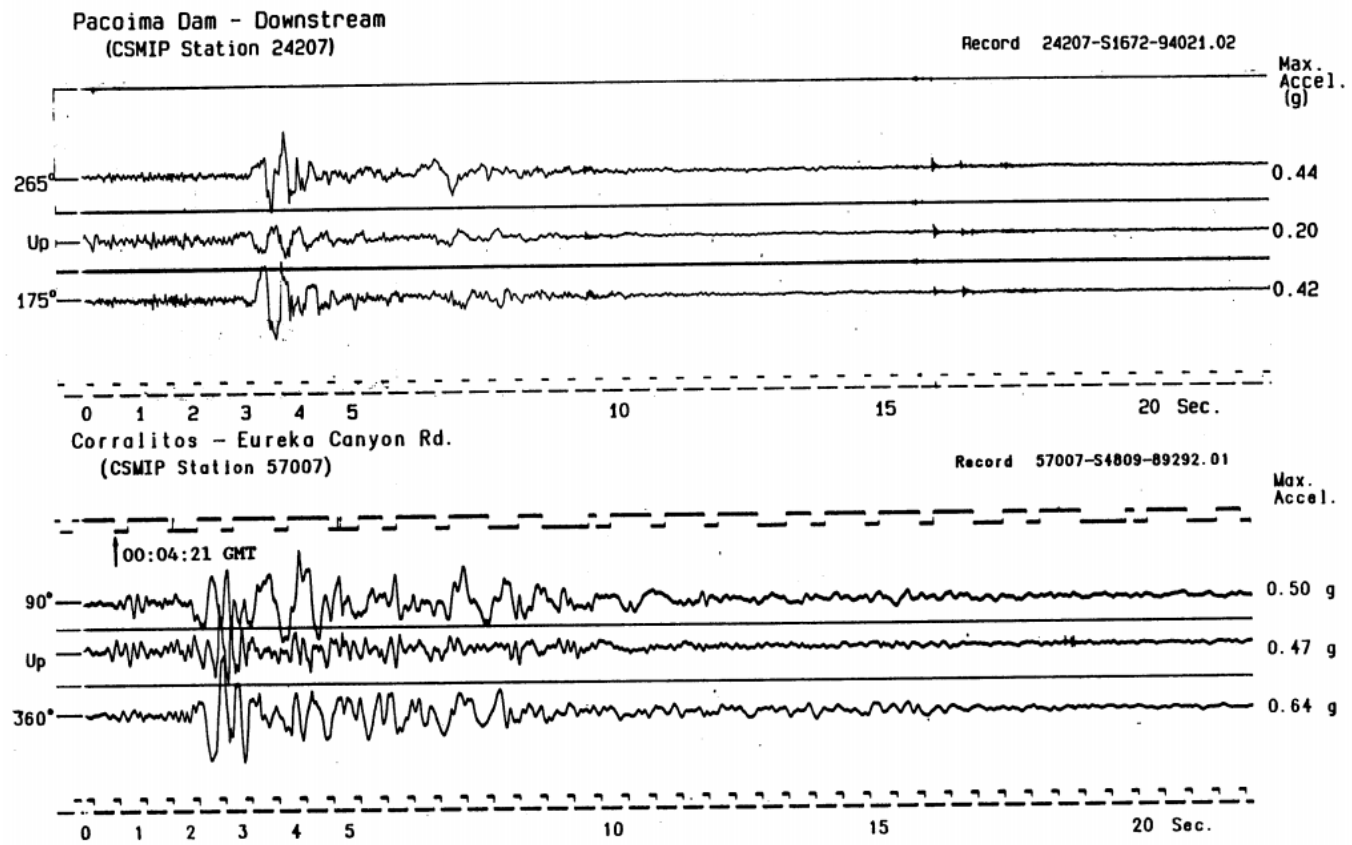

a. Rock sites from the 1994 Northridge event (top) and the 1989 Loma Prieta event (bottom)

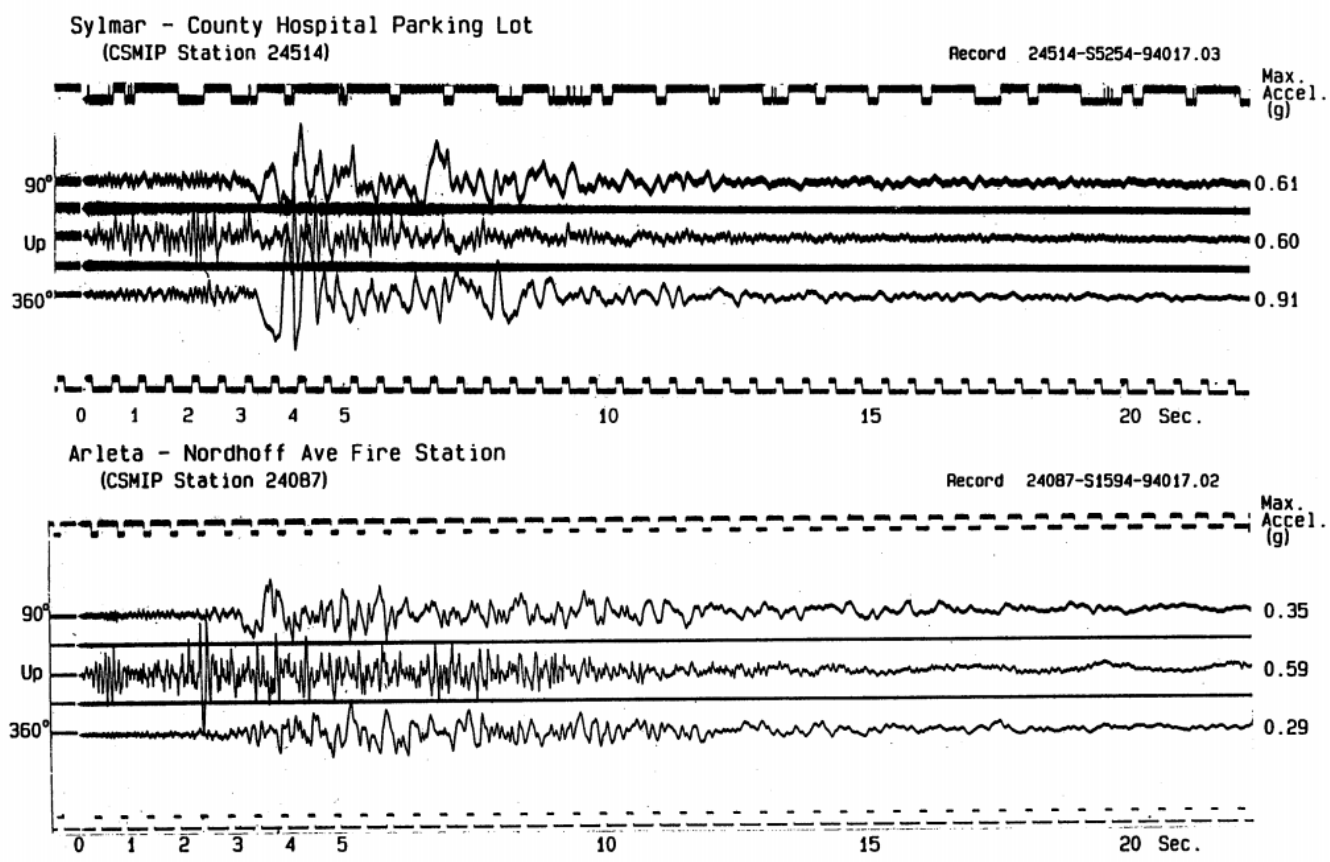

b. Close soil sites from the 1994 Northridge event

Figure 6.1. Horizontal and vertical component acceleration time histories from the 1994 Northridge and 1989 Loma Prieta events (Silva, 1997) 


\subsection{Connection Details and Experimental Validation}

The integral connections that were developed in this study are improvements of an existing Caltrans detail used for connecting I-shaped girders and inverted-tee cap beams. Figure 6.2a shows a precast inverted-tee cap beam prior to girder placement. Dapped-end I-shaped girders can then be positioned on the cap beam corbel, and a cast-in-place diaphragm can be used to provide connection continuity by encasing dowel bars positioned through the girder as shown in Figure 6.2b. The dowel/diaphragm detail provides some connection fixity, and the deck reinforcement provides tension continuity for the typical negative moment action that occurs at the girder-cap connection under normal dead and live load. However, neither of these mechanisms can provide direct tension continuity for positive moment action at the connection, which can occur during large seismic events.

In the experimental work, two different methods were investigated to provide this positive moment fixity. In the Grouted Unstressed Strand Connection (GUSC) detail, unstressed strand was run continuously through ducts in the cap beam and girder bottom flange and grouted in place, as shown in Figure 6.2b. In the Looped Unstressed Strand Connection (LUSC) detail, looped strands were extended out from the cap beam outside the girder, which also contained looped strands, and dowel bars were positioned between the loops as shown in Figure $6.2 \mathrm{c}$ and then anchored by the cast-in-place diaphragm. 


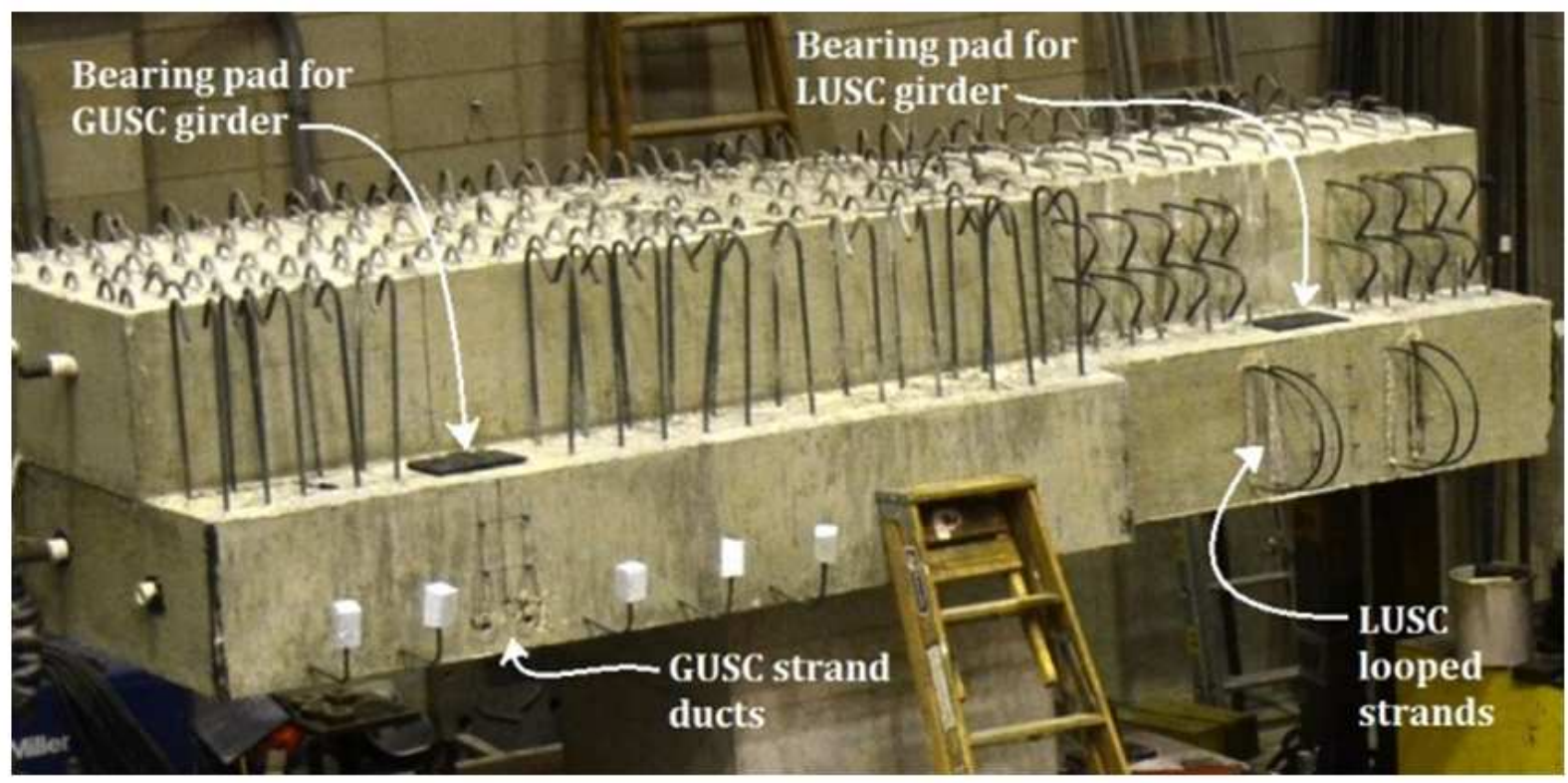

a. Precast concrete cap beam prior to girder and diaphragm placement

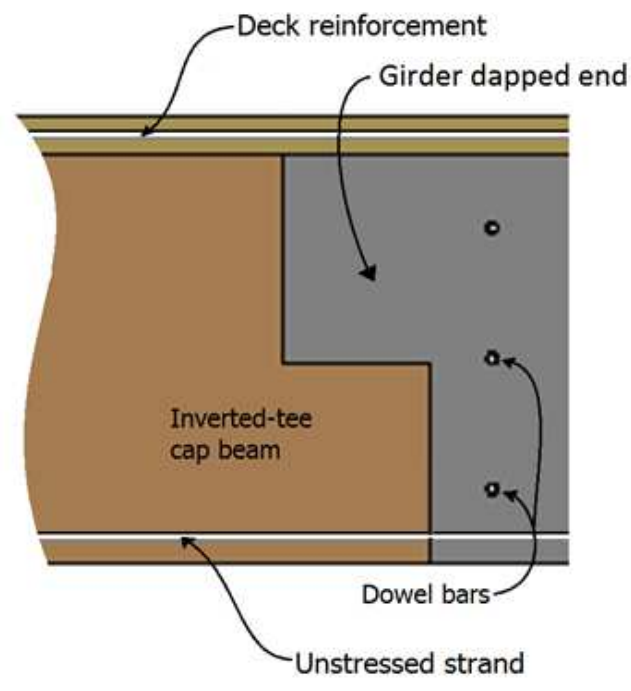

b. Section of GUSC detail

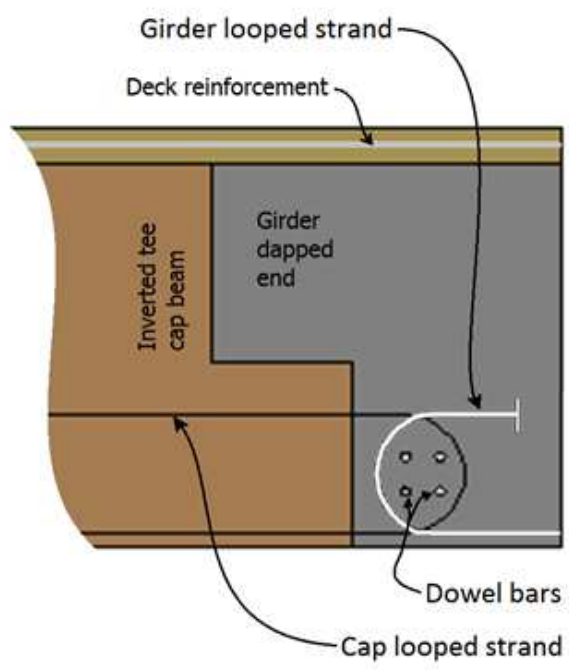

c. Section of LUSC detail

Figure 6.2. Connection concepts for inverted tee cap beam and dapped end girder

The connections were developed to be used in an overall inverted tee bridge system such as demonstrated in the prototype bridge shown in Figure 6.3. To investigate the validity of such a system, a large-scale experimental study was conducted that modeled the dashed region shown around Bent 3 in Figure 6.3. The $50 \%$-scale test unit included a foundation, a single concrete column, a concrete inverted- 
tee cap beam, and five I-shaped prestressed concrete girders on each side of the cap beam. Pseudostatic loading was used to simulate horizontal seismic loading. The horizontal force-displacement response of this bridge system is shown in Figure 6.4. The system performed well, with the superstructure remaining elastic during the entirety of simulated horizontal seismic loading. The superstructure behavior allowed the development of plastic hinges in both the top and bottom of the column. The system retained strength up to large horizontal displacements, maintaining full strength as high as ductility $\mu_{D}=8$ and still demonstrating significant strength at ductility $\mu_{D}=10$. To begin to investigate vertical acceleration effects, a second loading configuration was used that fully exercised the girder-to-cap connections and demonstrated significant vertical load reserve capacity in the connections beyond the demand generated under horizontal seismic loading conditions. Detailed information on both phases of testing is provided by Snyder et al. (2011).

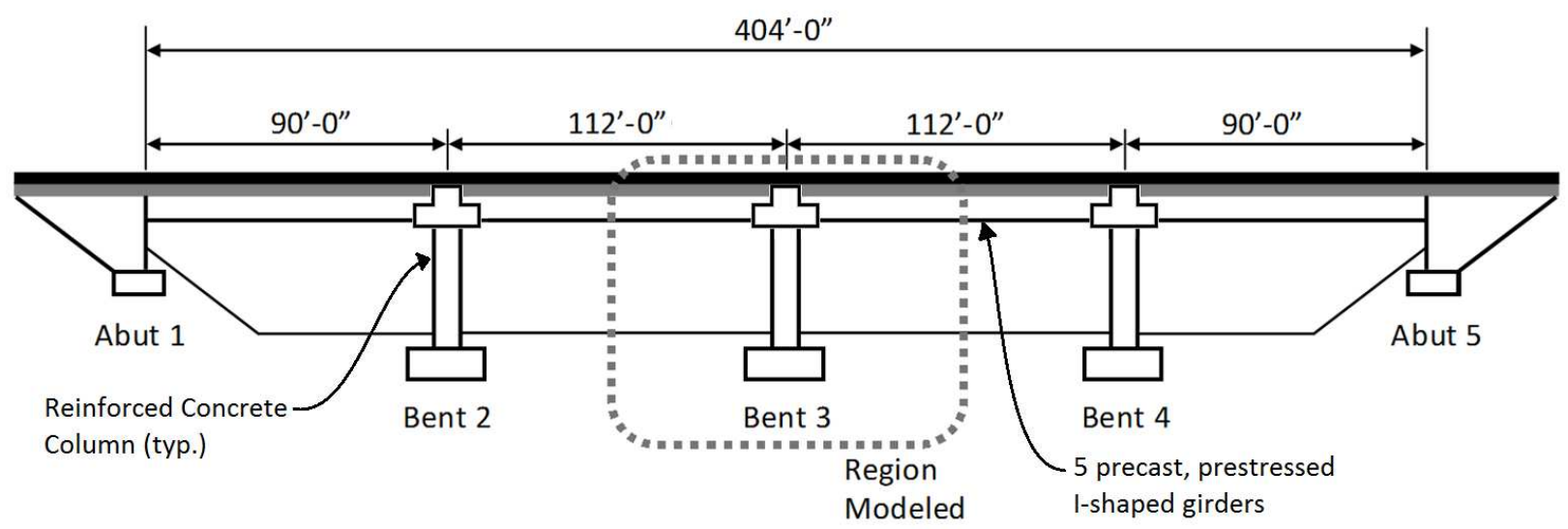

Figure 6.3. Prototype bridge utilizing the inverted tee system

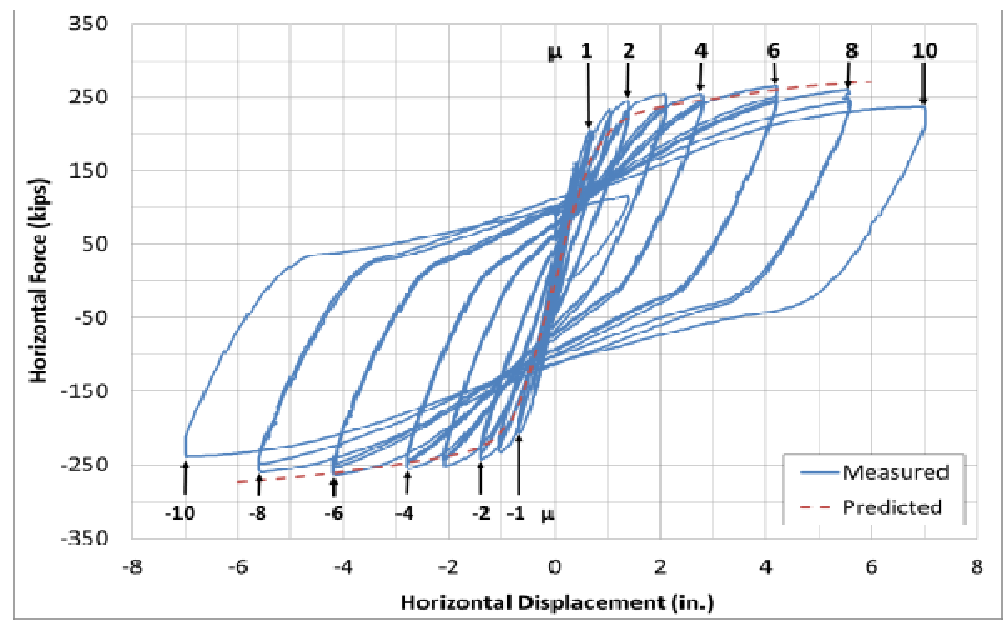

Figure 6.4. Experimental horizontal force-displacement response for the inverted-tee system 
To further investigate the capability of the girder-to-cap connections in the inverted tee system, a component test was conducted that focused on the GUSC and LUSC details presented above. This connection test utilized a 50\%-scale test unit that modeled a portion of the inverted tee cap beam and portions of two I-shaped precast girders, one incorporating the GUSC detail and one using LUSC detail. A split bridge deck was used between the two girders so each could be exercised individually. Figure 6.5 provides the moment-displacement response of the two connection details, including horizontal lines that represent how the moment magnitudes correspond to the gravity, horizontal, and vertical acceleration conditions in the bridge system. The maximum earthquake condition shown on these figures, represented by "G $+\mathrm{H}+1.0 \mathrm{~V}$," is based on the full gravity and full horizontal seismic moment (based on the column overstrength moment from the system test) with the addition of vertical seismic acceleration equal to $1.0 \mathrm{~g}$. As shown, the moment strength of both details demonstrated in the connection test in both the negative and positive moment directions was well beyond any of the critical earthquake levels.

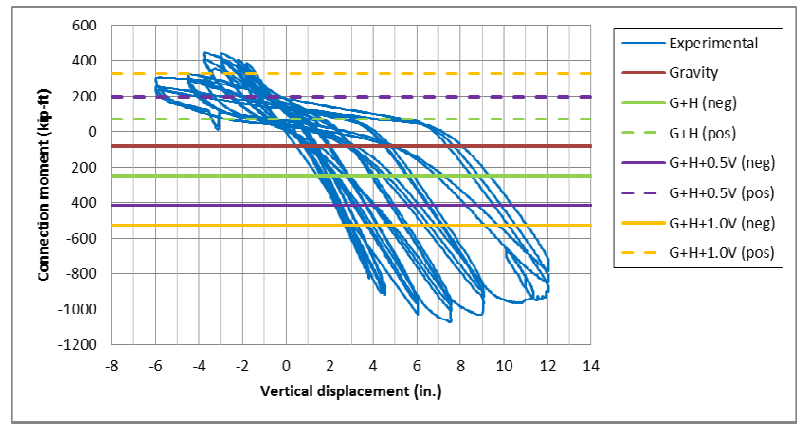

a. GUSC test

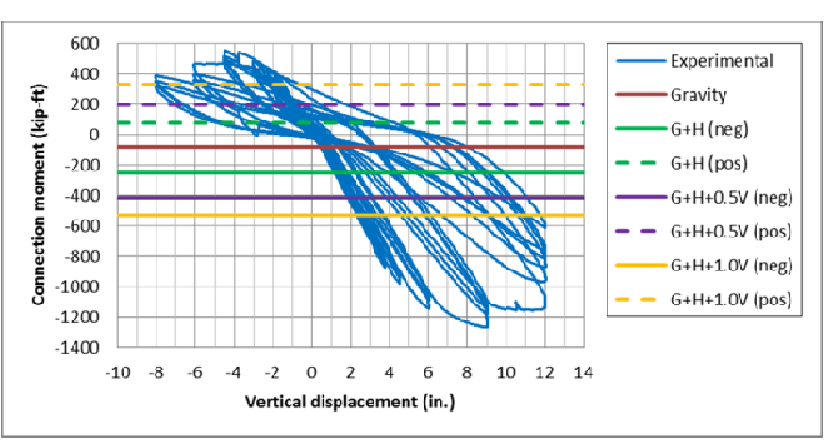

b. LUSC test

Figure 6.5. Connection moment as a function of vertical girder end displacement

\subsection{Development of the Analytical Model}

The vertical acceleration levels indicated in Figure 6.5 and used to determine the loading in the connection test were based on simple hand calculations accounting for the mass of the bridge structure and considering varying factors of gravity being applied both upwards and downwards. To further investigate the shear and moment conditions that would be experienced by an inverted-tee bridge system, an analytical model of the bridge system has been developed in OpenSees (2013). Using OpenSees for this analysis provides the capability of introducing real time-history ground motion to the model, digging deeper than simple constant acceleration simulations and increasing confidence in the 
performance of the connections under severe seismic load conditions. To allow simple comparison with previous analytical and experimental work, the test unit used in the system test study was chosen as the basis for the analytical model.

\subsubsection{Column: Fiber-Based Beam-Column Elements Incorporating Strain Penetration Effects}

Because a significant portion of the shear and moment that occurs in the superstructure connections of the inverted-tee system is related to the column plastic hinge behavior, it was crucial to model the column of the bridge system properly. Many studies have utilized fiber sections in OpenSees to successfully model nonlinear behavior of reinforced concrete elements under seismic loading (see, for example, Spacone et al., 1996). This method provides the opportunity to use different material models for confined and unconfined concrete and also allows the longitudinal reinforcement to be modeled using a steel material model and located and to be physically located in the proper locations.

Figure 6.6a provides a cross-section of the fiber section used to model the system test column. The core region of the column was modeled using confined concrete material properties based on OpenSees' Concrete02 material model (Yassin, 1994). The Concrete07 model, based on Chang and Mander's concrete model (1994) and developed for OpenSees by Waugh and Sritharan (2010), was considered, but this model produced some convergence issues and did not seem to noticeably improve the results from the Concrete02 model. The material properties used in the Concrete02 definition were based on the measured concrete strength from the system test, incorporating the recommendations from California's Applied Technology Council (ATC, 1996) and Priestley et al. (1996) to determine the appropriate material model parameters. The outer portion of the column cross-section was modeled using unconfined concrete material properties, also using the Concrete 02 material model. Similar recommendations were followed to establish the appropriate unconfined concrete parameters based on the measured system test properties. Table 6.1 lists the concrete material properties used in the model.

The Steel02 (Filippou et al., 1983) material model was used for the mild reinforcement. This material incorporates hysteretic behavior along with isotropic hardening in tension and compression. Appropriate material parameters for the model were determined based on the measured values of the reinforcement used in the system test. The steel material model properties are listed in Table 6.2. The values recommended by OpenSees were used for the isotropic hardening parameters. 
Using a fiber section allowed the three different materials described above to be modeled appropriately in the column section. Figure $6.6 \mathrm{~b}$ provides a close-up view of a small outer segment of the column cross-section as modeled. Each grid space in this view represents a single fiber in the model, which can be thought of as a very small beam element oriented in the column longitudinal direction (perpendicular to the page). Each of these fibers is defined with the appropriate material property. The steel reinforcing bars are modeled as single fibers with appropriate material properties and crosssectional area, with locations in the column cross-section matching the physical test unit locations. The fiber definitions are used to define an overall cross-section that is incorporated into beam-column elements used to define the column.

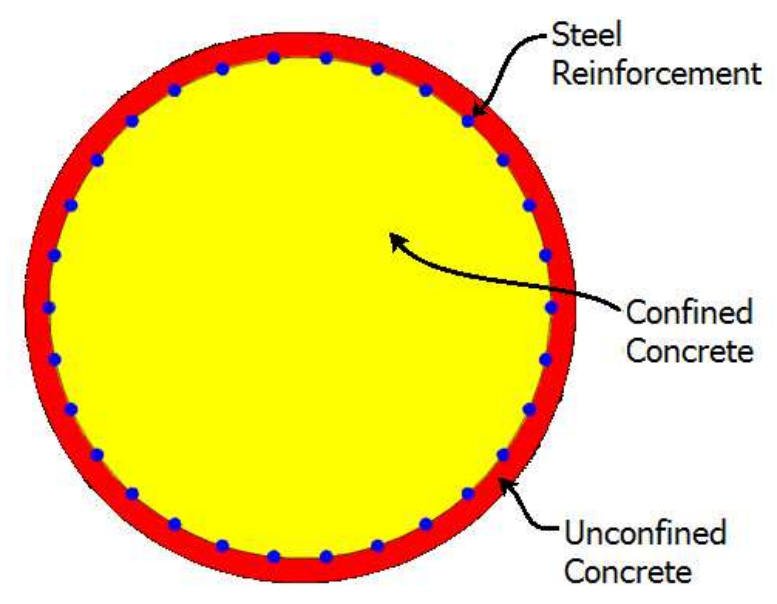

a. Column cross-section

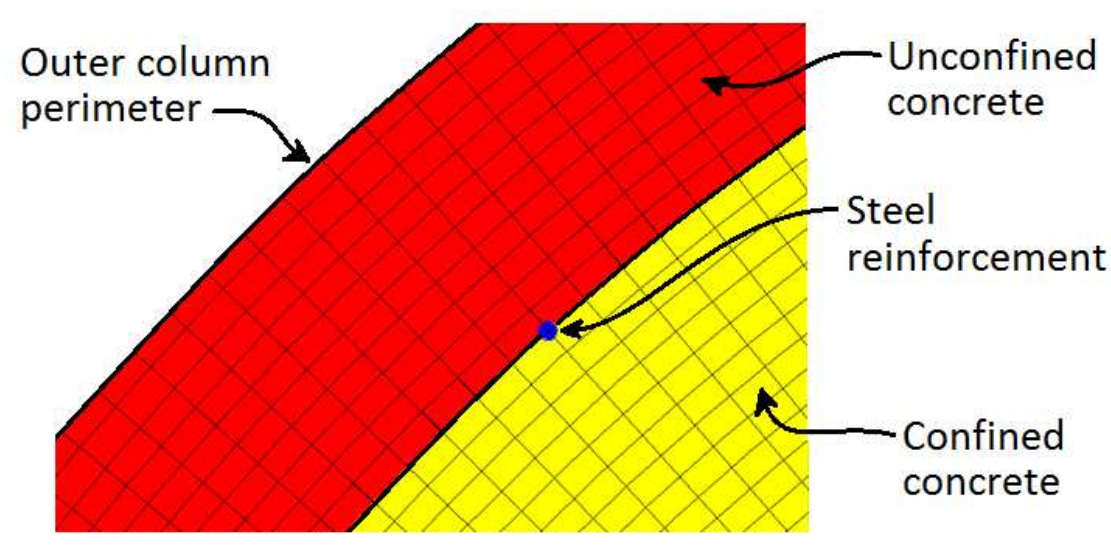

b. Close-up view of fiber arrangement

Figure 6.6. Fiber-based cross section for beam-column element used to model system test column in OpenSees analysis 
Table 6.1. Concrete material properties in OpenSees analysis

\begin{tabular}{|c|l|c|}
\hline Parameter & \multicolumn{1}{|c|}{ Description } & Magnitude \\
\hline$f_{c}^{\prime}$ & Measured test unit concrete compressive strength & $6.81 \mathrm{ksi}$ \\
\hline Confined Concrete Material Model & $8.52 \mathrm{ksi}$ \\
\hline$f_{\mathrm{pc}}$ & Concrete compressive strength & 0.0045 \\
\hline$\varepsilon_{\mathrm{psc} 0}$ & Concrete strain at maximum strength & $0.85 \mathrm{ksi}$ \\
\hline $\mathrm{f}_{\mathrm{pcu}}$ & Concrete crushing strength & 0.0904 \\
\hline$\varepsilon_{\mathrm{ps} U}$ & Concrete strain at crushing strength & 0.1 \\
\hline$\lambda$ & Ratio between unloading slope at $\varepsilon_{\mathrm{psc}}$ and initial slope & $0.0005 \mathrm{ksi}$ \\
\hline $\mathrm{f}_{\mathrm{t}}$ & Tensile strength & $1912 \mathrm{ksi}$ \\
\hline$E_{\mathrm{ts}}$ & Absolute value slope of the linear tension softening branch \\
\hline Unconfined Concrete Material Model & $6.81 \mathrm{ksi}$ \\
\hline $\mathrm{f}_{\mathrm{pc}}$ & Concrete compressive strength & 0.0023 \\
\hline$\varepsilon_{\mathrm{psc} 0}$ & Concrete strain at maximum strength & $0.68 \mathrm{ksi}$ \\
\hline $\mathrm{f}_{\mathrm{pcu}}$ & Concrete crushing strength & 0.0052 \\
\hline$\varepsilon_{\mathrm{psU}}$ & Concrete strain at crushing strength & 0.1 \\
\hline$\lambda$ & Ratio between unloading slope at $\varepsilon_{\mathrm{psc}}$ and initial slope & $0.0005 \mathrm{ksi}$ \\
\hline $\mathrm{f}_{\mathrm{t}}$ & Tensile strength & $1912 \mathrm{ksi}$ \\
\hline$E_{\mathrm{ts}}$ & Absolute value slope of the linear tension softening branch & \\
\hline
\end{tabular}

Table 6.2. Steel reinforcement material properties in OpenSees analysis

\begin{tabular}{|c|l|c|}
\hline Parameter & \multicolumn{1}{|c|}{ Description } & Magnitude \\
\hline$F_{\mathrm{y}}$ & Yield strength of the steel reinforcement & $62.3 \mathrm{ksi}$ \\
\hline $\mathrm{E}_{0}$ & Initial elastic tangent & $29000 \mathrm{ksi}$ \\
\hline$b$ & $\begin{array}{l}\text { Strain-hardening ratio (ratio between post-yield tangent and initial } \\
\text { elastic tangent) }\end{array}$ & 0.0092 \\
\hline $\mathrm{R}_{0}$ & Parameter for isotropic hardening behavior & 18 \\
\hline $\mathrm{C}_{\mathrm{R} 1}$ & Coefficient for isotropic hardening behavior & 0.925 \\
\hline $\mathrm{C}_{\mathrm{R} 2}$ & Coefficient for isotropic hardening behavior & 0.15 \\
\hline
\end{tabular}


Research by Zhao and Sritharan (2007) has shown that the incorporation of strain penetration effects in fiber-based analysis can improve the modeling of the plastic hinge regions. This method was incorporated in an effort to simulate the moment at the top of the column appropriately and subsequently provide appropriate moment and shear results in the superstructure connections adjacent to the column. In OpenSees, Zhao and Sritharan's material model for steel reinforcement incorporating strain penetration is defined as Bond SP01, and this model was used in the analysis. The material properties incorporated into the Bond SP01 material model are provided in Table 6.3. Recommendations from Zhao and Sritharan were incorporated to determine the appropriate parameters based on the measured material properties of the steel reinforcement.

Table 6.3. Steel reinforcement properties incorporating strain penetration effects

\begin{tabular}{|c|l|c|}
\hline Parameter & \multicolumn{1}{|c|}{ Description } & Magnitude \\
\hline $\mathrm{F}_{\mathrm{y}}$ & Yield strength of the steel reinforcement & $62.3 \mathrm{ksi}$ \\
\hline $\mathrm{S}_{\mathrm{y}}$ & Rebar slip at member interface under yield stress & $0.0167 \mathrm{in}$. \\
\hline $\mathrm{F}_{\mathrm{u}}$ & Ultimate strength of the steel reinforcement & $92.4 \mathrm{ksi}$ \\
\hline $\mathrm{S}_{\mathrm{u}}$ & Rebar slip at the loaded end at the bar fracture strength & $0.500 \mathrm{in}$. \\
\hline $\mathrm{b}$ & Initial hardening ratio in the monotonic slip vs. bar stress response & 0.5 \\
\hline $\mathrm{R}$ & Pinching factor for the cyclic slip vs. bar response & 1.0 \\
\hline
\end{tabular}

The strain penetration effects were incorporated into the column model by substituting the Bond SP01 material for the Steel02 material in the reinforcement fiber locations in zero-length-elements that were established at the top and bottom of the column. The concrete material properties in the zerolength-elements were also adjusted based on Zhao and Sritharan's recommendation. This adjustment consisted of modeling both the confined and unconfined concrete materials as remaining perfectly plastic once they degraded to $80 \%$ of their original strength. Without this adjustment, the concrete fibers produce unrealistically "soft" results when incorporated in the strain penetration section, because of the large deformations that occur in the section. The modified concrete properties used in the zerolength-elements in the plastic hinge regions are provided in Table 6.4. 
Table 6.4. Concrete properties in the zero-length elements

\begin{tabular}{|c|l|c|}
\hline Parameter & \multicolumn{1}{|c|}{ Description } & Magnitude \\
\hline $\mathrm{f}_{\mathrm{pc}}$ & Concrete compressive strength & $8.52 \mathrm{ksi}$ \\
\hline$\varepsilon_{\mathrm{psc} 0}$ & Concrete strain at maximum strength & 0.0045 \\
\hline $\mathrm{f}_{\mathrm{pcu}}$ & Concrete crushing strength & $6.82 \mathrm{ksi}$ \\
\hline$\varepsilon_{\mathrm{psU}}$ & Concrete strain at crushing strength & 0.0904 \\
\hline$\lambda$ & Ratio between unloading slope at $\varepsilon_{\mathrm{psco}}$ and initial slope & 0.1 \\
\hline $\mathrm{f}_{\mathrm{t}}$ & Tensile strength & $0.0005 \mathrm{ksi}$ \\
\hline $\mathrm{E}_{\mathrm{ts}}$ & Absolute value slope of the linear tension softening branch & $1912 \mathrm{ksi}$ \\
\hline
\end{tabular}

\subsubsection{Superstructure: Two-Dimensional Linear Elastic Elements}

To provide appropriate resistance at the top of the column, and to provide a means to investigate the distribution of the moment and shear from the column into the superstructure, OpenSees was used to develop a two-dimensional analytical model representative of the experimental system test unit. A two-dimensional model, rather than a more complex finite element analysis (FEA) or grillage analysis approach, was deemed appropriate since only the longitudinal horizontal and vertical effects were of interest. In addition, the experimental work had already verified that the superstructure remained elastic up to seismic load levels significantly higher than the column overstrength moment, including significant reserve capacity for vertical acceleration effects, so adding the complexity of nonlinear behavior to the superstructure model was deemed unnecessary.

The analytical model utilized the fiber-based beam-column elements described above for the column sections and incorporated two-dimensional linear elastic elements representative of the bridge superstructure. The model was based on the experimental system test unit. A schematic of the model is shown in Figure 6.7a, where elements 1-7 are the beam-column elements representing the column and elements 8-19 are the elastic elements representing the superstructure. 


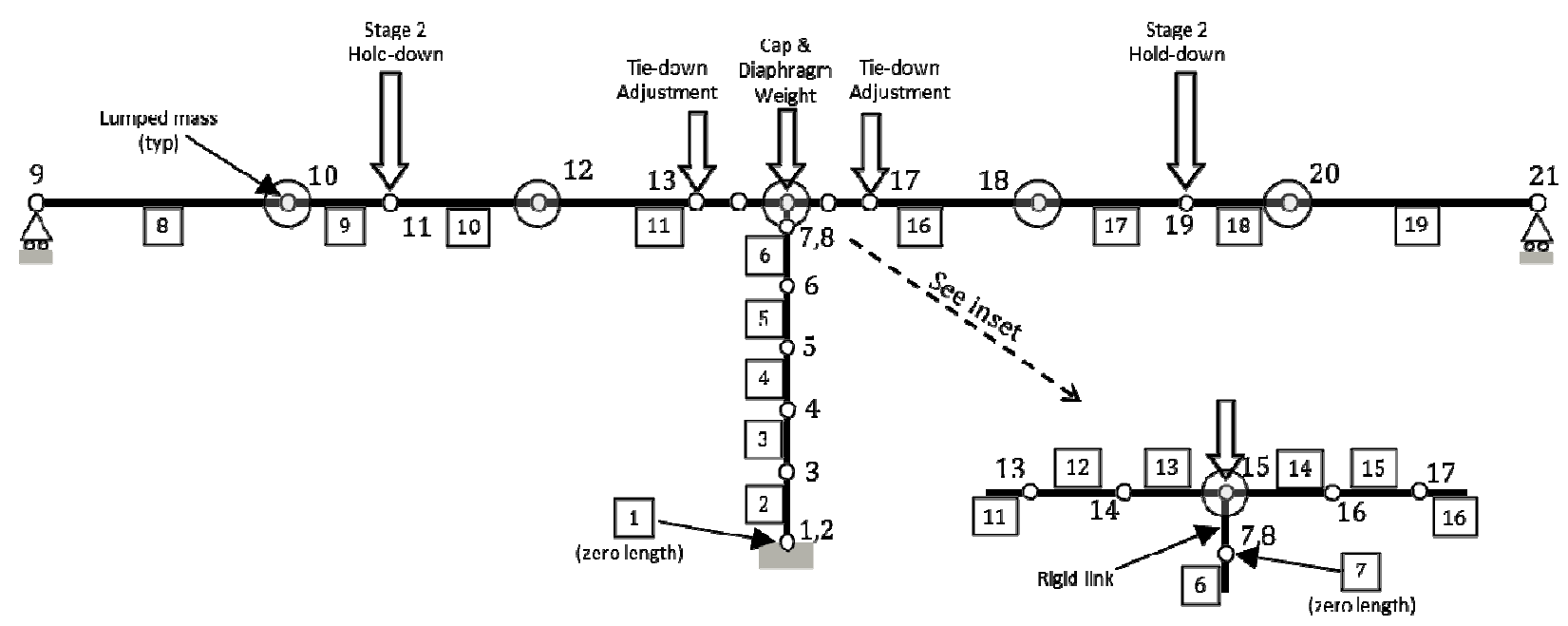

a. Original analytical model without staged superstructure elements

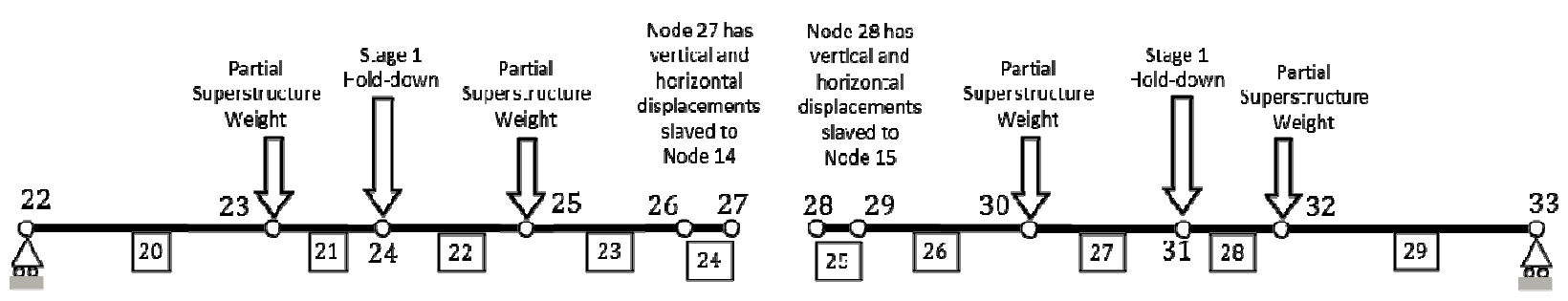

b. Staged superstructure elements added in parallel to the original model to incorporate staged loading

Figure 6.7. Analytical model of the system test unit, including column and superstructure

One limitation of this analysis method was that it did not allow the model to be used to investigate distribution of the load to the individual girders and individual connections. However, an FE study by Theimann (2010) on the prototype bridge and a grillage analysis by Snyder (2011) on the system test unit had already been conducted, and results from these studies were used to determine distribution factors for vertical and lateral load between the girders. In addition, an extensive study was conducted on the vertical and lateral load distribution in this test unit and three other large-scale experimental studies (Vander Werff and Sritharan, 2014), and the results from this work were used to provide confidence in the load distribution that would be experienced by the girders in the superstructure.

Concrete compressive strength from the test day was used, following American Concrete Institute recommendations $(\mathrm{ACl}, 2011)$, to establish the modulus of elasticity for the elastic elements. The cap beam and diaphragm region of the superstructure near the column was modeled as a solid rectangular element. For the elements representing the five-girder-and-deck cross-sections, the composite gross 
moment of inertia for the girders and deck was determined. Findings from the grillage analysis (Snyder, 2011) had indicated that elastic behavior of the girder sections under positive moment could be represented by using about $25 \%$ of the gross section properties, and elastic behavior of the girder sections under negative moment could be represented by about $65 \%$ of the gross section properties.

However, a main purpose of creating the OpenSees model was to provide the opportunity for a fullyreversible time-history analysis, meaning that different portions of the bridge superstructure would be subjected to varying positive and negative moment action during different stages of the time-history ground motion analysis. Consequently, incorporation of differing positive and negative moment section properties would require variable cross-section properties based on instantaneous load condition. Since the largest portion of the test unit bridge superstructure is subjected to positive moment action under any given loading, the positive moment section properties were used for the elastic superstructure elements. Results from initial analyses using the OpenSees model were compared with results from the earlier grillage analysis to verify the appropriateness of this approach. To provide appropriate superstructure stiffness, the final elastic superstructure section properties were reduced a bit from the grillage positive-moment section properties; this process is discussed in more detail below.

\subsubsection{Staged Loading of the Superstructure}

One of the challenges in modeling an integral bridge superstructure is that a portion of the structure self-weight is transferred through the girder-to-cap connection prior to fixity being established at the connection. When the girders are initially positioned, they merely rest on the cap corbel and thus behave as simply-supported beam elements. Thus, while the girders produce significant shear in the connection region during this stage (deemed "Stage 1"), there is no accompanying moment in the connection. When the deck and diaphragm concrete is initially, prior to curing, this Stage 1 behavior continues. It is only after the diaphragm concrete cures that fixity is established at the connection and true moment continuity is established. Since the concrete encasing the connection cures after the girder self-weight and deck concrete weight is already present, it hardens around the girder end in an alreadydeflected positioned, retaining the girder curvature from the Stage 1 condition. The end result is that the load transferred during Stage 1 continues to be carried through the connection region as if the girder end has no moment continuity, whereas all superstructure loads that occur after fixity is established (deemed "Stage 2") are transferred through a continuous moment connection. 
To account for the staged loading behavior, superstructure elements identical to and parallel with the initial elastic superstructure elements were established. These staged elements are shown in Figure 6.7b. The elements were modeled using independent nodes from the original superstructure. The only connections between the staged elements and the original elements occurred at nodes 27 and 28, where the horizontal and vertical translation degrees of freedom were slaved to nodes 14 and 16 of the original superstructure. Since only the translational degrees of freedom were slaved, the connections of the staged elements behaved as if they were pinned to the original superstructure at these locations. This configuration provided the ability to apply all Stage 1 loads to the staged elements, producing pinned-connection behavior in the superstructure, while all Stage 2 loads could be applied to the original superstructure elements, producing moment-connection behavior.

To investigate the importance of correctly modeling the staged loading behavior, a cyclic horizontal ground motion analysis was conducted using two identical models, except one of the models incorporated the staged superstructure elements and one did not. For the staged analysis, self-weight loads were applied using static concentrated loads at node locations along the staged elements and above the column as appropriate, and the superstructure mass that was excited by the ground motion was included as lumped masses on the fixed superstructure elements. For the fixed analysis, all of the self-weight loads and lumped masses were included on the fixed elements.

Figure 6.8 provides the results of these comparative analyses. Figure $6.8 \mathrm{a}$ compares the shear in the connection region for the two models as the superstructure was exercised horizontally back and forth, while Figure $6.8 \mathrm{~b}$ compares the moment in the connection region during the same horizontal excitation. The shear comparison between the two models is very similar, which is expected since a pin connection provides shear continuity. However, the moment comparison shows a dramatic difference. Horizontal earthquake excitation for the "Fixed" model never even generated a positive moment in the connection! If such connection moment was truly representative of the superstructure performance, the GUSC and LUSC details would not even be necessary, since the superstructure connections would never be subjected to fully-reversed positive moment action. Observation and experience has clearly demonstrated that such an analysis is misleading, and thankfully the "Staged" model provided much more realistic results. The connection moment in the staged model varied from about -170 kip-ft at peak horizontal ground motion in one direction to around +160 kip- $\mathrm{ft}$ at peak horizontal motion in the other 
direction. This analysis verified that the "Staged" approach provided a more desirable way to appropriately simulate connection conditions under seismic loading.

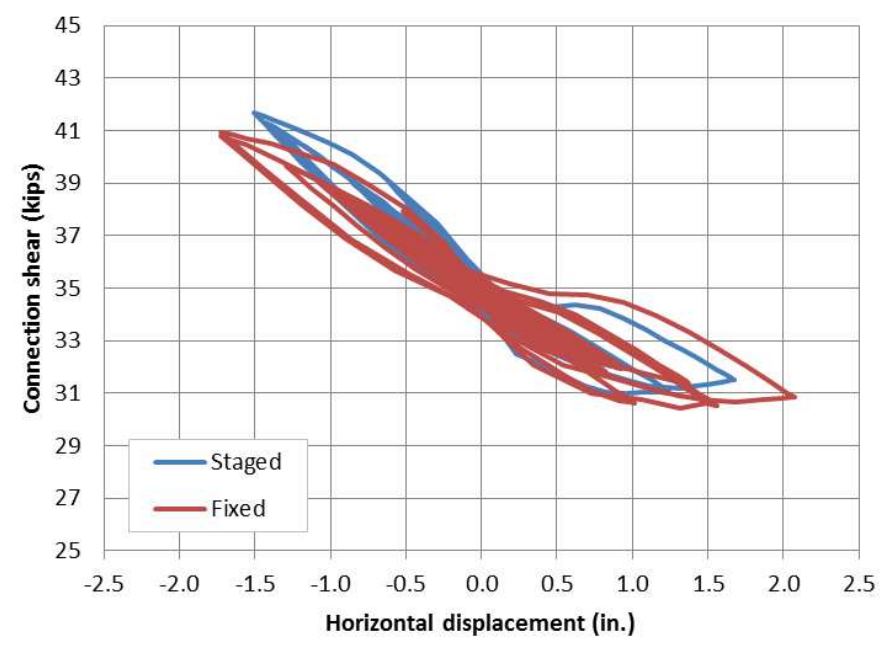

a. Connection shear

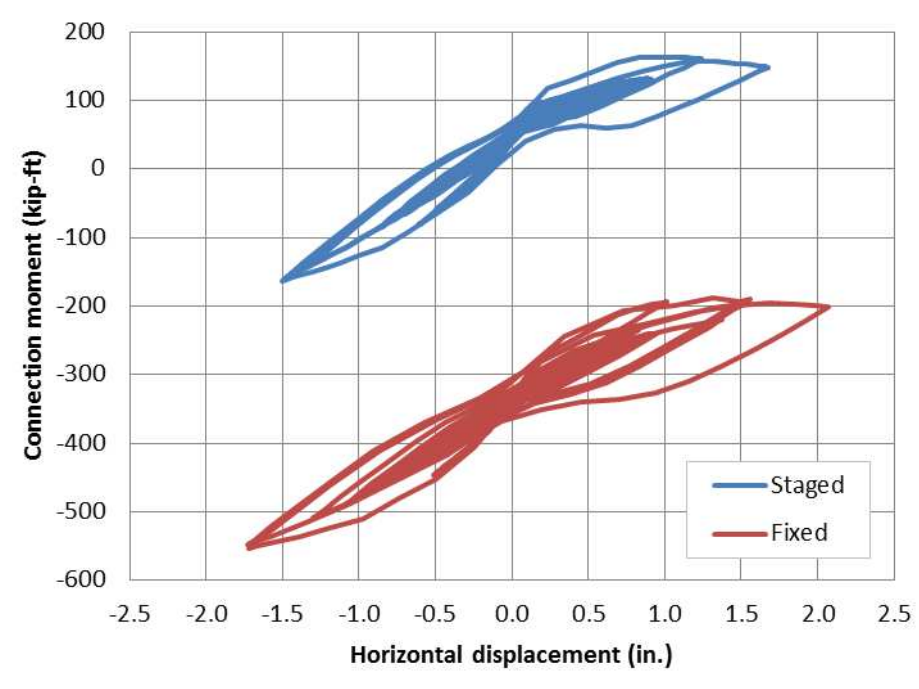

b. Connection moment

Figure 6.8. Connection behavior under cyclic horizontal ground motion analysis, comparing results with and without staged elements

The addition of the staged elements, when no vertical load is present, does not affect the rotational stiffness of the superstructure due to moments at the top of the column. The roller-type supports at the 
ends of the staged elements result in a link-mechanism type of behavior that freely rotates and slides back and forth when moments are introduced in the column region. However, when vertical loads are introduced along the superstructure elements, the additional parallel elements do affect the stiffness distribution throughout the structure, because of the combined flexural action that occurs in both of the staged and parallel superstructure elements. Care in maintaining a close representation of the actual relative stiffnesses was important to provide meaningful moment distribution results in the interaction of the column and the two sides of the superstructure.

To provide realistic relative stiffnesses in the model, the superstructure section properties were adjusted based on comparison of the OpenSees and grillage model results. The properties for the fixed superstructure elements were based on approximately 50 percent of the gross section properties, to provide a reasonable approximation of cracked and uncracked properties in the positive and negative moment directions. The section properties for the additional staged elements, however, were based on only 10 percent of the fixed element properties (approximately 5 percent of the gross section properties), to minimize their effect on the overall superstructure behavior. Figure 6.9 shows the comparison of shear and moment diagrams from the OpenSees and grillage analyses, following the superstructure stiffness adjustment, under a horizontal load condition producing the column overstrength moment in the top of the column. While the node locations and concentrated self-weight loads in the OpenSees model result in slightly different profiles along the girder length, as shown in Figure 6.9a, the shear values for the two models in the connection region compare very well. Figure 6.9b reveals an excellent comparison for the moment diagrams of the two models, both in the connection region and along the entire length of the girders. 


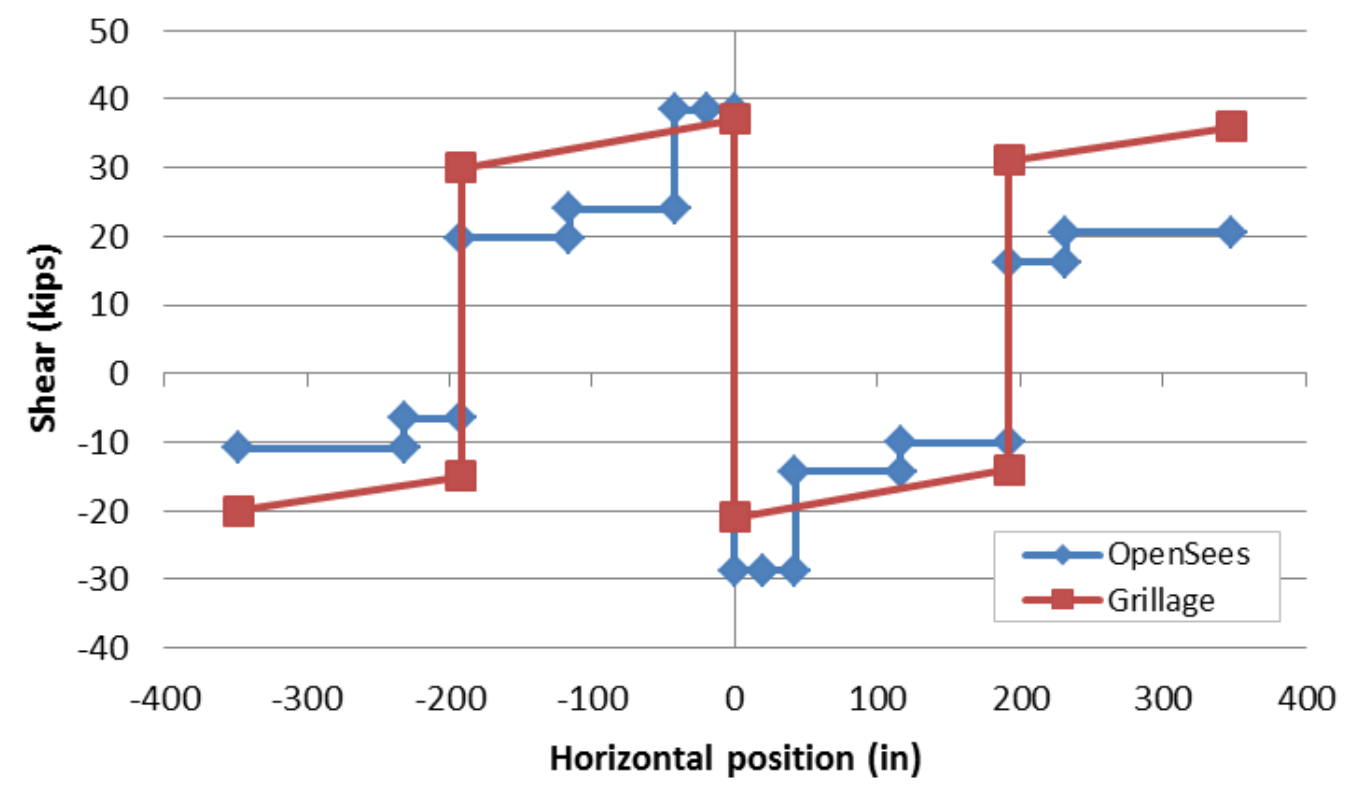

a. Shear diagram for center girder along girder length

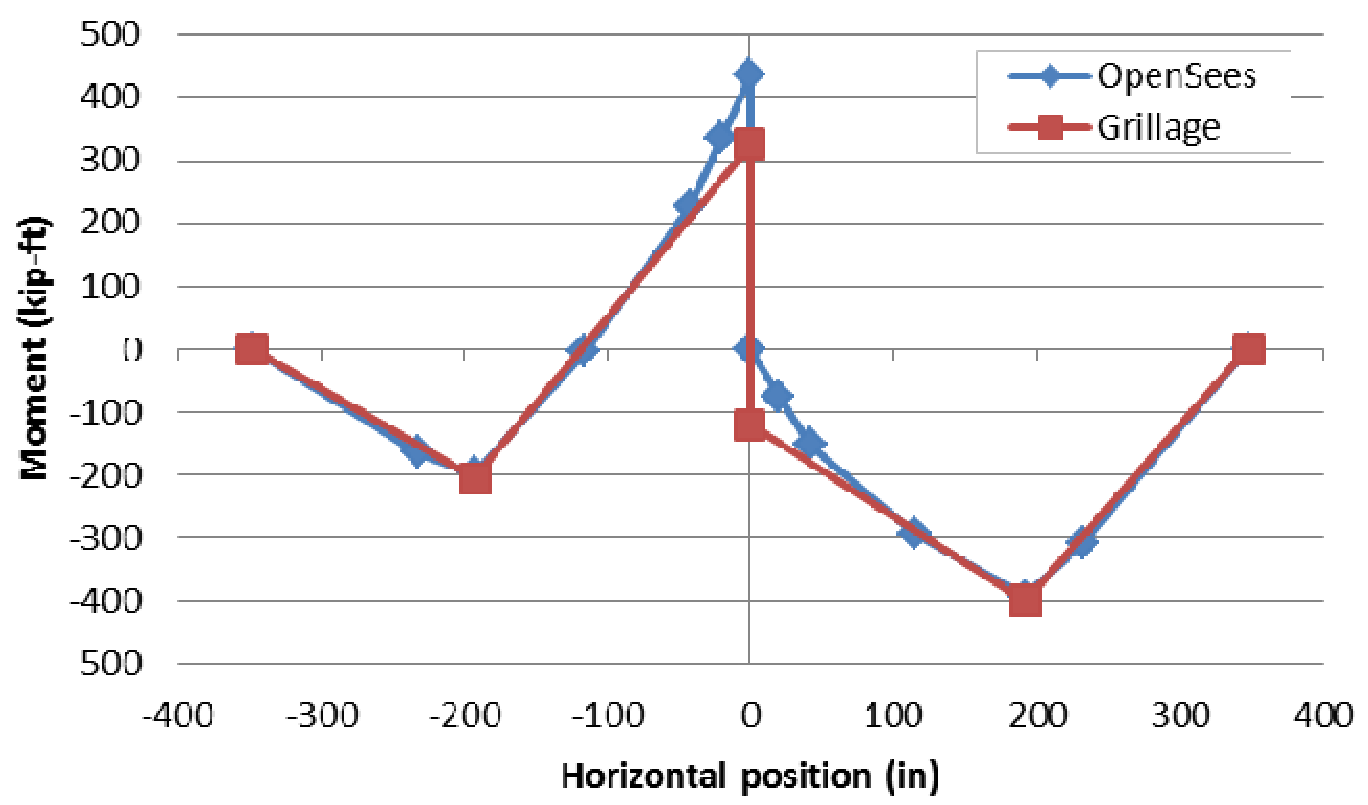

b. Moment diagram for center girder along girder length

Figure 6.9. Superstructure behavior under horizontal static analysis 


\subsection{Analytical Verification of the Superstructure Performance}

\subsubsection{Horizontal Loading for Verification of the Model}

Three different horizontal load/displacement analyses were conducted to investigate the overall performance of the analytical model prior to focusing on superstructure behavior and incorporating vertical acceleration effects. First, a pushover analysis was conducted, and the horizontal forcedisplacement response from the OpenSees model was compared with the system test experimental results. Figure 6.10a provides this comparison by showing the experimental results, the OpenSees results for the fixed model without staged elements, and the OpenSees results including the staged elements. The fixed model is seen to be a very close match with the experimental results, but the model including staged elements matches quite closely also. Since the primary purpose of the OpenSees model is to investigate the superstructure behavior, the results from the staged model are deemed to match closely enough with the overall results to provide meaningful superstructure action comparison.

These good comparisons verify that the fiber-based beam-column element approach for modeling the column, including the incorporation of strain penetration in the plastic hinge regions, is a good approach for incorporating nonlinear reinforced concrete column behavior. The comparison also indicates that the use of elastic elements to represent the superstructure, using appropriate stiffness values, provided a suitable representation of the overall behavior of the bridge system. 


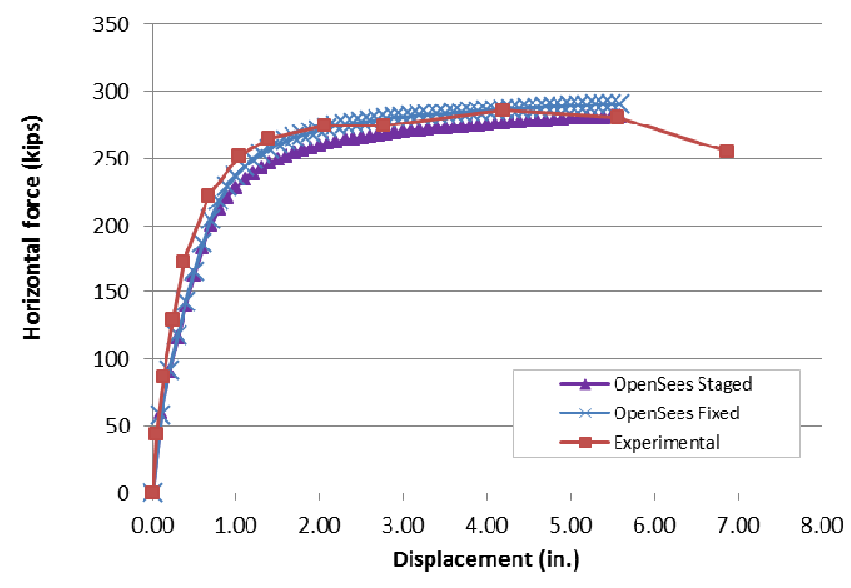

a. Pushover analysis

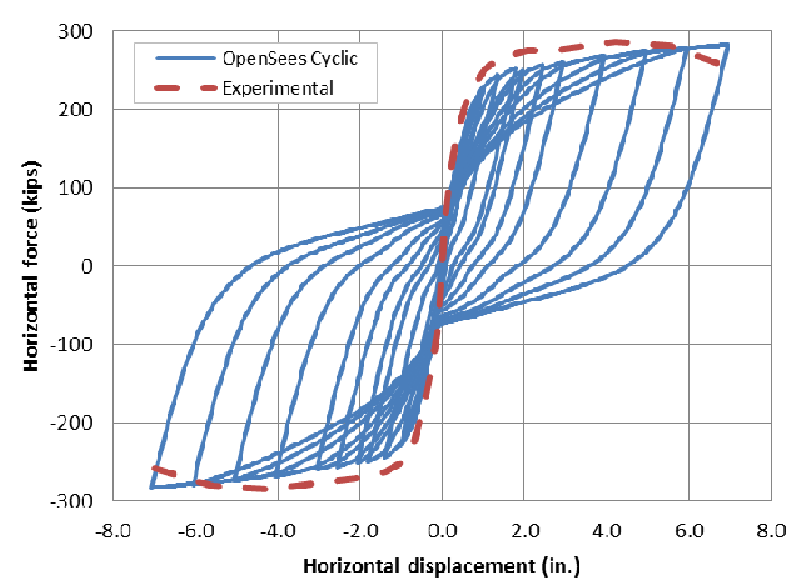

b. Cyclic pushover analysis

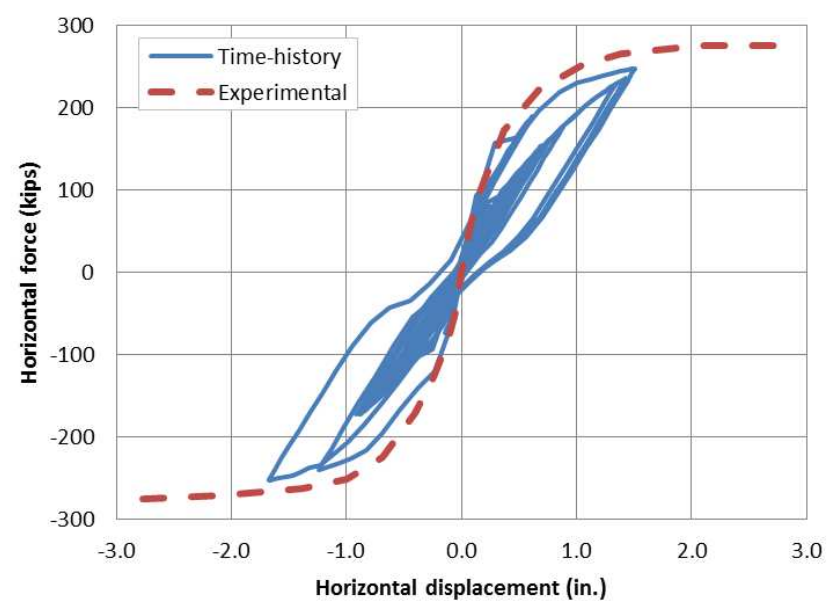

c. Time-history analysis using recorded ground motion from El Centro event

\section{Figure 6.10. Analytical horizontal force-displacement response for various excitation conditions}


The next horizontal load method that was used to investigate the model performance was a cyclic horizontal pushover analysis. Displacement control was used in the model to generate the results shown in Figure 6.10b. These results compare well with the experimental force-displacement envelope, also shown in the figure, further confirming the validity of the model.

The final verification based on horizontal load effects incorporated horizontal time-history ground motion data recorded during actual earthquake events. Figure $6.10 \mathrm{c}$ shows the results from an analysis that used ground motion data from the 1940 El Centro earthquake event in California, selected because of the large magnitude and relatively large ground motions recorded during this event. The results from the model again show envelope behavior that closely resembles the experimental envelope.

\subsubsection{Analytical Results in the Girder-to-Cap Connection Region}

Once the results from horizontal loading and ground motion analysis were used to verify the analytical model, vertical acceleration effects were incorporated to provide insight into the connection behavior. For comparison purposes, the three different approaches mentioned in the "Vertical Acceleration Analytical Approaches" section above were investigated. The first approach, which is the simplest from a modeling standpoint, was to introduce a uniform vertical acceleration to the model while utilizing time-history data for horizontal ground motion. A challenge of this approach, however, is deciding what uniform acceleration is appropriate.

One reference that provides insight into current thought related to vertical acceleration magnitude is Caltrans' Seismic Design Criteria (SDC, 2013). SDC currently requires that vertical acceleration must be incorporated for sites where the peak ground acceleration is at least $0.6 \mathrm{~g}$. When the vertical acceleration needs to be considered, SDC stipulates that the superstructure's nominal capacity shall be determined "based on a uniformly applied vertical force equal to $25 \%$ of the dead load applied upward and downward" (Section 7.2.2, SDC, 2013). Thus, an analysis that would include both dead load and vertical acceleration effects would consist of a constant load equal to $125 \%$ of the gravity load.

However, some earthquake events have revealed vertical accelerations considerably higher in magnitude than the $0.25 \mathrm{~g}$ stipulated above, the most notable being the Christchurch 2011 event where accelerations as high as $2 \mathrm{~g}$ were recorded (Kam and Pampanin, 2011). 0.25g seems to be a considerably unconservative estimate. Recall, however, the earlier discussion related to the rarity of vertical 
acceleration peaks and horizontal acceleration peaks occurring simultaneously. The lack of unanimity between peaks in the two loading directions means that applying a vertical acceleration equal to a onetime maximum peak magnitude that remains as a constant uniform load throughout the entirety of the varying horizontal ground motion magnitudes is likely overly conservative.

To investigate load magnitudes that comfortably satisfy the current SDC requirements yet are not unrealistically overconservative, a uniform vertical acceleration of $0.5 \mathrm{~g}$ was chosen for the constantvertical-acceleration analysis. The acceleration was applied to the model as a uniform ground motion, similar to using a vertical time-history record except using a constant value of $0.5 \mathrm{~g}$. The analysis was run twice, the first time incorporating a positive vertical acceleration and the second time using a negative vertical acceleration. For both runs, the recorded ground motion from the El Centro event was used for horizontal excitation.

The results for both connection shear and moment from these runs are provided in Figure 6.11. While the results from the vertical analyses are somewhat irregular, they reveal general trends that are unsurprising. In general, a positive vertical acceleration (signifying upward movement and therefore increased downward force) results in a considerable increase in connection shear as well as a negative shift in the connection moment. Conversely, a negative vertical acceleration (producing upward force) produces a similar shift in the opposite direction that decreases connection shear and shifts the connection moment in the positive direction.

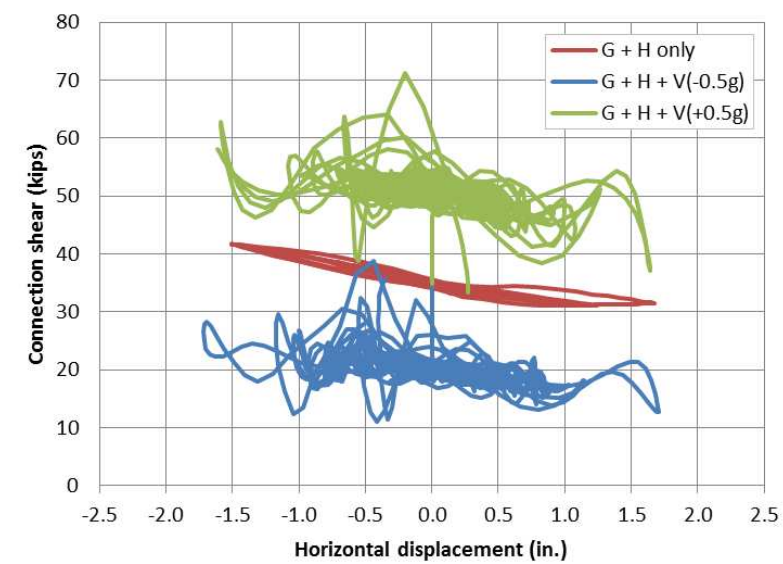

a. Connection shear

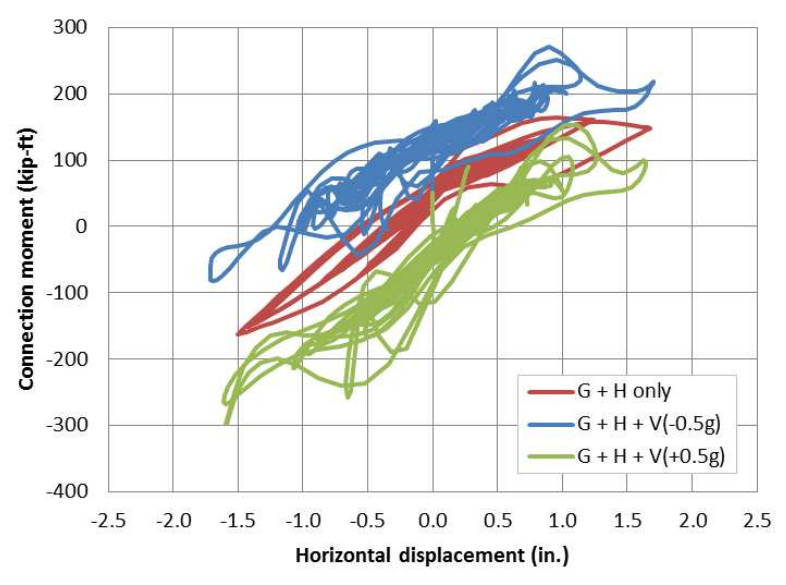

b. Connection moment

Figure 6.11. Connection behavior with El Centro horizontal ground motion and constant vertical acceleration $\pm 0.5 \mathrm{~g}$ 
Since the vertical acceleration during an earthquake is not really a constant magnitude but is rather much more sporadic, a more realistic way to model the vertical acceleration is to use the recommended $\mathrm{V} / \mathrm{H}$ ratio of $2 / 3$ based on $\mathrm{PGA}$ in both directions. For this approach, the recorded horizontal ground motion is used, and the vertical acceleration is defined as $2 / 3$ the instantaneous horizontal acceleration. This approach was utilized to produce the results shown in Figure 6.12, again using the El Centro ground motion. While the range of results from this analysis is considerably wider than the horizontal-only analysis, it is considerably lower than the envelope produced by the positive and negative vertical acceleration conditions in Figure 6.11. This comparison indicates that the use of a constant $0.5 \mathrm{~g}$ vertical acceleration is perhaps overconservative; this possibility is discussed further in the following section.

The other approach that was utilized for vertical acceleration incorporated actual recorded timehistory vertical ground motion data. Two events with especially large recorded vertical ground motions were used for this analysis, the 2011 Christchurch event in New Zealand and the 1994 Northridge event in southern California. To appropriate account for the $50 \%$ scale of the analytical model, the ground motion was factored by 2.0 and the time was factored by 0.5 , following the recommendation of Kumar et al (1997). Figure 6.13 provides the connection region results for these two analyses. In terms of shear and moment magnitude, the results in Figure 6.13a and Figure 6.13b, from the Christchurch event, show remarkably little change between the horizontal-only and the horizontal-plus-vertical ground motions. In fact, the maximum positive and negative moments from the horizontal-only condition are actually higher than the combined condition, because the addition of the vertical motion seems to have dampened the structure slightly and produced slightly reduced horizontal displacements. However, Figure $6.13 \mathrm{c}$ and Figure $6.13 \mathrm{~d}$ show a different result for the Northridge event. The addition of vertical acceleration makes a large difference, producing both shear and moment magnitudes even larger than the constant vertical acceleration magnitudes shown earlier in Figure 6.11. 


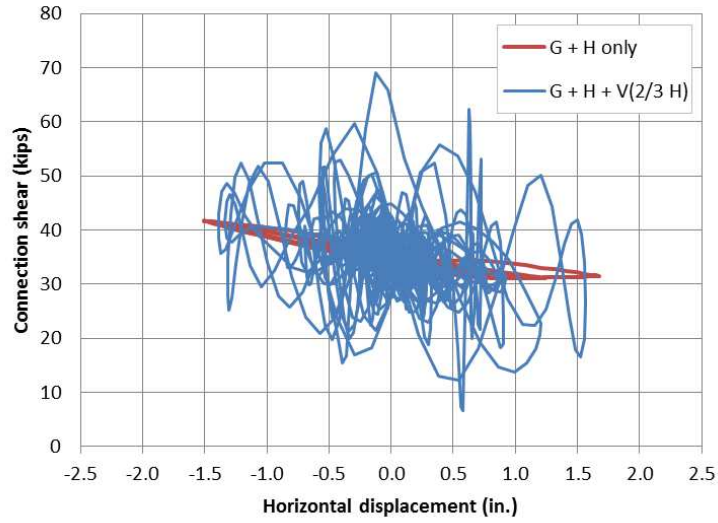

a. Connection shear

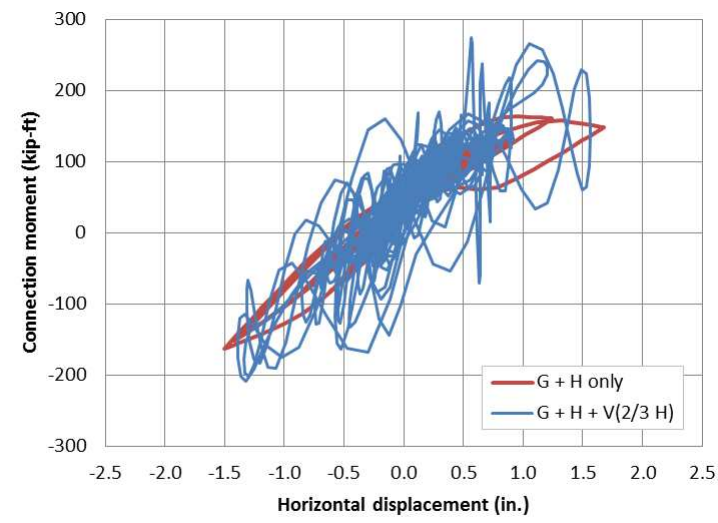

b. Connection moment

Figure 6.12. Connection behavior for El Centro horizontal ground motion and vertical ground motion equal to two-thirds horizontal ground motion

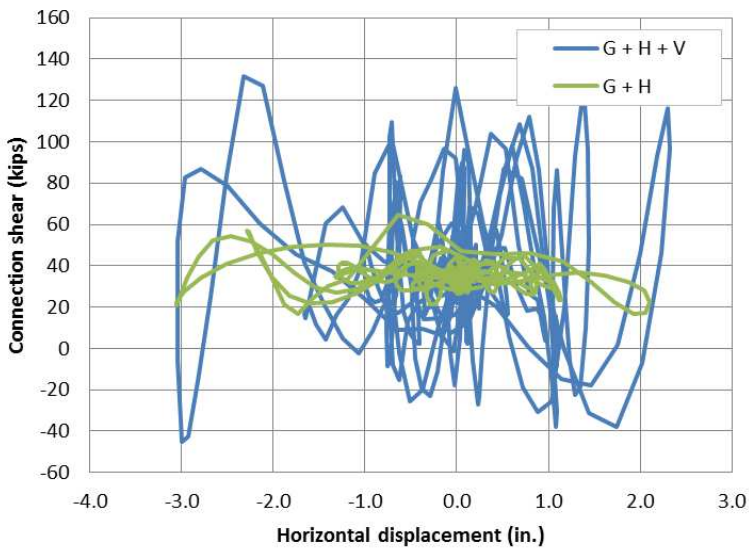

(a) Connection shear, ChristChurch event

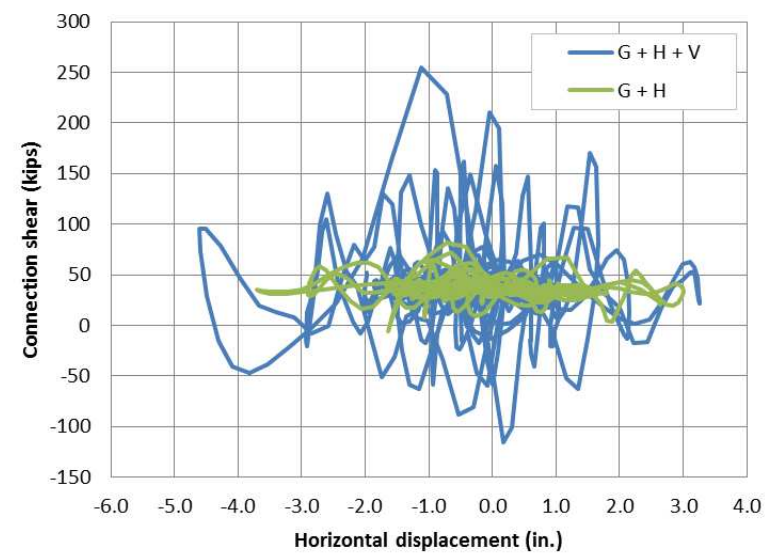

(c) Connection shear, Northridge event

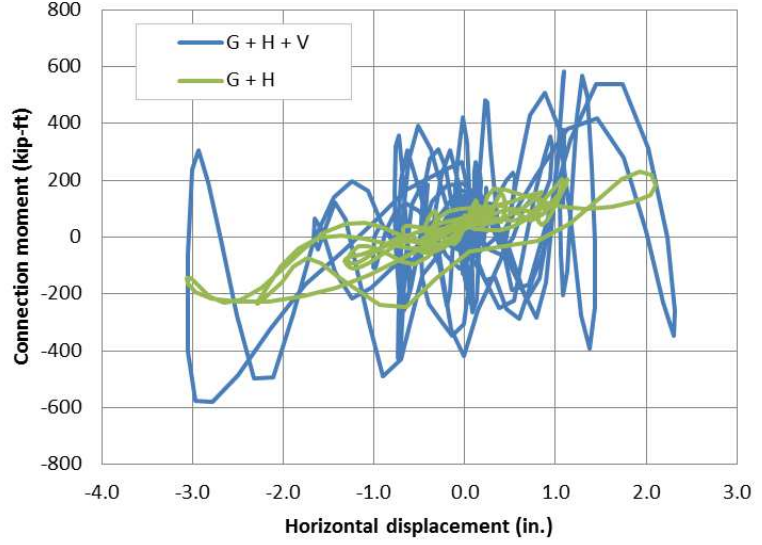

(b) Connection moment, ChristChurch event

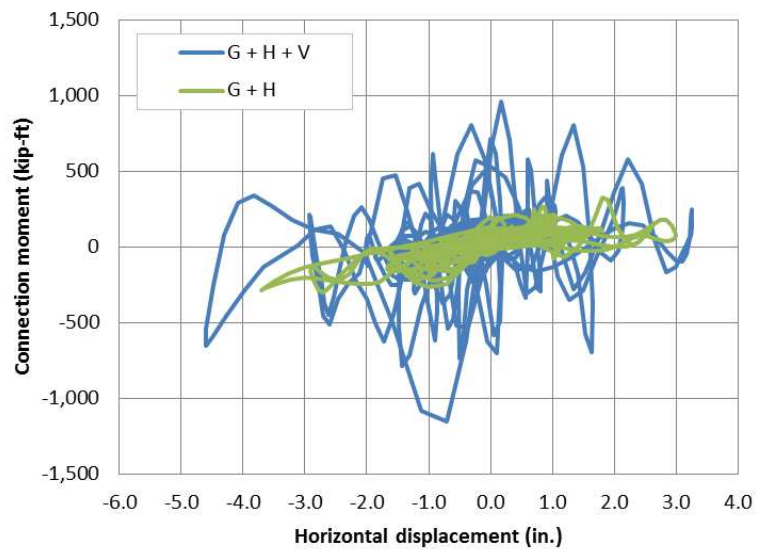

(d) Connection moment, Northridge event

Figure 6.13. Connection behavior using recorded horizontal and vertical ground motion 
The erratic behavior of the analyses presented above in Figure 6.11, Figure 6.12, and Figure 6.13 is somewhat unexpected. The actual recorded vertical accelerations used in Figure 6.13 might account for an irregular moment-displacement relationship when combined with different recorded horizontal accelerations, and likewise the factored actual recorded horizontal accelerations used in Figure 6.12 might be expected to produce slightly irregular results. However, the use of a constant vertical acceleration is expected to merely shift the horizontal-only curve while maintaining the horizontal-only shape, but as Figure 6.11 shows, the curves that include vertical acceleration have a significantly more irregular shape than the horizontal-only curves.

To investigate whether this irregularity is cause for concern, the connection shear history as a function of time for each of the curves in Figure 6.11a is presented in Figure 6.14. This plot reveals that the analyses that include vertical acceleration have a tendency to follow the horizontal-only analysis, except there is a high-frequency vibration that also occurs in addition to the lower-frequency horizontalonly behavior. Further investigation of recorded horizontal and vertical accelerations from the analysis has revealed that there is an issue with the vertical damping in the analysis. In the horizontal direction, the damping is sufficient to prevent the high-frequency vibrations, but the vertical damping is ineffective in preventing the vertical high-frequency vibrations. While continuing investigation of this issue would be beneficial, the high-frequency vibrations do not drastically affect the overall response of the model. The analyses detailed in Figure 6.11, Figure 6.12, and Figure 6.13 are primarily focused on peak values and envelope responses, and the high frequency vibration has little effect on these overall responses, so the analyses are still meaningful in improving understanding of vertical acceleration effects.

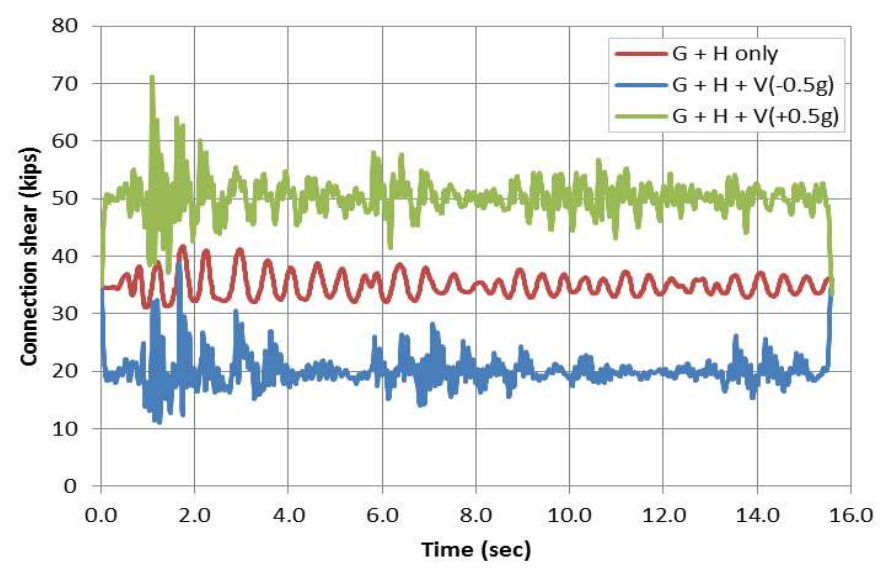

Figure 6.14. Connection shear history for El Centro horizontal ground motion and constant vertical acceleration $\pm 0.5 \mathrm{~g}$ 


\subsubsection{Comparison of the Experimental and Analytical Results}

Magnitudes of connection shear and moment demand during the experimental connection tests are provided in Table 6.5. " $\mathrm{G}+\mathrm{H}$ " represents the load condition simulating gravity load and full horizontal load, based on the column overstrength moment. The next three load conditions include $\mathrm{V}_{0.25 \mathrm{~g}}, \mathrm{~V}_{0.75 \mathrm{~g}}$, and $V_{1.25 g}$, with subscripts indicating the magnitude of vertical acceleration included in addition to the gravity and full horizontal seismic condition. The final three conditions, D1, D2, and D3, simply utilized large displacement conditions that were not intended to simulate specific seismic conditions. Rather, these conditions were utilized to fully exercise the girder-to-cap connections well beyond any expected earthquake loading. Percentage comparisons, identified as "\%(G $+\mathrm{H})$," are included to identify how each load condition relates to the full gravity-plus-horizontal condition.

Table 6.5. Connection behavior under experimental loading

\begin{tabular}{|c|c|c|c|c|}
\hline Load condition & $\begin{array}{c}\mathrm{V}(+) \\
(\text { kips })\end{array}$ & $\begin{array}{c}\mathrm{V}(-) \\
\text { (kips) }\end{array}$ & $\begin{array}{c}\mathrm{M}(+) \\
\text { (kip-ft) }\end{array}$ & $\begin{array}{c}\mathrm{M}(-) \\
\text { (kip-ft) }\end{array}$ \\
\hline $\mathrm{G}+\mathrm{H}$ & 25.5 & 38.6 & 76.4 & -251.3 \\
\hline $\mathrm{G}+\mathrm{H}+\mathrm{V}_{0.25 \mathrm{~g}}$ & 22.4 & 42.7 & 106.7 & -293.4 \\
\hline$\%(\mathrm{G}+\mathrm{H})$ & $-12.2 \%$ & $10.6 \%$ & $39.7 \%$ & $16.8 \%$ \\
\hline $\mathrm{G}+\mathrm{H}+\mathrm{V}_{0.75 g}$ & 8.8 & 57.9 & 239.1 & -434.4 \\
\hline$\%(\mathrm{G}+\mathrm{H})$ & $-65.5 \%$ & $50.0 \%$ & $213.0 \%$ & $72.9 \%$ \\
\hline $\mathrm{G}+\mathrm{H}+\mathrm{V}_{1.25 g}$ & -6.1 & 70.6 & 334.6 & -524.8 \\
\hline$\%(\mathrm{G}+\mathrm{H})$ & $-123.9 \%$ & $82.9 \%$ & $338.0 \%$ & $108.8 \%$ \\
\hline $\mathrm{D} 1$ & -23.8 & 61.8 & 379.7 & -824.6 \\
\hline$\%(\mathrm{G}+\mathrm{H})$ & $-193.3 \%$ & $60.1 \%$ & $397.0 \%$ & $228.1 \%$ \\
\hline $\mathrm{D} 2$ & -24.8 & 65.3 & 410.7 & -917.6 \\
\hline$\%(G+H)$ & $-197.3 \%$ & $69.2 \%$ & $437.6 \%$ & $265.1 \%$ \\
\hline $\mathrm{D3}$ & -26.3 & 69.9 & 436.2 & -1027 \\
\hline$\%(G+H)$ & $-203.1 \%$ & $81.1 \%$ & $470.9 \%$ & $308.7 \%$ \\
\hline
\end{tabular}


A quick look at the percentage comparisons in this table reveals the significant shear and moment demands that were generated (and successfully resisted) in the connection regions during the connection tests. Over three times the full gravity-plus-horizontal seismic moment was generated in both the positive and negative moment directions, and over double the positive (uplift) shear was generated. The lowest percentage increase exercised was in the downward shear direction, but even this load was over $80 \%$ higher than the full gravity-plus-horizontal seismic condition. The downward shear action is in fact a non-issue since this increase simply results in a more direct force transfer between the girder dapped end and the cap corbel; failure mechanisms related to the other three actions are much more likely. Thus, it appears the experimental load sequence was quite effective in generating connection region demands well in excess of what would be expected in a real structure. 
Table 6.6 provides some of the analytical results in a similar format for comparison purposes. The results shown in this table include the runs incorporating constant vertical acceleration upwards and downwards, identified as " $\mathrm{G}+\mathrm{H}+\mathrm{V}_{0.5 \mathrm{~g}}$ " and " $\mathrm{G}+\mathrm{H}-\mathrm{V}_{0.5 \mathrm{~g}}$." The run that incorporated vertical acceleration with a magnitude equal to $2 / 3$ the instantaneous horizontal acceleration is also included, identified as " $\mathrm{G}+\mathrm{H}+\mathrm{V}_{2 / 3 \mathrm{H}}$." Similarly to the experimental data, the full gravity-plus-horizontal-seismic condition is included, labeled " $\mathrm{G}+\mathrm{H}$," and the percentage comparisons of this load condition with the other load conditions are included. Noteworthy in this table is that the maximum values for positive shear, negative shear, and negative moment occur during one of the constant vertical acceleration load conditions. The only action where the $\mathrm{V}=2 / 3 \mathrm{H}$ condition produces the maximum magnitude is positive moment, but even this value is only $2.1 \%$ different from the maximum constant-vertical-acceleration magnitude. This observation indicates that the envelope established by analyzing the constant positive and negative vertical accelerations may provide a suitable (and perhaps oftentimes even conservative) approach in considering shear and moment demands during design. 
Table 6.6. Connection behavior from analytical models using El Centro ground motion

\begin{tabular}{|c|c|c|c|c|}
\hline Load condition & $\begin{array}{c}\mathrm{V}(+) \\
\text { (kips) }\end{array}$ & $\begin{array}{c}\mathrm{V}(-) \\
\text { (kips) }\end{array}$ & $\begin{array}{c}\mathrm{M}(+) \\
\text { (kip-ft) }\end{array}$ & $\begin{array}{c}\mathrm{M}(-) \\
\text { (kip-ft) }\end{array}$ \\
\hline $\begin{array}{c}\text { El Centro } \\
\mathrm{G}+\mathrm{H}\end{array}$ & 31.2 & 41.5 & 177.7 & -161.4 \\
\hline $\begin{array}{c}\text { El Centro } \\
\mathrm{G}+\mathrm{H}+\mathrm{V}_{0.5 \mathrm{~g}}\end{array}$ & 35.0 & 71.2 & 151.8 & -297.4 \\
\hline$\%(\mathrm{G}+\mathrm{H})$ & $12.2 \%$ & $71.6 \%$ & $-14.6 \%$ & $84.3 \%$ \\
\hline $\begin{array}{c}\mathrm{EI} \text { Centro } \\
\mathrm{G}+\mathrm{H}-\mathrm{V}_{0.5 \mathrm{~g}}\end{array}$ & 12.7 & 38.9 & 270.3 & -73.6 \\
\hline$\%(\mathrm{G}+\mathrm{H})$ & $-59.3 \%$ & $-6.3 \%$ & $52.1 \%$ & $-54.4 \%$ \\
\hline $\begin{array}{c}\mathrm{EI} \text { Centro } \\
\mathrm{G}+\mathrm{H}+\mathrm{V}_{2 / 3 \mathrm{H}}\end{array}$ & 7.4 & 69.1 & 274.0 & -200.8 \\
\hline$\%(\mathrm{G}+\mathrm{H})$ & $-76.3 \%$ & $66.5 \%$ & $54.2 \%$ & $24.4 \%$ \\
\hline
\end{tabular}

Another noteworthy observation is that the maximum analytical values are considerably lower than the demand generated during the experimental connection test. The maximum percentage comparisons for positive shear, negative shear, positive moment, and negative moment are $76 \%, 72 \%, 54 \%$, and $84 \%$, respectively, all significantly lower than the corresponding experimental demand percentage comparisons. This observation indicates that the demand generated during the experimental work was sufficient to fully quantify the connection behavior. It also helps to validate the conclusion from the experimental work that both the GUSC and LUSC details are sufficient to ensure elastic superstructure behavior in high seismic regions.

Table 6.7 provides similar comparisons as the previous two tables, but for the analytical runs that incorporated the actual vertical ground motion data from the Christchurch and Northridge events. The percentage changes from gravity/horizontal to gravity/horizontal/vertical here are consistently larger than either of the analyses in Table 6.6 that incorporated vertical acceleration. Observing the results the ChristChurch event, the percentage increase in magnitude for all four actions (positive and negative shear and positive and negative moment) are reasonably consistent, varying from $203 \%$ at minimum to a reversal of $273 \%$ at maximum. For the Northridge event, the percent increases are even higher, 
varying from $294 \%$ to $2057 \%$ (although the $2057 \%$ number is a bit of an anomaly because of the very small maximum shear magnitude for the gravity/horizontal analysis).

Table 6.7. Connection behavior using recorded vertical ground motion

\begin{tabular}{|c|c|c|c|c|}
\hline Load condition & $\begin{array}{c}\mathrm{V}(+) \\
\text { (kips) }\end{array}$ & $\begin{array}{c}\mathrm{V}(-) \\
\text { (kips) }\end{array}$ & $\begin{array}{c}\mathrm{M}(+) \\
\text { (kip-ft) }\end{array}$ & $\begin{array}{c}\mathrm{M}(-) \\
\text { (kip-ft) }\end{array}$ \\
\hline $\begin{array}{c}\text { ChristChurch } \\
\mathrm{G}+\mathrm{H}\end{array}$ & 16.5 & 64.9 & 231.5 & -236.1 \\
\hline $\begin{array}{c}\text { ChristChurch } \\
\mathrm{G}+\mathrm{H}+\mathrm{V}\end{array}$ & -45.1 & 131.8 & 560.4 & -579.2 \\
\hline$\%(\mathrm{G}+\mathrm{H})$ & $-273 \%$ & $203 \%$ & $242 \%$ & $245 \%$ \\
\hline $\begin{array}{c}\text { Northridge } \\
\mathrm{G}+\mathrm{H}\end{array}$ & -5.6 & 81.9 & 326.6 & -272.0 \\
\hline $\begin{array}{c}\text { Northridge } \\
\mathrm{G}+\mathrm{H}+\mathrm{V}\end{array}$ & -115.2 & 255.0 & 961.8 & -1152.7 \\
\hline$\%(\mathrm{G}+\mathrm{H})$ & $2057 \%$ & $311 \%$ & $294 \%$ & $424 \%$ \\
\hline
\end{tabular}

Comparing how much higher these percentages are than the vertical analyses presented earlier in Table 6.6, it appears that the constant vertical acceleration approach and the two-thirds-horizontal vertical acceleration approach might not be that predictive when it comes to earthquake events with extremely large vertical ground motions. However, it is probably more likely that the analysis is producing unreasonably high results when large vertical accelerations are introduced. The highfrequency vertical vibration that was noted earlier could play a larger role in affecting the results when large-magnitude vertical ground motions are introduced, unnecessarily magnifying the response. It would be beneficial to continue to investigate the vertical damping issue mentioned above to determine whether the resolution of this issue would produce more reasonable results for analyses that include both large horizontal and large vertical ground motions.

\subsection{Conclusions}

1. Based on the experimental and analytical results, a vertical acceleration magnitude of $0.5 \mathrm{~g}$ upward produces an increase in connection shear under negative moment loading of approximately $36 \%$ and an increase in negative moment magnitude of approximately $67 \%$ from 
the full gravity-plus-horizontal seismic condition. A vertical acceleration magnitude of $0.5 \mathrm{~g}$ downward produces a decrease in connection shear of approximately $70 \%$ and an increase in positive moment of approximately $140 \%$. Similarly, a vertical acceleration magnitude of $1.0 \mathrm{~g}$ upward produces increases in shear and negative moment of $75 \%$ and $90 \%$, respectively, and a vertical acceleration magnitude of $1.0 \mathrm{~g}$ downward produces a decrease in connection shear of $95 \%$ and an increase in positive moment of $270 \%$.

2. Addition of vertical acceleration does little to change the column behavior, which is largely dictated by horizontal ground motion and plastic hinge behavior.

3. While vertical accelerations higher than $0.25 \mathrm{~g}$ are likely to occur, they tend to occur nonsimultaneously with horizontal peaks. Consequently, while the $0.25 \mathrm{~g}$ vertical acceleration recommendation in Caltrans' SDC may be unconservative, it is a reasonable approximation. When a constant acceleration of $0.5 \mathrm{~g}$ vertical acceleration was used, the envelope of connection behavior was considerably larger than the envelope produced by considering vertical ground motion equal to $2 / 3$ the horizontal ground motion.

4. Fiber-based beam-column elements with zero-length elements including strain penetration effects in the plastic hinge regions provide an effective analytical model for predicting overall horizontal force-displacement response.

5. Two-dimensional elastic superstructure elements provide a viable way to model the girder-tocap connection response, including shear and moment effects.

6. The shear and moment demand generated in the experimental connection test was considerably higher than seismic effects on the connections predicted by an analytical model incorporating gravity, horizontal ground motion, and constant vertical acceleration. Likewise, the experimental demand was significantly higher than the demand predicted by an analytical model that incorporated gravity, horizontal ground motion, and vertical ground motion equal to two-thirds the horizontal ground motion. The sufficiency of the GUSC and LUSC details to ensure elastic superstructure behavior under high seismic load and displacement, as shown by the experimental work, is further validated by these analytical models.

7. The analyses that incorporated recorded vertical ground motion data from the ChristChurch and Northridge earthquake events did not compare well with the analysis that used constant vertical acceleration or the analysis that implemented two-thirds the horizontal ground motion in the vertical direction. While these discrepancies may indicate shortcomings in the constant 
acceleration or two-thirds horizontal approaches, more investigation is needed to verify the analyses incorporating recorded vertical ground motions.

\subsection{References}

Ambraseys, N. N., and Douglas, J. (2003). "Near-field horizontal and vertical earthquake ground motions," Soil Dynamics and Earthquake Engineering, 23(1), 1-18.

Ambraseys, N. N., Simpson, K. A., and Bommer, J. J. (1996). "Prediction of Horizontal Response Spectra in Europe." Earthquake Engineering and Structural Dynamics. 25, 371-400.

American Concrete Institute (ACI). (2011). Building Code Requirements for Structural Concrete (ACl 31811). Farmington Hills, MI: American Concrete Institute.

Applied Technology Council (ATC). (1996). Improved Seismic Design Criteria for California Bridges: Provisional Recommendations. Redwood City, CA: Applied Technology Council.

Caltrans, (2013), Seismic Design Criteria, Version 1.7, Caltrans, Sacramento, CA.

Chang, G.A., and Mander, J.B. (1994). "Seismic Energy Based Fatigue Damage Ananlysis of Bridge Columns: Part 1 - Evaluation of Seismic Capacity," NCEER Technical Report No. NCEER-94-0006, State University of New York, Buffalo, N.Y.

Gulerce, Z., and Abrahamson, N. N. (2011). "Site-specific spectra for vertical ground motion," Earthquake Spectra, 27(4).

Kalkan, E. and Gulkan, P. (2004). "Empirical attenuation equations for vertical ground motion." Earthquake Spectra, 20(3), 853-882.

Kam, W.Y. and Pampanin, S. (2011). General Building Performance in the Christchurch CBD: a contextual report. Christchurch, New Zealand: University of Canterbury. Online: http://www.dbh.govt.nz/ UserFiles/File/Reports/quake-contextual-report-canterbury-uni.pdf. Accessed October 2012.

Kumar, S., Itoh, Y., Saizuka, K., and Usami, T. "Pseudodynamic Testing of Scaled Models." ASCE Journal of Structural Engineering, 123(4), 524-526.

NCHRP (2011). "Application of Accelerated Bridge Construction Connections in Moderate-to-High Seismic Regions." NCHRP Report 698. Washington, D.C.: Transportation Research Board.

Open System for Earthquake Engineering Simulation (OpenSees). (2013). Version 2.4.1.2. http://opensees.berkeley.edu/ 
Priestley, M. J. N., Seible, F. and Calvi, G. M. (1996). Seismic Design and Retrofit of Bridges. New York: John Wiley \& Sons, Inc.

Snyder, Richard. (2010). Seismic performance of an l-girder to inverted-t bent cap bridge connection. Masters degree thesis. Ames, lowa: lowa State University.

Snyder, R., Vander Werff, J., Thiemann, Z., Sritharan, S., Holombo, J., (2011), Seismic Performance of an I-Girder to Inverted-T Bent Cap Connection, Final Report, Caltrans, Sacramento, CA, and lowa State University (ISU), Ames, IA.

Spacone E., Filippou F.C., Taucer F.F. (1996). "Fibre beam-column element for nonlinear analysis of R/C frames. Part I: Formulation." Earthquake Engineering and Structural Dynamics, 25:711-725.

Sritharan, S., Bromenschenkel, R., Vander Werff, J., \& Peggar, R. (2013). Two alternate connections for integral precast concrete girder bridges in seismic regions. In Proceedings of the Seventh National Seismic Conference on Bridges \& Highways. Oakland, CA.

Tezcan, J., and Cheng, Q. (2012). "A nonparametric characterization of vertical ground motion effects." Earthquake Engineering and Structural Dynamics. 41(3): 515-530, March 2012.

Thiemann, Zachary J. (2009). Pretest 3-D finite element analysis of the girder-to-cap-beam connection of an inverted-tee cap beam designed for seismic loadings. Masters degree thesis. Ames, lowa: lowa State University.

Vander Werff, J. and Sritharan, S. (2014). "Girder Load Distribution for Seismic Design of Integral Bridges." ASCE Journal of Bridge Engineering. (Currently under finalization for publication.)

Waugh, J. D., and Sritharan, S. (2010). "Lessons learned from seismic analysis of a seven-story concrete test building," Journal of Earthquake Engineering, 14(3), 448-469.

Yang, J., and Lee, C. M. (2007). "Characteristics of vertical and horizontal ground motions recorded during the Niigata-ken Chuetsu, Japan Earthquake of 23 October 2004," Engineering Geology, 94(12), 50-64, October 2007.

Yassin, M. H. M. (1994). "Nonlinear Analysis of Prestressed Concrete Structures under Monotonic and Cycling Loads", PhD dissertation, University of California, Berkeley.

Zhao, J., and S. Sritharan. (2007). "Modeling of strain penetration effects in fiber-based analysis of reinforced concrete structures." ACI Structural Journal, 104(2), 133-141. 


\section{CHAPTER 7. PRIMARY CONCLUSIONS}

The inverted tee bridge system with appropriate girder-to-cap connections has been proposed as a design that is well-suited for the implementation of $A B C$ methods in high seismic regions. Experimental and analytical investigations have been conducted to examine the sufficiency of the system and quantify various aspects of its performance under seismic loading. The following summaries describe the primary conclusions from the work that is presented in this dissertation.

\subsection{Inverted-tee bridge system}

The inverted-tee bridge system provides a viable design for implementing $A B C$ methods in seismic regions. Dapped-end precast girders can be easily positioned on cast-in-place or precast inverted-tee cap beams, providing simple and efficient field erection. Cast-in-place diaphragms can be used to establish fixity in the connections, providing an integral superstructure. Integral connections at the girder-to-cap connections allow the top of the column to be detailed as a plastic hinge, providing an additional location for energy absorption during high seismic displacements and improving the bridge structure's seismic performance. Significant moment capacity is provided by the existing Caltrans girderto-cap connection detail, which incorporates dowel bars that pass through the girder and are embedded

in the cast-in-place diaphragm. However, the connection performance under seismic loading can be markedly improved by providing positive moment tension transfer mechanisms between the girder and cap beam.

\subsection{Performance of GUSC and LUSC details}

The GUSC and LUSC details offer considerable improvements to the current Caltrans girder-to-cap connection detail for inverted-tee-cap/dapped-end-girder bridge systems.

In the GUSC detail, the dowel bars that are similar to the existing Caltrans detail act with the unstressed strand in the girder lower flange; each mechanism resists a portion of the connection moment. Preliminary findings from the connection test indicate that the combined dowel bar and strand mechanism increases the positive moment resistance by about 1.7 over what would be expected in the strand mechanism alone. Proposed design recommendations for the GUSC detail should take the combined dowel bar and strand mechanism into account, but additional investigation would be helpful to further quantify the performance of this mechanism and develop final design recommendations. 
The LUSC detail utilizes looped strands that extend from the cap beam into the cast-in-place diaphragm along with looped strand precast in the girder web and bottom flange. Dowel bars are then extended through the loops, protruding from each edge of the girder, and embedded in the diaphragm inside the cap beam loops. Although not providing a direct tension path for positive moment, the mechanism significant increases the positive moment performance of the connection region.

Both the GUSC and LUSC details were experimentally verified to provide full integral behavior up to seismic loading well in excess of the full gravity, horizontal column overstrength, and $1.25 \mathrm{~g}$ vertical acceleration condition. The experimental work demonstrated that the connection details were capable of remaining elastic when subjected to connection shear and moment conditions during extreme seismic loading, providing an integral superstructure and allowing formation of a plastic hinge in the column just below the cap beam. The performance of both details exceeded current Caltrans requirements and showed their capability to provide robust connections suitable for incorporating $A B C$ in high seismic regions.

\subsection{Integral bridge superstructure seismic load distribution}

Improvements are needed in current recommendations related to the distribution of column overstrength moment between interior and exterior girders in integral bridge superstructures. Experimental work from several large scale studies repeatedly showed that the exterior girder connections at the cap beam resist significant portions of the column moment due to lateral seismic load. The effectiveness of the exterior girders was observed at both small lateral loads as well as large lateral displacements. This performance is contrary to current recommendations for integral bridge superstructures.

A simple stiffness model was developed to predict the lateral load distribution between the interior and exterior girders. The model uses local member stiffness values and the overall structure schematic to develop the relative stiffness magnitudes of the interior and exterior girders. These stiffness comparisons are then used to predict how the lateral load will be distributed. Results from this model compared very well with more complex analytical techniques such as grillage and finite element models. The results also compared very favorably with the experimental results. The simple stiffness model can provide an effective approach for predicting lateral load distribution and designing girder connections in 
integral bridges structures more appropriately, in lieu of following the overly conservative approaches provided in current design recommendations.

\subsection{Design recommendations for the GUSC and LUSC details}

Experimental results from the connection tests of the GUSC and LUSC details were used to begin to formulate design recommendations for each of the details.

In the GUSC detail, the positive moment resistance is generated by two distinct mechanisms: shearfriction from the interaction between the dowel bars and diaphragm concrete, and the moment capacity generated by the tension in the unstressed strand and the compression in the region of the girder top flange. Under high seismic displacements, deterioration of the diaphragm concrete decreases the effectiveness of the shear-friction mechanism and transfers additional moment to the strand. Verification of the capacity of the shear-friction mechanism will allow the strand in the GUSC detail to be designed to resist the additional positive moment required to provide full strength, providing a clear design approach for the strand in the GUSC detail.

In the LUSC detail, the interaction between the dowel bars in flexure and the looped strands in confinement tension provides a viable positive moment tension transfer mechanism. A shear friction model considering the positive moment tension in the dowel bar region can be used to size the dowel bars. Subsequently, a force ratio of 1.0 between the dowel bar capacity and looped strand capacity can be used to size the looped strand. Further investigation is recommended to more fully quantify the dowel bar and looped strand behavior and finalize the design recommendations for this detail.

\subsection{Two-dimensional model for overall system seismic response}

A two-dimensional model incorporating fiber-based beam-column elements for the column and linear elastic elements for the superstructure works well for overall force-displacement response. A model using this approach was developed for the system test unit and provided excellent results for pushover, cyclic, and time-history loading approaches. The horizontal force-displacement responses for each of these analyses matched the experimental response very well. 


\subsection{Effect of vertical acceleration on integral bridge system performance}

Including vertical acceleration in the investigation of the seismic performance of the integral bridge system is useful. The vertical acceleration does little to affect the column performance, as the varying axial loads in the column do not significantly alter the column plastic hinge performance and the overall horizontal force-displacement response of the structure. However, the inclusion of the vertical acceleration makes a significant difference in the shear and moment demand generated in the girder-tocap connections. Including vertical accelerations of $\pm 0.5 \mathrm{~g}$ increases the connection shear magnitude by as much as $70 \%$ and increases the connection moment magnitude by as much as $140 \%$.

\subsection{Analytical approaches for vertical acceleration simulation}

Three different analytical approaches for simulating seismic vertical acceleration were investigated. The first approach utilized a constant vertical acceleration in addition to gravity and horizontal seismic loading. This approach is relatively simple analytically, but its usefulness is probably limited based on whether an appropriate vertical acceleration value can be determined.

A second approach incorporated varying magnitudes of vertical acceleration based on the instantaneous magnitude of the horizontal ground motion, using recorded horizontal time-history data and applying vertical acceleration magnitudes equal to two-thirds the horizontal acceleration. For the time-histories incorporated in this study, this approach was less conservative than the constant vertical acceleration approach (noting that a constant vertical acceleration of $0.5 \mathrm{~g}$ was chosen for the constant acceleration approach).

The third approach incorporated recorded time-history data for both vertical and horizontal ground motions. For the ground motions considered in this study, this approach resulted in the largest increase in connection shear and moment magnitudes. However, further work is needed to refine this analysis and verify these findings. 